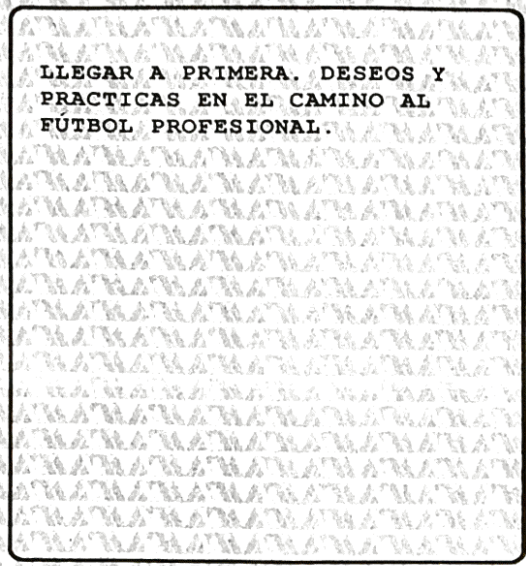

En la Ciudad de México, se presentaron a las 15:00 horas del día 21 del mes de julio del año 2016 en la unidad Iztapalapa de la Universidad Autónoma Metropolitana, los suscritos miembros del jurado:

DR. JUAN CASTAINGTS TEILLERY

DR. ANDRES ANTONIO FABREGAS PUIG

DRA. MARTHA LILIA DE ALBA GONZALEZ

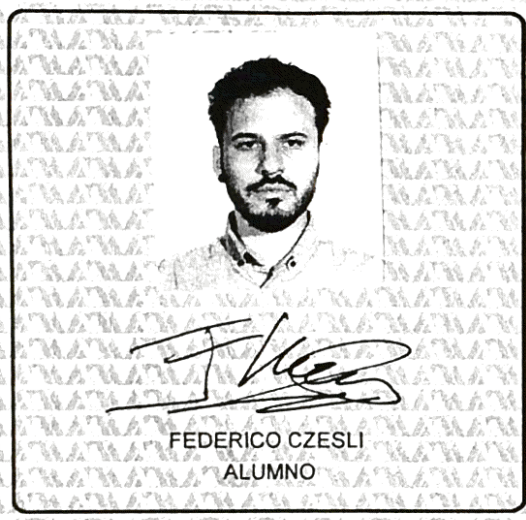

Bajo la presidencia del primero y con carácter de Secretaria la última, se reunieron para proceder al Examen de Grado cuya denominación aparece al margen, para la obtención del grado de:

MAESTRO EN CIENCIAS ANTROPOLOGICAS

DE: FEDERICO CZESLI

y de acuerdo con el articulo 78 fracción II del Reglamento de Estudios Superiores de la Universidad Autónoma Metropolitana, los miembros del jurado resolvieron:

\title{
A probar
}

Acto continuo, el presidente del jurado comunicó al interesado el resultado de la evaluación $y$, en caso aprobatorio, le fue tomada la protesta.

LIC JULIO CESAR DE LARA ISASS DIRECTOR DE SISTEMAS ESCOLARES

DIRECTORA DE LA DIVISIÓN DE CSH

RA. JUANA JUAREZ ROMERO

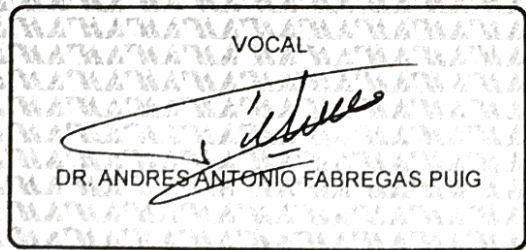

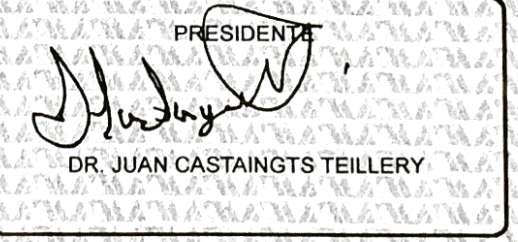

SECRETARIA

Mortha de clllece gy 


\title{
$\Delta 91$ \\ Casa abierta al tiempo \\ UNIVERSIDAD AUTÓNOMA METROPOLITANA \\ Unidad Iztapalapa
}

$$
\begin{array}{lr}
\text { Fecha } & : \\
\text { Página : } & 14 / 07 / 2016
\end{array}
$$

\section{CONSTANCIA DE PRESENTACION DE EXAMEN DE GRADO}

\begin{abstract}
La Universidad Autónoma Metropolitana extiende la presente CONSTANCIA DE PRESENTACION DE EXAMEN DE GRADO de MAESTRO EN CIENCIAS ANTROPOLOGICAS del alumnO FEDERICO CZESLI , matrícula 2143800124, quien cumplió con los 68 créditos correspondientes a las unidades de enseñanza aprendizaje del plan de estudio. Con fecha veintiuno de julio del 2016 presentó la DEFENSA de su EXAMEN DE GRADO cuya denominación es:
\end{abstract}

LLEGAR A PRIMERA. DESEOS Y PRACTICAS EN EL CAMINO AL FÚtBOL PROFESIONAL.

Cabe mencionar que la aprobación tiene un valor de 100 créditos y el programa consta de 168 créditos.

El jurado del examen ha tenido a bien otorgarle la calificación de:

Aprobar

JURADO

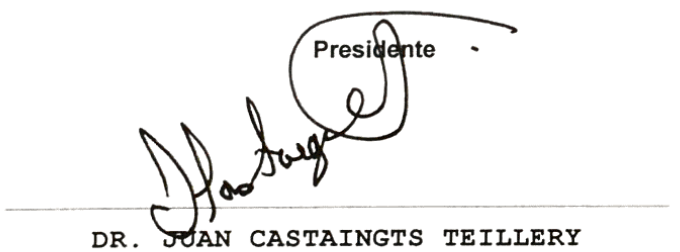

Secretaria

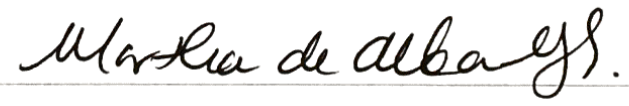

DRA. MARTHA LILIA DE ALBA GONZALEZ

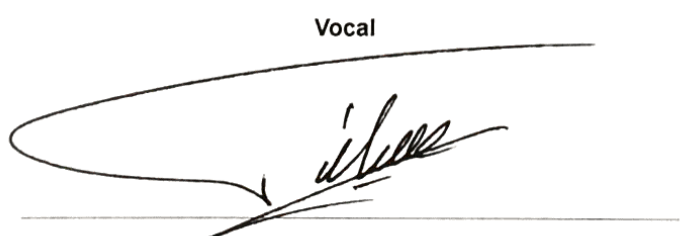

DR. ANPRES ANTONIO FABREGAS PUIG 


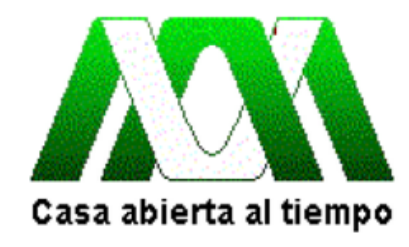

UNIVERSIDAD AUTÓNOMA METROPOLITANA

UNIDAD IZTAPALAPA

DIVISIÓN DE CIENCIAS SOCIALES Y HUMANIDADES

POSGRADO EN CIENCIAS ANTROPOLÓGICAS

\author{
Llegar a Primera. \\ Deseos y prácticas en el camino al fútbol profesional \\ Federico Czesli \\ Tesina de Maestría en Ciencias Antropológicas \\ Director: Dr. Juan Castaintgs-Teillery \\ Asesores: Dra. Martha de Alba \\ Dr. Andrés Fábregas Puig
}

México, D.F.

Julio de 2016 
Para Abraham, Aída, Elías y Lisa 


\section{Agradecimientos}

Agradezco en primer lugar al Dr. Juan Castaingts-Teillery por haberme acompañado a lo largo de todo el proceso, y a los Doctores Martha de Alba y Andrés Fábregas Puig por las sugerencias y comentarios.

Especialmente al Dr. Arce por permitirme realizar el estudio en Pumas, y a la confianza de Salas, Quique, George, Rafa, Ellan, Raúl, Iván, Pato Baeza, René, al doc Luis, a Magda Cáter, al Dr. Alcocer y sobre todo a los jugadores de Sub17 y la 2003, quienes brindaron su tiempo y testimonios con confianza y alegría.

En Estudiantes de la Plata, a Martín Gaimaro, Juan Krupoviesa, Rulo Salas, Hermes Desio, Leandro de Rose, Fabio Parini y a los jugadores de la Séptima. En Olympique de Marsella, a Rapha Guerreiro, Eric Rech, Thomas Lebegue, Sebastien, Nadja, Javier y a los jugadores de U17.

También agradezco a los Dres. Antonio Zirión y Angela Giglia por el apoyo permanente y cotidiano, pero también por el afecto y el trato directo con el que me recibieron.

A Fernando Segura Trejo, gracias a quien tuve la posibilidad de pensar en México, me ayudó en la postulación, me brindó su carta de recomendación y tantas enseñanzas sobre la vida mexicana. A Pablo Alabarces y Verónica Moreira por sus cartas de recomendación, su confianza y sus consejos. A Adriana Govea, por conseguirme los primeros contactos en Pumas

A José Garriga Zucal, referente permanente; a Diego Murzi, amigo, colega y socio en veinte proyectos al mismo tiempo; y a Juan Branz por su ayuda, apoyo y generosidad.

A Socorro Flores Rivas, sin cuya ayuda no habría podido jamás postularme a la maestría, ni tener un espacio donde vivir al aterrizar ni tantas otras cosas. Y a Hyldely Garduño, por su colaboración para sacar todo adelante, trimestre a trimestre.

Miles de gracias a Rodrigo Roque de Castro, amigo y huésped al arribar a México, y a Jesús González Jaramillo por el buen humor cotidiano.

A mis compañeros en la maestría, que hicieron de los dos años un transcurso sumamente placentero.

A Conacyt, por darnos la tranquilidad de cobrar puntualmente mes a mes.

Y por supuesto, a Víctor, Edith y Gabriel por el amor y la comprensión permanentes. 


\section{Exordio}

\section{En algo nos parecemos}

No soy veloz para leer ni escribir. Tampoco soy talentoso: tardo en incorporar las ideas de los autores. He perdido debates con más frecuencia de lo que recuerdo, y con vergüenza en ocasiones ni siquiera conocía el tema del que se hablaba. De noche trabajo mejor, pero eso generó que llegara a clase con pocas horas de sueño y que en consecuencia no rindiera con todo mi potencial. En ocasiones he sido impuntual pero no hubo docentes que me dieran más que una amonestación menor. Ninguno me echó de clase ni perdí la regularidad.

Nadie me negó a los cinco años la posibilidad de cambiar de jardín de infantes porque había un contrato de por medio y decían que yo les pertenecía. Tampoco tuve que viajar tres horas por día de ida y de vuelta, seis veces por semana, y estar en el aula como si no me hubiera afectado. Nunca me sentí absolutamente extenuado después de clase, no tuve que rendir exámenes semanalmente ni estuve a diario, por años, bajo observación de varias personas. A fin de año jamás sentí que mi carrera pudiera desvanecerse para siempre. No tuve que abandonar a mi familia y mudarme a los 13, 14 o 15 años a una casa con otros académicos, donde no sólo me tenía que encargar de mi ropa, de manejar el dinero y de cuidarme sino además demostrar, en cada una de mis acciones, que era merecedor de la posibilidad de vivir en esa casa. No salí llorando de un examen por sentir que ya no iba a poder ser investigador y así ayudar económicamente a mi familia.

Es decir: si los valores de la formación futbolística se aplicaran a la vida académica, yo no estaría escribiendo este texto.

Sin embargo, en algo nos parecemos.

Ellos saben que las posibilidades de convertirse en profesionales son ínfimas; yo, que las de entrar en la academia y vivir de eso también lo son. Después de muchos años de entrenamiento, los chicos temen no llegar a Primera y tener que salir a buscar trabajo, el que puedan encontrar. Después de muchos años de estudio yo también temo no conseguir un trabajo como académico que me permita vivir tranquilo, tener que desempeñarme en lo que pueda encontrar (y somos muchos con el mismo temor). Para ellos y para nosotros nuestras carreras pueden terminar pronto, y corremos con la sensación de que todo lo hecho puede quedar en la nada: una foto en la repisa, una tesis en la biblioteca, el recuerdo de una jugada brillante, algún párrafo muy bien escrito. Y que ya sin el status de ser futbolista o investigador, deportista o académico, que todo se reduzca a un haber sido, a un haber podido ser.

Mientras tanto avanzamos, y seguimos soñando. 
1. Introducción $\quad 6$

$\begin{array}{ll}\text { 1.1 Preguntas e hipótesis que sostuvieron la investigación } & 10\end{array}$

2. Metodología y enumeración de tareas realizadas 12

$\begin{array}{ll}2.1 \text { De lo hecho a lo dicho } & 16\end{array}$

3. Marco teórico 21

3.1 Influencia de la estructura social sobre los individuos $\quad 30$

$\begin{array}{ll}3.2 \mathrm{El} \text { deseo como disposición } & 32\end{array}$

$\begin{array}{ll}3.3 \text { Identificación y sujeción } & 35\end{array}$

$\begin{array}{ll}3.4 \mathrm{El} \text { centro de formación como organización } & 38\end{array}$

3.4.1 La organización como proceso $\quad 42$

3.4.2 Organización, estrategia y oportunidad 4

$\begin{array}{lr}3.5 \text { Representaciones y discurso } & 49\end{array}$

$\begin{array}{ll}3.6 \text { Breve panorama sobre estudios del deporte } & 54\end{array}$

$\begin{array}{lr}\text { 4. Las huellas del deseo } & 59\end{array}$

$\begin{array}{lr}4.1 \mathrm{La} \text { influencia familiar } & 59\end{array}$

4.1.1 La familia en el presente $\quad 65$

$\begin{array}{ll}\text { 4.2 Narraciones: la pobreza, el esfuerzo físico } & 71\end{array}$

$\begin{array}{lr}4.3 \mathrm{El} \text { impacto de los medios } & 80\end{array}$

$\begin{array}{lr}\text { 5. La estructura formativa } & 94\end{array}$

5.1 Ligazón contractual entre club y futbolistas 99

$\begin{array}{ll}5.2 \text { Pumas como organización } & 105\end{array}$

$\begin{array}{ll}5.3 \text { Actores que constituyen la formación } & 108\end{array}$

5.4 La organización real y la pelea política 112

5.5 "Todos tenemos un muerto en el closet" $\quad 117$

$5.6 \mathrm{El}$ conflicto entre formación y competitividad 123

5.7 Impacto de la estructura informal sobre el camino al profesionalismo. 125

6. El deseo, el poder, el placer. $\quad 131$

6.1 La estructura de observación y la oportunidad 135

$\begin{array}{ll}6.2 \text { La pedagogía aspiracional y la escasez } & 138\end{array}$

$\begin{array}{ll}6.3 \text { Premios y castigos, temor y esperanza } & 141\end{array}$

$\begin{array}{ll}6.4 \text { Pertenecer tiene sus privilegios } & 144\end{array}$

$\begin{array}{ll}6.5 \mathrm{El} \text { esfuerzo y la posibilidad siempre está } & 148\end{array}$

$\begin{array}{lr}\text { 7. Conclusiones } & 155\end{array}$

$\begin{array}{ll}\text { Referencias bibliográficas } & 168\end{array}$

$\begin{array}{ll}\text { Anexo } & 174\end{array}$ 


\section{Introducción}

A partir de las décadas del setenta y ochenta el fútbol se convirtió en una actividad económica y financiera de peso. La transnacionalización de la televisación de los partidos de fútbol -que luego se incrementó con la aparición de internet- convirtieron a este deporte, como plantea Luiz Carlos Ribeiro, en la gran vedette de la industria de la cultura y del placer en la sociedad contemporánea (Ribeiro 2008: 191).

Cuarenta años después, este segmento de la industria del entretenimiento continúa en crecimiento: el informe 2015 de la consultora Deloitte dedicado al negocio del fútbol expresa que las ganancias acumuladas de las cinco ligas más importantes (España, Francia, Inglaterra, Alemania e Italia) crecieron un $15 \%$ en la campaña 2013/14, que alcanzaron 11.300 millones de Euros (€11.3 billion) y que el mercado total del fútbol europeo superó los 20 mil millones de Euros (€20 billion) (Bosshardt, A. Green, M. y otros 2015). En México, la revista Forbes estimó el valor de la marca Chivas en 328,1 millones de dólares, del Monterrey en 248,9; del América en 219,2 y del Club Universidad en 160 millones de dólares ${ }^{1}$ (Pérez, 26 de enero de 2014).

Pero el fútbol no es únicamente una actividad económica sino que también es uno de los pocos espectáculos que semanalmente convocan multitudes en los cinco continentes. En México, puntualmente, el promedio de asistencia por fin de semana en el año 2013 fue de de 402.318 personas (Murayama 2014: 35), guarismo al que se deben agregar las cifras de los espectadores de televisión y que dan la pauta de la masividad del fenómeno ${ }^{2}$. A partir de esas cifras el fútbol produce narrativas de heroísmo contemporáneo, promueve adscripciones identitarias ${ }^{3}$, genera figuras para múltiples star

\footnotetext{
${ }^{1}$ Las cifras son sólo indicativas, ya que otros estudios marcan importantes diferencias en las valoraciones. A modo de ejemplo, mientras Forbes estimó al Real Madrid en 464 millones de dólares para la campaña 2015 (Ozanian 2015), la consultora Brand Finance ubicó su tasación en 873 millones de dólares (Brand Finance 2015).

2 Según datos de la cadena de televisión Fox Sports que recupera un artículo de revista Forbes, un partido de Copa Libertadores "mide" 7 puntos de rating, mientras que la final entre León y América la audiencia se incrementó a 13 puntos de rating (Perez, 10 de abril de 2015). Según el sitio neilsenibope.com.mx, el rating es la "proporción de personas que están expuestas a un medio en un momento determinado", de modo que 1 punto de rating equivale al $1 \%$ "del universo al que se hace referencia". Según mi interpretación es el $1 \%$ respecto del total de los televisores encendidos en 28 ciudades mexicanas a los que se les incorpora un dispositivo llamado "People Meter".

${ }^{3}$ Las adscripciones de las porras o barras bravas son las más "visibles”, pero lejos están de ser las únicas. Pablo Alabarces así lo resume: "...el discurso de la identidad futbolera viene acompañado inevitablemente por el de la pasión, que transforma una elección en un destino. Uno o una 'se hace de': pero, luego, la pasión -el discurso de la pasión- vuelve esa elección un dato definitivo. La identidad futbolera no pide nada, es democrática, no discrimina entre sus candidatos (...) Sólo se pide la inversión de un afecto - la pasión por el Columbus, digamos- y se devuelve la pertenencia a una comunidad de memorias, historias, sueños compartidos, goces prometidos" (Alabarces 2014: 44). Un trabajo propio sobre la identidad entre los aficionados al Club Platense, equipo de la Ciudad de Buenos Aires, se puede encontrar en Czesli 2013.
} 
systems, vehiculiza y es foco de políticas públicas ${ }^{4}$. Por todo esto, es también un símbolo dominante del mundo contemporáneo.

Para lograrlo se ponen en funcionamiento diversos recursos (estadios, campos para el entrenamiento, balones e indumentaria) y numerosos actores como patrocinadores, medios de comunicación, funcionarios públicos, directivos, dueños y accionistas de los clubes. Sin embargo, no es posible desarrollar el fútbol profesional sin los jugadores. Si, como sostiene Murayama, el éxito económico depende del éxito deportivo (2014: 25), entonces los players son la pieza central de toda esta estructura. Y para que lo sean es primero preciso que haya niños que deseen devenir futbolistas, $\mathrm{y}$ luego formarlos como tales.

En consecuencia, el objetivo de esta investigación consiste en analizar el proceso de profesionalización de los jugadores de fútbol en México en la época contemporánea a partir de la dimensión del deseo. Entiendo la profesionalización como el proceso social por el cual un individuo pasa desde una situación de conocimiento prematuro sobre una materia hasta adquirir las competencias que le permitirán acceder a la posibilidad de desempeñarse laboralmente en el medio para el que se formó. En el caso del fútbol esto tiene tres cuestiones a especificar: la primera es una paradoja, porque menos del 1 por ciento de los chicos que comienzan una carrera de futbolista en fuerzas básicas logra el objetivo de "llegar a Primera" (simbólicamente, "llegar a Primera" representa la meta por la que todos se esfuerzan). Si pensamos al espacio formativo a partir de su dimensión productiva, el fútbol trabaja con muchos individuos para que sólo unos pocos tengan valor deportivo y de mercado, de modo que aquí se observará cómo se desarrolla un proceso de profesionalización sobre muchos jugadores que no llegarán a profesionales.

El segundo elemento a considerar es que desde que los jugadores se incorporan a las fuerzas básicas de Pumas les hacen saber o sentir que ya son profesionales y que tienen que desempeñarse como tales, y los futbolistas asumen dicha propuesta. En consecuencia, la mirada que aquí se adopta de "profesionalismo" no es la nativa. Finalmente, que "llegar a Primera" no implica seguridad alguna para los jugadores. La dinámica profesional del fútbol es de cambios repentinos en función del rendimiento y de las posibilidades de negocio (y rendimiento y negocio no van estrictamente de la mano), y muy pocos profesionales tienen tranquilidad suficiente como para saber que en la siguiente temporada van a

\footnotetext{
4 A modo de ejemplo podemos mencionar la utilización de la "marca España" mediante la selección española (Fútbol Finanzas, 10 de enero de 2014) o la candidatura del jugador de fútbol Cuauhtémoc Blanco a la alcaldía de Cuernavaca como representante del Partido Socialdemócrata (PSD) (Tovar, 10 de febrero de 2015).
} 
continuar desempeñándose como futbolistas. E incluso en el mejor de los casos la carrera es corta, ya que en promedio no se extiende más allá de los 34 o 35 años 5 .

En consecuencia, en este trabajo no será relevante si los jugadores "llegan” o no. De las múltiples dimensiones que implica el proceso de profesionalización (por ejemplo el desarrollo físico y técnico, la inversión económica o la estructura organizacional) decidí poner el foco de la observación en aquellos elementos ligados al deseo de los jugadores: esto significa observar cómo surgen nuevos aspirantes y de qué manera la institución sostiene y desarrolla sus deseos. Este segundo eje de observación es central para pensar el camino al profesionalismo, porque el fútbol como deporte de alto rendimiento obliga a los jugadores a esfuerzos físicos extenuantes, a asumir una disciplina cotidiana estricta en términos de horarios, a estructurar la vida en torno del fútbol y en muchos casos a alejarse de sus familias y amigos en edades tempranas. Considero entonces que para sostener la práctica, pese a todo esto y a lo largo de siete u ocho años (incluso cuando todos saben que las posibilidades de lograr el objetivo son mínimas) se hace necesario mantener el convencimiento y el deseo de llegar a ser profesional.

Decidí poner el foco en el deseo porque me interesa pensar la reproducción de lo social, y el camino al profesionalismo es el espacio "material” en el que procuro observar dos cuestiones: de qué manera la estructura social condiciona o constituye el modo en que clasificamos el mundo (esto se materializa en preguntarnos por qué deseamos una cosa y no otra, por qué aspiramos para nuestras vidas a un camino y no a otro), y qué reglas y valores les propone la institución para posibilitarles alcanzar sus deseos y aspiraciones. De modo que las relaciones que se observaron al interior de la organización estuvieron guiadas por los modos en que la institución procura sostener el deseo de los jugadores.

Para comenzar a comprender esta cuestión decidí tomar una organización -un Centro de Formación de jugadores de fútbol profesional- y analizar las relaciones que allí establecen los actores. Metafóricamente, imagino que toda la sociedad confluye como en un embudo en esa "cantera", y que

\footnotetext{
${ }^{5}$ No se exponen en este trabajo datos del mercado futbolístico mexicano, pero observemos la información que menciona Arlei Damo respecto del caso brasileño de mediados de la década del 2000: "Los futbolistas son mal pagos, a excepción de pocos, cuyas ganancias se aproximan a las de los pop stars -una oscilación frecuente en carreras artísticas. Los datos provistos por la CBF [la Confederación Brasileña de Fútbol], respecto de la remuneración de los profesionales con contrato de trabajo registrado en la entidad, indican que la mayoría de los futbolistas recibe hasta 1 salario mínimo [un cuadro informativo indica que en 1999 el 51,6\% recibía hasta 1 salario mínimo, el 33,2\% de 1 a 2 , el 7,5\% de 2 a 5 , el 2,3\% de 5 a 10, y el 5,2\% más de 10 salarios mínimos] (Damo, 2004: 182, traducción propia).
} 
dichas relaciones ${ }^{6}$ permiten observar elementos que se dan en muchos otros espacios sociales. El Centro elegido no "refleja" la sociedad en su totalidad, pero sin lugar a dudas expone elementos que se presentan en muchos otros espacios sociales.

La organización seleccionada es la cantera del Club Universidad Nacional Asociación Civil, popularmente conocido como "Pumas" (utilizaré este término de ahora en más), cuya escuadra profesional compite en la Primera División de México. Allí se seleccionaron dos “categorías" de jugadores, que se clasifican por edad7: "la 2003" -es decir la de los chicos nacidos en el año 2003 y que durante el trabajo tenían doce años- y la "Sub17", que al momento del estudio agrupaba a jugadores nacidos entre 1998 y el año 2000. El objetivo de dicha selección fue intentar un análisis comparativo entre ambas que permitiera observar cómo a medida que los chicos van pasando tiempo en la organización van cambiando su mirada sobre la práctica que realizan. En paralelo a ese trabajo se realizaron observaciones y entrevistas en las categorías correspondientes a la Sub17 de dos instituciones de otros dos países: el Olympique de Marsella, de Francia, y Estudiantes de la Plata, de Argentina. La escritura del estudio finalmente puso a la Sub17 de Pumas como eje narrativo y a los tres planteles restantes como información complementaria o como punto de comparación del primero. En estos últimos casos lo que se procuró fue apelar al contraste para observar las arbitrariedades de cada formación cultural.

Tres preguntas conducen todo el trabajo: qué motivaciones llevan a los niños a desear convertirse en futbolistas, de qué manera la institución promueve el desarrollo y sostenimiento de dicho deseo, y qué estructura encuentran al ingresar a la institución. Asimismo, se pondrá el foco en la "recepción", es decir en cómo los futbolistas "reciben" -una recepción activa- las representaciones ligadas a ser profesionales de este deporte. Representaciones que se construyeron desde su infancia pero no únicamente allí, que surgen del club de fútbol pero también de medios de comunicación y consolas de videojuegos. Sin dudas los futbolistas también son productores de sentidos, pero su rango de influencia es mucho menor que el de actores como los medios de comunicación y el sistema de televisación internacional, las instituciones como la FIFA o la Federación Mexicana de Fútbol, los gobiernos nacionales y sus políticas ligadas a este deporte-espectáculo, las repercusiones de los modos de actuar

\footnotetext{
${ }^{6}$ Respecto de la metáfora del embudo, aquí debo aclarar que si el embudo sirve para conducir el agua caiga de arriba hacia abajo, las relaciones sociales son multidireccionales: allí el agua también fluye de abajo hacia arriba, de izquierda a derecha, de derecha a izquierda, en todas las diagonales y con todas las densidades posibles.

${ }^{7}$ En su etapa formativa los jugadores se clasifican por edad: (nacidos en) 2003, (nacidos en) 2002, sub 15 (agrupa a los nacidos en 2001 y 2000), tercera (agrupa a los nacidos en 2000 que se destacan y a los de 1999 que están rezagados), Premier, sub17 (nacidos en 1998 y 1999 más los que se destacan del año 2000), Segunda, Sub20 y Primera División.
} 
de los jugadores-estrella o los grandes patrocinadores y su aparato publicitario, por sólo poner algunos ejemplos de actores que propician sentidos ligados al fútbol, promueven consumos y compiten entre sí por imponer aquellos que los benefician.

\subsection{Preguntas e hipótesis que sostuvieron la investigación}

Párrafos atrás mencioné que el presente estudio se sostiene sobre tres preguntas: qué motivaciones llevan a los niños a desear convertirse en futbolistas, de qué manera la institución promueve el desarrollo y sostenimiento de dicho deseo, y qué estructura encuentran al ingresar a la institución.

La primera pregunta nos lleva a observar los procesos de constitución del individuo. Aquí el marco teórico que subyace son las teorías de la reproducción surgidas entre la década del sesenta y setenta del siglo XX a partir de un revisionismo del marxismo, y que pensaron a las sociedades a partir de sus continuidades antes que de sus transformaciones. Ese es el posicionamiento teórico general en el que se inscribe este trabajo. El abordaje se realizará a partir de las representaciones sociales presentes en los colectivos indagados, y si bien lo abordaremos en profundidad en el marco teórico, se trata de una perspectiva que supone que la percepción, la práctica y la experiencia del mundo son “incorporadas" y un efecto de las relaciones sociales, y que actuamos en el mundo dando por sentada nuestra percepción y sin cuestionarnos su arbitrariedad. No niego que existan procesos individuales sino que aquí trabajaremos sobre procesos colectivos, es decir que buscaré regularidades a lo largo de las observaciones.

La segunda interrogación está ligada a que no alcanza con que los chicos deseen ser futbolistas para que se conviertan en tales. Esto pone a las instituciones en el centro de la escena como promotoras de una normativa ${ }^{8}$, pero al mismo tiempo como organizaciones con órdenes propios y dosis de autonomía. Es decir, no hay constitución de un futbolista (ni de un empresario, de un comerciante o un antropólogo) que no pase por un proceso material de formación, y eso se realiza a través de organizaciones en las que numerosos valores y significaciones se han sedimentado.

\footnotetext{
${ }^{8}$ Me refiero a la normativa como estructura simbólica sedimentada respecto del fútbol y como reglas de juego al interior de la organización. Esto significa, por ejemplo, que promueven maneras específicas de ser futbolista, metas a las que los jugadores pueden aspirar, recursos que pueden utilizar para acceder a dichas aspiraciones, formas de relacionarse con los compañeros de equipo, maneras de relacionarse con la institución y con los entrenadores, representaciones de lo que el fútbol es y formas en las que los futbolistas deben conducirse en su vida personal y profesional.
} 
La tercera se justifica porque las organizaciones dedicadas a la formación de futbolistas son espacios donde la competitividad prima ante lo lúdico. Esto significa que compiten en certámenes con otras organizaciones, que para conquistar la victoria en dichos torneos precisan poner en el campo de juego a sus mejores futbolistas (lo que genera, además, que estos compitan entre sí por un espacio en el once inicial) y que deban maximizar el rendimiento de cada uno de ellos y apuntar a que sea lo más estable posible. En términos económicos se podría decir que así buscan reducir el riesgo de la derrota por malos desempeños. Como se planteó previamente, todo esto genera que los centros de formación promuevan distintos mecanismos para maximizar el rendimiento de los jugadores. Y como toda la práctica se sostiene sobre el deseo de los jóvenes de devenir futbolistas profesionales, los clubes buscan maximizar su rendimiento a partir de promover dicho deseo.

No obstante, el desarrollo de un trabajo como el presente distó de ser lineal, y las preguntas que hoy funcionan como eje no lo fueron en un principio. De modo que a continuación presento las principales preguntas que sostuvieron la tarea:

- ¿Cómo se produce el paso del amateurismo al profesionalismo en jóvenes de fuerzas básicas de fútbol mexicano desde el punto de vista "formal"?

- ¿Qué "normativa" de profesionalismo promueve la institución futbolística a los jugadores, entendiendo normativa como sinónimo de doxa en Bourdieu (2010: 111) ${ }^{9}$ ?

A partir de estas preguntas, se elaboraron las siguientes hipótesis o respuestas provisorias:

- El desarrollo de un jugador de fútbol es el producto de un proceso aprendizaje de competencias deportivas y sociales, que tiene como núcleo a la institución deportiva y a los jugadores, que incluye relaciones de poder, un intento de disciplinamiento y resistencias, y del que forman parte otros actores como las familias de los jugadores, los sponsors/patrocinadores y los representantes comerciales.

- La institución deportiva, a través de un proceso colectivo y de lucha con otros actores como padres o managers, transforma a los jóvenes aspirantes a futbolistas en mercancía. En consecuencia, la institución promueve la normativa mercantil.

- Como resultado de una estructura social que promueve la mercantilización de las personas, lo que motiva la práctica por parte de los jóvenes es el deseo de fama, dinero y reconocimiento social antes que el éxito deportivo.

Dicho esto, pasemos a la metodología de análisis y a las tareas realizadas.

9 “...relación de adhesión inmediata que se establece en la práctica entre un habitus y un campo al cual está acordado, esa muda experiencia del mundo como algo que se da por sentado y que el sentido práctico procura" (Bourdieu 2010: 111). 


\section{Metodología y enumeración de tareas realizadas}

El presente es un trabajo exploratorio en el que se han puesto en práctica diversas estrategias para realizar una primera indagación de las preguntas e hipótesis que lo motorizan. Como desde los inicios del trabajo hubo un eje centrado en la constitución del deseo de los jugadores y un segundo dedicado a las relaciones que se establecen al interior del centro de formación, se adoptaron dos abordajes y en consecuencia, dos metodologías.

Comencemos por el segundo. Respecto de las relaciones al interior de la cantera, se pensó en un abordaje procesual que luego se tradujo en la metodología adoptada: la primera decisión consistió en tomar dos categorías de jugadores al interior de Pumas para realizar una comparación entre ambas e intentar observar, a partir de las diferencias que pudieran aparecer, de qué manera influye la institución en el desarrollo de la normativa que se le propone a los jugadores, y cómo estos se van transformando a lo largo de los años. Se realizó entonces un mes de observación participante en la categoría Sub17 (nacidos en 1999 y 2000) y otro en la categoría 2003. Entre ambas hay de tres a cinco años de diferencia, lo que para algunos players significa el mismo tiempo de atravesar la institución.

Esta metodología presenta al menos dos bemoles a considerar y que en un trabajo posterior deberán ser resueltos: en primer término, que la mayoría de los jugadores se incorporan a la institución a sus 15 o 16 años, de modo que formar parte de la categoría Sub17 no implica necesariamente que hayan atravesado varios años en el club. Se ha privilegiado para este estudio realizar una muestra tirada al azar y es posible que los resultados no expresen plenamente el efecto de haber pasado varios años en un mismo club. No obstante, sin dudas los resultados expresarán el producto de la diversidad de trayectorias que componen la plantilla de la categoría, y el tipo de muestra elegida evita distorsiones en el resultado producto del favoritismo de la dirigencia o el cuerpo técnico de los clubes por uno u otro jugador, o de los prejuicios que los mismos puedan tener respecto de qué jugadores podrían brindarnos mejores respuestas.

La segunda cuestión a considerar es que no todos los jugadores que pertenecen a la categoría 2003 llegarán a Sub17, ya que al final de cada campeonato se produce una selección de jugadores y muchos son dejados "en libertad de acción" (lo que significa la posibilidad de irse a otro club libremente). Como resultado, el abordaje no es completo porque no incorpora a aquellos jugadores que fueron rechazados por el proceso de institucionalización (por falta de competencias técnicas, sociales o simbólicas) y que también forman parte del grupo a analizar. 
Como se anticipó en la introducción, además del trabajo realizado al interior de Pumas se utilizaron los materiales recopilados a lo largo de dos trabajos etnográficos realizados en dos centros de formación de dimensiones equivalentes: Estudiantes de la Plata, en Argentina, y Olympique de Marsella, en Francia. En estos casos se ha observado exclusivamente el equivalente de la categoría Sub17 ("la séptima", en Argentina, y "U17” en Francia), se han observado las estructuras formativas y realizado entrevistas en profundidad.

Respecto del análisis comparativo debemos decir que se encuentra desde los inicios de la antropología, en primer lugar en los abordajes de los evolucionistas que se proponían una aproximación positivista, es decir que partían de un sujeto que se percibía a sí mismo como “objetivo”, incapaz de ser tendencioso y que para alcanzar sus conclusiones realizaba observaciones de sociedades de las que se consideraba distanciado y cuyos procesos eran conscientes. Más adelante en el tiempo, y atravesando las críticas que en 1896 Franz Boas realizó al método ${ }^{10}$, Alfred Radcliffe-Brown expresó en el prefacio a Sistemas Políticos Africanos:

El método de la ciencia natural se basa siempre en la comparación de los fenómenos observados, y el objetivo de tal comparación es descubrir sus características comunes fundamentales mediante el examen cuidadoso de sus diferencias. Al aplicarlo a las sociedades humanas, el método comparativo utilizado como instrumento para la inferencia inductiva permitirá descubrir las características universales, esenciales, que pertenecen a todas las sociedades humanas, pasadas, presentes y futuras. La adquisición progresiva de este tipo de conocimiento debe ser el propósito de quienes creen que una verdadera ciencia de la sociedad humana es posible y deseable" (Fortes \& Evans Pritchard 2010: 43).

En este caso, por el contrario, apostamos a la comparación para observar las diferencias y particularidades. Los tres equipos analizados tienen puntos en común: pertenecen a ligas profesionales de sus países y a una federación internacional, la FIFA. Los tres tienen equipos que pertenecen a la principal liga de cada país y una estructura que busca educar a los jugadores para que la plantilla se componga con jugadores surgidos de sus canteras; tienen en consecuencia sistemas de reclutamiento y selección de jugadores a quienes les proponen uno o varios estilos de juego; se sostienen sobre una historia y sobre elementos simbólicos como los momentos exitosos del equipo; durante dicho proceso los jugadores incrementan su valor de mercado... Aún estructurados de manera medianamente similar, el trabajo fue pensado a partir de la idea de que las formas que adopta cada centro de formación son

$10 \mathrm{Si}$ bien se trata de una crítica que no afecta a la investigación presente es propio reproducirla: "debe entenderse claramente que la investigación antropológica que compara fenómenos culturales similares, de varias partes del mundo, para descubrir la historia uniforme de su desarrollo, plantea la suposición de que el mismo fenómeno etnológico se ha desarrollado de la misma manera en todos los lugares. Aquí está el defecto en el argumento del nuevo método, ya que no se puede dar tal prueba. Incluso la revisión más rápida muestra que los mismos fenómenos pueden desarrollarse de multitud de maneras". (Boas 1993: 87; 90). 
efecto de representaciones sobre cómo debe desarrollarse a un futbolista. Como consecuencia se procuró que el análisis comparativo sacara a la luz aquellos elementos que en los tres países -por separado- están naturalizados, y finalmente exponer la arbitrariedad de los modos de formación de jugadores ${ }^{11}$. Algunas particularidades teóricas sobre las implicancias del análisis comparativo y cómo fueron resueltas en este trabajo se pueden encontrar en el Anexo *1.

Para abordar el eje dedicado a la constitución del deseo de los jugadores se adoptó la metodología de realizar entrevistas en profundidad con una muestra tirada al azar ${ }^{12}$ de los jugadores y se indagó en el recorrido realizado hasta arribar al club, en sus inicios en la práctica deportiva, en el contexto familiar y su influencia en las representaciones que tienen del fútbol, en sus imágenes sobre el profesionalismo y en los modos de sostener la práctica. Las entrevistas también permitieron completar el trabajo, ya que la necesidad de legitimarse al interior del entrenamiento generó que me acercara a aquellos que lo coordinan, es decir al cuerpo técnico. El entrenamiento, además, es un espacio de pocos diálogos y testimonios por parte de los jugadores - una falencia que a futuro podría ser resuelta a través de una observación participante en la casa-club- de modo que la realización de entrevistas fue necesaria.

Dado que la primera experiencia -realizada en Estudiantes de la Plata- expuso que los jugadores ofrecían respuestas políticamente correctas, en este segundo caso se experimentó con dos alternativas: en primer lugar se les solicitó a los jugadores que dibujaran tres sueños ligados a lo futbolístico, que luego se les pidió que describieran para evitar una sobreinterpretación por mi parte. Estos dibujos fueron analizados y cotejados con el relato desde un punto de vista temático, y no se observaron ni los elementos estilísticos ni la estructura retórica o enunciativa ya que existe un alto riesgo de realizar una interpretación errónea o desmesurada.

En segundo término, al finalizar la entrevista se propuso un ejercicio de asociación libre: se les mencionaron diez palabras y se pidió que expresaran los 5 primeros conceptos que se les venían a la mente. A partir de estos conceptos se intentó observar tendencias, posibles contradicciones respecto de lo dicho previamente, definir líneas de investigación futuras y se puso el foco en aquellos elementos que pudieran indicar una distancia o una ruptura con los testimonios que brindaron previamente.

\footnotetext{
11 Por falta de tiempo el análisis comparativo finalmente no fue realizado en profundidad, pero es una tarea que se llevará a cabo en un estudio de doctorado.

12 El método aleatorio para la selección de los entrevistados consistió pedirles que tomaran de una bolsa papeles numerados: aquellos que sacaban del 1 al 10 fueron los seleccionados.
} 
Cuando en el Club Universidad se comenzó a abordar el segundo mes de trabajo -la observación con la categoría 2003- hallé una dificultad inesperada: no era posible realizar entrevistas en profundidad con los jugadores de 12 años, en parte porque era difícil gestionar la autorización familiar y en parte porque implicaba que se quedaran después de hora en el entrenamiento ya que lo finalizaban a las 6 de la tarde.

Tomé entonces una decisión pragmática en función de generar materiales para realizar la Idónea Comunicación de $\operatorname{Resultados}^{13}$ : realicé una encuesta escrita y anónima a todos los jugadores de la categoría 2003 con los mismos ejes de abordaje de las entrevistas en profundidad que, como se trató de un análisis comparativo, luego implementé en la categoría Sub17. Para su preparación realicé un primer test con diez jugadores de la categoría 2003, y tras aplicar algunas correcciones a partir de sus respuestas y de escuchar los comentarios de los cuerpos técnicos la apliqué al resto de los jugadores en ambas categorías. En líneas generales la experiencia expuso tantas virtudes como limitaciones, ya que si bien permitió inferir algunos ejes de abordaje futuros -y sobre todo, permitió acceder a un testimonio del plantel completo- expuso dificultades para observar representaciones porque no permitía repreguntar o profundizar más allá de las respuestas escritas. No obstante, a lo largo del texto utilizaré aquellos datos que considero válidos.

Dicho todo esto, a continuación enumeraré las acciones realizadas para recopilar la información:

a) En México - Club Universidad Nacional A.C. (Pumas): Se realizó un trabajo etnográfico de 2 meses: uno con la categoría Sub17 (jugadores nacidos entre 1998 y 2000) y otro con la categoría 2003 (nacidos en dicho año). Este trabajo implicó una observación participante consistente en presenciar los entrenamientos en el campo de juego junto a los futbolistas y el cuerpo técnico, tomar nota de los ejercicios físicos y charlas técnicas que se realizaron, de las indicaciones que dieron los técnicos y de las respuestas y actitudes de los jugadores. Se observó la dinámica del público en los partidos. Se realizaron 10 entrevistas en profundidad con jugadores de la categoría Sub1714, que incluyeron ejercicios de asociación libre y de representaciones gráficas. Las entrevistas fueron sistematizadas con el objetivo de buscar tendencias en las respuestas. Se realizó una encuesta anónima y por escrito con los jugadores presentes en un entrenamiento aleatorio de ambas

\footnotetext{
${ }^{13}$ No me interesa solapar la dimensión material del trabajo científico realizado, que se acota a temporalidades específicas y que obliga, para darle continuidad y profundidad a la indagación, a presentar resultados en un tiempo determinado. Es sin dudas una condición de producción del discurso científico y debe ser explicitada, así como sus efectos sobre los resultados obtenidos.

${ }^{14}$ Los ejes para la entrevista se pueden encontrar en el Anexo *2.
} 
categorías. Se realizaron 22 encuestas a la categoría Sub17 y 26 a la categoría $2003^{15}$. Se realizaron numerosas conversaciones orientadas, con valor de entrevista, con los técnicos de ambos planteles, con los preparadores físicos, con el entrenador de arqueros, con el utilero y con el médico. Se realizaron entrevistas con el abogado de la institución a cargo de los contratos y con la encargada de la educación de los jugadores. Se realizó una enumeración de la infraestructura del Centro de Formación. Se tomaron fotografías descriptivas de las instalaciones y de los entrenamientos.

b) En Argentina - Club Estudiantes de la Plata: Se realizó un trabajo etnográfico de un mes en la categoría "séptima” (jugadores nacidos en 1998 y 1999). Se realizó una observación participante con las características descriptas en el caso de Pumas. Se realizaron 8 entrevistas en profundidad. A ese material se agregaron dos entrevistas realizadas por el sociólogo Diego Murzi, quien en ocasiones se incorporó a la observación participante. Se realizaron conversaciones orientadas con valor de entrevista con el cuerpo técnico, el personal de la cocina de la casa-club y el trabajador social que coordina la escuela que pertenece a la institución, se entrevistó al Coach del Centro de Formación, se tomaron fotografías descriptivas de las instalaciones y de los entrenamientos.

c) Francia - Club Olympique de Marseille: Se realizó un trabajo etnográfico de dos semanas en la categoría "U17”. Este trabajo consistió en una observación participante con las características descritas previamente. Se acompañó a los jugadores a un evento de presentación del último calzado de Adidas, empresa patrocinadora del club, y se conversó con el responsable a cargo por parte de la consultora en publicidad que lo coordina. Se realizaron conversaciones orientadas con valor de entrevista con los técnicos del plantel, con los preparadores físicos y con el trabajador social que coordina la casa-club que pertenece a la institución y en la que a la que acude la mayor parte de los jugadores. A este material recopilado incorporaron las entrevistas y datos de campo en función de su pertinencia, material de primera mano recopilado por el sociólogo Diego Murzi.

\subsection{De lo hecho a lo dicho}

En este apartado dedicaré algunos párrafos a la escritura del trabajo. Lo primero a mencionar es que su realización en un marco académico y con el fin de alcanzar el título de Maestro también define que el primer destinatario sea dicho círculo y que buena parte de la aproximación a la problemática se realice en diálogo con autores que de allí provienen. Por eso una de las particularidades del estudio -

\footnotetext{
${ }^{15}$ El cuestionario se puede encontrar en el Anexo*3.
} 
desde mi punto de vista es una falla- es que se trata de una tesis sobre fútbol donde el fútbol está prácticamente ausente. He incorporado adrede epígrafes y algunas notas etnográficas con el objetivo de que estas hojas transpiren un poco el espíritu de la práctica deportiva (y que disimulen las horas sentado que implicó) pero no encontré la manera de que verdaderamente quede plasmado. Por otra parte, debo admitir que escribí pensando en otros públicos: en primer lugar los coordinadores, entrenadores y preparadores físicos de fuerzas básicas de Pumas, de Estudiantes y del Olympique de Marsella, porque en el fondo uno anhela que el trabajo inspire algunas acciones concretas; en segundo lugar en mi familia y algunos -pocos pero buenos- amigos con tiempo libre. Sucede que la experiencia indica que ellos terminan siendo la mitad de los lectores, de modo que en diversas etapas del texto intenté reponer supuestos y debates teóricos que quizás no habrían sido necesarios en el caso de dirigirme exclusivamente al mundo académico. Por otra parte, recordemos, agradezcamos y reconozcamos que es la sociedad mexicana a través de sus impuestos e instituciones la que me dio la posibilidad de realizar este estudio de manera financiada (y darme trabajo estable por dos años), de modo que escribir para el lector no académico es más que relevante.

Sostengo además que el presente es un estudio científico y que las ideas aquí expuestas no son opiniones. Marco así una distancia entre el conocimiento científico y el conocimiento general, y no es por presumir sino que se trata de llevar a la práctica un marco teórico, una metodología y sobre todo por intentar pensar críticamente y relativizar las propias ideas. De los diversos autores que abordaron esta cuestión menciono a Umberto Eco, quien como una de las condiciones de la cientificidad indicó que

La investigación debe suministrar elementos para la verificación y la refutación de las hipótesis que presenta, por tanto tiene que suministrar los elementos necesarios para su seguimiento público. Este requisito es fundamental. Puedo pretender demostrar que hay centauros en el Peloponeso, pero tengo que hacer cuatro cosas precisas: (a) presentar pruebas (como se ha dicho, por lo menos un hueso caudal); (b) decir cómo he procedido para hacer el hallazgo; (c) decir cómo habría que proceder para hacer otros; (d) decir aproximadamente qué tipo de hueso (u otro hallazgo) mandaría al cuerno mi hipótesis el día que fuera encontrado. De este modo no sólo he suministrado las pruebas de mi hipótesis, sino que lo he hecho de modo que también otros puedan seguir buscando para confirmarla o ponerla en tela de juicio (Eco 1988: 49)

Esto nos lleva a una tercera cuestión: la confidencialidad de quienes brindaron la información. Se trata de un tema muy sensible porque trabajé en un espacio reducido, en el que dialogué sobre todo con dos cuerpos técnicos -tres personas cada uno- y en un contexto de peleas políticas internas. Aquí hay dos problemas en potencia: el primero es que por esa cercanía cualquier declaración les sea atribuida a 
ellos, cuando mucho de lo aquí escrito proviene de otras fuentes; la segunda, que sus puestos de trabajo se pongan en riesgo.

Por ese motivo decidí ser muy cuidadoso en el modo de utilizar los testimonios, sobre todo en aquellos casos en que se trataron temas controversiales. Muchas veces, por otra parte, los datos no fueron producto de entrevistas sino de estar presente y escuchar conversaciones ajenas, utilizar lo oído como información a confirmar y a través de distintas estrategias ir dándoles forma. En los casos en que fue necesario expliqué todo el recorrido hasta asegurarme de la validez de la información. Como consecuencia de todo esto, se observará que en ocasiones me refiero a eventos de manera superficial y que evito mencionar a las fuentes. Es ahí donde se ubica verdaderamente el intento por resguardar la confidencialidad de lo dicho y al mismo tiempo exponer la mayor cantidad de elementos que me permiten elaborar mis reflexiones y conclusiones, en línea con lo que mencionaba Umberto Eco.

En relación con los jugadores la cuestión fue más sencilla porque son muchos y sus testimonios surgen de entrevistas al azar que otros actores en general no conocen. Todos ellos están incorporados de manera anónima a través de una nomenclatura: Entrevistado P1 a P10 (la P corresponde a Pumas), Entrevistados E1 a E10 para los de Estudiantes, y OM1 a OM10 para los del Olympique de Marsella. Al mismo tiempo intenté omitir aquellos datos que pudieran indicar a quién corresponde cada testimonio.

Asentemos ahora algunos apuntes sobre lo que implica hacer etnografía en un centro de formación de futbolistas. Lo primero que hay que decir es que toda la estructura está atravesada por la competencia: se trata de ganar, ya sea en presente y/o cuando los jugadores lleguen a Primera. Por supuesto, las autoridades repiten una y otra vez que además tienen que educar a los chicos, que es una responsabilidad de la institución porque sólo llega a Primera uno de cada cien y los 99 restantes no pueden quedar en la calle sin herramientas para afrontar la vida. Pero al final del día, desde mi punto de vista se trata de formarlos para ganar. Los equipos compiten entre sí en un campeonato, los jugadores compiten entre sí por ganarse el puesto en la cancha y los entrenadores compiten entre sí por acceder a los puestos de privilegio. En resumen, no es posible hacer etnografía sin sumarse a una dinámica de competencia, y esto tiene algunas particularidades.

Lo primero: no es lo mismo hacer etnografía en un equipo que gana que en uno que pierde. Cuando se gana la dinámica es tranquila y los entrenadores trabajan relajados (los entrenadores sobre todo, porque los jugadores -aunque en los clubes se piense lo contrario- entrenan alegres hayan ganado 
o perdido; es el club el que intenta promover en ellos que cuando se pierde tienen que sentir bronca, porque la mayoría de ellos no la siente naturalmente); y cuando se pierde todo está en conflicto: los entrenadores que se equivocaron dan excusas y explicaciones, están tensos, hay un clima de "tenemos que resolver la causa del problema", y ese problema, sin ir más lejos, puede ser atribuido al joven extranjero que apareció con su anotador y su grabador y cambió el equilibrio energético del lugar, y que fácilmente puede ser considerado mufa. Y si al investigador se le atribuye la mala suerte no hay etnografía ni entrevistas ni tesis.

De modo que a medida que uno comienza a trabajar junto a los planteles, escucha charlas técnicas, observa sus esfuerzos, conversa informalmente, conoce historias de vida, escucha anhelos y frustraciones, los acompaña cuando juegan como visitantes, extiende la mano para gritar con ellos la porra previa al partido (el famoso "Goya" Puma), a medida que sucede todo eso uno también comienza a desear que ganen, que les vaya bien en sus carreras y, de paso, le eviten al investigador el dolor de tener que alejarse.

Para cerrar este apartado volvamos al principio. Su título es "De lo hecho a lo dicho" porque si bien en la metodología expuse todas las tareas realizadas a lo largo de la investigación, me atrevo a decir que en la práctica utilicé cerca del 40 por ciento del material recopilado. No hay finalmente un análisis estructurado a partir de la comparación entre tres países para observar las estructuras formativas y un segundo cotejo entre las dos categorías de Pumas para observar la influencia de la institución. El límite de páginas y de tiempo para hacer la etnografía (de manera efectiva fueron 3 meses y medio de trabajo de campo, más cuatro de análisis, lectura de marco teórico y escritura) me llevó a condensar todo el análisis en tres capítulos y a utilizar como eje narrativo a la categoría Sub17 de Pumas. Con la Sub13 trabajé casi tanto tiempo como con la 17 y excepto situaciones contadas no incorporé dicho análisis. No utilicé los dibujos de las entrevistas en profundidad ni las asociaciones libres, y algunos buenos ejes de las entrevistas en profundidad quedaron afuera, como por ejemplo la trayectoria de los chicos hasta llegar a la institución.

Entonces ¿qué es "lo dicho”, qué hay escrito a continuación? En el próximo capítulo se ofrece el marco teórico que sostiene el análisis; parto de la teoría de las representaciones sociales y concluyo en las relaciones discursivas de poder. A partir de ahí, la tesis está organizada simulando la trayectoria de los jugadores: comienza con los inicios de los chicos en el fútbol (de modo que el capítulo 4 se refiere a la constitución del deseo en los futbolistas y a la presencia de sus familias tanto en sus inicios como en 
sus presentes) y a partir de ahí dos capítulos que representan la incorporación de los futbolistas al centro de formación. En el número 5 expongo la estructura formativa de Pumas porque no hay deseo desligado de las organizaciones. Me referiré a las relaciones formales e informales y el modo en que éstas afectan directamente las posibilidades de los chicos de devenir profesionales. Luego, el capitulo 6 está dedicado a los mecanismos de poder que se ponen en práctica en Pumas con el objetivo de lograr que los chicos maximicen su rendimiento, y finalmente las conclusiones. 


\section{Marco teórico}

"Connaitre, c'est naître avec"

(Conocer, es nacer con)

Pierre Bourdieu, El Sentido Práctico, p.108

El eje nodal del abordaje teórico que proponemos pone a la noción de representaciones sociales en el centro del análisis. En primer lugar porque toda nuestra materia prima para la realización del trabajo son representaciones, signos, mediaciones de lo que el fútbol y el futbolista "es", y en segundo término porque pensamos a dichas representaciones como el efecto de sentido de una estructura social que promueve unas y no otras formas de ver el mundo, propicia deseos, aspiraciones y devenires. Esto significa que el fútbol no es "nada" por fuera de las diversas formas en que es percibido y construido por los distintos actores que establecen una relación con ese concepto.

La idea que sostiene esta perspectiva es expresada con mucha claridad en el siguiente párrafo de David Kertzer:

La realidad humana no es provista desde el nacimiento por el universo físico, sino que se va diseñando (fashioned) por los individuos a través de la cultura en la que nacen y las experiencias que tienen, experiencias que lo ponen en contacto con otras personas y con diversas formas de naturaleza. (...) El orden es provisto por el sistema de símbolos que aprendemos como miembros de nuestra cultura, un sistema que posibilita tanto la creatividad social como la idiosincracia individual (Kertzer 1988: 4, traducción propia).

Esto significa que no tenemos acceso al mundo, no percibimos ni actuamos sin una mediación del orden simbólico de nuestra cultura, efecto del contacto con otras personas, de la época y lugar en que nacemos y de las experiencias que vamos atravesando a lo largo de nuestras vidas. Como vimos en las preguntas e hipótesis de investigación, si aquí nos preguntamos qué motiva el deseo de los chicos para devenir jugadores, hipotetizamos que es producto de la relación que van estableciendo con la estructura social, es decir de la conformación del sistema de símbolos. Si bien un trabajo posterior deberá realizar una precisa y profunda conceptualización de la noción de "deseo", en este estudio y a partir de la lectura de autores como Deleuze 1995, Tudela Sancho 2000 o Parrini 2015 se lo pensará como un anhelo mental y corporal asociado a diversas imágenes placenteras o a la satisfacción de necesidades o carencias, sean estas conocidas o desconocidas por el individuo, y que puede impulsar un movimiento, 
una acción para su obtención ${ }^{16}$. El deseo no es estático sino que se transforma, y por su transformación es uno y es muchos: se asocia a diversas cadenas de significantes, es efecto de una estructura simbólica, es reproducción y creación. Por estar asociado a esas cadenas de significantes es también un relato sobre las decisiones y acciones que tomamos ("tomo esta decisión porque deseo tal cosa"), pero dicho relato es sólo un ancla, una fijación contingente y temporaria porque al estar asociado a significantes el deseo es escurridizo.

La propuesta que aquí se adopta es que los deseos están socialmente construidos (incluso los que atañen únicamente a un individuo, porque si el deseo es efecto de relaciones primigenias, tales relaciones son sociales) y que es un espacio donde se funde lo individual y lo social. No obstante, el presente estudio se interroga por aquellos deseos que aparecen con regularidad en una o distintas sociedades (como el deseo de devenir futbolista profesional), y a partir de ahí se hipotetiza que el deseo es "efecto" de una estructura social que promueve unas y no otras formas de estar en el mundo, y que es también a partir de esa promoción (el “esto es para mí, esto no es para mí” al que se refería Bourdieu con su noción de habitus, y que luego abordaremos), que las sociedades reproducen y transforman las posiciones que ocupan los individuos que a ellas pertenecen, sus aspiraciones y posibilidades. Considero que estos deseos no se conforman exclusivamente en etapas primigenias de la constitución del sujeto sino que su formación continúa a lo largo de las vidas de los individuos y por su contacto con instituciones de todo tipo (escuela, familia, trabajo o medios de comunicación, entre otras), con experiencias y narrativas (veremos algunas en este trabajo).

\footnotetext{
${ }^{16}$ Desde la teoría freudiana, la definición clásica de deseo está ligada a la "vivencia de satisfacción", como la vivencia del individuo que en su primera infancia y ante la necesidad satisfecha por la madre, produce "vías asociativas" entre el acontecimiento "actual" y las imágenes-recuerdo".(Uribe Echeverry 2015). La noción del deseo también ha sido estudiada desde las neurociencias, que postulan que para que el cuerpo humano satisfaga las necesidades que le permiten mantenerse vivo y reproducirse, a lo largo de la evolución se fue desarrollando un sistema en el cerebro que "premia" aquellas funciones con "sensaciones sumamente agradables" (Logatt Grabner sin fecha). Dado que la dopamina es el neurotransmisor que se encuentra en las áreas cerebrales ligadas al deseo, cuanto mayor sea su nivel "mayor será el nivel de motivación que un ser vivo tendrá para alcanzar su objetivo" (ídem). El autor agrega que "En los centros hedónicos, uno de los neurotransmisores que se libera ante un estímulo placentero, por ejemplo el olor o la visión de un chocolate, es la encefalina, que coopera, a su vez, para que se pueda liberar otro neurotransmisor en las neuronas postsinápticas vecinas, la anandamida. Al difundirse este nuevo neurotransmisor desde su lugar de liberación, interacciona con receptores ubicados en la primera neurona que había liberado encefalinas aumentando la liberación de éstas. Creándose así un ciclo de retroalimentación positivo que permite intensificar el placer percibido" (ídem). Existe además un "Sistema de anticipación de recompensa", y que significa que no se necesita siempre probar una sensación placentera para producir dopamina: "Por ejemplo, la primera vez que probamos una cucharada de helado su agradable gusto nos producirá dopamina, pero a partir de ahí no necesitaremos ingerirlo para liberarla. Su recuerdo o su olor serán suficientes para producirla y generar el deseo de comerlo" (ídem).
} 
En consecuencia postulamos que el deseo -de devenir algo o alguien en nuestro caso- y la creencia de que devenir eso es posible es producto "no exclusivamente" de factores psicológicos individuales sino de una estructura social que lo promueve y efecto de relaciones de poder.

Hago hincapié en ese "no exclusivamente" porque no es posible separar lo individual de lo social, analizar al individuo por fuera de sus relaciones ni a la estructura social sin tomar en consideración a los individuos en que se encarna. Como planteó el psicólogo social Serge Moscovici en un artículo en el que defiende su disciplina frente a las corrientes psicológicas que hacían foco en el individuo,

Todo sería sencillo si uno pudiera decir sin titubeos: esto es lo individual y esto es lo social como si cada una fuera una entidad autónoma. Esto significaría que uno podría conocer a un individuo sin conocer a los demás como si se tratara de dos mundos ajenos. (...) la psicología social justifica su existencia en la medida en que se dedica a un único problema: ¿qué es lo que causa el conflicto entre el individuo y la sociedad? Se dedica a este deber al estudiar concretamente cómo el individuo se integra a las colectividades, por imitación y conformidad, por las presiones a la uniformidad ejercida por las masas y los grupos, por la diseminación de estereotipos y la necesidad de reducir la disonancia entre las presiones externas y las creencias y deseos internos (Moscovici 2004: 19)

En el caso de esta investigación, postulamos que este conflicto se materializa en los actores con los que los jugadores se relacionan a diario: el Centro de Formación como organización, el cuerpo técnico, sus familias, los representantes deportivos, los medios de comunicación y los patrocinadores. Y de ellos, hemos dicho, pondremos el foco en la relación que los jugadores establecen con el Centro de Formación, el cuerpo técnico y sus familias.

Como el sentido individual y social de objetos como los pertenecientes al ámbito del fútbol no están “dados” sino que son el resultado de numerosos factores, considero que entre los distintos actores que lo ponen en práctica se establecen pugnas y consensos por el establecimiento de los sentidos que circulan. Representaciones sobre qué es un buen jugador, qué significa ser profesional, qué estilo de vida debe llevar o qué sentimientos debe portar están en permanente transformación a partir de dichas pugnas y consensos. Esto significa también que nos afiliamos a una concepción sociosemiótica de cultura, entendida en términos de producción, circulación y consumo de significaciones en la vida social (García Canclini 2005: 35).

¿Qué es una "representación”? Soy partidario de la mirada de Charles Peirce. Su definición primera es la siguiente:

Un signo, o representamen, es algo que, para alguien, representa o se refiere a algo en algún aspecto o carácter. Se dirige a alguien, esto es, crea en la mente de esa persona un signo equivalente, o, tal vez, un signo aun más desarrollado. Este signo creado es lo que yo llamo el interpretante del primer signo. El signo está en lugar de algo, su objeto. Está en lugar de ese objeto, no en todos los aspectos, sino sólo con referencia a una suerte de idea, que a veces he 
llamado el fundamento del representamen. (Peirce 1974: 22, los destacados en negrita me pertenecen).

Veamos de manera resumida a qué se refiere. Primero, el signo o representamen -yo le diré representación- está en lugar de su objeto. Si vemos una pintura de un árbol, imaginamos un árbol al que puede estar haciendo referencia y en consecuencia la pintura está en lugar del árbol; si vemos una obra de teatro o una película, sabemos que lo que vemos es una teatralización -una "representación", justamente- pero es verosímil porque nos genera la idea de que eso en efecto podría estar sucediendo (en nuestro mundo o en uno posible, como en el caso de la ciencia ficción). Cuando en un cumpleaños entregamos un regalo, el regalo es un signo de nuestro cariño por la persona, y por eso es común bromear que si se recibe un par de calcetines el regalo fue por compromiso y no por afecto verdadero. Entonces, la representación ocupa el lugar de otra cosa, y la ocupa no expresando todos los aspectos de ese objeto sino sólo algunos. Por ejemplo, una fotografía de una manzana puede exponer los colores de la manzana pero no su sabor ni aroma, o cuando vemos humo interpretamos que hay fuego pero no sentimos el calor.

Ahora bien, si se relee el último párrafo y nos detenemos en los verbos que utilicé, encontramos “imaginamos", "sabemos", "nos genera"... Esto significa que, como dice Peirce, en nuestras "mentes" -y podríamos agregar en nuestros cuerpos- se crea un signo equivalente: vemos una película y quizás en nuestros cuerpos y mentes nos identificamos con eso que vemos y nos emocionamos, la película nos atraviesa. Pero quizás no nos pasa nada, y por eso es importante ese "para alguien" que aparece en la definición de Peirce: la película puede ser excelente y su director haber ganado todos los premios, pero lo que esa película "significa" también depende de cómo es recibida por cada persona o por un colectivo de personas. Esto está ligado a que nuestra interpretación del mundo no es "individual" sino que también depende de los grupos a los que nos sentimos pertenecientes o deseamos pertenecer. Un ejemplo esquemático pero claro: porque el deseo es colectivo sería difícil encontrar entre una tribu urbana como los "cholos" individuos que afirmen que su gusto musical está ligado al jazz, algo que quizás aparece en otra tribu como los "hipsters" (donde, por ejemplo, difícilmente consuman música del género banda). Sin dudas puede suceder, pero en la práctica no es común y aquí trabajamos y nos preguntamos por los movimientos colectivos, por las regularidades. En términos teóricos ampliaremos esta cuestión al referirnos a la noción de campo en Pierre Bourdieu.

Por todo esto, el fútbol puede significar/ser muchas cosas. Por ejemplo: el periodista argentino Dante Panzeri tituló un libro y afirmó que es la "dinámica de lo impensado"; un entrenador de Pumas 
afirmó que "después de todo, esto se trata de duelos individuales y duelos colectivos"; Diego Maradona le dio un tono sagrado cuando entre lágrimas expresó que "yo me equivoqué y pagué, pero la pelota no se mancha"; la campaña 2016 de Nike asocia el fútbol al riesgo cuando postula Risk Everything (arriesga todo); la FIFA también hizo su aporte cuando salieron a la luz los múltiples sobornos en torno de las elecciones de sedes mundialistas. Y todas estas son representaciones que dicen algo del fútbol, contribuyen a su construcción. Ni "fiesta popular" ni "puro negocio", lo que el fútbol sea depende de ese "para alguien" individual y colectivo. No será igual la mirada del fútbol de un directivo, de un periodista, de un futbolista consagrado o de un futbolista juvenil, porque cada uno se ubica respecto del fútbol a partir de su "posición" en el "campo" de relaciones. Por eso elegimos nuestro alguien -ese alguien con el que trabajaremos en este estudio- y esos son los futbolistas de fuerzas básicas de Pumas. En ellos observaremos qué representaciones hay sobre el fútbol, con qué fútbol se identifican, qué fútbol les genera deseo, a qué fútbol aspiran. Este "para alguien” justifica que nuestra metodología se asiente sobre la etnografía y sobre las entrevistas en profundidad: desde mi punto de vista no hay otro fútbol que aquel que pasa por las mentes y cuerpos de los jugadores y quienes entran en contacto con ellos.

Por este gesto colectivo es que no hablamos de representaciones a secas sino de "representaciones sociales". Este concepto apareció en 1912 con la publicación de Las formas elementales de la vida religiosa, un libro clásico del sociólogo francés Émile Durkheim, y allí él propuso que las "categorías de la percepción" no surgen de la experiencia misma sino que vienen del pasado. Esto significa que los futbolistas no son pasivos frente a las representaciones y que absorben todo lo que se les presenta, sino que a partir de la cultura en que se nace el individuo las va construyendo. Como decía Kertzer en la cita que inaugura este apartado, la realidad no es provista desde el nacimiento por el universo físico sino que se va diseñando por los individuos a través de la cultura en la que nacen y las experiencias que tienen.

En consecuencia, el modo de clasificar lo que observamos y su significado no provienen de la "realidad empírica", de los objetos mismos, del fútbol mismo, sino que su sentido viene "del pasado", un pasado que no es la razón divina sino que es "la sociedad": todos los hombres de una misma civilización, afirmó Durkheim, comparten el mismo sistema de distinciones, y este sistema se reproduce en nuestras conciencias. 
Este sistema de distinciones o "categorías de entendimiento" que son "esencialmente colectivas" en otros pasajes tomará el nombre de "representaciones sociales" o "conceptos" y son producto del saber de "largas series de generaciones" (Durkheim 1912: 20), lo que da la pauta de que miramos el mundo condicionados por el modo en que nuestros antepasados lo miraron. Estas categorías son “necesarias", agrega dicho sociólogo, porque gracias a que posibilitan una concepción homogénea del tiempo, del espacio y de otros conceptos de base, permiten a los hombres la vida en común. El primer punto de llegada, entonces, es que desde la publicación de su libro la manera en que percibimos el mundo no es subjetiva y psicológica sino colectiva y representacional.

Ahora bien, si al mundo accedemos a través de representaciones colectivas, una pregunta que surge es de qué manera se produce la relación de los individuos con el mundo que los rodea. Sabemos que viene del pasado, pero ¿son esos sentidos completamente arbitrarios (es decir que cualquier representación podría referirse a cualquier objeto), es el individuo el que determina y le da sentido al objeto o, a la inversa, son los objetos los que condicionan o incluso determinan el sentido que de sí se aprehende? Durkheim se acerca a la tercera opción cuando sostiene que existe una dimensión empírica por fuera de la representacional, y que esa dimensión corresponde a aquello que es aprehendido por el aparato perceptivo humano. Es decir que no estaríamos en el mundo sólo por signos sino que existe la experiencia, una instancia individual (no colectiva) de la percepción que está ligada al modo en que los sentidos son impactados. Esto significa, además, que en su concepción las representaciones no son del todo arbitrarias sino que están condicionadas por los objetos existentes en el mundo.

En lo que respecta a nuestro trabajo, comparto con Durkheim su idea de que existe una dimensión empírica que condiciona los sentidos que de ella pueden surgir, aunque no estoy tan preocupado por el hecho de que la percepción cambie por las diferencias en los aparatos perceptivos. Sí me interesa plantear que las representaciones posibles son múltiples pero no infinitas, condicionadas por el objeto al que hacen referencia, en nuestro caso el fútbol. A modo de ejemplo, podríamos pensar que el hecho de que al fútbol se juegue en estadios que tienen un tipo de arquitectura que posibilita el espectáculo de masas, un enrejado que separa a los jugadores de los aficionados y a las parcialidades entre sí, reglas de juego y una terna arbitral o cámaras de TV, todo eso condiciona los sentidos que surgen de la relación social en torno del fútbol y abre la puerta a un análisis "en producción”, tanto sobre sus condiciones 
estructurales como sobre los principales productores de sentidos en torno del fútbol: los medios de comunicación, los Estados, los patrocinadores ${ }^{17}$.

En segundo término, aún si cada aparato sensorial humano percibe de manera individual el entorno que lo estimula, es sobre los aspectos sociales y colectivos que pondré el foco. En este sentido soy seguidor de la mirada del lingüista ruso Valentin Voloshinov, para quien la significación es siempre social. Observemos su propuesta:

La vivencia -lo expresado y su objetivación externa- están hechos, como ya sabemos, del mismo material. No hay vivencia fuera de su encarnación sígnica. Por consiguiente, desde un principio ni siquiera puede plantearse una diferencia cualitativa entre lo interno y lo externo. Pero es más que eso: el centro organizativo y formativo no se encuentra en el interior (es decir, no en el material de los signos internos) sino afuera. No es la vivencia la que organiza la expresión, sino por el contrario, la expresión la que organiza la vivencia, le da por primera vez una forma y una determinación del sentido. (...) Esto sucede porque un enunciado se construye entre dos personas socialmente organizadas, y aunque un interlocutor real no exista, siempre se prefigura como una especie de representante del grupo social al que el hablante pertenece (Voloshinov 1976: 120 y 121, el destacado me pertenece).

No rechazo la posibilidad de que un individuo genere asociaciones exclusivamente propias, pero dado que ubico el foco de mi atención en el modo en que las representaciones son incorporadas de manera activa por los individuos, comparto con Voloshinov que toda representación surge de la relación del individuo con lo social. En la investigación que realizaremos, esto se traduce en la búsqueda de tendencias entre los testimonios recopilados. Es decir, cada individuo tiene una historia propia, cada uno interpreta el fútbol y su práctica de manera individual y subjetiva, pero me interesan las repeticiones, las regularidades, aún si estas no se expresan de manera idéntica. En términos epistemológicos aparece, de manera contundente, la capacidad interpretativa del analista, la capacidad de realizar abducciones a partir de los elementos que expuso la observación.

Respecto de la relación entre individuo y sociedad,, la psicóloga social Denise Jodelet postuló que trabajar en términos de representaciones sociales procura observar específicamente el cruce:

Antes que nada concierne a la manera como nosotros, sujetos sociales, aprehendemos los acontecimientos de la vida diaria, las características de nuestro medio ambiente, las informaciones que en él circulan, a las personas de nuestro entorno próximo o lejano. (...) Este conocimiento se constituye a partir de nuestras experiencias, pero también de las informaciones, conocimientos y modelos de pensamiento que recibimos y transmitimos a través de la tradición, la educación y la

17 Dentro de esta categoría yo incluyo al trabajo del Dr. Juan Castaingts Teillery, que parte de pensar al fútbol como "lenguaje de emociones", analiza las relaciones sintagmáticas y paradigmáticas que se establecen ente los jugadores, propone que como juego de conjunto el fútbol se basa en una estructura reticular y postula y postula, entre otras ideas, que "En el mundo moderno la épica a no se refiere a hazañas militares o guerreras y mucho menos, a la épica política hoy desvalorizada en todo el mundo, sino a la épica del deporte y a la épica de la empresa (...) Tanto el deporte como la empresa conducen a una sociedad de competencia generalizada. En esa competencia se le da gran valor al individuo y se ensalzan la cualidades de flexibilidad, independencia, movilidad, autonomía, la de buscar y encontrar sus referencias en sí mismos y la de realizarse por medio de su acción personal" (Castaingts Teillery 2011: 327) 
comunicación social (...) el hecho de que la representación social constituya una forma de conocimiento implica el riesgo de reducirla a un acontecimiento intraindividual, donde lo social tan sólo interviene en forma secundaria. El hecho de que se trate de una forma de pensamiento social entraña el peligro de diluirla en fenómenos culturales o ideológicos" (Jodelet 1986: 473 y 474).

Durkheim hacía hincapié en el pasado social en la determinación de las clasificaciones, pero medio siglo después el psicólogo social Serge Moscovici se propuso discutir con el psicoanálisis que imperaba en Francia desde mediados del siglo XX. Por eso una de las líneas generales de su estudio consiste en exponer que la significación está multicentrada y no sólo es resultado de procesos primigenios -sociales también, pero primigenios- como la resolución del Complejo de Edipo o el estadío del espejo y la constitución del sujeto a partir de la emulación de la figura paterna (más adelante retomaremos esta cuestión). Su otra fuerte polémica consistió en defender la capacidad creadora del individuo en su relación con el entorno frente a una corriente de la psicología social ${ }^{18}$. En este sentido sostuvo que

El objeto está inscripto en un contexto activo, móvil, puesto que, en parte, fue concebido por la persona o la colectividad como prolongación de su comportamiento y sólo existe para ellos en función de los medios y los métodos que permiten conocerlo (...) no reconocer el poder creador de objetos, de acontecimientos, de nuestra actitud representativa equivale a creer que no hay relación entre nuestro 'repositorio' de imágenes y nuestra capacidad de combinarlas, de obtener de ellas combinaciones nuevas y sorprendentes (Moscovici 1979: 32).

Moscovici sostiene la propuesta durkheimiana por la cual mediante las representaciones damos un orden al mundo (ídem: 36), volverlo familiar, pero el centro de su propuesta es el individuo y no la sociedad, postula un sujeto que se relaciona con "documentos" como las conversaciones, los artículos de diario, un libro, un reportaje por TV y que se interesa por "estar al corriente", "no ser ignorante". En lo que respecta a la propuesta analítica general, Denise Jodelet se encamina en la misma perspectiva de Moscovici, a quien profundiza ${ }^{19}$. También observa un individuo que busca dominar y comprender el entorno, y por eso su materia prima son los sistemas de referencias, categorías, fenómenos, teorías, imágenes, "actividad mental", comunicación... elementos todos que la autora propone como fenómenos ligados a las representaciones y la comprensión de la vida social (Jodelet 1986: 472). De

18 “...los individuos, en su vida cotidiana, no son únicamente máquinas pasivas que obedecen a aparatos, registran mensajes y reaccionan los estímulos exteriores; los trata de ese modo una psicología social sumaria, reducida a recoger opiniones e imágenes. Por el contrario, poseen la frescura de la imaginación y el deseo de dar un sentido a la sociedad y al universo que les pertenecen" (Moscovici 1979: 37).

19 En otros apartados profundiza la idea: “... siempre se trata de lo mismo. A saber: una manera de interpretar y de pensar nuestra realidad cotidiana, una forma de conocimiento social. Y correlativamente, la actividad mental desplegada por individuos y grupos a fin de fijar su posición en relación con situaciones, acontecimientos, objetos y comunicaciones que les conciernen. Lo social interviene ahí de varias maneras: a través del contexto concreto en que se sitúan los individuos y los grupos, a través de la comunicación que se establece entre ellos; a través de los marcos de aprehensión que proporciona su bagaje cultural; a través de los códigos, valores e ideologías relacionados con las posiciones y pertenencias sociales especificas" (Jodelet 1986: 473). 
manera más específica, a partir de la propuesta de esta autora abordaremos las tradiciones y experiencias a través de las historias de los jugadores que recopilamos en entrevistas y encuestas, mientras que las relaciones y comunicaciones las observaremos en la trama que se establece al interior del Centro de Formación.

Si bien en el trabajo que aquí se presenta no tengo críticas hacia el tipo de análisis que tanto Moscovici como Jodelet proponen, mi abordaje plantea una distancia (un énfasis distinto, mejor dicho) en el sentido de aquí continúa teniendo peso "la sociedad" como máquina productora de sentidos, aún pensando al individuo como activo y pensando que es en las relaciones cotidianas donde se promueven dichos sentidos y relaciones de poder. Pero mi perspectiva para este trabajo, como veremos más adelante, propone pensar las representaciones como efecto de relaciones de poder, y en ese sentido me siento alineado con Foucault y su concepción del "discurso".

Profundicemos un poco sobre la actividad de los individuos que veíamos en Serge Moscovici. En El psicoanálisis, su imagen y su público criticó la pasividad del sujeto que estaba presente en la mirada durkheimiana, así como la idea de pensar las representaciones colectivas como la sumatoria de las de los individuos:

Toda representación está compuesta de figuras y expresiones socializadas. Conjuntamente, una representación social es una organización de imágenes y de lenguaje porque recorta y simboliza actos y situaciones que son o se convierten en comunes. Encarada de forma pasiva, se capta como el reflejo, en la conciencia individual o colectiva, de un objeto, un haz de ideas, exteriores a ella. (...) A decir verdad, debemos encararla de forma activa. Puesto que su papel es dar forma a lo que proviene del exterior, más bien es asunto de individuos y de grupos que de objetos, de actos y situaciones constituidos por medio de y en el transcurso de miríadas de interacciones sociales. (Moscovici 1979: 16)

La relación del individuo con la estructura social, añadió, es antes que nada activa porque implica referir las representaciones a un sistema de valores, nociones y prácticas que le permiten al individuo orientarse en el contexto social. Como podemos observar en la siguiente cita, reproducción y transformación de la estructura social se producen al mismo tiempo:

Es cierto que reproduce. Pero esta reproducción implica un reentramado de las estructuras, un remodelado de los elementos, una verdadera reconstrucción de lo dado en el contexto de los valores, las nociones y las reglas con las que, en lo sucesivo, se solidariza (ídem: 17).

Pero existe otro motivo que hace inexorable la transformación, y es que las representaciones no son algo abstracto ni exclusivamente mental sino que se ponen en escena a través de prácticas que implican al cuerpo de diversas maneras (incluso pensar es una acción corporal). Ya Durkheim había propuesto que la religión como sistema de pensamiento es un sistema de mitos, dogmas, ritos y 
ceremonias (Durkheim 1912: 40) y Moscovici añadió que las representaciones sociales "circulan, se cruzan y se cristalizan sin cesar en nuestro universo cotidiano a través de una palabra, un gesto, un encuentro. (...) Sabemos que corresponden, por una parte, a la sustancia simbólica que entra en su elaboración y, por otra, a la práctica que produce dicha sustancia” (Moscovici 1979: 27).

Ambas frases nos dan la pauta de que los sistemas de clasificaciones son materiales, que poseen una dimensión material y se hacen cuerpo. Esto es sumamente importante para el análisis de una práctica deportiva como el fútbol, donde una propuesta institucional y numerosos valores se transmiten a través de los ejercicios físicos que realizan a diario. Pero al mismo tiempo, postular las representaciones en términos de prácticas corporales implica correrlas de cualquier tipo de linealidad, de que el sentido sea estable y estático. El cuerpo tiene su propia lógica, sus propios movimientos y formas, sus límites y posibilidades. Como el mismo Moscovici afirma, el acto de comunicar

...nunca se reduce a transmitir los mensajes originales o a transportar informaciones inmutables, sino que diferencia, traduce, interpreta, combina, así como los grupos inventan, diferencian o interpretan los objetos sociales o las representaciones de los otros grupos" (1979: 18).

Esta inventiva, interpretación y combinación no es estrictamente mental sino que aquí proponemos que se está en el mundo de manera corporal. En consecuencia, las representaciones no son solamente el efecto de la pugna entre distintos actores intencionales que proponen asociaciones en torno de algunos conceptos sino inevitablemente el efecto de prácticas corporales individuales y colectivas.

\subsection{Influencia de la estructura social sobre los individuos}

De manera resumida, hasta aquí vimos que desde el momento en que nacemos -o antes inclusovamos incorporando una manera de ver y estar en el mundo y lo vamos clasificando, es decir que lo que percibimos, producimos y experimentamos pasa a estar asociado a muchas otras representaciones: conceptos, imágenes o ideas. Que ese proceso es corporal y no únicamente mental, que no hay un significado establecido para nuestro entorno sino que en nuestra práctica la vamos construyendo. Con el tiempo, algunas de esas representaciones se van "sedimentando", van formando una especie de sustrato que damos por sentado y que prefigura nuestra aproximación al mundo. En paralelo, observábamos que si a Durkheim se le puede criticar la pasividad del individuo y el determinismo social, en el caso de Moscovici parecería haber una prevalencia del sujeto que parece menospreciar la influencia de la estructura. 
Planteábamos también que en el trabajo que aquí realizamos tiene peso "la sociedad" como máquina productora de sentidos. No lo hacíamos explícito pero estábamos haciendo un enlace con la idea propuesta por Karl Marx en el tomo 2 de El Capital de que toda sociedad necesita, para continuar en el tiempo, reproducir las condiciones de producción, es decir, las fuerzas productivas (tanto los medios de producción como la fuerza de trabajo) y las relaciones de producción existentes (es decir, las relaciones entre los hombres respecto de las cosas).

En lo que a nosotros compete, el espectáculo futbolístico, para propagarse en el tiempo, precisa reproducir "la fuerza de trabajo", es decir generar jugadores de fútbol. Siguiendo el modelo marxista, esto implica lograr que los futuros jugadores tengan sus necesidades básicas cubiertas, incrementar su calificación para hacerlos competentes o -en nuestro caso- lo suficientemente "competitivos" como para que ganen partidos de fútbol. Y en el caso que abordamos se hace necesario un tercer elemento: que la relación que los niños establecen con el fútbol sea de deseo y no sólo de deseo; que vean como factible o al menos posible devenir profesionales del fútbol. Es decir que como aquí trabajo sobre la dimensión representacional de los fenómenos sociales, observaré qué representaciones contribuyen a la reproducción de la fuerza de trabajo y a las relaciones de producción.

En consecuencia, en este apartado abordaré tres teorías que trabajaron en esta línea, que procuraron explicar de qué manera las sociedades se reproducen. Sin dudas hay muchas otras, pero tomo estas tres porque considero que nos brindan elementos concretos para aproximarnos a nuestra problemática. Se trata de las nociones de acolchado e identificación de Slavoj Zizek para preguntarnos “con qué fútbol se identifican los jugadores"; la noción de habitus de Pierre Bourdieu para pensar las relaciones familiares y el concepto de "discurso" de Michel Foucault para pensar la relación entre las representaciones, las instituciones y la promoción de una normativa. Con este último autor incorporamos a las representaciones, entonces, las relaciones de poder.

Los autores que abordaremos pusieron el foco del análisis en términos de reproducción y continuidad antes que de transformación (aunque aquí no pensemos una sin la otra), y rechazan la idea de que el individuo construye su percepción en la experiencia misma sino que su percepción es producto de la relación entre la influencia del pasado y el acontecimiento presente. Sin embargo me interesaría hacer una salvedad: lo dicho no implica que toda representación o estructura simbólica esté en función de la reproducción del capitalismo como sistema de generación de riqueza: postular que en última instancia todo se trata de reproducir el sistema ("un" sistema) de acumulación implicaría una 
mirada funcionalista de la que ya he intentado desmarcarme. Por otra parte, podríamos conceder que si evaluamos los dispositivos de promoción del fútbol por parte del Centro de Formación -y de los valores asociados- es difícil no hacer una lectura que exponga que los clubes realizan una inversión en los jugadores de cantera con el objetivo de reducir los riesgos en pos de generar una ganancia económica, incluso cuando los balances en este aspecto den negativo.

Un estudio distante de la temática que aquí trabajamos fue el que me dio la pauta del abordaje que intento realizar. Respecto del trabajo infantil en India, la Dra. Valentina Glockner afirmó lo siguiente:

...no se puede entender y mucho menos reducir o eliminar los costos y consecuencias del trabajo infantil sin comprender a profundidad el contexto sociocultural en el que este se origina y reproduce. Pero limitarnos únicamente a este ámbito de análisis, concluyendo que el trabajo infantil se reproduce de la mano de las jerarquías y las estructuras tradicionales' de dominación sería igual de limitado y contraproducente. (...) el trabajo infantil surge, se transforma, adapta y reproduce también como un medio, una herramienta y una de las pocas estrategias que las poblaciones migrantes tienen para adaptarse a las condiciones de precariedad laboral y económica impuestas por el capitalismo (Glockner 2014: 146).

Es decir, si transportamos su propuesta a nuestro trabajo, lo que encontramos es que el modo de generación y acumulación capitalista está ahí, presente en el campo de juego, genera sentidos con los que todos los actores dialogan de manera más o menos explícita. Pero no es determinante de los sentidos y los individuos no son sumisos frente a un poder suyo con mayúsculas. Entiendo que no hay "un" capitalismo sino que es permanente la transformación a partir de la puesta en cuerpo y en acción de los actores que lo llevan a la práctica, y en consecuencia lo que me interesa es observar cómo los jóvenes jugadores surgen, se transforman, adaptan y reproducen -los cuatro verbos de Glockner- en un contexto sociocultural que sí, que propicia estructuras de percepción y acción en el mundo.

\subsection{El deseo como disposición}

Una mirada de la que tomaremos elementos para pensar el modo en que el pasado influye sobre el presente es la de Pierre Bourdieu. Lo incorporo a mi propuesta teórica porque se pregunta qué pasado es ese que se reproduce, qué forma toma la estructura social. El sociólogo francés decidió sintetizar las posturas objetivistas -aquellas que como en Saussure, Levi-Strauss o Althusser privilegian el sistema simbólico sobre la actividad humana- y las subjetivistas, que proponen un individuo cognoscente libre que se enfrenta al mundo y lo construye a cada momento. Frente a ambas, con la publicación en 1980 de El sentido práctico se propuso buscar "el principio de las prácticas [es decir, la 
motivación de las acciones] en la relación entre constricciones externas que dejan un margen muy variable a la elección y disposiciones que son el producto de procesos económicos y sociales casi completamente irreductibles a esas coerciones puntualmente definidas" (2010:82)

En Bourdieu el mundo social no es únicamente una representación ni las prácticas, ejecuciones de "partituras" previas. Para él los objetos de conocimiento son construidos pero esto no significa que sea una construcción libre de constricciones ${ }^{20}$. El principio de las prácticas, sostiene, es "el sistema de las disposiciones estructuradas [por el pasado que influye] y estructurantes [porque promueven nuevas estructuras] que se constituye en la práctica, y que está siempre orientado hacia funciones prácticas" (Bourdieu 2010: 85, el destacado me pertenece). Se puede observar que hay tres conceptos centrales: las prácticas, las disposiciones y el que conjuga todo: el habitus. El sociólogo francés lo define de la siguiente manera:

Los condicionamientos asociados a una clase particular de condiciones de existencia producen habitus, sistemas de disposiciones duraderas y transferibles, estructuras estructuradas predispuestas a funcionar como estructuras estructurantes, es decir, como principios generadores y organizadores de prácticas y de representaciones que pueden ser objetivamente adaptadas a su meta sin suponer el propósito consciente de ciertos fines ni el dominio expreso de las operaciones necesarias para alcanzarlos, objetivamente 'reguladas' y 'regulares' sin ser para nada el producto de la obediencia a determinadas reglas y, por todo ello, colectivamente orquestadas sin ser el producto de la acción organizadora de un director de orquesta. (2010: 86, el destacado de me pertenece)

Bourdieu concede que el mundo se presenta como natural y necesario, pero esto se produce porque las regularidades (y no reglas) “están en el principio de los esquemas de percepción y de apreciación a través de los cuales son aprehendidas" (ídem: 87). Esas regularidades, disposiciones, propensiones a la práctica, surgen de condiciones de existencia, de las libertades y las necesidades, las facilidades, los impedimentos. Todos esos elementos del pasado, sedimentados ("ley interior", define en página 89), condicionan las prácticas, definen lo posible y lo imposible, lo pensable e impensable, dan forma a marcos de realidad e irrealidad. Es por este motivo que cuando pensamos en los futbolistas no sólo nos preguntamos por su deseo sino por los motivos que hacen que ese deseo les resulte alcanzable, verosímil. Observemos las siguientes líneas:

...dado que las disposiciones inculcadas perdurablemente por las posibilidades e imposibilidades, las libertades y las necesidades, las facilidades y los impedimentos que están inscritos en las condiciones objetivas (...) engendran disposiciones objetivamente compatibles con esas

20 "La coherencia sin intención aparente y la unidad sin principio unificador inmediatamente visible de todas las realidades culturales que son habitadas por una lógica cuasi natural (...) son el producto de la milenaria aplicación de los mismos esquemas de percepción y de acción que, no habiéndose constituido jamás en principios explícitos, no pueden producir sino una necesidad no buscada, y por ende necesariamente imperfecta, pero también un poco milagrosa, y muy próxima en ese sentido a la de la obra de arte" (2010: 28) 
condiciones y en cierto modo preadaptadas a sus exigencias, las prácticas más improbables se ven excluidas, antes de cualquier examen, a título de lo impensable. (2010: 88)

Tres páginas después agrega

En una palabra, siendo el producto de una determinada clase de regularidades objetivas, el habitus tiende a engendrar todas las conductas 'razonables', de 'sentido común', que son posibles en los límites de esas regularidades (...) al mismo tiempo tiende a excluir 'sin violencia, sin arte, sin argumento', todas las 'locuras ('eso no es para nosotros'), es decir todas las conductas condenadas a ser sancionadas negativamente por incompatibles con las condiciones objetivas. (2010:91)

El habitus, producto de la historia, "hipótesis prácticas fundadas en la experiencia pasada” (ídem: 88) da origen a prácticas individuales y colectivas, posibilita la reproducción y al mismo tiempo la transformación porque no solamente genera continuidades sino que se adapta a las situaciones nuevas para cumplir "las antiguas funciones" (ídem: 89):

Si la génesis del sistema de las obras o de las prácticas engendradas por el mismo habitus (...) no puede describirse ni como desarrollo autónomo de una esencia única y siempre idéntica a sí misma, ni como continua creación de novedad, es porque ella se realiza en y por la confrontación a la vez necesaria e imprevisible del habitus con el acontecimiento... (ídem: 90)

A partir de Bourdieu y su noción de habitus, en este trabajo intentaremos observar los modos en que el pasado se hace presente en los jugadores, y nos preguntaremos si aparecen elementos respectivos a las condiciones de existencia pasadas que influyen sobre las representaciones que los jugadores ponen en escena en sus prácticas. Somos conscientes de las limitaciones que implica proponer que son las condiciones de existencia las que se reproducen, aunque comprendemos su eficacia para observar la reproducción de las relaciones entre las distintas clases sociales, objetivo de dicho sociólogo.

Al respecto, una vía a indagar es aquella que recupera Néstor García Canclini en su lectura de Bourdieu, cuando observa que en el sociólogo francés la clase social

no puede ser definida por una sola variable o propiedad (ni siquiera la más determinante: 'el volumen y la estructura del capital'), ni por 'una suma de propiedades' (origen social + ingresos + nivel de instrucción), 'sino por la estructura de las relaciones entre todas las propiedades pertinentes que confiere a cada una de ellas y a los efectos que ella ejerce sobre las prácticas su valor propio'. (García Canclini 1990: 15)

A esta lectura, García Canclini propone pensar la categoría de clase no solamente a partir de las condiciones de producción -como aparece en parte de la obra del sociólogo francés- sino a partir de poner el foco en el consumo. En este sentido, observaremos en este trabajo si pese a las diferencias en las condiciones económicas que pueden existir existen consumos similares ligados al fútbol, como por ejemplo los mediáticos. Si aparecieran, podríamos preguntarnos si el fútbol está generando una ruptura en la idea de Bourdieu de tres modos de producción diferenciados (burgués, medio y popular, cada uno 
con públicos, tipo de obras e ideologías político-estéticas propias) y así distanciarnos de la idea de distribución desigual de bienes materiales y simbólicos.

\subsection{Identificación y sujeción}

Ya se mencionó que el objeto condiciona las significaciones respecto de sí -que son múltiples pero no infinitas-, dije también que no las determina y expusimos que el sentido es el efecto de consensos y pugnas entre distintos actores. Para relacionar todo eso con la necesidad de la estructura social de reproducirse pondremos el foco en la relación que los actores establecen con la estructura social $^{21}$, y específicamente en la relación de adhesión que los actores van estableciendo, es decir aquella relación por la cual los individuos se identifican con algunos de sus elementos, valores, grupos de ideas o personas, entre muchas formas.

Para pensar esta cuestión decidimos trabajar con la propuesta de Slavoj Zizek respecto de los modos de significación. El filósofo esloveno se preguntó cómo es posible que pese a que existe una lucha significante en torno de un objeto -y en consecuencia que se produzcan transformaciones permanentes respecto de su significación- se mantenga la referencia a ese mismo objeto, su “identidad”. Recuperó entonces de Ernesto Laclau la idea de que el espacio ideológico está hecho de elementos sin amarrar a los que denominó "significantes flotantes" cuya identidad está "abierta", sobredeterminada por la articulación de los mismos en una cadena con otros elementos.

A partir de allí postuló que lo que "fija” su significado, al menos momentáneamente, es un "punto nodal". Por eso para él la significación es retroactiva, la lucha consiste en definir qué "punto nodal" determinará el sentido:

Si sostenemos que el point de capiton es un 'punto nodal', una especie de nudo de significados, esto no implica que sea simplemente la palabra 'más rica', la palabra en la que se condensa toda la riqueza de significado del campo que 'acolche': el point de capiton es, antes bien, la palabra que, en tanto que palabra, en el nivel del significante, unifica un campo determinado, constituye su identidad: es, por así decirlo, la palabra a la que las 'cosas' se refieren para reconocerse en su unidad (1992: 136).

21 Ya Jodelet expresaba que “...siempre debemos recordar esta pequeña idea: toda representación social es representación de algo y de alguien. Así, no es el duplicado de lo real, ni el duplicado de lo ideal, ni la parte subjetiva del objeto, ni la parte objetiva del sujeto. Sino que constituye el proceso por el cual se establece su relación. Sí, en el fondo de toda representación debemos buscar esta relación con el mundo y con las cosas. (...) El acto de representación es un acto de pensamiento por medio del cual un sujeto se relaciona con un objeto. (...) Representar es sustituir a, estar en el lugar de. En este sentido, la representación es el representante mental de algo: objeto, persona, acontecimiento, idea, etc. Por esta razón, la representación está emparentada con el símbolo, con el signo. Al igual que ellos, la representación remite a otra cosa. No existe ninguna representación social que no sea la de un objeto, aunque éste sea mítico o imaginario" (Jodelet 1986: 374). 
La definición de la Real Academia Española de "acolchar" nos puede brindar algunas pistas de su propuesta: "Poner algodón, seda cortada, lana, estopa, cerda u otras materias de este tipo entre dos telas y después bastearlas". Es decir, Zizek dice que los significantes asociados a un objeto están "flotando" (la palabra es mía) hasta que aparece un significante que les da "puntadas" (el basteado) y realiza una suerte de costura que los ubica a todos en línea y fija su movimiento, al menos momentáneamente. Ese "acolchado", además, está ligado al proceso de "inversión” por el cual ese significante nodal pasa a ocupar el lugar del objeto al que representa. Dejemos que un ejemplo esclarezca a qué se refiere:

Tomemos el caso del famoso anuncio de Marlboro: la imagen del vaquero bronceado, las extensas praderas y demás -todo ello 'connota', por supuesto, una imagen determinada de Estados Unidos (...), pero el efecto de 'acolchado' tiene lugar únicamente cuando ocurre una cierta inversión; ésta no ocurre hasta que los norteamericanos 'reales' empiezan a identificarse (en su experiencia ideológica) con la imagen creada por el anuncio de Marlboro (ídem).

En la perspectiva de Zizek no es el objeto el que condiciona el sentido sino su point de capiton, y por eso es antiesencialista: no habría ninguna posibilidad de definir algún conjunto de propiedades que se mantuviera en "todos los mundos posibles". Lo que a él le importa es que esa inversión implica que la potencia del sentido está en el significante Marlboro, o Coca Cola (o fútbol) más allá de la forma que tome cualquiera de ellos, “el objeto-causa de deseo, ese 'algo inalcanzable' que está 'en Coke más que Coke' y que, según la fórmula lacaniana, podría cambiar de repente y convertirse en excremento, en lodo no potable". No importa lo que sea el objeto, dice Zizek, lo que importa es lo que pese a todo sigue significando, y esa significación está ligada a la identificación de los individuos con esos significantes. Es decir, si traducimos esto al mundo del fútbol, lo que buscaremos en los jugadores es con qué significantes identifican al fútbol (cuáles ocupan el lugar de Marlboro) para comprender qué termina "siendo" el fútbol para ellos al punto de que los convoca a aspirar a devenir profesionales.

Un breve rodeo ligado a la representación: para explicar este proceso, Zizek apela a Lacan y comparte con autores como Louis Althusser que el "acolchamiento" es producto de la interpelación, entendida esta como el resultado del pasaje de individuo a sujetos ${ }^{22}$. No es esta la mirada que sostendremos en este trabajo porque desde nuestro punto de vista no es únicamente en los primeros años de vida cuando se produce el proceso de "sujeción" sino que a lo largo de toda la vida y a través

22 "El point de capiton es el punto a través del cual el sujeto es 'cosido' al significante, y al mismo tiempo, el punto que interpela al individuo a transformarse en sujeto dirigiéndole el llamado de un cierto significante amo "Comunismo", "Dios", "Libertad", "Estados Unidos") -en una palabra, es el punto de subjetivización de la cadena del significante" (1992: 142). 
de la propaganda estatal, la publicidad o instituciones como el Centro de formación de futbolistas es que los individuos transforman y reproducen su relación.

No obstante, tiene a su favor que pone en el centro la incorporación de la estructura social de manera naturalizada, es decir la cadena significante en torno de un determinado objeto es esencial:

Estamos 'en transferencia' cuando nos parece que la libertad real es 'en su naturaleza misma' opuesta a la libertad formal burguesa, que el estado es 'en su naturaleza misma' sólo un instrumento de la clase dominante, y demás. La paradoja reside, por supuesto, en que esta ilusión transferencial es necesaria, en la medida misma del éxito de la operación de 'acolchado: el capitonnage, es fructífero únicamente la medida en que borra sus propias huellas (1992: 144)

La noción de identificación en Zizek -que retoma de Lacan- se divide en dos: identificación simbólica e imaginaria. Por la primera se refiere a una identificación con alguna característica significante del orden simbólico mismo,

representa al sujeto para otro significante'; asume una forma concreta, reconocible en un nombre o en un mandato que el sujeto toma a su cargo y/o se le otorga (...) es la identificación con el lugar desde el que nos observan, desde el que nos miramos de modo que nos resultamos amables, dignos de amor. (1992: 147)

Asumiendo que me faltan lecturas para comprender la teoría lacaniana en profundidad, interpreto que en este párrafo Zizek propone que parte de la identidad de sujeto está ligada a satisfacer una mirada ajena, la mirada de lo que se espera de él, y que en consecuencia -en busca de ese amor- nos ubicamos en posiciones que posibiliten recibir tal afecto. La identificación imaginaria está ligada al Edipo, a la idea de que para constituir identidad propia el sujeto se debe identificar "con el otro imaginario, se ha de enajenar- pone su identidad fuera de él, por así decirlo, en la imagen de su doble"23; por eso expresa que se trata de la imagen que representa "lo que nos gustaría ser" (1992: 147).

El autor se distancia, sin embargo, de la idea corriente de que la identificación consiste en imitar modelos, ideales, héroes populares, deportistas. A esta mirada le critica en primer término que la identificación no siempre es una característica encantadora o con elementos "positivos", y en segundo lugar que implica que pasa por alto "el hecho de que la identificación imaginaria es siempre identificación en nombre de una cierta mirada en el Otro. Así pues, a propósito de cada imitación de una imagen modelo, a propósito de cada 'representación de un papel', la pregunta a plantear es: ¿para

23 Jacques Lacan sostuvo que el paso de la existencia biológica a la existencia humana "se opera bajo la Ley del Orden, que yo llamaré Ley de Cultura". El pasaje consiste en dos etapas: la primera consiste en un momento dual, en la que el niño tiene una relación con la madre en la que no se distingue a sí mismo, y vive esta relación siendo él mismo ese otro, la madre. La satisfacción llega en respuesta al pedido: el niño llora y la madre lo alimenta, lo limpia o lo acuna. La segunda etapa, el momento conocido como el Edipo, implica la incorporación del tercero, el padre, que al interrumpir la relación dual con la madre "introduce al niño en lo que Lacan llama el Orden Simbólico", que le permitirá al pequeño adquirir identidad propia. Una identidad que surgirá a partir de la emulación de la figura paterna: para ser como él deberá conseguir su propia mujer. (Althusser 1976: 27) 
quién actúa el sujeto este papel? ¿Cuál es la mirada que se tiene en cuenta cuando el sujeto se identifica con una determinada imagen?" (ídem: 148). Para Zizek siempre la mirada del Otro predomina sobre la construcción de la imagen del individuo. Por este motivo, porque ese Otro social predomina sobre el individuo, el filósofo esloveno asegura que esa interacción entre identificación imaginaria y simbólica bajo el dominio de la identificación simbólica "constituye el mecanismo mediante el cual el sujeto se integra en un campo socio-simbólico determinado -el modo en que él/ella asume ciertos 'mandatos' (1992: 153)"

La última etapa de su análisis consiste en aplicar todo lo visto al individuo mismo. Su planteo implica que el sujeto percibe que la sociedad lo ubica en un espacio determinado -se sabe perteneciente a la red simbólica-, pero no en qué espacio lo ubica: si el individuo mismo es ese Marlboro, esa Coca Cola, eso que aún en sus transformaciones mantiene su identidad, permanentemente le pregunta a ese Otro imaginario “¿cuál es ese objeto plus en mí que hace que el Otro me interpele, me ‘salude’ como... [rey, amo, esposa]? (Lacan, 1981, p.315)" (Zizek 1992: 157). En nuestro análisis, esto implica preguntarse qué point de capiton se dirige sobre los jóvenes futbolistas que "acolcha" el significante futbolista y al que los jugadores buscan satisfacer: qué quiere la sociedad de ellos, después de todo.

\subsection{El centro de formación como organización}

Expresamos en la introducción que aquí se considerará el Centro de Formación como el espacio donde confluyen las estructuras sociales, y que las relaciones que allí se establecen permiten observar elementos que se dan en muchos otros espacios aunque no podamos hablar de "reflejo" de la sociedad. Dado que el Centro de Formación es una “organización” comenzaré por exponer algunos principios de la definición de "organización" que me permitieron observar la cantera. Para esto decidí tomar como punto de partida el libro de Richard Hall Organizaciones, estructura y procesos, que en su capitulo 2 realiza una lectura de las distintas corrientes que abordaron la cuestión y de la cuales enumeraré los elementos que resultarán útiles para el presente texto.

Lo primero que debemos decir es que se trata de espacios que involucran relaciones sociales, es decir la interacción de individuos. Esta interacción tiene una estructuración, un orden impuesto por la organización misma -o mejor dicho, por sus líderes en casos como el Centro de Formación. De aquí arribamos a un segundo elemento: las organizaciones tienen jerarquías, y esas jerarquías están en 
función de una "meta". Las organizaciones, expresó Max Weber, están diseñadas para "hacer algo" (Hall 1982: 30).

En 1964, Richard Scott compartió la idea de la consecución de objetivos como el fin principal de la organización, pero amplió su definición a otros elementos:

"queda claro que las organizaciones tienen características distintivas aparte de la continuidad y especificidad de metas. Estas incluyen fronteras relativamente fijas, un orden normativo, niveles de autoridad, un sistema de comunicación, y un sistema de incentivos que permite que varios tipos de participantes trabajen juntos en la consecución de metas comunes”. (Hall 1982: 31)

Su definición pone en escena una cuestión central de las organizaciones: si las metas de la organización están “codificadas” más allá de los individuos, o si están ligadas a estos. Hall menciona el trabajo de Herbert Simon, quien en 1964 ganó el Premio Nobel en Economía por su trabajo sobre organizaciones y postuló que las metas no pueden considerarse aparte de los actores individuales, pero Hall opta por definirlas como codificadas. En el caso del Centro de Formación estudiado y donde he encontrado que muchos jugadores tienen metas individuales más allá de las de la organización, voy a trabajar a partir de la mirada de Simon y observando que las metas son múltiples.

De la definición precedente también observaremos la noción de "frontera", profundamente ligada a los métodos de reclutamiento y selección de jugadores. Señala Hall que esta idea implica la existencia de algo externo a la organización, un "ambiente" que también es sumamente importante. Un primer “ambiente” está ligado al plano físico -en nuestro caso la ubicación geográfica, por ejemplo- y un ambiente social ligado a los "competidores, reguladores y otras fuentes de presión y oportunidades para las organizaciones" (Hall 1982: 33). Veremos que esto también es relevante para el reclutamiento de jugadores.

Un elemento más sumamente importante, y que Hall recupera de Benson y Heydebrand: que las organizaciones "se caracterizan por la diferenciación interna". Esto significa, en Hall, que se trata de entidades políticas, "con diversos partidos, tanto individuos como unidades, luchando por el control (...) Las organizaciones contienen fuerzas de oposición. Estas fuerzas pugnan por el control" (Hall 1982: 33).

Ahora bien, las organizaciones no operan en contextos estáticos sino que deben adaptarse permanentemente a entornos dinámicos. La teoría que abordó esta cuestión es la "sociopoiética", y que se propuso "abordar comprensivamente los procesos organizacionales como conjuntos dinámicos de selecciones adaptativas y de control" (Arnold-Cathalifaud, 2008). Por ese motivo para esta corriente el entorno en el que se encuentra la organización es central, así como su capacidad de adaptación. Desde 
la perspectiva del chileno Marcelo Arnold-Cathalifaud, esta adaptación es producto de las informaciones que recibe la organización y de cómo éstas son apropiadas para tomar y comunicar “decisiones" a partir de las alternativas consideradas. Mediante estas informaciones y las decisiones posteriores, añade, las organizaciones buscan controlar la incertidumbre. En paralelo, agrega la importancia de la dimensión cultural en la toma de decisiones:

las culturas operarían como medios por donde circulan las operaciones del decidir, y como sustrato estabilizador, en forma de premisas, decisiones que operan como incuestionables o transparentes y que se han constituido en las formas naturales y obvias de observar el mundo de y desde la organización [Rodríguez 2001] (Arnold-Cathalifaud, 2008: 12)

La dinámica interna de la organización también puede ser pensada a partir de la noción de campo, tanto en su vertiente bourdieana como turneriana. Bourdieu la conceptualizó como "una red o configuración de relaciones objetivas entre posiciones", que se definen

objetivamente en su existencia y en las determinaciones que imponen a sus ocupantes, ya sean agentes o instituciones, por su situación actual y potencial en la estructura de la distribución de las diferentes especies de poder (o de capital ${ }^{24}$ ) cuya posesión implica el acceso a las ganancias específicas que están en juego dentro del campo y, de paso, por sus relaciones objetivas con las demás posiciones (dominación, subordinación, homología, etc.) (Bourdieu y Wacquant, 1995: 64) [en Fernández \& Puente (2009)]

En la introducción a Sociología y Cultura, Néstor García Canclini explica que la noción de campo en el sociólogo francés constituye su intento por evitar pensar los productos (artísticos, políticos, futbolísticos) como efectos directos de un modo de producción, y propone pensar a los actores de cada campo (en nuestro caso los futbolistas) a partir del sistema de relaciones que se establece al interior del campo y que "determina las condiciones específicas de producción y circulación de los productos" (García Canclini 1990: 18). Luego se pregunta:

¿Qué es lo que constituye un campo? Dos elementos: la existencia de un capital común y la lucha por su apropiación. A lo largo de la historia, el campo científico o el artístico han acumulado un capital (de conocimiento, habilidades, creencias, etcétera) respecto del cual actúan dos posiciones: la de quienes detentando el capital y la de quienes aspiran a poseerlo. un campo existe en la medida en que uno no logra comprender una obra (un libro de economía, una escultura) sin conocer la historia del campo de producción de la obra. (García Canclini 1990: 19)

Si proyectamos esta definición sobre la organización analizada podemos referirnos a dos aspectos: las relaciones entre los distintos integrantes del staff formativo (cuerpos técnicos, coordinadores y preparadores físicos sobre todo), quienes como veremos en el capitulo 5 disputan por

\footnotetext{
${ }^{24}$ Bourdieu divide al capital en cuatro formas. En primer término menciona el "capital económico", que tiene que ver con el control sobre recursos económicos. En segundo término, el "capital social", que consiste en la pertenencia a grupos, las relaciones, los contactos: un capital de reciprocidades. Tercero, el capital cultural, donde el énfasis está puesto en las formas de conocimiento que incrementan el status de la persona en su sociedad. Finalmente, el capital simbólico, como el prestigio acumulado o poder adquirido en la medida que sea reconocido por los demás agentes del campo.
} 
poder y por dinero, aunque también por imponer un modo de pensar a las fuerzas básicas (el rol que ocupan en la estructura general y en el club en términos empresariales), al tipo de jugador a promover, las formas de entrenarlos, de relacionarse con ellos y el tipo de fútbol a desarrollar. En segundo término, la relación que se establece entre los jugadores, quienes desde mi punto de vista pugnan por demostrar que son los más adecuados para portar el mote de "promesa" del club universitario.

Bourdieu piensa el conflicto antes que nada a partir de la pugna entre "pretendientes y dominantes", es decir entre dos posiciones con diferentes espacios de poder en relación a la "doxa", que en él es el sentido común. Ambos grupos de actores (él piensa en términos de colectivos) compiten por "aquello que está en juego e intereses específicos", y esos elementos en competencia, que son los que definen el campo, sólo son percibidos por aquellos que nacieron para entrar en el campo, porque en su perspectiva la noción de habitus -que expresa antes que nada que el pasado estructura “disposiciones” generadoras de prácticas 25 - es un estado de cuerpo, con el que se nace.

Esto implica que, lejos de las miradas voluntaristas de la acción, en su perspectiva el accionar del individuo es inconsciente ${ }^{26}$, adaptadas a una meta sin propósitos conscientes, ajeno a cálculos estratégicos. No niega la estrategia, pero la subsume a esas disposiciones incorporadas. Bourdieu afirma que se actúa a partir de una estimación de oportunidades que

“en principio se definen, por fuera de todo cálculo, con relación a potencialidades objetivas, inscritas de manera inmediata en el presente (...) en relación con un por venir probable que, al contrario del futuro como 'posibilidad absoluta' (...) se propone con una urgencia y una pretensión de existir que excluye la deliberación" (Bourdieu 2010: 87).

Su preocupación está enfocada en fundamentar la posibilidad de la acción práctica pero sin caer en el finalismo (la idea de que todo lo que los individuos realizan es en función de un objetivo específico consciente), causalista (lo económico determinaría los simbólico) o el mecanicismo (la idea de que la consecución de una serie de acciones llevan a una serie de efectos), y por eso propone al habitus como un sistema de disposiciones adquiridas que es asimismo un sistema de esquemas

25 Considero pertinente la siguiente observación de Néstor García Canclini: “Al querer explicar la estructura de todos los campos según la lógica de su lucha interna por el poder, entre la de los que tienen y la pretensión de los que aspiran, Bourdieu deja dos problemas afuera. El primero: lo que sucede específicamente en cada campo. ¿No hay diferencias esenciales entre el campo científico y el artístico..." (...) La otra cuestión tiene que ver con la relación entre los campos y la historia social. No parece posible explicar a Courréges sólo por su búsqueda de legitimidad dentro del campo. Su uso de exigencias sociales (la vida "práctica y activa" de la mujer actual, la necesidad de mostrar el cuerpo) sugiere interrelaciones entre moda y trabajo, que evidentemente contribuyeron al éxito de ese modisto y a la reformulación de su papel en el campo de la moda." (García Canclini 1984: 20; por Courréges se refiere a un modisto cuyo posicionamiento en el campo de la moda consistió en "vestir a la mujer moderna que debe ser a la vez activa y práctica", y cambió el escenario que hasta ese momento se dirimía entre Balmain y Scherrer).

26 "El inconsciente (...) no es nunca otra cosa que el olvido de la historia que la historia misma produce al realizar las estructuras objetivas que ella engendra en esas cuasi naturalezas que son los habitus" (Bourdieu 2010: 91) 
generadores, un "ajuste anticipado a las exigencia de un campo, lo que el lenguaje deportivo llama 'el sentido del juego' (como 'sentido de la ubicación', arte de 'anticipar', etc.)”:

"es lo que hace que el juego tenga un sentido subjetivo, es decir una significación y una razón de ser, pero también una dirección, una orientación, un por-venir, para aquellos que participan en él y que en esa misma medida reconocen en él lo que está en juego [les enjeux] (es la illusio en el sentido de inversión en el juego y las apuestas [les enjeux], de interés por el juego, de adhesión a los presupuestos -doxa- del juego). (Bourdieu 2010: 107).

La pertenencia al campo es entonces nativa, y por ese motivo todo lo que ocurre en él parece sensato. Por eso en Bourdieu la creencia es constitutiva de la pertenencia al campo, y la pertenencia es “natal, indígena, originaria". Se opone entonces a la noción de "fe pragmática" de Kant, que Bourdieu interpreta como "adhesión decisoriamente acordada, para los requerimientos de la acción, a una proposición incierta" (ídem: 109). La pertenencia al campo es corporal y no es efecto de una decisión.

Si bien podemos concordar con la distancia que pone respecto de las posturas voluntaristas y que piensan los movimientos de los actores a partir de estrategias racionales, calculadas en función de los recursos con los que cuentan (ver apartado 3.4.2), también podemos preguntarnos de qué manera entonces influye la organización y su normativa. Si las disposiciones son plenamente "natales, originarias" (es decir, si vienen de "la casa"), los jugadores (o los cuerpos técnicos o coordinadores) ¿operarían de igual manera en cualquier club? ¿No importan en absoluto las normas de cada espacio en particular porque el joven desde antes de ingresar ya conoce las "reglas" y pertenece al campo desde su tierna infancia? Parece difícil de sostener. Comparto que los individuos actúan a partir de disposiciones, formadas en muchos casos a partir de relatos de los padres, de experiencias propias desde que se iniciaron hasta que ingresan a la cantera, de lo que observaron en medios de comunicación, de los modos en que ellos fueron interpretando la normativa del fútbol. Pero desde mi punto de vista esto se confronta y actualiza en el acontecimiento, en las relaciones que establecen con entrenadores, coordinadores y compañeros.

\subsubsection{La organización como proceso}

Con una temporalidad epistemológica distinta de la bourdeana, Victor Turner postula una teoría de los campos cuyo foco no radica en el plano sincrónico sino en el plano procesual y diacrónico. Desde su punto de vista, la noción da cuenta de "dominios culturales abstractos donde los paradigmas son formulados, establecidos y se ponen en conflicto [come into conflict]. Dichos paradigmas consisten en conjuntos de reglas desde las que muchos tipos de secuencias de acción social podrían ser generadas 
pero de las cuales algunas son excluidas”. (2002 [1974]: 17, traducción propia).

Victor Turner también parte de una premisa distinta: si Bourdieu se proponía explicar la reproducción de lo social, el antropólogo escocés está dedicado a preguntarse por la transformación. Postula que lejos de una evolución ligada a una programación genética, las especies son adaptativas y escapan a las ataduras a partir de la "acción simbólica cultural humana" (ídem: 15). Es decir: lo simbólico aquí no es referencia a lo prefigurado, a las “constricciones” culturales, sino que se relaciona con procesos de apertura, de "finales abiertos" en la evolución biológica: "Creo que las encontramos en esas liminales formas de acción simbólica, esos géneros de actividad fuera de tiempo [free-time activities], en el que todos los estándares previos y modelos están sujetos a la crítica y se formulan algunas formas nuevas de describir e interpretar la experiencia sociocultural” (íbid: 15) ${ }^{27}$.

Lo liminal es central en su teoría. En "La selva de los símbolos” se refiere al período liminar como un "estado de transición”, un momento culturalmente reconocido y de "proceso, un llegar a ser, y, en el caso de los rites de passage, incluso como una transformación" (1980: 104). Turner retoma a Van Gennep y recupera su análisis de las fases de los ritos: separación, margen (o limen) y agregación. Durante la segunda, que es la que aquí se torna relevante, “el estado del sujeto del rito (o «pasajero») es ambiguo, atravesando por un espacio en el que se encuentra muy pocos o ningún atributo, tanto del estado pasado como del venidero" (ídem). En la misma senda, posteriormente afirma que "El ser transicional o 'persona liminar' se halla definido por un nombre y un conjunto de símbolos", a la par que afirma que se trata de un ser estructuralmente indefinible, que escapa a las definiciones y clasificaciones de una cultura.

No es sencillo pensar al centro de formación a partir de la liminalidad. Algunos elementos de la experiencia que atraviesan los jugadores sí tienen puntos en común (porque pertenecen al club y marcan una diferencia de sus pares pero aún no son profesionales reconocidos) pero tampoco es simple realizar un análisis desde dicha perspectiva. No obstante, Turner es central para pensar la dimensión procesual en el centro de formación. Por su intento de analizar la transformación propuso comprender a las sociedades como "mundo del devenir" y observar las comunidades a partir del "drama social", es decir de los conflictos y su estructura temporal.

27 En otros apartados explica que en el proceso liminal hay una liberación de las normas y se abre la posibilidad de lo nuevo (1974: 13); y que en su teoría justamente es la liminalidad lo que evita que un programa, un diseño, determine al performance. "Pero, dada la liminalidad programas prestigiosos pueden ser socavados y programas de alternativas múltiples pueden ser generados". 
El mundo social es un mundo del devenir, no del ser (salvo cuando el ser es una descripción de los modelos estáticos y atemporales que los hombres tienen en mente) y por esta razón los estudios de la estructura social como tal son irrelevantes, sus propias premisas básicas son erróneas porque no hay tal cosa como "acción estática" (Turner 2002: 36)

Quiero insistir en que este enfoque procesal decisivo es la guía para comprender el comportamiento social humano. Las instituciones religiosas y legales, entre otras, sólo dejan de ser reglas muertas o frías cuando se observan desde el principio como fases del proceso social, como patrones dinámicos. Es necesario aprender a pensar en las sociedades como 'fluyentes', como una 'peligrosa marea $[\ldots]$ que nunca se detiene o muere [...] Y que, si se la detiene por un momento, quema la mano", como alguna vez lo expresó W.H.Auden (Turner 2002: 48).

Postular que las sociedades se encuentran en un devenir permanente implica pensar que el cambio es intrínseco a los procesos sociales y que "tienen un carácter dinámico, vi movimiento y estructura, persistencia y cambio" (Turner 2002: 45). En lo que respecta a la formación de los jugadores esto supone asumir que lo que observamos y expondremos no es estático, que apenas se trabajó a lo largo de un mes en un proceso que en general comienza a los seis años y que -si completan la formación- se puede extender hasta los veinte. Como se pudo ver en el apartado metodológico, el intento que realizamos para sortear esa dificultad consistió en realizar dos "cortes", un abordaje en dos categorías separadas por cuatro a cinco años con el objeto de intentar observar si existen cambios entre una y otra. Sin embargo, es preciso mencionar que aunque hayamos realizado dos cortes, pensamos a los sujetos de nuestra investigación no como estáticos sino en permanente transformación.

En relación a las organizaciones sucede algo similar: si bien en las categorías en las que hicimos el corte el abordaje se sustenta sobre el plano sincrónico, el Centro de Formación es comprendido como en permanente transformación. En las páginas subsiguientes esto se pondrá de manifiesto en el capítulo 5, a partir de las luchas de poder al interior del centro de formación, de los cambios en la conformación de los cuerpos técnicos y de la organización de la cantera, en la observación de las tradiciones y formas de hacer pasadas que se ponen en juego.

Ahora bien, el eje de análisis de Turner se sostiene sobre pensar los procesos de transformación a partir de su forma "dramática", es decir de los conflictos y pugnas que se presentan en la comunidad. Sabe y afirma Turner que no todo proceso es dramático, ni que toda comunidad se relaciona a través del conflicto sino que también existen formas de cooperación, pero sí afirma que es en esas instancias donde las estructuras de la sociedad aparecen con mayor claridad para el observador ${ }^{28}$. Algo de eso pude encontrar en el estudio pero no es una metodología que haya aplicado plenamente porque implica

28 "El conflicto parece visibilizar los aspectos sociales, normalmente encubiertos por las costumbres, y hace aterradoramente prominentes los hábitos de la rutina diaria. La gente debe tomar partido como imperativo moral, muchas veces en contra de sus preferencias personales. La elección es rebasada por la obligación" (Turner 2002: 47). 
trabajar en un plazo temporal más extenso para así observar diversas "unidades procesales" ni las cuatro etapas del drama social con sus implicancias ${ }^{29}$. En consecuencia, es otro elemento que queda pendiente para un trabajo posterior.

La estructura del centro de formación parece estar más ligada a la idea de organización que veníamos viendo con Richard Hall, y que Turner recupera a partir de Raymond Firth. Para este autor hay un "proceso de reordenamiento de la acción y de las relaciones respecto a fines socialmente dados, en términos de ajustes que resultan del ejercicio de elección por parte de los miembros de la sociedad [1964: 45]" (Turner 2002: 45), y en consecuencia el foco es la búsqueda de resultados. En el caso de los jugadores de fútbol la meta consiste en alcanzar la Primera División, y por parte de la organización serían dos los fines: llevar la mayor cantidad de jugadores de la cantera a la Primera División y ganar la mayor cantidad de partidos en la propia categoría. Como veremos en el apartado 5.6, la tensión entre apostar a la búsqueda de resultados o a la formación de jugadores es central a la cantera y sobre ambas se establecen numerosas luchas de poder. Páginas más adelante Turner agrega -y estamos de acuerdoque

Debido a que sus focos son metas, los factores psicológicos, tales como la voluntad, motivación, rangos de atención y nivel de aspiración, son importantes para el análisis (...) debido a que las metas en forma significativa incluyen las metas sociales, el estudio de las estructuras temporales involucra el análisis del proceso de comunicación, incluyendo las fuentes de presión para comunicarse dentro del grupo y entre grupos. Esto implica inevitablemente el estudio de los símbolos, señales y signos verbales y no verbales, que la gente emplea para lograr las metas personales y grupales. (Turner 2002: 49)

De modo que se hace interesante observar la ligazón que existe entre la perspectiva de Turner y la teoría de las representaciones sociales expuesta. El deseo, según observamos en este trabajo, es uno de los elementos (pero no el único) que propicia la búsqueda de alcanzar metas. En efecto, desde su punto de vista lo que motoriza los eventos sociales es

...un grupo de ideas, imágenes o conceptos con la etiqueta de 'estructuras atemporales'. Se trata de modelos de lo que la gente 'cree hacer, debería hacer o gustaría hacer' [Richards 1939: 160] (...) En las representaciones colectivas intersubjetivas de un grupo se descubrirán las estructuras y los sistemas, los patrones de acción propositivos y, en niveles más profundos, los marcos categóricos. Estas estructuras individuales y grupales, inherentes a la mente y al sistema nervioso, tienen una función directriz y cibernética en la sucesión interminable de los eventos sociales, ya que les imponen su orden $\mathrm{y}$, ciertamente, dividen las unidades procesales en etapas (...) Las fases

\footnotetext{
29 "Una historia del caso ampliado es la historia de un solo grupo o comunidad durante una extensión temporal considerable, recogida como secuencia de unidades procesales de diferentes tipos, incluyendo los dramas y las empresas sociales ya mencionadas. Es más que una mera historiografía, ya que involucra la utilización de cualquier herramienta conceptual que la antropología social y cultural nos ha legado. Lo procesal incluye un análisis en términos dramáticos. (...) En el orden de presentación de los hechos, una estrategia útil es presentar un esquema sistemático de los principios sobre los que está construida la estructura social y medir su importancia, intensidad y variación relativas, desde diferentes circunstancias, de ser posible, con datos numéricos y estadísticos" (Turner 2002: 55).
} 
estructurales de un drama social no son producto del instinto sino de los modelos y metáforas que los actores tienen en la mente. (Turner 2002: 48)

\subsubsection{Organización, estrategia y oportunidad}

Diversas teorías -sobre todo desde una perspectiva económica- abordaron las organizaciones como espacios en los que los actores compiten en pos del acceso a beneficios. Una de ellas es la del neoinstitucionalismo estadounidense, cuyo principal referente es Douglass North. Este economista e historiador postuló que las instituciones son

...las reglas del juego en una sociedad o, más formalmente, son las limitaciones ideadas por el hombre que dan forma a la interacción humana. Por consiguiente, estructuran incentivos en el intercambio humano, sea político, social o económico. El cambio institucional conforma el modo en que las sociedades evolucionan a lo largo del tiempo, por lo cual es clave para entender el cambio histórico. (North 1990: 13)

El propósito de las reglas es definir la forma en que el juego se desarrollará. Pero el objetivo del equipo dentro del conjunto de reglas es ganar el juego a través de una combinación de aptitudes, estrategia y coordinación; mediante intervenciones limpias y a veces sucias. (idem: 15)

En esta línea, postuló que las instituciones reducen la incertidumbre porque proporcionan una estructura a la vida diaria, y que en términos económicos definen y limitan el conjunto de elecciones de los individuos porque "estructuran incentivos". Se trata entonces de una definición muy amplia, que abarca desde el sistema constitucional hasta un acuerdo entre pares. No obstante, es un buen punto de partida para acercarse a una instancia de trabajo etnográfico, ya que propone observar tanto las prohibiciones que promueve el club en relación a las conductas de los jugadores como las normas informales que se llevan a cabo entre los practicantes mismos o las violaciones a las normas y su castigo, por ejemplo: "Las normas y códigos informales a veces son violados y en seguida se aplica el castigo corrector. Por consiguiente, una parte esencial del funcionamiento de las instituciones es lo costoso que resulta conocer las violaciones y aplicar el castigo" (ídem: 14).

Con base en la teoría de los juegos, North propone que las normas formales e informales y el tipo y la eficacia de su obligatoriedad determinan "la índole total del juego", concepto que no es explícitamente definido pero por el que los distintos actores pugnan. A diferencia de las teorías institucionalistas clásicas, que postulaban un actor racional que desarrolla estrategias conscientes y calculadas en pos de un objetivo definido, North se distancia y afirma que dicha racionalidad está limitada sobre todo por la capacidad de medir y conocer su entorno. Por eso, como observábamos en la mirada de Arnold-Cathalifaud -y a diferencia de la de Bourdieu- en esta mirada son más relevantes los procesos cognitivos de los individuos que los simbólicos. 
Si bien un estudio más detallado podría encontrar formas de complementariedad entre ambas teorías (después de todo, pensar en procesos cognitivos puede implicar poner en escena las disposiciones incorporadas), a priori me inclino por distanciarme de la mirada racional, en el sentido de que considero que la observación, la toma de decisiones y la acción no son "transparentes" sino que están plenamente atravesadas por ese pasado sedimentado y naturalizado. Tomo distancia también de postular que los actores operan principalmente a partir de la búsqueda de capital y en función de las oportunidades que se les presentan, y que el modo de operar dependa de una lógica de costo/beneficio (que en la medida que ir por los caminos normativos sea rentable, no irán hacia los alternativos).

Castaingts-Teillery amplía esta mirada e incorpora la teoría de los campos de Víctor Turner, aunque también parte de pensar la acción colectiva como "conjunto estructurado de juegos" en el que se conjugan actores, relaciones y reglas bajo un contexto de premios o castigos; con jerarquías entre lo individuos y relaciones de poder.

Un campo es un espacio social y/o físico en el que se encuentran involucrados actores, relaciones y reglas; se puede concebir como un conjunto estructurado de juegos en los cuales los actores están sujetos a reglas y premios o castigos en función del juego de cada actor.

En el campo los actores que participan en él no son iguales sino que hay jerarquías, entre ellos existen relaciones de autoridad (legitimidad y prestigio) y además de poder (capacidad de mando sobre otros). En el campo moderno se encuentra el Estado que es diferente a los demás actores pero que se sitúa en el juego de éstos. En el campo se integran tanto un espacio social como simbólico en el que hay contradicciones, confrontaciones y cooperación por eso, se concibe el campo como un espacio de disputa reglamentado. (Castaingts-Teillery 2016)

Castaingts también observa las organizaciones a partir de sus múltiples relaciones y postula que no sólo se trata de espacios de competitividad sino también de cooperación ("Configuran relaciones instrumentales coordinadas para alcanzar sus fines de producción y reproducción de sus estructuras" [2016]), se acerca a la teoría autopoiética cuando incorpora no sólo la necesidad de autoreproducirse sino además la relación con la recepción y el manejo de información y propone que las organizaciones

"están inscritas en el interior de una cultura. A través de las culturas se establecen los medios de comunicación que son vitales en los procesos organizacionales. Desde un punto de vista antropológico, la cultura proporciona: ética, representaciones mentales y sociales, referencias simbólicas, cosmovisión, sistemas de comunicación, sistemas de información, operadores lógicos, bloques de construcción, sistemas arquitectónicos. (Castaingts Teillery 2016)

Si bien la ampliación es más que pertinente, observo que en ambos casos estos autores coinciden en observar a los actores individuales y colectivos como estrategas racionales en pos de beneficios. Frente a ellos, y desde una línea bourdieana con la que me siento más afín, las decisiones “estratégicas", la ponderación de costos y beneficios es también efecto del habitus o de procesos 
inconscientes. Creo que tenemos menos control de lo que deseamos y de los recursos con los que creemos que contamos para alcanzarlo, y que las decisiones están más desligadas del cálculo que lo que dichas posturas proponen.

Para cerrar observemos brevemente un aspecto más de esta cuestión: la existencia de relaciones informales al interior de la organización. Como al pasar mencionamos el planteo de Douglass North por el cual los actores operan "mediante intervenciones limpias y a veces sucias" y que resaltaba la importancia de castigos correctores para contrarrestar la violación de las normas. En el mismo sentido, Castaingts-Teillery afirmó que

La lucha por las recompensas y beneficios hace que los actores se brinquen las reglas y realicen trampas de mayor o menor gravedad, por ello es indispensable que el campo cuente con reglas y árbitros que vigilen el cumplimiento de las reglas e impongan castigos a los infractores. En todo campo hay un cierto nivel de corrupción que no afecta una reproducción más o menos adecuada del mismo, pero puede existir un nivel de corrupción que deforme o haga problemática la reproducción del campo. (Castaingts-Teillery 2016).

De estas dos miradas podríamos pensar que la informalidad aparece sólo ligada al oportunismo, al deseo de sacar un provecho mayor que el que permiten las reglas. Otra mirada aparece en la introducción a "El nuevo institucionalismo en el análisis organizacional” (Powell \& Di Maggio 1991), donde Jorge Javier Romero indica que

Las diversas posiciones institucionalistas podrían compartir, en mayor o menor medida, la idea de que el proceso de reproducción social, en tenso equilibrio entre la paz y la violencia, ha ido generando dos tipos de reglas para normar el comportamiento humano: por un lado, las que establecen constreñimientos de carácter informal, prácticas sociales provenientes de una información socialmente transmitida y que forman parte de la herencia que llamamos cultura; por el otro, las reglas formales jerárquicamente ordenadas que constituyen el mundo del derecho. (Powell \& Di Maggio 1991: 20)

Ambos elementos los encontraremos en el capítulo 5, donde observaremos la influencia de las relaciones informales sobre el devenir de los jugadores.

En resumen, en este trabajo la definición de organización que utilizaré se puede plantear de la siguiente manera: es un espacio que involucra relaciones formales e informales entre individuos en pos de un conjunto de metas colectivas e individuales, con una frontera relativamente identificable y un ambiente físico y social, un orden normativo, jerarquías, un sistema de comunicación, un sistema de incentivos y luchas de poder por el control y la dirección de la organización. Dichas organizaciones están en permanente transformación, no sólo por su dinámica interna sino por la necesidad de adaptarse a entornos cambiantes. A partir de la teoría de los campos podemos agregar la pugna entre distintos actores por capitales económicos y culturales (sobre todo entre la coordinación y cuerpo técnico), y 
culturales entre los jugadores, a partir de la búsqueda por ser considerado "promesa". Dado que entre estos la pugna es entre individualidades y no entre colectivos, no será tan sencillo discernir colectivos dominantes y pretendientes. En dicho campo, además, los actores ponen en escena estrategias que son producto del cálculo, pero dicho cálculo está atravesado el habitus, de modo que no es un cálculo "racional" como lo pensaba la teoría neoclásica. No es únicamente la lucha lo que determina las dinámicas en el campo sino que también existe consenso y solidaridad entre los actores. Como planteaba Turner, dichas dinámicas involucran "símbolos, señales y signos verbales y no verbales, que la gente emplea para lograr las metas personales y grupales”, pero también se ponen en juego factores psicológicos individuales.

\subsection{Representaciones y discurso}

Ahora bien, esta noción no expone la relación que existe entre la organización y el resto de la estructura social. Si hasta aquí señalé que pensamos al Centro de Formación como un espacio donde confluyen las estructuras sociales, es hora de profundizar dicha relación, y para ello encontré en Michel Foucault los argumentos que más se ajustan a la propuesta. El pensador francés parte de pensar "la institución" como uno de los mecanismos a través de los cuales se evita la multiplicidad de sentidos. Esto significa que las representaciones están atravesadas por relaciones de poder, y que en consecuencia "lo pensable" es previamente controlado, seleccionado y redistribuido por un "cierto número de procedimientos que tienen por función conjurar los poderes y peligros, dominar el acontecimiento aleatorio y esquivar su pesada y temible materialidad" (Foucault 1973: 11).

Pero admitamos que con Kertzer, Durkheim, Jodelet y Moscovici ya veíamos que la estructura social construye las mediaciones a través de las que nos aproximamos al mundo que nos rodea, vimos también que esas representaciones son producto de la producción, circulación y consumo de significaciones en la vida social, que el individuo realiza una apropiación activa de dichas significaciones e incluso que la perspectiva aquí adoptada hace hincapié en la estructura como productora de sentidos. Luego con Zizek fuimos a los procesos psicológicos a través de los cuales nuestra realidad se acota y nos identificamos con los sentidos en circulación; con Bourdieu encontramos sobre todo la influencia de las condiciones de existencia en el desarrollo de disposiciones corporales. Lo nuevo, entonces, es que en Foucault la sociedad recupera peso como productora de 
significaciones y sobre todo negadora de muchas otras, promotora antes que nada de exclusiones. Así lo expresa:

El discurso, por más que en apariencia sea poca cosa, las prohibiciones que recaen sobre él, revelan muy pronto, rápidamente, su vinculación con el deseo y con el poder. Y esto no tiene nada de extraño: ya que el discurso -el psicoanálisis nos lo ha mostrado- no es simplemente lo que manifiesta (o encubre) el deseo; es también lo que es el objeto del deseo; y ya que -esto la historia no cesa de enseñárnoslo- el discurso no es simplemente aquello que traduce las luchas o los sistemas de dominación, sino aquello por lo que, y por medio de lo cual se lucha, aquel poder del que quiere uno adueñarse. $(1973: 12)^{30}$

Si mi interpretación de Foucault no es incorrecta, aquí postula que existe un "deseo" que -así como el sueño- está latente, una suerte de "real" (el término es mío, Foucault utiliza propiamente "deseo"31) que no puede dejar de estar atravesado por las relaciones de poder y dominación (en el sueño sería la censura) ${ }^{32}$. Pero que sí es posible de objetivarse, de igual manera que como objetivamos el sueño mediante el psicoanálisis, desentrañamos su jeroglífico y accedemos a lo latente. Por eso dice “el discurso no es simplemente aquello que traduce las luchas o los sistemas de dominación [esto equivaldría a decir: el contenido manifiesto del sueño no es simplemente aquello que nos expone que hubo un proceso de censura] sino aquello por lo que, y por medio de lo cual se lucha, aquel poder del que quiere uno adueñarse [sino que sólo a través del sueño podemos acceder al contenido latente; sólo

30 Creo que el intertexto aquí hace referencia a la relación en Freud entre ideas latentes y contenido manifiesto en el sueño. Para explicarlo brevemente recurro a Carolina Collazo (2011). El contenido manifiesto es lo que recordamos soñar, pero que se nos presenta como "jeroglífico"; para darle solución debemos traducir cada uno de sus signos al lenguaje de las ideas latentes. El contenido manifiesto no es una reproducción de lo latente porque en la medida que el deseo onírico no se puede resolver (por la "censura" de la instancia psíquica), se expresa deformado mediante dos procedimientos, condensación y desplazamiento. Mientras en el primero los signos del contenido manifiesto son puntos de convergencia en los que se reúnen las ideas latentes, el segundo es una significación por metonimia, por asociación. Por esto "cada uno de los elementos del contenido manifiesto demuestra hallarse superdeterminado y múltiplemente representado en las ideas latentes [...] De un elemento del sueño conduce el camino de asociación de varias ideas latentes y de una idea latente, a varios elementos del sueño" (2011: 35).

31 Páginas después se preguntará: “¿qué es por tanto lo que está en juego sino el deseo y el poder? El discurso verdadero, que la necesidad de su forma exime del deseo y libera del poder, no puede reconocer la voluntad de verdad que le atraviesa; y la voluntad, ésa que se nos ha impuesto desde hace mucho tiempo, es de tal manera que la verdad que quiere no puede no enmascararla. Así no parece ante nuestros ojos más que una verdad que sería riqueza, fecundidad, fuerza suave e insidiosamente universal. E ignoramos por el contrario la voluntad de verdad, como prodigiosa maquinaria destinada a excluir" (1973: 20).

32 Páginas después aclara que no considera que exista un "gran discurso ilimitado, continuo y silencioso", que se hallaría reprimido o rechazado "y que tendríamos por tarea que levantar restituyéndole finalmente el habla (...) no resolver el discurso en un juego de significaciones previas, no imaginarse que el mundo vuelve hacia nosotros una cara legible que no tendríamos más que descifrar" (1973: 44). En efecto, no se trata de que haya una "verdad" última que atraviesa todos los procesos históricos; por el contrario propone "concebir el discurso como una violencia que hacemos a las cosas, en todo caso como una práctica que les imponemos; es en esta práctica donde los acontecimientos del discurso encuentran el principio de su regularidad" (ídem). Entonces, partir del acontecimiento -de los hechos y discursos concretos, no de la idea de esencialidad-, a partir de allí observar "sus condiciones externas de posibilidad", es decir que ese discurso es efecto de regulaciones y límites que le dan una regularidad en relación con otros. Propone así trabajar a partir de "conjuntos de acontecimientos discursivos". (Para comprender la noción de acontecimiento y la crítica al estructuralismo de Foucault -no contradicen la mirada expuesta en este trabajo-, sugiero Foucault 1980: 179). 
a través del discurso podemos observar su arbitrariedad y las luchas de poder que hicieron que tomara esa forma. Objetivar el sueño -el discurso- es un gesto de poder]”.

A partir de aquí Foucault pone el foco en los modos de exclusión (las formas de censura) y en sus zonas críticas, la sexualidad y la política. Lo prohibido es el primer procedimiento de exclusión: no se tiene derecho a decirlo todo; en segundo término, la relación entre razón y locura, porque los discursos del loco no pueden circular de igual manera. Quién define qué es sano y qué no es en esta teoría sumamente relevante. En tener lugar, la oposición entre lo verdadero y lo falso, y nuevamente qué figura está socialmente legitimada para marcar la diferencia entre una y otra. Añade el filósofo francés que existe una continuidad entre los distintos procedimientos de exclusión, una suerte de lógica que se repite en el tiempo, pero que a ella sólo accedemos a través de un análisis diacrónico:

Ciertamente, si uno se sitúa al nivel de una proposición, en el interior de un discurso, la separación entre lo verdadero y lo falso no es ni arbitraria, ni modificable, ni institucional ni violenta. Pero si uno se sitúa en otra escala, si se plantea la cuestión de saber cuál ha sido y cuál es constantemente, a través de nuestros discursos, esa voluntad de verdad que ha atravesado tantos siglos de nuestra historia, o cuál es en su forma general el tipo de separación que rige nuestra voluntad de saber, es entonces, quizás, cuando se ve dibujarse algo así como un sistema de exclusión (sistema histórico, modificable, institucionalmente coactivo). (1973: 15)

La "voluntad de verdad", añade, se apoya en un soporte institucional que consiste en un conjunto de prácticas (ejemplifica con la pedagogía, el sistema de libros, las sociedades de sabios) y por "la forma que tiene el saber de ponerse en práctica en una sociedad, en la que es valorizado, distribuido, repartido y en cierta forma atribuido" (ídem: 18), de modo que este poder ligado a la construcción de verdad tiene un soporte, una distribución mediante instituciones y ejerce sobre otros discursos una presión, un "poder de coacción”.

Los tres primeros procedimientos de control son el "comentario", el "autor" y la "disciplina"33. Por "comentario" Foucault se refiere a un conjunto de relatos que se cuentan y repiten, "fórmulas, textos, conjunciones ritualizadas de discursos que se recitan según circunstancias bien determinadas", que se distancian de aquellos que desaparecen "con el acto mismo que los ha pronunciado" ya que originan nuevos discursos "que los reanudan, los transforman o hablan de ellos, en resumen, discursos que, indefinidamente, más allá de su formulación, son dichos, permanecen dichos, y están todavía por decir". Foucault ejemplifica con los textos religiosos o jurídicos, aunque sabe que se transforman con el tiempo porque justamente eso les permite construir nuevos discursos. Por eso luego afirma que "limita

33 No lo trabajaremos aquí, pero por “autor", se refiere no al individuo que pronuncia o escribe un texto, sino al principio de agrupación del discurso, "unidad y origen de sus significaciones, como foco de coherencia" (1973: 24). 
el azar del discurso por medio del juego de una identidad que tendría la forma de la repetición y de lo mismo", lo que significa que todos sus discursos posteriores remiten a esa "identidad" que brinda el primero. Respecto de la disciplina, la define de la siguiente manera:

... una disciplina se define por un ámbito de objetos, un conjunto de métodos, un corpus de proposiciones consideradas como verdaderas, un juego de reglas y de definiciones, de técnicas y de instrumentos: todo esto constituye una especie de sistema anónimo a disposición de quien quiera o pueda servirse de él, sin que su sentido o su validez estén ligados a aquel que se ha concentrado con ser el inventor (...) en una disciplina, a diferencia del comentario, lo que se supone al comienzo, no es un sentido que debe ser descubierto de nuevo, ni una identidad que debe ser repetida; es lo que se requiere para la construcción de nuevos enunciados (1973: 27).

Interesa aquí este procedimiento de exclusión porque es esto lo que se les transmite a los futbolistas al ingresar al centro de formación: reglas, definiciones, técnicas e instrumentos, y observaremos que muchos de los testimonios que nos brindaron los jóvenes responden a ese sistema, dialogan permanentemente con aquello que se supone debe experimentarse al practicar futbol, mientras que los testimonios de los entrenadores remiten a debates al interior de la disciplina del fútbol y de la formación de jugadores. La disciplina, afirma el filósofo francés, impone condiciones a la producción de discursos porque se dirige a un determinado plan de objetos (no cualquier modo es "jugar fútbol"), define un horizonte teórico (Mourinho, Bielsa, Guardiola, Menotti o Bilardo, Cappa), reconoce proposiciones verdaderas y falsas ("todos los goles valen lo mismo"; "el balón tiene un imán: hay que saber cuándo te atrae y cuándo no"; "no se entrena igual después de la victoria que de la derrota"). Por más que un discurso sea verdadero, debe responder a la verdad de la época y de la disciplina a la que pertenece para que sea considerado como tal. La disciplina, concluye, "es un principio de control de la producción del discurso. Ella le fija sus límites por el juego de una identidad que tiene la forma de una reactualización permanente de las reglas" (1973: 31).

Pero en dos entrevistas posteriores, una con la ensayista Finas y la otra con Fontana, el filósofo francés se encargó de aclarar que el poder no es únicamente "negativo" (interpreto "coercitivo") sino también performativo, productor de placeres:

...me parece que la noción de represión es totalmente inadecuada para dar cuenta de lo que hay justamente de productor en el poder. Cuando se definen los efectos del poder por la represión se da una concepción puramente jurídica del poder; se identifica el poder a una ley que dice no (...) pienso que esta es una concepción negativa, estrecha, esquelética de poder que ha sido curiosamente compartida. Si el poder no fuera más que represivo, si no hiciera nunca otra cosa que decir no ¿pensáis realmente que se le obedecería? Lo que hace que el poder agarre, que se le acepte, es simplemente que no pesa solamente como una fuerza que dice no, sino que de hecho la atraviesa, produce cosas, induce placer, forma saber, produce discursos; es preciso considerarlo como una red productiva que atraviesa todo el cuerpo social más que como una instancia negativa que tiene como función reprimir (1980: 182). 
Esto nos conduce a una cuestión que en esta ocasión decido dejar afuera, pero que es central a nuestro trabajo: es la dimensión afectiva en las relaciones de poder y en la reproducción de lo social. En efecto veremos a lo largo del trabajo que el deseo de devenir futbolista está atravesado por placeres, potenciales y presentes, y que de hecho sería imposible desligar el poder y su afectividad de los procesos de identificación imaginaria y simbólica que ya vimos con Zizek.

En la entrevista con Lucette Finas aparece de manera un poco más profunda la idea de red productiva y ofrece algunas precisiones que nos permiten comprender de mejor manera las relaciones que se establecen al interior de la organización -y su conexión con la idea de estructura social que venimos mencionando. Allí plantea antes que nada que nunca se está fuera de las redes de poder, que no hay márgenes para estar en ruptura -es decir, el poder no es "central", estatal, sino disperso, cotidiano y afecta a todas las relaciones; y que las relaciones de poder están imbricadas en otros tipos de relación (de producción, de alianza, de familia, de sexualidad) donde juegan un papel a la vez condicionante y condicionado; que no existen relaciones de poder sin resistencias y que las relaciones de poder 'sirven' en efecto, pero no porque estén 'al servicio' de un interés económico primigenio, sino porque pueden ser utilizadas en las 'estrategias' (1980: 170).

Para Foucault esta malla de poder que atraviesa todas las relaciones sociales posee una relativa autonomía de la "estructura social". Es casi una herejía lo que voy a decir, pero al menos en las lecturas realizadas no encontré una respuesta clara a la pregunta de "qué sociedad" es la que se reproduce o promueve discursos de verdad (concretamente: ¿el fútbol necesita reproducir la fuerza de trabajo -a los jugadores- para reproducir una industria del espectáculo mediático, "el capitalismo" en su totalidad u otra cosa que no es ninguna de las dos anteriores? ¿a quién "sirve" una y no otra voluntad de verdad?). Si bien afirma que no hay "un poder" que subyace a todos los intercambios, no deja de postular que todas esas relaciones de poder sí forman parte de una malla, de una red de relaciones. En negrita expongo los elementos sobre los que se sostienen mis dudas:

Entre cada punto del cuerpo social, entre un hombre y una mujer, en una familia, entre un maestro y su alumno, entre el que sabe y el que no sabe, pasan relaciones de poder que no son la proyección pura y simple del gran poder del soberano sobre los individuos; son más bien el suelo movedizo y concreto sobre el que ese poder se incardina, las condiciones de posibilidad de su funcionamiento. La familia, incluso hasta nuestros días, no es el simple reflejo, el prolongamiento del poder de Estado; no es la representante del Estado respecto a los niños, del mismo modo que el macho no es el representante el Estado para la mujer. Para que el Estado funcione como funciona es necesario que haya del hombre a la mujer o del adulto al niño relaciones de dominación bien especificas que tienen su configuración propia y su relativa autonomía. (1980: 157) 
En resumen, las relaciones que observaremos en este trabajo están atravesadas por esta perspectiva. Partimos de la dimensión representacional/simbólica del mundo, comprendemos la influencia del pasado y que es en el encuentro con el acontecimiento donde dichas representaciones se actualizan, reproducen y transforman, pero las pensamos asimismo como efecto de relaciones de poder que se encarnan en cuerpos, en disposiciones hacia la acción, en concepciones sobre lo que es y no es “para mí," que producen deseos y placeres, posiciones también desde las que se especula que se será amado. Todo eso se pone en práctica en los centros de formación.

\subsection{Breve panorama sobre estudios del deporte}

Las ciencias sociales sólo en las últimas décadas incorporaron al deporte como objeto de estudio, y aún hoy que existen algunas publicaciones especializadas está lejos de consolidarse como campo teórico. Para brindar un panorama por las investigaciones en torno del deporte, del fútbol y de la formación de jugadores de fútbol -en ese orden- decidí recurrir al trabajo de tres autores y sumar algunos elementos propios.

El sociólogo mexicano Fernando Segura Trejo observó tres grandes escuelas sociológicas que trabajaron sobre deporte. La primera es la de Norbert Elías y Eric Dunning, quienes en 1986 publicaron Deporte y ocio en el proceso de civilización y observaron cómo en Reino Unido el deporte formó parte de una nueva estrategia de gobierno ligada al desarrollo del Estado parlamentario que consiste en una gestión y regulación de las emociones e impulsos individuales: “Un uso 'codificado' de la violencia en los deportes es encuadrado como uno de los lugares donde se expresa la división entre la violencia inaceptable y la violencia tolerable por la sociedad" (Segura Trejo 2008, 211). Fueron las "public schools" inglesas -los establecimientos destinados a formar a la elite del imperio británico- las instituciones sobre las cuales se apoyó el deporte como proyecto pedagógico. Estos dos autores, en paralelo, fueron precursores de los estudios sobre violencia en los estadios de fútbol a partir de considerar a la violencia como un valor y un fin en sí misma por parte de los hooligans ingleses. Ellos influenciaron a autores franceses como Roger Chartier, Patrick Mignon o Christian Bromberger, quienes realizaron además un abordaje culturalista del fútbol $\mathrm{y}$, en el caso de Bromberger, una etnografía en Marsella, Turín y Nápoles.

En segundo lugar, Segura Trejo menciona a Jean-Marie Brohm, quien ya influenciado por la escuela de Frankfurt postuló que el deporte moderno es un "elemento enajenante, portador de una 
ideología que contiene las mismas características que el capitalismo: productividad y competitividad" (ídem: 213), un espacio de manipulación y para desviar la atención de las masas. Esta también fue una de las presencias más influyentes en el incipiente campo latinoamericano, y la mirada del fútbol como opio de los pueblos estuvo muy extendida al menos en Argentina. De hecho para Pablo Alabarces es uno de los elementos que impidió un desarrollo del campo antes de la década del ochenta:

En el caso argentino ese prejuicio tuvo nombre, el fantasma que recorre la academia: el populismo. (...) Complementariamente, otros dos problemas colaboraron en este cuadro: uno epistemológico, otro académico. El primero fue el clásico calificativo del opio de los pueblos, como señaló oportunamente Roberto DaMatta (1982) (...) No en vano, a principios de la década de 1980 sólo podían contabilizarse dos libros importantes, ambos producidos desde esta sociología crítica y apocalíptica, y traducidos al español por editoriales latinoamericanas: el clásico de Gerhard Vinnai, El fútbol como ideología, de 1970 y traducido en un temprano 1974; y el de Jean-Marie Brohm, Sociología policial del deporte, traducido en 1982. (Alabarces 2010: 71)

En último lugar Segura Trejo recupera el trabajo de Pierre Bourdieu, quien propuso pensar al deporte como campo, dentro del cual existen sub-campos donde los agentes compiten por recursos. Desde este punto de vista, el acceso a un deporte forma parte de un habitus de clase, ligado no sólo a una forma de distinción social sino también a un consumo. Segura Trejo menciona también al francés Christian Pociello como uno de los seguidores más importantes de sus propuestas. Finalmente, se refiere a Jean Michel Faure y Charles Suaud, quienes en 1999 publicaron Le Football Professionel a la Française donde analizaron las relaciones entre el estado francés, instituciones como la Federación Francesa de Fútbol y los centros de formación de los clubes.

En Latinoamérica el puntapié lo dieron el argentino Eduardo Archetti y el brasileño Roberto DaMatta. El primero trabajó sobre todo en la ligazón del fútbol con la identidad nacional y la masculinidad y realizó una aproximación a los trabajos sobre aficionados al fútbol. Fue él quien en 1985 observó la relación que los "barras bravas” ponían en escena su identidad de género a través de los cánticos y la violencia:

...los hinchas ponen en juego no sólo el prestigio del club sino partes de su identidad posicional. Los cantos son parte del elemento dramático asociado a la masculinidad y a las fronteras entre géneros. La sexualidad es lo que está en discusión, lo que se juega es la condición de macho, la virilidad y la conservación de ese espacio que distingue a los 'verdaderos hombres' de los otros, 'de los hombres disfrazados de hombres’, de los homosexuales (Archetti 1985: 9).

Este trabajo fue también la base de una segunda camada de investigadores, entre los que se encuentran Julio Frydenberg -dedicado a los orígenes del fútbol- y Pablo Alabarces, quien se convirtió en referente del incipiente campo. Este último, por ejemplo, fue promotor de algunos libros-hito de la literatura latinoamericana como Cuestión de Pelotas (1996), Deporte y Sociedad (1998, junto con 
Frydenberg y Di Giano, editado por Eudeba y con prologo de Archetti), Peligro de gol (2000) y Futbologías (2003), este último una compilación de los estudios realizados en América Latina en torno de la problemática de la violencia en el fútbol y donde se observaron las relaciones entre fútbol e identidad, se trabajó la dimensión ritual de la hinchada y la tribuna como campo de disputa simbólica y resistencia.

En un artículo sobre la fundación del campo de los estudios del deporte, María Graciela Rodriguez relata que en 1997 se formó un Grupo de Trabajo de CLACSO coordinado por Alabarces que dio a luz a una de las temáticas centrales de los estudios en Argentina: la relación entre fútbol y nación.

¿Por qué fútbol y nación? Probablemente las razones tuvieron que ver con estrategias de coyuntura doblemente orientadas: adentro del campo el momento expansivo hacer del fútbol la mercancía más operable para dar cuenta de la perspectiva crítica que se postulaba necesaria: es popular, es masivo, toca cuestiones relacionadas con la economía, posee una profunda imbricación histórica con las dinámicas sociales locales, y especialmente con la conformación de los sectores populares (...) nación era un tópico suficientemente serio como para convocar la atención de la academia local, cuyas tradiciones hasta el momento habían aceptado muy a regañadientes por tratarse de un objeto menor. Nación, en ese contexto de los inicios, equilibraba los resquemores (Rodríguez 2013: 343)

De esta temática surgió Fútbol y Patria (2002), tesis de doctorado de Alabarces. A posteriori, una tercera camada de investigadores que puso el foco en la violencia en el fútbol lo hizo a través de etnografías y mantuvo diálogos no sólo académicos sino con el periodismo y la política, que pensaba una y otra vez las conductas violentas en términos de "irracionalidades" o a partir de motivaciones económicas. Algunos de ellos son José Garriga Zucal, María Verónica Moreira, Gastón Julián Gil, Christian Dodaro o Juan Pablo Ferreiro. De este colectivo surgió el libro Hinchadas (2005), una compilación de artículos, y Haciendo amigos a las piñas (2007), de Garriga Zucal. En paralelo, la continuidad del trabajo histórico de Frydenberg la propuso Rodrigo Daskal. Esta tercera camada abrió también un nuevo campo, el de las políticas públicas ligadas al deporte, e incluso incursionó en algunas experiencias desde el Estado.

Por esa época se gestaba también una cuarta generación de investigadores, algunos de los cuales continuaron con las etnografías en hinchadas (Nicolás Cabrera en Belgrano de Córdoba y quien escribe en el Club Atlético Platense de Buenos Aires) y otros que ampliaron la mirada. El sociólogo Diego Murzi analizó las políticas públicas en Europa desde los ochenta; Juan Manuel Sodo y Javier Szlifman, los medios de comunicación; Sebastián Sustas hizo un trabajo sobre el marco normativo hacia la violencia; Santiago Uliana observó la configuración de los estadios; Nemesia Hijós, las estrategias de marketing en Boca Juniors. El presente estudio, continuación del que en 2014 escribimos junto con 
Diego Murzi para la FIFA, se enmarca en esta suerte de ampliación del campo de batalla, por parafrasear a Michel Houellebecq. En ese contexto, algunos de ellos -de nosotros- nos incorporamos a una ONG, Salvemos al fútbol, desde la que buscamos promover las ideas surgidas de la práctica académica y ponerlas en juego con actores provenientes del campo político, judicial o periodístico.

Por fuera del caso argentino, las investigaciones son múltiples aunque mi recorrido dio resultados algo más dispersos. En Brasil, decíamos que Roberto DaMatta fue pionero con O universo do futebol, donde también aparecía un artículo de Simoni Guedes, autora en 1977 de la primera tesis de posgrado de fútbol en el continente, según reporta Alabarces (2015: 15) y de numerosos artículos que relacionan al fútbol con nociones como identidad, pueblo o nación. Por el mismo camino ha trabajado Máximo Pimenta, y Carmen Rial puso el foco sobre el género y el fútbol, específicamente sobre el practicado por mujeres (y su negación); desde la Universidad de San Pablo, Luiz Henrique de Toledo trabajó sobre las hinchadas y su relación con la política de partidos. Debemos mencionar también la publicación digital "Esporte e Sociedade" publicada por el Núcleo de Estudos e Pesquisas sobre Esporte e Sociedade (NEPESS). Luiz Carlos Ribeiro tiene estudios que abarcan desde cuestiones identitarias hasta el análisis de las relaciones de poder entre la FIFA y la UEFA. El Mundial de Fútbol realizado en 2014 en Brasil también motivó numerosos estudios, como el de Bernardo Borges Buarque de Hollanda sobre el estadio Maracaná (Buarque de Hollanda 2014)

En Colombia, Beatriz Vélez es la principal exponente, dedicada sobre todo al estudio de las fantasías, y John Alexander Castro Lozano publicó en 2010 una recopilación de las etnografías sobre porras en Latinoamérica (Castro Lozano 2010). Allí encontramos a Andrés Recasens en Chile, también con el foco puesto en la violencia. En Ecuador, uno de los pioneros fue sin dudas Jacques Paul Ramírez Gallegos, dedicado a hinchadas y territorio.

Finalmente, en México encuentro cinco referentes. El primero es Andrés Fábregas Puig y su libro Lo sagrado del rebaño (2001), dedicado a la simbología y la identidad entre los aficionados del Club Guadalajara. Desde la Universidad Iberoamericana, Samuel Martínez es uno de los precursores de los estudios en Latinoamérica, ha sido uno de los promotores del campo en tierra azteca, compilador del libro Fútbol-espectáculo, cultura y sociedad (2010) y coordinador de un diplomado homónimo junto con Roger Magazine. Desde la misma universidad, Magazine se dedicó al estudio de la porra de Pumas y escribió artículos en sociedad con Sergio Fernández González (UAM-Xochimilco), quien observó las relaciones de parentesco en la porra La Sangre, del Cruz Azul. También es preciso mencionar a 
Fernando Segura Trejo, del CIDE, actualmente radicado en Brasil y dedicado no sólo al estudio de las políticas públicas en el fútbol sino al las experiencias de fútbol comunitario y la Homeless World Cup. Fue además compilador junto con Bernardo Buarque de Hollanda en el número dedicado a las Políticas Públicas del Deporte de la revista Gestión y Política Pública, del CIDE, publicado en octubre de 2015. Finalmente, Sergio Varela Hernández, cuyos trabajos versan entre el análisis de la porra del América, las identidades y el análisis de medios. Muchos de estos autores han constituido además la Red de Investigación sobre Deporte, Cultura y Sociedad.

Sobre formación de jugadores de fútbol, la bibliografía desde las Ciencias Sociales es contada. Sin dudas hay numerosos trabajos sobre táctica, técnica y algunos sobre psicología del futbolista adolescente, pero en relación con nuestra temática dos son centrales: la tesis de doctorado del brasileño Arlei Sander Damo (2005), quien estudió no solamente la formación en Brasil sino también en el Olympique de Marsella, y la investigación en Francia de Julien Bertrand (2007), quien cerca de nuestra perspectiva buscó ubicar las performances deportivas dentro de las condiciones sociales para analizar cómo estructuran las experiencias subjetivas de los jugadores.

Además de estos textos académicos es menester mencionar Niños futbolistas, del chileno Juan Pablo Meneses (2013), una crónica periodística en la que el autor se propone "comprar” un jugador de fútbol y recorre las diversas instancias del circuito productivo en busca de asesoramiento, y las numerosas biografías de futbolistas y entrenadores en las que son presentados no sólo como deportistas sino como estrategas (Otra manera de ganar, sobre Pep Guardiola), líderes (Los 15 escalones del liderazgo. Mis valores en el fútbol y en la vida, sobre Javier Mascherano) y de las que personalmente rescato la biografía sobre Lionel Messi escrita por Guillem Balagué. Estas pasan a ser sumamente importantes cuando observamos que para los jóvenes futbolistas, las estrellas no son sólo modelos a seguir por sus desempeños deportivos sino por su imagen pública ligada a valores determinados. 


\section{Las huellas del deseo}

- ¿Desde ese momento ya estabas convencido que querías ser futbolista?

-No, yo creo que desde niño ¿no? Ver en la tele a mi papá, verlo en la cancha jugar, yo creo que te pega ¿no?

Siento que al verlo jugar en Primera División a mi papá creo que tú dices yo quiero ser igual que mi papá. Pues es lo que yo creo, que desde muy chico ¿no? desde muy temprana edad, de los 3 años, creo que desde que nací quería ser futbolista, la verdad.

Entrevistado P8

En la introducción expliqué que este trabajo expresa una primera aproximación a las maneras en que la estructura social condiciona o constituye nuestras clasificaciones del mundo, afirmé que una de las preguntas que conducen todo el trabajo es qué motivaciones llevan a los niños a desear convertirse en futbolistas e indiqué que aquí se postula que el deseo de devenir jugador de fútbol (y la idea de que es posible de ser realizado) es socialmente construido. A partir de ahí me propongo rastrear en los jóvenes futbolistas las marcas de esa construcción.

Se mencionó también que esa construcción social "viene del pasado" como producto de largas series de "generaciones", que el objeto "fútbol" condiciona los sentidos que de él pueden surgir, y que el individuo es creador de sentidos en torno de ese objeto a partir de la combinación de elementos... es decir, el objeto se actualiza a partir del contacto del individuo con su contexto social. En nuestro caso, esto nos remite las experiencias que vive al interior de la institución y el contacto del individuo con los discursos sobre el fútbol, específicamente con los que se transmiten de manera massmediática.

En este capítulo, entonces, intentaré una aproximación a los modos en que se constituye socialmente el deseo en los jugadores. Para eso abordaré la influencia familiar en sus inicios y en sus presentes, observaré representaciones sobre los contextos sociales de origen, indagaré en las imágenes del fútbol profesional al que aspiran y finalmente se hará una lectura de la relación que los jugadores establecen con la fama. Para llevarlo a cabo trabajaré con los testimonios surgidos de las encuestas y las entrevistas en profundidad, material al que le destinaré abundante espacio para exponer las bases a partir de las cuales se construyen mis ideas y observaciones.

\subsection{La influencia familiar}

Comencemos este apartado con una breve descripción de lo que indican las encuestas respecto de los inicios de los futbolistas. En total se tomaron 48 registros; de ellos, 26 corresponden a la categoría Sub13 y 22, a la Sub17. De los más jóvenes podemos decir que el 30,7\% dice haber comenzado a jugar 
a los 3 años y un 38\% entre los 4 y 5 años, de modo que casi el $70 \%$ se habría iniciado entre esas edades. Cuando indagamos en el espacio en que se iniciaron (las opciones eran abiertas) 10 mencionan haber comenzado en la escuela (de estos, 7 dicen que en su escuela había clases de fútbol), 9 en una escuelita de fútbol ${ }^{34}$ y 7 en la filial de un club grande (5 fueron distintas filiales de Pumas), mientras que sólo 6 (23\%) afirman haber comenzado en el barrio o en la calle. Esto nos da la pauta de que en la mayoría de los casos desde los comienzos la relación con el fútbol se realiza en el marco de instituciones.

En el caso de los Sub17, el 27\% indicó haber comenzado a los 4 años, mientras que otro 36\% entre los 5 y 6 años, de modo que el 63\% se habría iniciado entre esas edades. Respecto de los espacios donde comenzaron a jugar (nuevamente con respuestas abiertas), es mucho más importante la presencia del barrio o la calle, que se encuentra en primer lugar (45\%), seguido de la escuela primaria (36\%), donde además 5 chicos (el 60\% de los que comenzaron en escuela) reportan que había clases de fútbol.
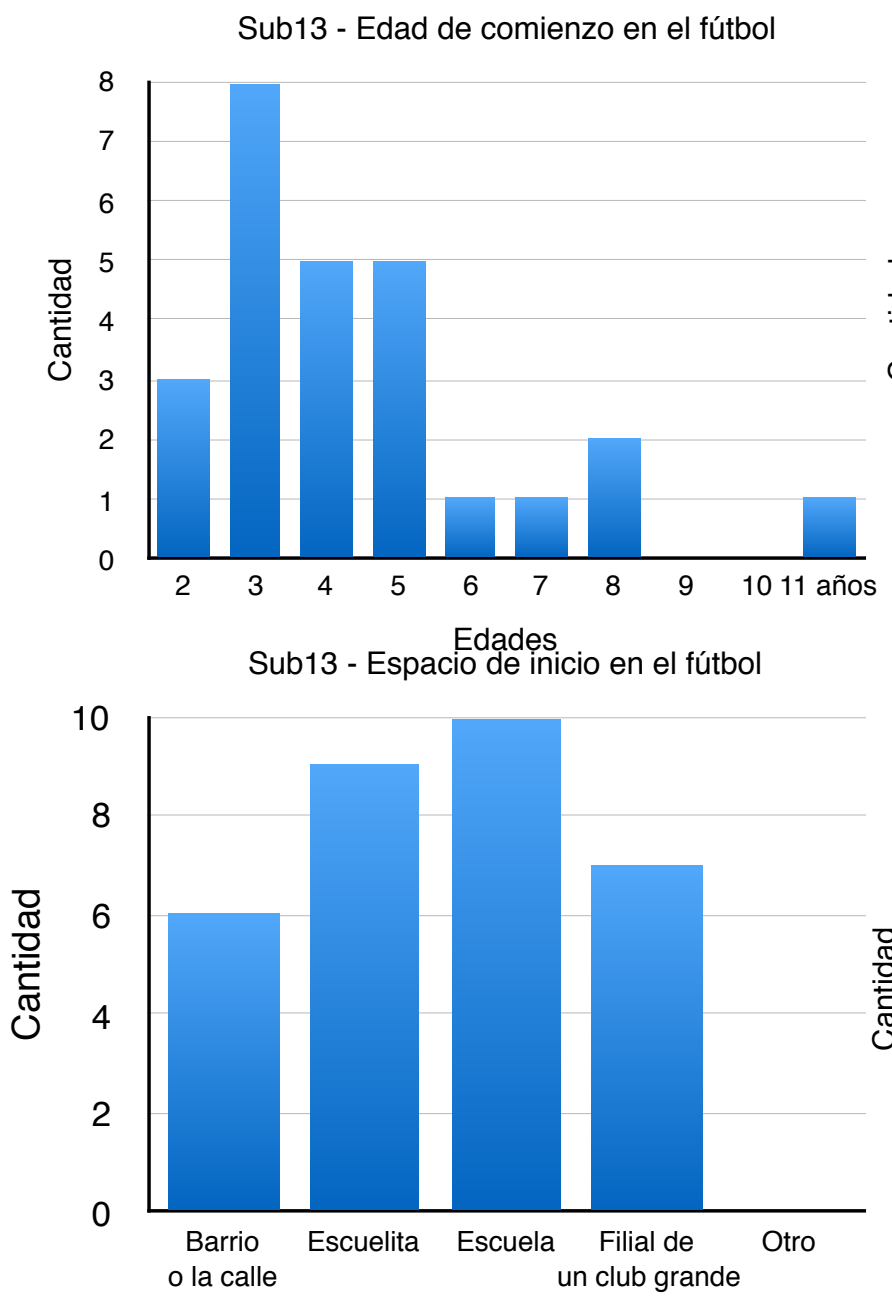

Sub17 - Edad de comienzo en el fútbol

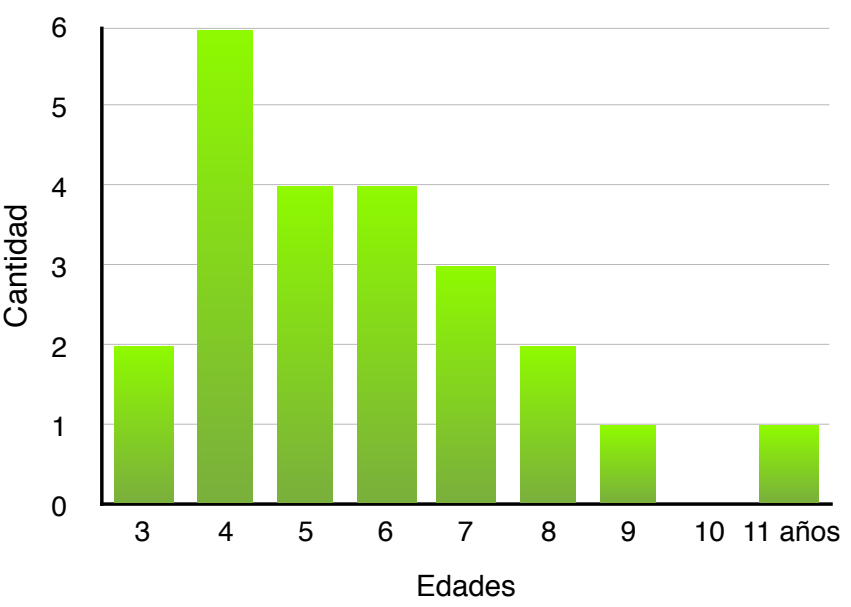

Sub17- Espacio de inicio en el fútbol

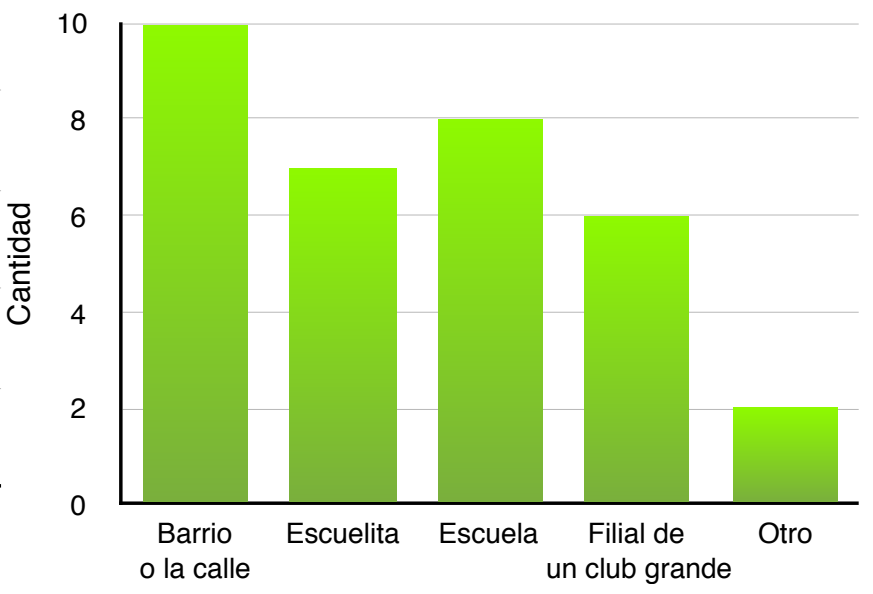

34 Se trata de una institución de paga, no necesariamente ligada a un club de fútbol profesional. 
En tercer lugar, las escuelitas de fútbol (31\%) y finalmente, las filiales (27\%), donde a diferencia de lo observado en la Sub13, aquí dicen provenir de 5 clubes diferentes ( 2 de Pachuca y 1 de Pumas, Toluca, Cruz Azul y Chivas). Aquí se muestran claramente los efectos de la selección e incorporación de jugadores $^{35}$. Esta información expone la presencia de un contexto social proclive al desarrollo del fútbol -que en la escuela hubiera clases de este deporte es un buen ejemplo- pero no constituye el deseo ni la adhesión.

Ahora bien, si vamos a las entrevistas en profundidad encontramos que los inicios de los jugadores en la mayoría de los casos no se puede desligar de la influencia familiar, con hincapié en la figura paterna ${ }^{36}$. Es decir, los relatos que los jóvenes muestran que no se trata de chicos "talentosos" o con una inclinación hacia el deporte que jugaban en la calle o en la escuela con amigos, hacían mucha diferencia respecto de sus pares, disfrutaban del juego y a partir de ahí decidieron ir a un centro de formación. No, aquí se observa una influencia familiar clara que toma al menos tres formas. Las primeras son tradicionales, las más conocidas: padres que jugaban con sus hijos, familiares futbolistas a los que los niños observaron con admiración desde pequeños, o padres que llevan a sus hijos a escuelitas de fútbol:

- ¿Qué fue lo que te generó ganas de ir a jugar o dedicarte al fútbol?

- Primeramente porque pues yo lo veía en mi papá, siempre le veía jugar y (...) Eso me llamaba la atención, me gustaba.

- ¿Pero tu papá era futbolista, o solamente con amigos?

- Era futbolista pero así con, digamos que, del barrio.(...) No, en ningún equipo profesional pues. Pero sí para mí que era muy bueno mi papá.

- ¿De qué jugaba?

- Media punta. Ps, de verle jugar me impresionaba pues.

- ¿Por qué, qué era lo que te impresionaba?

35 Como se puede ver a partir de los cuadros, las tendencias en ambas categorías son similares. Aunque no se nos puede escapar que el mayor número en Sub13 comenzó a los 3 años, mientras que el pico en Sub17 se encuentra a los 4 . Es muy arriesgado observar que hacia 2003 los chicos estén comenzando a jugar un año antes que en 1999, pero tampoco es descabellado proponer un estudio más profundo y riguroso que apunte a confirmarlo.

36 El caso del Entrevistado P5 expone que la influencia no proviene del padre como de los tíos: “...mi papá una vez me llevó, je, porque yo antes, por mis tíos, que les gusta mucho el béisbol... Yo empecé a practicar desde los 4 años, 5 años béisbol, pero un día mi papá me trajo, me llevó a C.U. [Ciudad Universitaria] y pues ya, yo estaba viendo a los niños y todo y dije, bueh por qué no me traes aquí. Y me llevó. (...) - ¿Y que había en C.U. en ese momento? -Eh, se llama Pumitas, no sé si has llegado a escuchar de Pumitas. Si ahí Pumitas, me llevó, y pues me gustó. Me gustó el deporte y desde ahí ya comencé a jugar fútbol, desde los 5, 6 años, y ya no me he despegado je, para nada. - $i \mathrm{Y}$ tu padre de qué manera se relacionaba con el fútbol? -Pues, no es, es apasionado al fútbol pero él practicó fútbol americano, pero a él nunca le ha importado, nunca me inculcó así el fútbol americano, él me decía que lo que yo escogiera ps él me iba a apoyar en todo. (...) -Así que eres algo así como la oveja negra de la familia. -Sí, je, no tanto, porque dos de mis tíos sí jugaron en Pumas. Profesional, pero ya hace mucho tiempo. (...) - ¿Y son los mismos a los que les gusta el béisbol? -Sí, porque ellos, o sea la familia de mi mamá, porque ellos eran con los que más nos juntábamos. La familia de mi mamá, o sea por parte de mi papá jugaban béisbol, pero los 2 tíos que si jugaban al fútbol, si llegaron a hacerlo profesionalmente. (...) - $i$ Y tus tíos, estos dos tíos que fueron profesionales tienen algo que ver en tu formación? -Sí, pues han sido muy importantes porque me han guiado de una manera. 
- Pues su regates y era muy habilidoso (...) Con el balón. Y goleador pues. (...) Mi papá también me promovió, digamos porque pues siempre practicaba con él, y así.

- ¿En qué momentos practicaban?

- Entre semana siempre íbamos a la unidad deportiva ahí de la ciudad. Y este... practicábamos, balón, balón. (...) pases y así, centros.

- O sea, era una práctica, no es que iban a jugar...

- Ajá, no. Ajá, nomás entre nosotros, pues, mi papá y yo. (Entrevistado P6) ${ }^{37}$

Si sobre el mismo eje vamos a las encuestas vemos que la presencia de familiares es una tendencia absoluta, ya que 39 jugadores $(81,25 \%)$ sobre un total de 48 expresan tener parientes que estuvieron ligados a este deporte (en Sub13 sólo 3 niños negaron historias previas, y seis en Sub17).

Sub13 - Número de menciones de familiares que jugaron fútbol

\begin{tabular}{|c|c|c|c|c|c|c|c|c|}
\hline Padre & Hermana & Hermano & Tío & Abuelo & Primos & Padrino & Madre & Ninguno \\
\hline 15 & 2 & 5 & 10 & 8 & 2 & 2 & 1 & 3 \\
\hline
\end{tabular}

Sub13 - Trayectorias de los familiares

\begin{tabular}{|c|c|c|c|c|c|c|c|c|}
\hline Primera & Sub20 & Tercera & Sub17 & Segunda & Sub15 & $\begin{array}{c}\text { Fútbol } \\
\text { Ilanero }\end{array}$ & $\begin{array}{c}\text { Fuerzas } \\
\text { básicas }\end{array}$ & Escuelita \\
\hline 4 & 2 & 1 & 3 & 1 & 1 & 2 & 5 & 1 \\
\hline
\end{tabular}

Sub17 - Número de menciones de familiares que jugaron fútbol

\begin{tabular}{|c|c|c|c|c|c|c|c|}
\hline Padre & Hermana & Hermano & Tío & Abuelo & Prima & Madre & Ninguno \\
\hline 15 & 1 & 5 & 6 & 2 & 1 & 1 & 6 \\
\hline
\end{tabular}

Sub17 - Trayectorias de los familiares

\begin{tabular}{|c|c|c|c|c|c|c|c|c|}
\hline Primera & Sub20 & Tercera & Sub17 & Segunda & Sub15 & $\begin{array}{c}\text { Barrio/ } \\
\text { Talacha }\end{array}$ & $\begin{array}{c}\text { Fuerzas } \\
\text { básicas }\end{array}$ & $\begin{array}{c}\text { Liga } \\
\text { amateur }\end{array}$ \\
\hline 5 & 1 & 1 & 0 & 3 & 1 & 2 & 1 & 2 \\
\hline
\end{tabular}

37 Otros testimonios: -... tenía como 4 años, jugaba en una unidad así en una unidad de por mi casa. Con mi papá que me llevaba a jugar, con mi hermano y así. Pues yo al principio no sabía ya, fui aprendiendo y vieron que me gustó y siempre seguí los pasos de mi hermano. Él también jugaba fútbol. -¿Jugaba o juega? -Jugaba, ya no (...) Y él estaba jugando en Toluca Planetarios, una escuela de fútbol (...) Y le dije a mi papá que si me metía ahí (...) Y ya me metió ahí a jugar y pues al principio yo lloraba porque dejaban solo ahí y se iban mis papás. (Entrevistado P7). Otro caso: "Empecé a los 6 años porque me gustaba estar con mi papá y jugar, vi que me metieron a una escuela de futbol, a una filial de Pumas, que queda en Tepepa, que queda cerca de donde vivo. (...) Sí, pues realmente era como un hobby, pero pues ahí yo creo que fue muy importante que fuimos campeones y que las cosas salieron bien (...) -Antes al jugar con tu papá ¿cómo jugaban? -Pues realmente era como estar peloteando ahí, pasando el balón. A mí me gustaba mucho verlo, entonces entre que me gustaba jugar y verlo que me animé..." (Entrevistado P2). Otro: “- ¿Tus papás de qué trabajan? -Mi papá tiene una escuelita en Chilpancingo, tiene una escuelita (...) De fútbol, sí, jugó en primera mi papá. - ¿Ah sí? -Y pues quiero lograr el mismo sueño ¿no? Que él tuvo. -¿Dónde jugó? -Jugó en San Luis, Cruz Azul, Pachuca, Zacatepec y Chapulineros. Sí, pues más que nada eso ¿no? Llegar a lo que él hizo y ps qué más me daría superarlo ¿no? (...) - ¿Cuando eras chiquito tu papá jugaba todavía? -Sí, jugaba todavía, cuando tenía 8 mi papá estaba jugando en Primera -¿De qué jugaba tu papá? -Lateral izquierdo [es la misma posición del jugador]. - ¿Y qué te acuerdas de esa época? -Pues de esa época lo único que recuerdo más o menos es que a mi papá lo veía, igual estaba chico pero me acuerdo muy bien pues. Lo veía y se rompía el alma ¿no? En la cancha, se rompía el alma y pues toda mi familia (...) mis abuelitos emocionados ¿no? de verlo jugar. Y pues qué más daría yo que eso pasara conmigo, que ellos me fueran a ver a C.U., a jugar en el estadio, pues más que nada eso ¿no? Sería como un agradecimiento hacia mi familia llegar a lograr mi sueño ¿no?” (Entrevistado P8) 
Cuando profundizamos encontramos que en ambas categorías 15 jugadores se refirieron a los padres (30 en total), los tíos aparecen mencionados 16 veces, 10 veces los hermanos y otras 10 los abuelos, entre diversos familiares.

Pero no se trata únicamente de haber jugado, sino que al indagar en qué tan lejos llegaron en sus carreras encontramos que del total de jugadores 9 familiares se desempeñaron en Primera División, 6 entre Sub20 y Segunda, 5 en Sub17 y Tercera y muchos otros en fuerzas básicas (extrañamente, el número decae a medida que bajan las categorías), es decir que no hubo un camino amateur sino que la presencia de jugadores -algunos también en Pumas- está sumamente presente. Hay deseos y formas de devenir adulto que se repiten a través de las generaciones, intentos también en las historias de aquellos que no "llegaron", placeres e imágenes que buscan reproducirse y, por supuesto, experiencias (argucias, estrategias, frustraciones entre otras) sobre la vida futbolística en las fuerzas básicas que los jugadores ponen en práctica de manera consciente o inconsciente en su ejercicio cotidiano.

Existe una tercera forma de influencia que es aquella en la cual los niños no parecían tener una inclinación por el fútbol pero los padres insistieron y finalmente terminaron realizando la práctica hasta el día de hoy. Sobre diez entrevistas esto apareció en tres testimonios, de modo que no se trata de casos aislados:

- Pues, empecé desde mis, 7 años, jugando fútbol. (...) pero no eran tiempos en los que me llamaba tanto la atención el fútbol. Era un chico que no sabía golpear el balón. Tomaba el balón con las manos. Me llegaba a los pies y yo lo recogía con las manos. Yo tomaba el balón con las manos, me regañaban, marcaba falta, pero, en un tiempo así me empezó a gustar y ya. (...)

- ¿Qué pasó como para que a los 7 años no te gustara y de golpe empezaste a dedicarte a eso?

- Pues más que nada, digamos que no saber jugar (...) yo no nací con un talento, un don así como otros jugadores, yo lo fui desarrollando por mí mismo, con mucho trabajo y esfuerzo, pues, me fui aguerriendo [sic] a aprender a jugar. Siempre iba con mi padre no, pues, vamos a patear un poco. Y ya no ponía mis manos atrás para no tocarla con la mano, y así fui aprendiendo. [Eso fue a] $\operatorname{los} 7$, eh 8, 9 años, algo así. (...)

- ¿A los 7 años me dijiste que jugabas dónde?

- En un fut 7 que mi papá organizó. Un equipito.

- ¿Y quiénes eran tus compañeros?

- Eran amigos de ahí de la colonia. Eran muy cerca las canchas. (...) Eran equipos sabaderos, equipos organizados por chiquitos, no tan reconocidos, nada más para diversión.

- Entonces era un poco tu padre el que iba organizando todo... ¿Puede ser que fuera también tu padre el que te decía de ir a jugar y a practicar?

- Sí.

- ¿En qué momentos del día o de la semana lo hacían, te acuerdas?

- Pues, era casi siempre. Al llegar de la escuela. Yo salía a las 4 de la escuela, comía a las 5 y a las 6 ya le decía "No pues, vamos a patear un poco". Él siempre estuvo dispuesto para ir.

- ¿Tienen como algún parquecito cerca, o en el fondo de la casa? 
Lo expuesto hasta aquí confirma lo que expusimos en el marco teórico: la influencia del pasado en el devenir de los jugadores. Para completar la indagación deberíamos trabajar con niños que no se hayan dedicado al fútbol y observar si allí también hubo padres que promovieron el fútbol y en consecuencia el fracaso de esa voluntad, pero en principio encontramos que los futbolistas no son producto del libre albedrío, de la voluntad individual ${ }^{39}$, sino de diversas prácticas y representaciones que en algunos casos devenían condicionamientos, y que se pusieron de manifiesto sobre todo en los primeros años de vida.
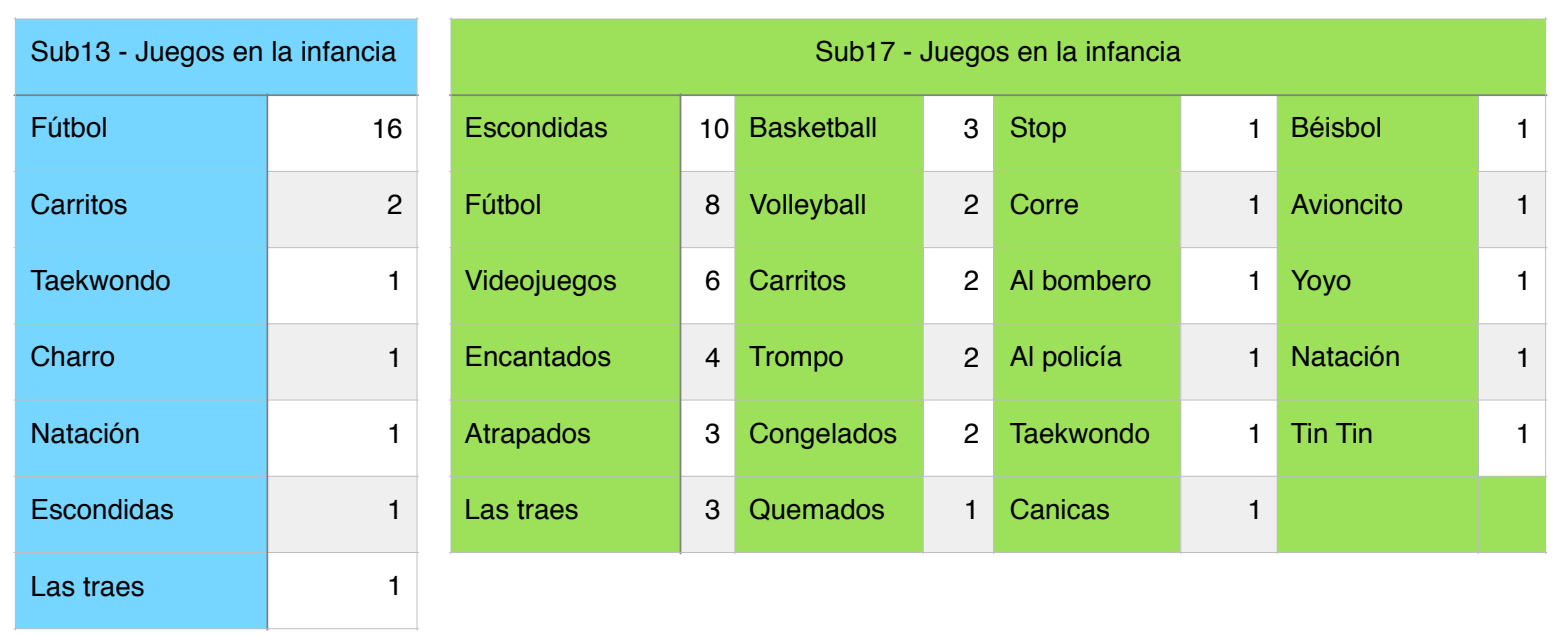

Ahora bien, las encuestas exponen un dato que nos podría hacer relativizar esta idea. Una de las preguntas indagaba “¿A qué jugabas cuando eras chiquito?”, y las respuestas mostraron, en primer

38 Observemos los otros casos: “...pues mi papá también me promovió, digamos por que pues siempre practicaba con él, y así. - ¿En qué momentos practicaban? -Este, de entre semana pues. Siempre íbamos a la unidad deportiva ahí de la ciudad. Y este, practicábamos, balón, balón. -¿Cómo era la practica? -Este, pases y así, centros. -O sea, era una práctica, no es que iban a jugar. -Aja, no. Nomás entre nosotros, pues, mi papá y yo. Ya fue cuando mi papá me decía me registraba pues en un equipo así de barrio. Este, pues antes no tenía minutos, no jugaba casi. -¿Eso a que edad? -Unos 10. Era medio malito. Pues sí, después me sacó y ya fue cuando llevó a la ciudad y a una filial pues de Pachuca, como te decía, la formación así de jugadores y eso. Ya me, me registró mi papá, pero ahí entonces era como que de paga. (...) Pues fui ahí, agarré nivel fue con, me elevó pues más. Ya era, ya era como un capitán, ya era capitán, pues digamos" (Entrevistado P6). “-Me imagino que él [por su padre] te llevo por primera vez a una canchita... - ¡Sí! a mí no me gustaba el futbol. - ¿No te gustaba? - ¡No! De chiquito, él me cuenta que a mí no me gustaba el fútbol... Cuando él me decía 'vamos hijo', porque me dice 'mi rey' o carnal... él me decía 'mi rey vamos al partido', cuando yo estaba chiquito, y yo le decía ¡No! ¡No me gusta! Y me quedaba en el carro, y que un día llegó al carro y que ya no estaba, y que se preocupó mucho, y... me vio que yo estaba con un balón pegándole a la pelota, entonces desde ahí siempre, ahí fue cuando me llevo a una escuelita que se llamaba Puma Chalco, porque era en ese entonces lo máximo para mí, yo pasaba en el carro y le decía 'Mira papá, yo quiero estar ahí' y él me decía 'No mi rey, este es muy caro, bueno pero vamos a ver', y ya hizo lo posible porque yo estuviera en esa escuelita" (Entrevistado P3).

39 Una buena crítica a esta postura se puede encontrar en el capítulo 2 de "El sentido práctico": "Si el mundo de la acción no es otra cosa que ese universo imaginario de posibles intercambiables, el cual depende enteramente de los decretos de la conciencia que lo crea, y por lo tanto enteramente desprovisto de objetividad, si es conmovedor porque el sujeto elige ser conmovido, indignante porque elige indignarse, entonces las emociones y las pasiones, pero también las acciones mismas son tan sólo juegos de la mala fe" (Bourdieu 2010: 69). 
término una diferencia notable entre las respuestas que brindaron en ambas categorías ${ }^{40}$, y en segundo lugar que en la Sub17 el fútbol no fue el juego principal sino que apareció junto con otros 22 juegos y deportes. Si bien son influyentes, estos datos parecen exponer que los juegos no generan una relación de determinación con los devenires.

\subsubsection{La familia en el presente}

La influencia familiar no sólo se expresa en los inicios, en haber promovido el fútbol sino que continúa en el presente, ya no como promotora del deseo pero sí como sostén de la "motivación" de muchos jugadores. Un elemento central a la hora de observar cómo se incorpora en el desarrollo de los jugadores es la distancia: no se da la misma situación en Pumas u Olympique de Marsella, donde la mayoría de los chicos continúan durmiendo en la casa familiar, que en Argentina, donde 7 de 10 jugadores entrevistados se encuentran a horas de distancia de sus familias y las ven, con suerte, mensualmente.

La primera forma de influencia familiar es la contención, que en general los jugadores expresan como aquellos que ante la adversidad o los obstáculos les recuerdan que le "echen ganas", que sigan adelante y que no se desmotiven ${ }^{41}$. Son también personas de confianza en un ambiente de mucha competitividad $^{42}$, esfuerzo físico y en el que semana a semana los chicos (re)descubren su posición en el plantel: si juegan desde inicio, si son suplentes o si quedan afuera del plantel. Si verdaderamente los jugadores creen que están "dejando todo” y aún así no encuentran su lugar en el equipo necesitan trabajar mucho sobre la motivación para continuar entrenando aunque no vean resultados.

\footnotetext{
40 Esta pregunta en la Sub13 se hizo en total a 19 jugadores ya que en el primer ensayo de la encuesta -realizada a 7 futbolistas- no aparecía. Por otra parte las condiciones en que se realizó la encuesta fueron muy similares, es difícil atribuir un "contagio" en los Sub13 como producto de dichas condiciones.

41 “-¿De qué manera te dan apoyo? -Eh, tanto moralmente y se podría decir en parte económica también y en porque vienen, se van... - ¿Cada cuánto vienen? -Cada semana, cada fín de semana. Y pues más que nada moral ¿no? En decirme, 'venga, sí puedes'. De hecho si no estoy convocado para una lista de salir a jugar, pues me agarran del hombro, me dicen que esto es así, que el fútbol da vueltas pero que cuando se deja de trabajar pues ya no hay manera, que yo siga metiéndole, trabajando y solito se van a dar las cosas" (Entrevistado P8)

42 “- ¿Te aconseja [tu padre]? ¿Qué te dice? - ¡Sí! Él es mi mejor amigo en todo. (...) O sea, le cuento todo lo que me pasa, que si me regañaron (...) y él me dice que trate de hacer lo que ellos me digan, o sea, en ese sentido mi papá es como que el... mi único amigo que tengo, ahora sí que mi verdadero único amigo que tengo. -¿Pero por qué? ¿Mucha desconfianza? ¿Esas cosas así? - ¡Pues! Tanto... más por la envidia... por... no sé... pero o sea, con él siempre estoy para todo, no salgo ni a fiestas ni a nada, si me invitan a una fiesta y me dice papá que 'vamos a quedarnos a acostarnos hoy en la sala mi rey', ya pues me quedo con él, o sea con él paso todo el tiempo, es con el que más estoy... toda mi vida” (Entrevistado P1).
} 
Existe una segunda forma de "apoyar" que tiene que ver con ofrecer consejos y comentarios que expresan -nuevamente, los padres ante todo- después de los partidos jugados ${ }^{43}$ :

- Me decías que tu papá te viene a ver a los partidos, también que te ha ayudado mucho, ¿me cuentas qué consejos te da?

- En cada partido lo que esperas es que te felicite, o si haces un túnel o algo así que te diga "Ay muy bien mi rey". Él no es de esos, o sea... él si después del túnel le pegué al rival... él ve eso y me lo dice (...) Me da consejos de lo que estoy fallando o de lo que tengo que mejorar. (...) Mi papá me dice que tengo que ser un [omitimos su posición en la cancha] diferente a todos (...) me dice "Tú tienes que ser diferente en algo y si lo tuyo es llevarla y quitarte 2 y mandar un centro y regresar es lo tuyo" (...).

- ¿Por qué crees que para tu papá es tan importante que seas diferente?

- Porque sabe que si soy igual que todos va ser más difícil que tenga éxito, que trascienda, que o sea así que sea diferente, porque pues... para ser diferente bien, de no tener malos hábitos, va ser más fácil de que pueda yo cumplir mis sueños. (...)

- ¿Durante los partidos estás muy pendiente de él?

- Mmm no... yo estoy en lo mío y él también sabe que estoy en lo mío, y que él me puede chiflar y no lo voy a pelar, entonces él lo que hace es cuando termina el primer tiempo me chifla, cuando voy caminando al vestidor me chifla, y es cuando me da una señal de lo que tengo que hacer para el siguiente tiempo. (Entrevistado P1) ${ }^{44}$

Quizás este sea el testimonio en Pumas que expone un mayor condicionamiento desde lo futbolístico hacia el jugador, sobre todo porque el mandato de ser "diferente" generaba movimientos que contradecían el orden que le pedía el director técnico. Pero en México no parece producirse algo que sí apareció en Marsella y en Estudiantes de la Plata, y es quedan en algunos casos esos comentarios implicaban fuertes formas de presión de LosPumasUnam.com padres hacia los hijos ${ }^{45}$. Posiblemente el caso más paradigmático en este sentido es el del Entrevistado E7, cuyo padre se mudó en 2012 desde su provincia hacia la ciudad de La Plata, y quien relataba lo siguiente:

- ¿Tu papá te va a ver a la cancha?

43 En el trabajo realizado con Murzi expresábamos lo siguiente respecto del caso francés: "varios jugadores sienten que lo que les dicen los padres tiene valor de verdad: frases como 'Cuando soy un desastre me dice que soy un desastre, cuando ando bien no me dice nada" (Entrevistado OM2), "[Me dice] La verdad, si jugué mal o si jugué bien" o "no quiero que mi mamá me venga a ver por el momento porque me desconcentra" dan la pauta de que algunas familias se constituyen como una figura que presiona y exige sobre sus desempeños, que los jugadores deben dialogar con esa mirada externa a la que buscan agradar y que aunque también sostengan que son más importantes las indicaciones del entrenador que las familiares, en algunos casos éstas pueden significar un distanciamiento respecto de la propuesta institucional. No podemos olvidar que en numerosos casos los padres también fueron jugadores de fútbol (...) Sus conocimientos no sólo abarcan cuestiones técnico-tácticas sino que se hacen presentes las experiencias vividas, sus frustraciones y sus relaciones con los técnicos; es sobre todo en estos casos cuando los padres propician representaciones del juego distanciadas de las del Centro de Formación" (Murzi \& Czesli 2014: 63).

44 Un caso en este sentido es el del Entrevistado P3, que no percibe niveles de presión: “-¿Qué te dice? -Pues, cómo ve, que si me vio mal o me vio bien, me dice que le eche ganas. -¿Él sabe de fútbol? -Pues le gusta mucho, pero así como aficionado, ya profesionalmente y las tácticas no. -¿Para ti influye cuando los ves en la tribuna? - Sí, este, a mí en lo personal me gusta mucho mucho que vengan a verme, lo siento así como más apoyado, con mucha más seguridad. Y hasta es un motivo como para echarle más ganas ¿no? trabajar más por ellos”.

45 En otros casos los jóvenes y sus padres acordaron formas que les resultan más adecuadas. Ver en Notas de Anexo, referencia $* 4$ 
- Sí, todos los partidos

- ¿Eso a vos te presiona?

- Sí, me presiona, porque por ahí hago algo mal, hago algo mal, y viene el grito de afuera. Es como que también...

- ¿Qué te grita?

- Nada, me grita como para que haga las cosas bien, pero yo me lo tomo mal, y eso me pone más nervioso todavía. Como que tengo que jugar en base a lo que me va a decir mi viejo después ¿entendés?

- Claro, porque después cuando termina el partido ¿qué cosas te dice?

- Y, depende. Siempre me dice lo que hago mal. Si tengo un partido bien y no me dice nada yo me doy cuenta que jugué bien, pero si ya cuando subo al auto me empieza a mirar con cara más rara es que algo mal hice. (...) Y nada, por ahí yo hay algún día que estoy bajo de ganas de entrenar o me salen las cosas mal y no quiero venir, que sé yo, y me dice que no sea boludo, que a él le pasó eso y que lo tengo que hacer para que todos estemos bien y qué sé yo, para mi familia.

- Perdón que pregunte, ¿tu familia está en dificultades económicas?

- No, pero es como que mi familia vive pendiente de mí. Que si me va bien, si me va mal, cómo me está yendo ${ }^{46}$.

Como se puede percibir, -y como veremos al trabajar sobre la estructura de observación en Estudiantes de la Plata, en el capítulo 6- lo que este diálogo parece mostrar es que el modo de relacionarse entre el jugador y su padre le generaba tanto stress y nerviosismo que no le permitía expresar su mejor juego. Asimismo, podemos observar que el chico considera que el padre lo apoya pero que es él quien no lo sabe o puede manejar: "me grita como para que haga las cosas bien, pero yo me lo tomo mal", sumado a la centralidad que el joven ocupa en el entorno familiar dan la pauta del altísimo nivel de presión con el que se relaciona. De estos testimonios podemos ver que si bien todos los futbolistas dicen que sus familiares los apoyan, esta idea puede remitir a muchas formas distintas de relacionarse, desde sobreabundantes elogios a su juego hasta una crítica férrea que sólo encuentra elementos a mejorar.

Ahora bien, una constante en los testimonios es que ninguno es futbolista contra el designio familiar, que a lo sumo pide que continúen con los estudios en la escuela. Frases como "darles la satisfacción a mis padres de verme jugar a diario" (Entrevistado P1), "obviamente les encanta [que juegue fútbol], están metidos de lleno todos" (P2), "están muy, muy orgullosos de mí. Te digo siempre me apoyan al 100\%" (P3) o "Mi familia que siempre me ha apoyado en todo y pues, me gustaría, bueno siento que están orgullosos, pero quiero verlos feliz" (P4) nos pone también de cara a otro factor

46 En otro caso es el del Entrevistado E1, donde queda clara la tensión existente y la imposición por parte del jugador de un modo de relacionarse. “- ¿Viene a ver los partidos tu papá? -Sí. -¿Y viene a hablar acá [a hablarle a los técnicos]? -No, eso no, con los técnicos no. (...) No lo conocen. Igual yo le digo, no me gusta que les hablen, porque si les hablan después me cagan a pedos a mí [los técnicos lo regañan] - ¿Te dice cosas en el medio del partido? -Sí, pero no le hago caso, no me gusta. Cuando era más chico le decía que se calle, estaba jugando y me decía que haga tal cosa y le decía que se calle, me molestaba, me molesta cuando me hablan. -¿Y después del partido te dice cosas? -No, vamos todos callados en el auto." 
central en el deseo de los futbolistas: el placer que sienten por satisfacer la mirada ajena, ese "Otro" al que se refería Slavoj Zizek con la identificación imaginaria. Esto tiene dos aristas más profundas. La primera es que en algunos relatos aparece la idea de que toda la familia es la que participa en el desarrollo del joven como futbolista ${ }^{47}$. A partir de allí, que la familia se "sacrificó" o sacrifica para que ellos puedan jugar ${ }^{48}$. Y a partir del sacrificio, que los chicos no juegan únicamente por sí mismos sino que juegan por esos otros.

En el apartado metodológico se mencionó que uno de los mecanismos utilizados en las entrevistas en profundidad fue pedirles a los jugadores que dibujaran sus sueños futbolísticos y luego, para evitar interpretaciones incorrectas, les pedimos que los describieran. Sin restricciones, el intento procuró hurgar en las imágenes -ya no sólo las frases verbales- que los jugadores asocian a sus futuros ideales. El resultado expuso que en cuatro de los diez casos aparece la familia ligada al éxito ${ }^{49}$. Se puede ver, entonces, que si bien no es una tendencia mayoritaria, sí está claramente presente y que el deseo, entonces, también está asociado al peso que implica no defraudarlos.

- ¿Para venirte estuviste ahorrando mucho tiempo?

- Sí, pues, mi papá hizo un esfuerzo grande ¿no? Que, que pues se lo debo a él porque por él estoy acá e hizo un enorme esfuerzo y por eso fue que aproveché para estar aquí ¿no?

- ¿El esfuerzo es que te dio plata o pidió un préstamo o algo así?

- Pues la verdad no sé, eso no me dijo nada (...)

- ¿Haces algún proceso interno también para darte ánimo cuando las cosas no te salen?

- Pues, pienso mucho en mi familia ¿no? Que es lo único porque pues por ellos estoy aquí ¿no?

- ¿Qué significa que por ellos estás acá?

- O sea que, pues, su apoyo que me dieron, tengo mucho apoyo sobre mi familia, te digo que por ellos estoy acá.

- Con el apoyo ¿te refieres a eso que hizo tu padre para que tú vinieras? ¿O te refieres a otras cosas?

47 Observemos algunos ejemplos: “... a ellos también les gusta estar checando las estadísticas, las tablas.(...) Y pues me apoyan mucho, todo, y por supuesto siempre me han dicho que obviamente sería un sueño que yo llegara a Primera División pero pues también siempre me dicen que pues que es muy incierto, que le tengo que seguir echando ganas a la escuela... ¿Pero ellos te dicen que sería un sueño para ellos que tú jugaras al fútbol o...? -Entienden que primero es para mí, por mí, siempre me dicen que no van a querer nada ellos Que el sueño es mío pero pues que ello también estarían muy muy felices si sucediera ¿no? -¿Por qué crees que sería así? -Porque creo que ellos también saben lo que he pasado y por lo queremos pasado, yo y por consecuencia ellos. -Cuando dices "por lo que hemos pasado" ¿a qué te refieres? En el fútbol hay momentos buenos y malos y siempre cuando son buenos estamos muy contentos y juntos, pero también cuando se complican un poco las cosas ellos han estado al lado de mí y siendo conmigo ¿no?” (Entrevistado P2).

48 “-Así que a tu familia le hace muy feliz que tú estés acá. -Sí, pero a la vez se sienten tristes ¿no? por que qué darían [para] que yo estuviera allá igual. -Claro. -Al igual que yo quisiera estar allá pero, pues igual ¿no? Me dan todo el apoyo que tengo y que me han brindado y, pues, contentos se sienten mis papás pues por mi propio esfuerzo que he hecho de llegar hasta donde estoy ahorita (Entrevistado P8).

49 Las imágenes y los testimonios asociados se pueden encontrar en el Anexo *6 
- No, a eso que mi papá hizo, y que pues toda mi familia igual me da aliento ¿no? Que yo le eche ganas, que me quieren ver acá ¿no? (Entrevistado P9) ${ }^{50}$

La inversión económica que realizó la familia para sostener sus posibilidades es un elemento presente -y en muchos casos sumamente importante- pero no el único, ya que también puede estar ligado a llevarlos y traerlos cuando las distancias son largas, a toda una organización familiar en torno del futbolista o incluso a mantenerlo en el club aún si los padres están sin trabajo. El caso que se expone a continuación muestra que toda la familia "sufrió" la discriminación por motivos económicos, lo cual le da al proyecto del futbolista un sentido colectivo, una suerte de revancha familiar:

“...cuando tenía 9, 10, 11,12 este... se hacían viajes aquí en Pumas, pero costaban 1200 dólares $^{51}$. Entonces mi familia ahora sí que... vive al día, no somos así de 'Ay vámonos de vacaciones'. (...) Y una vez le preguntaron a mi mamá: “¿Sí va ir [nombre del jugador]? Y mi mamá: 'Este no, no va ir pues...', 'Ay bueno qué lastima', y así como que... no tanto ayudar sino para burlarse y en ese entonces [el técnico] se le acercó a mamá y dijo: ¿¿Qué paso?, ¿Por qué no va ir? Acabo de escuchar', y mamá le explicó que nosotros no teníamos dinero (...) y [el técnico] le dijo 'Mira, tú no te preocupes por nada, va ir gratis, pero que nadie se entere' (...) En todos los viajes llevaban 300 dólares ellos, 500 dólares, yo llevaba 15 y con esos 15 hacía lo posible para traerle cosas a mi papá, a mi mamá, porque yo siempre he pensado en ellos... y ha sido como mi motivación, que a pesar de que... me han humillado, yo he seguido y seguido para ayudarlos para... que si me daban 15 dólares mi tía... yo le traía un Mickey. A mi papá, a mi mamá le traía un collar que me costaba 1 dólar y entonces yo sentía así como que orgullo de mí que... en el torneo era el mejor, y aun así con ese dinerito que yo llevaba le compraba cosas a mi mamá, a mi papá y así fueron mínimo 8 viajes seguidos que lo más que yo lleve fueron 100 dólares que toda mi familia los juntó (...) ellos están muy orgullosos de mí por lo que soy, por lo que... les doy todo a ellos sin recibir nada a cambio, nada más... ahora sí que doy todo por mi familia sin recibir nada a cambio, entonces sí me llegaba

$50 \mathrm{Al}$ menos cuatro jugadores más exponen situaciones similares, de modo que la mitad de los entrevistados presentan esta relación con la familia: "Yo siempre me he dicho que si bien lo hago por mis sueños y por lo que quiero, también lo hago por ellos ¿no? En el sentido de que siempre me han apoyado y siempre han estado ahí conmigo y pues que la forma de... No sé si de retribuirles o pues de agradecerles es pues también demostrarles que estoy aprovechando todo lo que me están dando ¿no? también están pagando la escuela, y hacen esfuerzos por estar en los partidos, entonces esa también es mi forma de agradecerles” (Entrevistado P2). “-¿Qué, que significa 'cuando no te salen las cosas’? - Pues cuando tratas de, o sea tú tratas de hacer lo mejor posible que puedas y de repente no puedes dar un pase bien, no puedes burlar a alguien, te desconcentras... - ¿En estas situaciones en quién piensas? ¿O en qué piensas? -Pues en estas situaciones lo que pienso es, pues todo lo que he trabajado para, para estar viviendo esto, todo el esfuerzo que han hecho tanto yo como mi familia. $-i \mathrm{Tu}$ familia de qué manera hizo el esfuerzo? -Pues siempre me han apoyado en todo, que pues, simplemente de que me dan las fuerzas para seguir adelante y que no hay momentos malos sino. O sea, no hay momentos malos que no se puedan corregir" (Entrevistado P5); “-¿Cómo te das ánimos? -Pues pensando en mi familia, siento que pensando en ellos, este, mi motivación, es lo que me da ánimos. -Antes los mencionaste, dijiste que buena parte de todo lo que te pasa o lo que haces viene de ellos ¿Qué significa eso? -Pues eso, que cuando entro a la cancha y juego fútbol, pues siempre, aparte de pensar en mí, en lo que voy a hacer, este, pienso en ellos, en hacerlo por el bien. Y este, ps son motivación cuando me vienen a ver, te digo que este, sí, me levantan el ánimo” (Entrevistado P3). “-¿Te da miedo la posibilidad de no llegar a primera? - Sí, sí, si siento que no sé, que sería algo, algo muy feo para mi no llegar a primera división. Como que tanto tiempo, tanto esfuerzo para nada sería como, sí me frustraría mucho yo conmigo mismo. Existe la posibilidad de que no, por que eso, es casi el, es un 50 y 50. Y pues te vas haciendo la idea de que puedes llegar, de que no puedes llegar, pero estas trabajando para llegar y si no llegas pues no sé, como que te frustras ¿no? En lo personal yo si me frustraría mucho no sé, con mi familia, pues algo que le prometí a mi familia, a mis abuelos y todo (Entrevistado P7). Un caso similar en Argentina es el del Entrevistado E8, presente en el Anexo *5.

51 En la actualidad los viajes que realizan no implican ningún costo para los futbolistas. No pude confirmar si en el pasado la situación era otra. 
afectar de chiquito todo lo que me criticaban, lo que... hablaban de mí, lo que me humillaban, entonces eso me enseñó a ser más fuerte, a cada vez ser más alegre, que la gente nunca me viera triste de lo que se decía de mí, si hablaban, que yo fuera más fuerte cada vez, eso era lo que... me enseñaba mi papá y mi mamá porque así te digo que era en todos los viajes”. (Entrevistado P1)

En Argentina este discurso es potente, sobre todo porque dedicarse al fútbol implica el destierro y distanciarse de la familia, y pone en el centro de la escena que los futbolistas también precisan de un capital social y económico para avanzar en sus carreras (ya volveremos sobre este tema). Allí aparece otro discurso similar, que consiste en hacerlo no por otros sino por ellos mismos, pero a partir del sufrimiento (o de un discurso que sostiene la motivación sobre el sufrimiento). En este caso recuperaremos el testimonio del Entrevistado E5, de Estudiantes de la Plata:

- Sinceramente creo que sigo porque amo esto, amo lo que hago y me da felicidad, no dejo la familia, no dejás la familia por venir acá y estar triste. La dejo porque justamente creo que es algo que me hace más feliz, y no dejo los amigos, no dejo la casa por venir acá y que te dé igual, lo hacés porque te gusta y porque es algo hermoso. Pero en el futbol, desde mi punto de vista, para llegar a Primera División, tenés que pasar por lo peor de lo peor y lo peor.

- ¿Qué es lo peor de lo peor de lo peor?

- Y, desilusiones, amargura, momentos en los que no querés saber más nada, querés dejar todo y no sé, volverte a tu casa y darle un abrazo a tu vieja, a tu viejo y decirle no sé, que no querés jugar nunca más. Sinceramente uno dice "amás al futbol”, yo sinceramente amo al futbol y no lo cambio por nada, pero como todo llega un momento en que tenés la cabeza en blanco y no querés hacer nunca más nada. Pero para mí, desde mi punto de vista, podés ser un crack, pero si no tenés sacrificio, no te sirve de nada. Para mí llega el que pasa por lo peor. (...) Un técnico una vez me dijo, siempre me acuerdo, me acuerdo que me había esguinzado con la Selección Nacional. Había jugado cinco minutos y me esguince el tobillo, salía llorando de la cancha, no me consolaba nadie. Me agarró en el vestuario y me dijo que me acuerde siempre que para llegar a lo más alto voy a pasar por lo peor siempre (...) creo que es así, y eso me ayuda mucho, pensar así, porque si pienso que el día de mañana voy a tener una caída y no me levanto más, no me sirve de nada"52.

Representaciones como esta sin dudas impactan sobre las motivaciones que los impulsan día a día a desarrollar y continuar con los entrenamientos. El discurso del sufrimiento o del mártir está ligado no sólo a los sentimientos de los jugadores -sin dudas posibles, aunque también construidos y socialmente aceptados- sino a la construcción de la historia del futbolista en términos épicos, donde ellos asumen el rol de héroes que superan numerosos obstáculos y alcanzan la gloria sobre todo a partir del esfuerzo. Esto nos pone de cara al próximo apartado, donde observaremos si discursos como estos son regulares.

52 En Pumas, un testimonio similar: "-Estas situaciones como llegar a la Selección Nacional, ¿cómo te imaginas esos momentos? - Pues, muy duros porque yo soy de las personas que piensa que lo que llega fácil, fácil se va y que primero tienes que picar piedra para poder lograr todo esto. Tienes que sufrirle y así va a haber momentos muy malos, otros muy buenos, otros mas o menos" (Entrevistado P7). 


\subsection{Narraciones: la pobreza, el esfuerzo físico}

Decíamos en el marco teórico que al trabajar por el deseo de los futbolistas también nos estamos preguntando por la reproducción de la sociedad, por el nacimiento y desarrollo de los actores que luego son el centro del espectáculo futbolístico. Al trabajar a partir de representaciones sociales proponemos que no nos interesa observar si los chicos provienen "materialmente" de contextos sociales de vulnerabilidad o pobreza sino si se refieren a ella como un discurso a partir del cual sostienen su práctica y su deseo de devenir futbolistas. Y nos preguntamos esto porque la propuesta es observar cuál es la influencia de los relatos en la configuración del deseo, hasta qué punto al asumir una trayectoria buscamos materializar un relato, o mejor aún: hasta qué punto el pasado social se hace presente en forma de relato, un drama a través del cual encabalgamos nuestras trayectorias..

Fueron testimonios como el del Entrevistado E5, pocas líneas atrás, los que me llevaron a pensar esta posibilidad, ya que cuando hablaba de "pasar por lo peor", sufrir y levantarse, parecía exponer reminiscencias del relato bíblico de Jesús, sus muertes y resurrecciones. Y una idea recurrente cuando se piensa en los futbolistas es que el deseo está ligado a salir de la pobreza, que el fútbol es un camino para romper, justamente, con una suerte de destino prefijado ligado a las carencias económicas. Imágenes como las de Maradona en las canchas de tierra del barrio Villa Fiorito ${ }^{53}$, Cristiano Ronaldo en el marginal Quinta do Falcao o los inicios de Carlos Tévez en Fuerte Apache son algunos de los ejemplos que alimentan esta idea (y luego de leer historias como la de Darío Coronel, amigo de Tévez y promesa del fútbol quien a los 17 años se suicidó, ya sin club, acorralado por la policía para evitar lo atraparan o asesinaran [Gallota 2010], uno tiende a pensar que, en efecto, o es el fútbol o es la pobreza).

Para esbozar una definición operativa recurrí a cuatro textos que trabajan sobre el mito en la configuración social. El punto de partida lo tomaremos de Blanca Solares y de Juan Castaingts Teillery. Para ambos el mito es central a la existencia humana, y mientras la primera afirma que "no existe ninguna cultura que pueda dejar de remitir su origen a una historia sagrada, ni de organizar en torno a

53 Pablo Alabarces analiza la configuración de la figura heroica de Maradona. De ella recuperaremos sólo algunos párrafos: "Los datos del nacimiento e infancia de Maradona se acumulan en una sola dirección: la pobreza, el origen humilde, una condición social baja. (...) la marca básica que permitirá estructurar a posteriori una épica del pobre está condensada en el nombre del vecindario, Villa Fiorito. Con un juego de sentido falaz: la palabra villa evoca en el español de Buenos Aires el aglomerado caótico y marginal del asentamiento más pobre, la villa miseria. Pero Villa Fiorito no es una villa miseria; la villa designa aquí, neutralmente, un vecindario. (...) Pero la operación de mitificación se completará con el verbo: salir. De Fiorito se sale, para llegar a la fama, al mundo, a la gloria, pero sin olvidar. (...) Maradona es el pobre ascendido, el que sale, pero no se olvida de sus orígenes. (...) Así, Maradona personifica un clímax: no se aparta de la clásica épica deportiva -porque no es únicamente futbolística- del ascenso social, sino que por el contrario la lleva a su máxima síntesis: es el pibe de Fiorito, y a la vez - o como culminación- llega a ser el nombre más conocido del mundo (Alabarces 2001: 172). 
ella sus actividades, ni de extraer de ahí su inspiración filosófica, política y artística” (Solares 2003: 110), Castaingst Teillery indica que "los mitos son relatos que el hombre tiene y que le sirven para comprender el mundo social y natural que le rodea, para estructurar sus creencias y para orientar su acción" (Castaingts Teillery 2011: 11). Este autor, que en el trabajo citado enlaza el estructuralismo simbólico con las neurociencias, añade que la mente humana está construida para pensar en términos de narrativas, y recupera a Lévi-Strauss para afirmar que “...los mitos nos enseñan mucho sobre las sociedades de las que proceden, ayudan a exponer los resortes íntimos de su funcionamiento, esclarecen la razón de ser creencias, de costumbres y de instituciones cuyo plan parecía incomprensible de buenas a primeras..." (ídem: 14).

Solares, por su parte, parte de una mirada psicoanalítica para sostener que las figuras del mito son expresión simbólica de deseos, temores y tensiones inconscientes que nos acosan desde la infancia, producto de la producción y reproducción milenaria. En su propuesta, que asocia el mito a los rituales y a la sabiduría tradicional, "canto antes que agua, música más que palabras”, enumera una serie de "funciones" del mito, y allí indica que tiene una función social, que consiste en fundamentar un cierto orden social naturalizado y que están en consonancia con "el orden o ethos establecido socialmente" (2003: 112).

Otro de los autores que trabajó centralmente sobre esta noción fue Roland Barthes, quien define al mito como un sistema de comunicación que no se define por el objeto de su mensaje sino por la forma en que se lo profiere. Tras hacer un paralelismo entre la tríada saussuriana (significante, significado y signo) y la freudiana (sentido manifiesto de la conducta, sentido latente y el sueño como la relación entre ambas), el semiólogo francés sostuvo que la particularidad del mito es que se edifica a partir de una cadena semiológica que existe previamente:

...es un sistema semiológico segundo. Lo que constituye el signo (es decir el total asociativo de un concepto y de una imagen) en el primer sistema, se vuelve simple significante en el segundo. Recordemos que las materias del habla mítica (lengua propiamente dicha, fotografía, pintura, cartel, rito, objeto, etc.) (...) se reducen a una pura función significante: el mito encuentra la misma materia prima; su unidad consiste en que son reducidas al simple estatuto de lenguaje (Barthes 2010: 205).

Para Barthes el mito es una "segunda lengua en la cual se habla de la primera", y por eso a él no le importa el contenido sino cómo es esa relación entre el primero y el segundo, su mirada del 
simbolismo es que la estructura siempre hace referencia a algo primero 54 . Así, sostiene que "el mito no oculta nada: su función es la de deformar, no la de hacer desaparecer" (Barthes 2010: 213), y agrega tres elementos: que si bien el signo es arbitrario, la significación mítica contiene una dosis de analogía; en segundo término, que el mito naturaliza la historia, porque la historia primera no es puesta en duda sino que la comprensión la da por sentada. Finalmente, que en el gesto de naturalización el mito borra la historicidad del relato, "las cosas pierden en él el recuerdo de su construcción” y por eso, es un habla “despolitizada" (ídem: 238).

Esta perspectiva -compartida por Castaingst Teillery y por Carolina Collazo- antepone la forma que estructura el mito y se desentiende de su contenido, bajo la premisa de que lo que importa es observar cómo el mismo fenómeno se produce en diversas geografías y a lo largo de la historia. Collazo, por caso, parte de la observación de Lévi-Strauss sobre la similitud entre los mitos de las diversas geografías y postula que el mito se trata de una estructura "que proporciona un modelo lógico general más allá del carácter enteramente contingente de su contenido" (Collazo 2011: 32), de modo que desde su perspectiva interesan las "unidades constitutivas del mito que resultan imposibles de aislar más allá de los 'haces de relaciones' que sólo a partir de la forma de sus combinaciones adquieren una función significante" (ídem: 33)

Pero rechazar el contenido como materia de interés no es la perspectiva que aquí adopto, porque percibo que es a través de ese contenido -interiorizado, sedimentado, naturalizado- que lo social se reproduce: desde mi punto de vista no operaría de igual manera que los jóvenes, sólo por ejemplificar, desearan ser futbolistas por creencia en un designio astrológico que por un estudio genético determinara su predisposición al deporte. Si nos desentendiéramos de ese contenido estaríamos remitiendo el sentido a esa estructura previa y no a su confrontación con el acontecimiento (Bourdieu 2010: 90), que la transforma y actualiza. Propongo entonces que el sentido y la reproducción social surgen de esa combinación significante y no de su estructura "primera", porque lo que mediatiza nuestra relación con lo real no es la estructura sino la trama significante.

54 "Un significado puede tener varios significantes: éste es especialmente el caso del significado lingüístico y del significado psicoanalítico. Es también el caso del concepto mítico, que tiene a su disposición una masa ilimitada de significantes: puedo encontrar (...) mil imágenes que me signifiquen la 'imperialidad' francesa” (Barthes 2010: 211) 
Por este motivo no estoy considerando aquí la propuesta metodológica de Castaingts-Teillery de retomar a Algirdas Greimas ${ }^{55}$, aunque en un trabajo futuro puede ser una herramienta para observar los relatos de los jugadores sobre su práctica. Recupera además a Claude Bremond, de quien tomaremos el ciclo narrativo heroico de la siguiente manera: comienza con la búsqueda por parte del héroe de una mejora en su situación, lo que da el puntapié para un proceso de su búsqueda; continúa con la posibilidad de una degradación y en tercer lugar se enfrenta a un conjunto de obstáculos, para los cuales se vale de medios y el modo en que se utilizan. También se agrega el modo en que cumple con sus propósitos, y se complementa con la posible intervención del aliado o eliminación del adversario, negociaciones, agresiones, retribuciones (recompensa, venganza o ambas), más la posibilidad de atravesar sacrificios para alcanzar su cometido (Castaingts Teillery 2011: 122). Claro está que este recorrido no puede ser tomado al pie de la letra sino como indicio para pensar las narraciones de los futbolistas $^{56}$ pero si observamos la descripción que Pablo Alabarces hizo sobre Maradona (en nota al pie 53) comprendemos que tiene sentido preguntarse si los futbolistas continúan atravesando dichas historias.

Finalmente observemos algunos otros elementos del trabajo de Carolina Collazo, quien cruza a Lévi-Strauss con Althusser y Freud, y propone que en los tres casos se pone en evidencia el problema de la articulación entre lo real y la representación. La autora establece una relación con la teoría marxista de la ideología, específicamente a partir de Althusser:

La ideología es profundamente inconsciente, es un sistema de representaciones que "se imponen como estructuras a la inmensa mayoría de los hombres sin pasar por su conciencia [...] la ideología concierne, por lo tanto, a la relación vivida de los hombres con su mundo [...] a condición de ser inconsciente".

$(\ldots)$

Si la ideología vela algo, ese algo no podría definirse como una realidad verdadera e inaccesible. Lo que se oculta no está por fuera de ella en cuanto ente. Sin mayores problemas podemos afirmar que la ideología es un velo que no vela nada o, en otras palabras, vela un vacío. Se pone así de relevancia tanto el problema de la representación como el del estatuto de lo real, ya que si lo real para Althusser mantiene en su núcleo la imposibilidad de simbolización, la representación es ella

\footnotetext{
55 En Greimas el método consiste en buscar similitudes y diferencias entre mitos diversos: "De lo que se trata es de establecer sintagmas en cada mito y luego compararlos con otros sintagmas de otros mitos (...) explicar el mito comparándolo con otros mitos y correlacionar determinados elementos narrativos de un mito con otros de otros mitos. Estas relaciones entre mitos que conducen a conjunciones y disyunciones así como las transformaciones subsecuentes, permiten llegar a tres conclusiones importantes: 1) Permiten definir sintagmas narrativos del relato mítico; 2) Posibilitan afirmar la existencia de relaciones necesarias entre los elementos y sintagmas de los mitos; 3) Favorecen la definición de los elementos míticos por medio de sintagmas y paradigmas" (Castaingts Teillery 2011: 119)

56 Como aquí buscamos la relación de los individuos con los mitos hacer esa relación "entre mitos" implicaría que la significación no es producto de la actualización del relato y su relación con otros significantes actuales sino de su relación con relatos previos, con los que tiene un paralelismo estructural. Debo reconocer, sin embargo, que hasta el momento no encontré trabajos sobre el mito desde una perspectiva no estructuralista y que es menester hacerlo un estudio más profundo.
} 
misma la expresión de una falta constitutiva que anula toda vinculación con un referente. (Collazo 2011: 36)

Si mi interpretación no es equivocada, debo decir que no comparto que por fuera de la representación no haya un referente (es decir, que haya un "vacío"), pero sí comparto, como indiqué largamente en el marco teórico, que no existe acceso al mundo por fuera de la representación. El foco de su trabajo consiste en observar la estructura por la cual las cosas se presentan como naturales aunque sean producto de un proceso histórico, y no su contenido ${ }^{57}$. Ahora bien, me interesa detenerme en su noción de "creencia", ya que los relatos de los futbolistas parecen estar más ligados a este concepto que al de mito. Para ello, recuerda a Slavoj Zizek y plantea que

“lejos de ser un estado 'íntimo', puramente mental, se materializa siempre en nuestra actividad social efectiva: la creencia sostiene la fantasía que regula la realidad social (...) Que una creencia se materializa como actividad social -reafirmando su carácter no individual-, implica que ésta circule permanentemente, es decir, que se mueve y se escurre en el orden de las coyunturas concretas. Y si bien es incapaz de fijarse de una vez y para siempre, regula la realidad social, es decir, que su inscripción en el proceso histórico social asume, aunque temporalmente, un lugar común de decir/hacer social". (Collazo: 38 , el destacado me pertenece) ${ }^{58}$

En resumen, partiremos de pensar estos relatos como elementos para la comprensión del mundo, que estructuran creencias y orientan la acción de los individuos, que están en consonancia con el orden establecido socialmente. Se trata de sistemas semiológicos segundos, pero desde mi punto de vista no porque hagan referencia a un relato previo que lo dota de sentido, sino porque expone un paralelismo con otros relatos previos, y esos otros relatos se presentan como significantes asociados a este primero. Finalmente, que estos relatos son creencias, en el sentido de que operan como actividad social y sostienen la fantasía a través de la cual el sistema simbólico es mediador de la relación con el mundo.

Ahora bien ¿hasta qué punto los datos confirman la imagen comúnmente difundida de que los jugadores "buscan salir de la pobreza”? ¿Podemos sostener a partir de la etnografía que el deseo de ser futbolistas está asociado a discursos sobre condicionamientos de "clase", que se encabalgan sobre la representación de que jugar al fútbol es uno de los pocos caminos posibles y verosímiles para salir de la pobreza? Para exponer lo observado voy a partir de Estudiantes de la Plata. En la institución argentina encontré que el 50 por ciento de los jugadores buscaban ser profesionales "para ayudar a sus familias",

\footnotetext{
57 “Así llegamos a la conclusión que tanto la ideología como el inconsciente y el mito sólo pueden pensarse a partir de sus efectos y que sus respectivos contenidos específicos no son más que la vía a posteriori del análisis de sus formas generales o estructuras. Más aún, estas estructuras son, en todos los casos, no conscientes y, sin embargo, ordenan y clasifican los objetos del mundo, constituyen las subjetividades y regulan las prácticas sociales" (Collazo 2011: 36).

58 Para Collazo este concepto restituye el carácter colectivo de la constitución del mito, pero es porque para ella -a partir de Lévi-Strauss- el mito tuvo un comienzo individual que luego deviene social.
} 
un concepto que en general abarca a los padres y a los hermanos ${ }^{59}$. Pero además aparecen dos conceptos centrales: la humildad y el sacrificio. En el trabajo escrito junto al Mg. Diego Murzi afirmamos lo siguiente:

El principal deseo en ese sentido consiste en "comprarles una casa", retribuir de esa manera el "esfuerzo" que, sostienen, la familia realizó por ellos. Esto está ligado a que los jugadores inscriben su discurso en el de la "humildad", un valor que no sólo significa el esfuerzo diario, la ausencia de ego y de ostentación, sino que al mismo tiempo es un eufemismo para hablar de la pobreza económica ${ }^{60}$. De esa manera, hacen propia la imagen del obrero para contraponerla con la imagen del futbolista afamado y rodeado de lujos.

En el mismo sentido opera el concepto de "futuro". Son tres los jugadores que sostienen que el fútbol "es su futuro", que interpretamos como el modo que tienen de poner en escena la importancia de elaborar un modo de vida a través del fútbol y en consecuencia de distanciarse de la práctica como un acto puro de placer sino de ponerlo ya en el marco de una carrera profesional (Murzi \& Czesli 2014: 85).

Es decir, la mayoría de los jugadores en Argentina (entre ambos conceptos alcanzan al 60\%) inscribe claramente su práctica en la imagen del trabajador que sólo cuenta con su cuerpo y esfuerzo para salir adelante ${ }^{61}$. No se confía en el talento porque implicaría asociarse a los jugadores-estrella rodeados de lujos -o, para ser más precisos, de distanciarse de la idea de lujo como una merma en el trabajo. El discurso de la humildad y el sacrificio también está alineado con la propuesta institucional que promueve el esfuerzo permanente.

De igual manera, al momento de elegir a sus referentes cuatro también ponderaron valores y elementos de la personalidad de los seleccionados: dos chicos optaron por Javier Mascherano y Carlos Tévez como sus referentes (los dos juntos) y un tercero seleccionó solamente a Tévez. Cuando observamos los motivos uno se refirió a la "humildad y el sacrificio" (Entrevistado E1), el Entrevistado E2 amplió y afirmó que "[Mascherano] tiene lo que a mí me gustaría al jugar, que sea aguerrido, esfuerzo, compañerismo, humildad, y eso..." Sobre Carlos Tévez indicó que

...la peleó desde chiquito. Cristiano Ronaldo no sé muy bien su historia, pero no sufrió lo que sufrió Tévez. Messi tampoco sufrió lo que sufrió Tévez. En la escuela estamos viendo ahora un 'Cuento

\footnotetext{
${ }^{59}$ A modo de ejemplo, reproducimos tres testimonios: [Diálogo con Entrevistado E1] “-P. La plata es importante para vos en términos de... -R:. Y, más o menos, o sea, si ganaría [sic] plata le daría la mitad a mi familia, a mi viejo, a mi vieja, que siempre me ayudaron, que siempre me dan, y después si, vería”; [Diálogo con Entrevistado E3] "-P: ¿Vos también estás pensando en poder ayudar a tu familia? -R: Claro, eso es lo que más pienso yo. Yo siento que muchos piensan que cuando haces el primer contrato comprás un auto. -P: ¿Y vos en qué pensás? -R: En mi primer contrato ayudar a mi familia e ir juntando para una casa porque si no ¿a dónde vas a vivir, arriba de un auto?”; [Diálogo con Entrevistado E8]. -P: ¿Cómo hacés para tener confianza, para seguir entrenando todos los días? -R: Yo sigo por mi familia. -P: ¿Por qué? -R: Por lo que han hecho por mí. -P. ¿Qué hicieron por vos? -R. Y... me han bancado. Cuando estuve acá una semana acá a prueba estuve en un hotel allá en el Banco Provincia, y no sé cuanto salió, estuve cuatro días".

${ }^{60}$ En Argentina, una persona "humilde" es aquella que debe trabajar a diario para lograr su manutención.

${ }^{61}$ A modo de ejemplo observemos el testimonio del Entrevistado E1: “...el sacrificio, la humildad, el compañerismo, la solidaridad, todo eso... Podés jugar bien, pero si no tenés eso no llegás a nada, no te hacés profesional".
} 
de un pibe', de Maradona, y vos te ponés a comparar lo de Maradona con Tévez y es casi igual la trayectoria.

Entonces, en Argentina aparece un relato con el que los jugadores se identifican y a partir del cual buscan desarrollarse: el mito Tévez como aquel que salió de la pobreza mediante el esfuerzo (tres menciones), el mito Javier Mascherano como representante del esfuerzo permanente (dos veces), y luego numerosos otros jugadores. De Messi, el único joven que lo mencionó destacó su personalidad porque pese a las críticas que recibe "se queda callado" (aparece aquí la idea de "demostrar con hechos y no con palabras"), así como el manejo de su vida privada como producto de que "se fue criando solo"62, pero queda claro que este jugador está lejos de ser tendencia ${ }^{63}$.

Pero en Pumas es muy difícil encontrar un relato ligado a la precariedad económica. Si partimos de las encuestas la tendencia es claramente a favor de destinar dinero a la familia, sobre todo entre los Sub17 (ver cuadro en página siguiente). Ahora bien, si vamos a las entrevistas en profundidad, la familia pierde peso de manera notable, y es difícil observar una narración homogénea. Tres jugadores lo expresan aunque con diversas derivaciones. Quizás el más claro sea el Entrevistado P1 que expusimos en el apartado anterior, no sólo porque relata sus dificultades económicas sino porque fue discriminado por sus compañeros, de modo que cuando juega también lo hace para demostrarles a todos -a sus compañeros, a su familia, quizás a la opinión pública- que pudo llegar a Primera sin aval monetario. Es el único futbolista que además afirma que prefiere no aceptar un lugar en la casa-club y seguir viajando dos horas y media por día para ir y para volver sólo para demostrarles que es “diferente”, que logró su objetivo pese a todo; el único que expresa lo más parecido a un relato épico:

Por ejemplo ayer me han dicho que me quede en casa club pero... aparte que no es tanto que me guste, no sé si mi mentalidad esté bien o mal pero... yo quiero lograrlo y que se hable así como que 'Ve todo lo que él hizo y aun así siguió, ¿no? O sea, casa-club suena ya como... yo quiero digamos

62 Los jóvenes que observaron cuestiones deportivas eligieron al defensor argentino Walter Samuel tras la recomendación de un técnico porque "jugaba a no confundirse” (E4), otro al alemán Toni Kross y a los argentinos Juan Román Riquelme y Gonzalo Martínez (Entrevistado E7), un tercero a Robin Van Persie (E8) y un último a Ángel Di María, al holandés Arjen Robben y a Marcos Rojo, de los que destaca la entrega física y que "son diferentes, piensan diferente, entrenan diferente". Como se puede observar, las respuestas son disímiles y es difícil encontrar representaciones claras sobre los modelos de jugadores a partir de los casos presentados.

63 En su trabajo sobre la relación entre el fútbol y los discursos patrióticos, Pablo Alabarces explica por qué Lionel Messi, aún siendo la estrella máxima de fútbol mundial, no suscita identificaciones: "En resumen: de todas las condiciones de mito que Maradona presentaba, Messi tiene solo una. Nada menos que la condición excepcional de su juego: pero eso es ampliamente suficiente para hablar de fútbol, y bastante insuficiente para hablar de mitos racionalistas y narrativas patrióticas. Messi, entonces, desprovisto de los desgarramientos y los conflictos -y de la condición plebeya, radicalmente popular- de un Maradona, no puede, pudo ni podrá articular ese relato deportivo de la patria. (...) Messi es irreductible a la lógica del aguante, a la épica de los huevos y el corazón: por eso, porque la cultura futbolística argentina precisa siempre un héroe que funcione en esa serie, encontró a Javier Mascherano, una suerte de Maradona de segundo grado. El pobre Mascherano, un jugador excepcional, un centrojás como mandaba la tradición argentina, se vio reducido a un esforzado gritón que pone todo y se rompe todo, un sorpresivo modelo moral" (Alabarces 2014: 132). 
una comodidad, pero yo quiero ser diferente, que digan 'Mira, él vivió en la salida de Puebla y económicamente no muy bien pero logro lo que él quería",... quiero que... aparte no tanto de que se hable de mí, pero... demostrar que realmente, a pesar de tantas cosas que pasen o te lleguen a pasar, ver que si se puede realizar, y que si tú lo quieres, si lo puedes... Realizar, esa seria mi mentalidad, que tengo. (Entrevistado P1).

La segunda forma de relato es la de dos jóvenes que expresaron provenir de contextos con dificultades y que mediante el profesionalismo se proponen sacar a la familia adelante. Uno de ellos es el Entrevistado P964, un joven que ya en la descripción del gráfico sobre los sueños futbolísticos expresó que "mi sueño es jugar en un estadio profesional y no, pues, ayudar un poco a mis papás, sobre el tema económico y este pues un representante que me dé mis propios tacos [calzado de fútbol], que yo tenga mis tacos nada más". Este futbolista, que al momento del trabajo vivía en la casa-club, recibe sus zapatos de un colega de más edad que logró el patrocinio de una empresa de indumentaria. En el relato de su familia indicó que su padre trabaja en Pemex pero que está sin contrato, que pese a eso le pagan la colegiatura a un hermano en Ingeniería Petrolera y que en consecuencia él no quiso pedir nada: “y pues yo le digo no pues apóyenlo a él que ya tiene su carrera y va muy bien como para que deje de llegar por estarme apoyando a mí, mejor apóyalo a él le digo, yo acá veo cómo le hago". Si no pudiera dedicarse al fútbol dice que estudiaría pero que no sabe qué sino que sólo buscaría "lo que más

\begin{tabular}{|c|c|c|c|}
\hline \multicolumn{2}{|c|}{ Sub-13 ¿Qué harías con tu primer salario profesional? } & \multicolumn{2}{|l|}{ Sub17 - ¿Qué harías con tu primer salario profesional? } \\
\hline Lo ahorraría & 11 & Se lo daría a mi familia / Apoyar a mi familia & 13 \\
\hline Apoyar a mis padres & 6 & Ahorrarlo / Guardarlo & 7 \\
\hline Compraría una casa para vivir & 6 & Comprarle algo a mi familia / Gastarlo en mi familia & 2 \\
\hline Comprar un carro & 3 & Comprar ropa / cosas que me falten & 2 \\
\hline Comprarme zapatos & 2 & & \\
\hline Gastos y algunos lujos & 1 & Invertirlo & 1 \\
\hline Donaría a huérfanos & 1 & & \\
\hline invitar a mis padres en algún lugar & 1 & & \\
\hline Lo invertiría & 1 & & \\
\hline Un viaje & 1 & & \\
\hline No sé & 1 & & \\
\hline
\end{tabular}

64 El otro es el Entrevistado P6, quien indica que a los 12 años le pagaban 300 pesos por jugar, que cuando lo vio un visor y le propuso probarse en Pumas no tenía recursos pero que trabajó un verano pintando una escuela. Sacar adelante a su familia es central en este jugador: “-¿En qué o quién pensás cuando las cosas no te salen? -Últimamente pues o sea me pongo a hablar con mi familia, pues son los que, digamos, que mi mayor motivación, son los que me, me apoyan. - ¿Piensas en ellos cuando juegas? -Sí. -¿En qué piensas? -Pues en que, ps en sacarlos adelante, o algo así. -¿Qué significa sacarlos adelante? Pues, o sea no ¿cómo te digo esta? Em... pues ahorita vivimos en un pueblito ya te he dicho, ps, no sé, de mejorar nuestro nivel de vida y así". 
deje dinero". Finalmente, el Entrevistado P8 afirma que viene "de una familia trabajadora". ¿A qué se refería?

Pues que por ejemplo yo soy de Chilpancingo, te podría decir como, tipo pueblito y pues, ahí mucha gente $\mathrm{mm}$, o sea no tiene muchas ¿cómo se podría decir?, oportunidades así de salir adelante (...) Y pues mis papás siempre han luchado para que yo esté bien pues, en muchos sentidos, tanto lo que me gusta que es deportivamente, tanto estudios y mi familia. Es lo que me han enseñado, pues que para ser alguien se tiene que trabajar pues, desde los principios básicos que fue cuando mis papás me enseñaron pues los valores y todo lo que es trabajar (...)

- ¿Y tu papá te da consejos deportivos así, sobre el puesto y todo eso?

- Se basa mucho en eso pues, mi papá, se podría decir que pasó por donde quiso pues [su padre fue futbolista profesional], me dice que el fútbol a veces es honesto, pero siempre y cuando va a ser honesto cuando tú te rompas el alma en cada entrenamiento, des todo de ti y eso no, que trabaje y siga trabajando para lograr lo que él hizo ¿no?

- ¿Qué significa que el fútbol es honesto?

- O sea, para mí pues, que estés trabajando ¿no? constantemente, trabajar y trabajar y si no estás jugando en la posición que quieres de titular, pues si tu sigues trabajando, no aflojas y sigues constante y con mucha disciplina, se te van a dar las cosas ¿no?

Desde mi punto de vista, más allá de ligeras continuidades ${ }^{65}$ se trata de tres discursos sumamente diferentes. También hay otros relatos ligados a los orígenes materiales de los jugadores: el del Entrevistado P7, cuyos padres están separados y a quien si bien su padre le da dinero, él reenvía una parte de su salario a su madre, que trabaja en un tianguis (un mercado itinerante); el del entrevistado P4, que indica que el año pasado, cuando aún no cobraba, a sus padres se les complicaba su manutención (pero en ningún momento habla de la necesidad de sacarlos adelante). También hay relatos ligados a cierta "holgura": tres chicos que reciben ayuda de sus padres; uno de ellos, incluso, dice que "mis papás siempre me dijeron que ese dinero [su salario] lo ahorrara, que yo seguía siendo finalmente hijo de familia (...) y que después lo invirtiera en algo más importante” (Entrevistado P2).

En mi opinión no hay aquí un relato colectivo ligado a las condiciones materiales que sostenga la formación, y -si bien faltan lecturas más profundas y una indagación más extendida- eso nos llevaría a dudar de pensar que son éstas (las condiciones materiales) las que motivan los deseos de los futbolistas y sus trayectorias. Cuando en el marco teórico inicial expusimos la teoría de Pierre Bourdieu del habitus observamos que desde su punto de vista son "los condicionamientos asociados a una clase particular de condiciones de existencia" lo que se encuentra en el origen de las "disposiciones" que a su vez engendran prácticas. ¿Hasta qué punto podemos pensar que es así si, como expusimos en el caso de Pumas, las condiciones de existencia pasadas a las que remiten los futbolistas son diversas? Lo que exponen los datos presentados es que el fútbol aglutina en el mismo equipo y con la misma meta 
jugadores de diversas procedencias sociales, y que el deseo de llegar a Primera es compartido más allá de los orígenes.

Lo segundo a mencionar es que en el ámbito del fútbol la escuela es uno de los elementos que condiciona trayectorias, aunque si el fútbol comienza entre los 3 y los 6 años en promedio, significa que en paralelo a sus inicios escolares ya experimentan el fútbol y nos llevaría a privilegiar a la familia u otras instituciones previas a la escolaridad. Pero la escuela no está ausente: recordemos los datos de las encuestas y observemos que los chicos indican que la escuela sigue siendo un espacio de inicio en el fútbol. Esto confirmaría, en principio, el planteo del pensador francés Louis Althusser, que propuso que es el complejo familiar-escolar de Aparatos Ideológicos del Estado el que resulta más influyente a partir del proceso de secularización de la modernidad ${ }^{66}$. Pero también puede llevarnos a observar, dado que trabajamos en sociedades contemporáneas de masas, a los constructores de relatos masivos: los medios de comunicación. Como consecuencia, en los próximos apartados intentaremos observar si existen otros relatos no ligados a la vulnerabilidad económica, y de qué manera impactan los medios de comunicación sobre los futbolistas. Es decir, lo que seguimos buscando es ¿qué motiva y sobre qué se sostienen las aspiraciones de los jugadores por devenir profesionales del fútbol?

\subsection{El impacto de los medios}

- ¿Cuándo fue el momento en el que tú dices 'yo quiero esto'? -Pues, desde casa, esto viene desde casa, digamos de que ves jugar futbolistas profesionales en la tele y a tus ídolos, Cristiano Ronaldo, y dices "yo quiero ser como él”. Tal vez mejor, quiero superarlo así, esto, salir en la tele, que te conozca la gente, ps es algo bonito. Pues ahi es donde tú dices no, pues, yo quiero ser futbolista.

(Entrevistado P6)

66 Para este autor la reproducción de la fuerzas productivas era producto ya no de un aparato represivo sino de los Aparatos Ideológicos del Estado, una idea inspirada en Antonio Gramsci y que a diferencia del aparato represivo refiere a un conjunto de "instituciones" que pueden provenir del ámbito privado y que no funcionan mediante la violencia sino mediante lo que él denominaba la "ideología”. En esta perspectiva la ideología es "una 'representación' de la relación imaginaria de los individuos con sus condiciones reales de existencia", es decir que lo que se representa no son las condiciones de existencia de los hombres sino "la relación que existe entre ellos y las condiciones de existencia". Esta relación estaría dada por las instituciones: el sistema de Iglesias, de escuelas, la familia, los sindicatos, los medios de comunicación o los campos culturales y deportivos serían espacios de construcción de poder hegemónico (es decir, por consenso), y aún en su diversidad y relativa autonomía constituirían el soporte de la reproducción de las relaciones sociales de producción. Son estos los "Aparatos Ideológicos del Estado", que si bien no son represivos no dejan de estar subordinados a la "ideología dominante", que sería la que representa los intereses de la clase dominante. Una de las hipótesis centrales de este filósofo es que tras la revolución francesa, el ascenso de la burguesía y el proceso de secularización hubo un pasaje del aparato ideológico eclesial al escolar (Althusser 1988: 18). Un trabajo posterior y más profundo debería indagar en las relaciones que los jóvenes desarrollan en esos establecimientos, ya que no sería lo mismo si los chicos jugaban fútbol en los recreos que si tuvieran clases de fútbol como parte de las currículas. 
Cuando en el marco teórico incorporamos al filósofo esloveno Slavoj Zizek dijimos que nos preguntamos con qué fútbol se identifican los jugadores, qué representaciones sobre el fútbol se pone en escena y suscitan el deseo. Para Zizek, recordemos, la identificación simbólica implica la relación del individuo con aquella posición en la que se siente digno de amor. Recibir amor, entonces, aparece como un elemento central en la adscripción de los jugadores con una posición en el mundo. La segunda forma de identificación, la imaginaria, está ligada a esos otros que nos gustaría ser: el camino del desarrollo propio a partir de emular a un Otro, como el niño que para devenir hombre debe emular la figura paterna. Por este motivo en este apartado vamos a observar con qué fútbol se relacionan, en qué posición desearían posicionarse como profesionales, a qué futbolistas admiran y por qué, qué hay en el fútbol que les genera deseo.

Los jugadores se relacionan con el fútbol desde la primera infancia, y dado que la mayor parte de sus vidas las pasaron en centros de formación, un primer contacto que influye sobre las representaciones que tienen del fútbol es ese contacto directo, esa experiencia de la práctica, los mensajes de entrenadores que "quedan grabados". Sin embargo, en Pumas no aparecen trayectorias claras, respuestas que nos permitan pensar el deseo a partir de esas experiencias. Sí queda claro que en muchos casos las trayectorias no son lineales, algo que encontrábamos también en Estudiantes de la Plata y para nada en el Olympique de Marsella: si en Argentina los jugadores pasaban por un promedio de cuatro instituciones antes de llegar a Estudiantes -y en esos cambios había representantes, entrenadores, padres que los “sacan" y “ponen”- en Francia encontramos que la trayectoria era más lineal: jugaban en la calle o en una escuela y eran reclutados al Marsella. Pumas, en este sentido, expone un punto medio: jóvenes que comenzaron en las filiales de Pumas, les propusieron hacer una prueba y desde ahí entrenan en la cantera hasta jugadores que pasaron por varios equipos, se alejaron de sus familias a los 12 años para ir a jugar a -por ejemplo- Chiapas y tras quedar libres arribaron en Pumas. Son datos interesantes que impactan sobre el modo en que los jugadores llevan adelante su práctica cotidiana y desarrollan tácticas para seguir creciendo, pero la ausencia de regularidades nos llevó a ponerlas en un segundo plano.

Una segunda forma de relación de los futbolistas con el deporte son las imágenes que surgen como producto del contacto con medios de comunicación. Lo primero que observamos al recurrir a las encuestas es que de las diversas formas de lectura o acceso mediático (TV, internet, periódicos) la gran mayoría se refirió a programas de TV (sólo 3 jugadores agregaron sitios de internet, y dos hablaron del 
periódico Récord). Al indagar en la cantidad de horas por semana que miran televisión, 8 de ellos expresaron que miran entre 1 y 5 horas por semana, 9 miran de 6 a 10 horas y cuatro, más de diez (dos no respondieron).

Cuando en las entrevistas en profundidad indagamos en los contenidos que buscan seguimos encontrando una diversidad de respuestas. El total de jugadores que respondieron esta pregunta fueron siete y frente a una pregunta general, 3 de ellos dijeron ver fútbol mexicano (P1, P3 y P10); otros tres, a jugadores de su puesto para ver cómo resuelven jugadas ( $\mathrm{P} 1^{67}$, P3 y P4); dos miran programas de debates sobre fútbol (P268 y P9); otros dos, ligas extranjeras (P3 y P10), dos miran videos por Instagram (P8 y P9; esto da la pauta de la importancia del teléfono celular entre los dispositivos); dos resúmenes de goles y jugadas destacadas (P9 y P3); y finalmente uno mira programas de reportajes y otro, resúmenes de goles y jugadas destacadas.

Como se puede ver, esta dispersión de respuestas por ahora no nos permite afirmar que haya tendencias claras en términos de búsquedas de objetos de deseo: no parecen ser específicamente seguidores de jugadores, de equipos, de ligas del extranjero o locales. Es difícil tomar alguna definición, pero podríamos pensar (sobre todo como hipótesis a futuro) que quienes miran videos por Instagram más el jugador que mira jugadas destacadas se relacionan con el fútbol a partir de sus escenas más espectaculares y de los aspectos del fútbol ligados al star system, algo que con un poco de esfuerzo podríamos pensar que sucede en los programas de debate, cuya lógica es repetir las jugadas destacadas y polemizar al respecto. Aquí podríamos ver una diferencia respecto de los jugadores que miran partidos completos o a sus referentes de sus posiciones para observar gestos técnicos.

Un testimonio significativo es el del Entrevistado P10, que expone cómo ver la Copa Mundial le generó el deseo de ser futbolista en la infancia:

-¿Cómo te imaginas el Mundial?

-Mm, me lo imagino pues como, pues como otra cosa ¿no? O sea, lo que desde niño sueñas, y pues sería un honor vivirlo.

-¿Cuándo fue la primera vez que lo soñaste?

-Desde que empecé a jugar fútbol que fue a los 4 años. Fue cuando vi el Mundial del 2002, cuando Brasil fue campeón; desde esa vez que yo quería jugar ahí, o sea representar a mi país jugando Mundial.

67 "Nada más me las paso viendo a los dos laterales, tanto derecho como izquierdo; es lo único que veo en todo el partido. Bueno, ahora sí que... si hacen una falta y se avientan y o sea... Eso si lo veo, pero veo detalles de lo que se ha estado fallando ahora sí que en el futbol mexicano" (Entrevistado P1)

$68-¿$ Qué te interesa de esos programas? -Siempre son diferentes los puntos de vista de todo el mundo, entonces pienso en el mío y pienso en lo que dicen... y de ahí saco conclusiones (Entrevistado P2). 
Observemos ahora con qué jugadores se identifican, intentemos de esa manera observar los valores o las trayectorias que destacan. Ya veíamos en el epígrafe que abrió este capítulo que Cristiano Ronaldo es una de las figuras destacadas. De él se destaca su esfuerzo y su compromiso, que se opone al "talento natural" de Lionel Messi, su principal contrincante en términos de récords futbolísticos, Balones de Oro y patrocinios publicitarios.

Pues lo que tiene Messi es talento puro, pero me gusta mucho el ímpetu y las ganas y el compromiso que tiene Cristiano Ronaldo. No es tanto talento puro y es mucho trabajo, disciplina... Aparte de que tiene capacidades, yo creo que las explota y las trabaja, entonces yo creo que me inclino por Cristiano Ronaldo. (Entrevistado P2)

- ¿Qué te interesa de Cristiano Ronaldo?

- Pues, su trabajo ¿no?, porque yo creo que Cristiano para ser el mejor jugador se ha esforzado mucho en eso. Ha trabajado mucho en el trabajo, en ser constante, en cada entrenamiento y pues con calidad y trabajo yo creo que está donde quiere estar. (Entrevistado P8)

Son cuatro los jóvenes que lo mencionan: de los otros, uno se refiere a sus condiciones deportivas y el otro, a su relación con la fama y la popularidad. Ese es otro tema central en las elecciones: el perfil público de los jugadores. De Ronaldo dos jugadores destacaron su relación con la familia ${ }^{69}$, y uno mostró que algunos jugadores no representan el mérito deportivo sino una forma de vida, una serie de aspiraciones posibles, un modelo moral:

- ¿En la casa club hablan, por ejemplo, de la fama y todo eso?

- Casi no hablamos, más bien casi siempre hablamos de cómo nos está yendo. Nos echamos carrilla los que no jugamos. (...) Pues de la fama sólo comparaciones, que dices 'Ah, imagínate ser Cristiano Ronaldo' ¿no?

- ¿Qué es lo bueno de ser Cristiano Ronaldo?

- Pues yo pienso que su vida es perfecta ¿no? Tiene todo.

- ¿Qué es todo?

- Dinero, familia, mujeres, juega en el mejor equipo del mundo, es todo ¿no? Yo pienso que su vida es, pues obviamente sí tiene problemas pero no sé, la verdad, no soy Cristiano Ronaldo para decir, pero yo pienso que su vida es perfecta, casi, sí.

(Entrevistado P7)

En segundo lugar es elegido Lionel Messi no sólo por ser "el mejor del mundo" (algo que confirma la representación del talentoso) sino que en un caso está ligado a su "mentalidad", a su capacidad para mantenerse motivado, y en el otro, a la "humildad"

-¿Cómo qué jugador te gustaría ser? 69 - ¿Qué recuerdas de eso que leíste [sobre Ronaldo]? - Me quedo mucho con... él cuenta que su papá se muere cuando él
estaba todavía muy joven, y que él no toma alcohol y no se tatúa. Y eso también habla mucho del tipo de persona que es. Y
también por qué es así, por qué llego a ser un futbolista tan comprometido y que trabaja tanto. Me quedo mucho con esa
parte de su vida que me fue familiar. - ¿Te identificaste con algo de todo eso? - Pues que a lo mejor él decía que desde chico
sabía que su sueño era ser futbolista y trascender y triunfar, y yo creo que pues también busco eso. Desde ahorita verme y
trabajar por lo más alto. (Entrevistado P2) 
- Como Messi ¿no? Ps, creo que es el mejor del mundo y creo que sabe qué hacer con el balón, tiene una mentalidad que, pues $100 \%$ ¿no? Positiva. Para todos los partidos, y tiene mucho talento ¿no?

-¿Y tú sientes que lo puedes emular? Digo, ¿que lo puedes igualar?

-Ps con trabajo, solamente con trabajo y ser constante, saber mantenerse acá y no fracasar ¿no?

-¿Qué significaría no fracasar?

-O sea, fracasar significa que, o sea que vayas para abajo ¿no?

-¿Pero en la práctica qué significaría para ti fracasar acá?

-Que no le eches ganas, que pues que pues que te valga ¿no? Todo el entrenamiento que eches relajo. (Entrevistado P9) ${ }^{70}$

El Barcelona parece ser efectivo no sólo en materia de triunfos deportivos, también en la construcción de imagen de sus jugadores. Otros dos jóvenes eligen a los centrocampistas Xavi Hernández y Andrés Iniesta, y un tercero al lateral Dani Alves. De ellos, además de su capacidad deportiva, se destaca "el respeto", "la sencillez", "la humildad":

...Como Xavi Hernández. Pues porque Xavi es una persona muy, muy respetuosa y sencilla, tanto fuera y dentro de la cancha, porque lo he visto en reportajes de él que hacen cuando está él fuera de la cancha y se me hace una persona súper sencilla y humilde. Y aparte que es un excelente jugador de fútbol. (Entrevistado P5) ${ }^{71}$

Además de estos cinco jugadores, todos pertenecientes a la liga española y a las dos escuadras con mayores ganancias por derechos de televisación -datos no menores- algunos jóvenes han optado en la pregunta abierta “¿Como qué jugador te gustaría ser?” por futbolistas surgidos de la competencia local. Eduardo Herrera, delantero de Pumas, es elegido por el Entrevistado P3 por sus condiciones deportivas y Miguel Layún, lateral izquierdo que actualmente se desempeña en el Porto portugués, por su capacidad de superar las críticas

porque pese a las críticas que tenía en el América, de que era un jugador malo, yo creo que eso le a recibir los malos comentarios y mejorarlos y trabajó, una vez lo vi entrenar, se quedaba horas extras. Yo creo que eso le dio para llegar a donde está ahorita, en el extranjero. (Entrevistado P8)

Como se puede ver, ninguno de los jugadores mencionó por motu propio y frente a esa pregunta al jugador más importante de la historia mexicana y salido de Pumas, Hugo Sánchez. Y no es un dato para nada menor. Sin embargo, considero que su figura e historia sí están presentes y son una referencia

70 - ¿Como qué jugador te gustaría ser? -Pues, como Messi, pero yo creo que está muy difícil ¿no? -No sé. -Pues sí, me gustaría jugar como Messi. - Y, digamos en los aspectos personales... -Ah, pues sí, ser igual que él digo, no igual que él pero seguir unas cosas que es muy humilde y terminó sus estudios también. (...) - ¿Y de Messi digamos, aparte de su juego hay algo que te interese? -Mm, pues te digo, su humildad, pues porque me interese... o sea, es muy callado y yo digo que él no echa, sí, no echa relajo pues, lo echa en la cancha ¿no? O sea con lo que hace ps no le puedes decir nada (Entrevistado P10)

71 "Iniesta [por] su técnica. Es algo que me llama mucho la atención. -¿Pero él juega en otra posición no? -Sí, juega en otra posición, pero, como bueno, como te digo te digo, yo jugaba de la contención, y es, era como mi máximo, yo lo veía y decía puta "yo quiero ser como este guey". Ps, su facilidad de tocar el balón era impresionante, su tranquilidad" (Entrevistado P4). 
inevitable para los jugadores. Frente a la pregunta “¿Qué ídolos de Pumas conoces?” (formulada sobre todo para observar la relación de identificación con el club) fueron seis los jugadores que lo mencionaron, seguido por dos referencias al defensor central Darío Verón, vigente en la actualidad. Más allá de las menciones específicas, creo que la figura de Sánchez está presente por las implicancias simbólicas asociadas: es el jugador que salió del país, "llegó” al Atlético de Madrid y al Real Madrid, tuvo una carrera exitosa, enfrentó la discriminación y retornó "lleno de gloria”. Por eso, también, su imagen es la de aquel mexicano que no tiene "mentalidad" mexicana, una representación que circula al interior del club $^{72}$. El entrevistado P7 fue el único que describió las significaciones asociadas a Sánchez:

...Hugo Sánchez es el que más, es como, me sé toda su historia y así, del Atlético de Madrid y todo. Y es como el que más, es el mexicano pues el que, el que no tiene mentalidad de mexicano pues, que se fue a España con todo en contra y siguió luchando, siguió luchando, siguió luchando y así.

- ¿Cuál es la mentalidad del mexicano?

- Pues yo veo a Raúl Jiménez, veo a Giovanni dos Santos y digo 'no, eso qué', o sea, Giovanni dos Santos estando en España se viene a Estados Unidos, es como una mentalidad pues de mediocres ¿no? De ganar dinero nada más. Y pues Raúl Jiménez, pues, que no aprovechó la oportunidad que le dieron. Y Hugo Sánchez, que la gente que en el Atlético de Madrid, que los compañeros le decían indio, la gente le gritaba 'fuera indio'... Y así, que ya lo habían corrido y él pidió chance de entrenar en el Atlético de Madrid y siguió, siguió, siguió y hasta que pues el profe lo vio y ya lo registraron y lo empezó a meter y así. Y él decía en una entrevista, que sus compañeros le aventaron unos pases bien feos, y dice 'y por eso yo me quedaba en los entrenamientos y practicaba las chilenas', dice 'para aprovechar esos malos pases'. Luego decía que él festejaba ya y luego así [simula el gesto], que cuando hacía eso ya les decía "chinga tu madre". Que les decía así "chinguen a su madre" cada vez que festejaba. Y ya a pues eso, es como el coraje de salir adelante, ¿no? Es

72 Una de las iniciativas de la coordinación de fuerzas básicas consistió en implementar encuentros de coaching para los cuerpos técnicos y algunos jugadores destacados. En la charla general de introducción a las reuniones, uno de los profesionales se refirió así a la "mentalidad mexicana”: “QQuién me diría cuál es la diferencia entre algunos deportistas mexicanos y algunos deportistas americanos? ¿Qué se les ocurre? Podrían decir la mentalidad, ¿no? Pues sí, ¿y cómo se mide eso? Muchos de ustedes ya han ido a jugar giras internacionales, estoy en lo cierto ¿no? O han jugado con gente de Estados Unidos o de Europa. ¿Cómo se explica esa mentalidad? [No responden] (...) ¿Tú qué crees? [El chico responde: pues aparte de la mentalidad, yo creo que nos ponen un 'pero' y ya no podemos solucionar las cosas. Como que siempre nos dicen que no y ya no no le cae bien; los americanos yo creo que aunque les pongan peros encuentran la forma de sacarlo adelante] (...) Les voy a contar una anécdota, y de ahora en más les voy a pedir que pongas atención a las entrevistas de los deportistas mexicanos y los americanos. Ahora van a ser las olimpiadas. Un mexicano consigue su pase a las olimpiadas y sale en el periódico: lo logró, consiguió su pase a las olimpíadas. [Teatraliza una entrevista] 'Oye Samuel, conseguiste tu pase a las olimpiadas, ¿cómo te sientes? Y responde Samuel, mexicano: sí, para esto me preparé toda mi vida, y lo logré’. (...) Y vean cuando van saliendo de la alberca los deportistas americanos: '-Oye, acabas de conseguir tu clasificación a las olimpiadas. -Sí, este es el paso normal en la búsqueda de romper el récord mundial'. ¿Lo han oído? ¿Hay diferencia o no? (...) Como hablamos creamos nuestra realidad. Acá: 'para esto me preparé toda mi vida, para calificar a las olimpiadas'. Claro, llega a las olimpiadas y se queda en la primera eliminatoria, ¿no? Y hay algunos que se empiezan a cambiar el chip. ¿Se ve la diferencia? En cómo se habla se crea la realidad. (...) ¿Para qué nos preparamos en Mexico comúnmente en el fútbol, a nivel de selección? Para calificar al Mundial. Para que califiquemos y busquemos el quinto partido. Pero uno no puede contra el país, contra 120 millones que piensan así. Entonces vamos a la concentración para el Mundial: bien muchachos, vamos a prepararnos para calificar". 
entrenador, a mí me gusta mucho como entrenador, como futbolista y todo. Se me hace una persona bien, como bien centrada y bien seria, Hugo Sánchez ${ }^{73}$.

Esta trayectoria aparece en algunos jugadores en Pumas. En parte mediatizada por la propuesta del equipo de coaches que les propuso como aspiración para sus carreras devenir un "símbolo Puma", una imagen que desde el punto de vista del expositor englobaba todas las otras aspiraciones de los futbolistas $^{74}$. El Entrevistado P1, por ejemplo, recupera la imagen de Hugo Sánchez como aquel que por excelencia representa al símbolo Puma, y la postula como su anhelo de trayectoria:

[En referencia a uno de los sueños dibujados] Sería... haber regresado a Pumas, pero ya haber hecho algo importante en Europa y llegar siendo un símbolo, o sea, ser así como que el que fue a Europa y (...) hizo muchas cosas, y fue titular y... No sé... todos los partidos los jugó, llegar acá jugando ya ahora sí que de titular, y seguir manteniéndome para poder ser un símbolo.

-¿Esto viene un poco de la charla de coaching?

-Si, es algo que... no es tanto que lo tenía, no pensado, pero... lo veo pensado correctamente, o sea como dándole una, como te diría, una definición a lo que quería.

- ¿Conoces jugadores de Pumas que hayan hecho eso que tu quieres?

-Sí, no como Hugo Sánchez pero no va en mi posición (...) Ya quisiera empezar a luchar desde ahorita para ser un símbolo en Pumas pero en mi posición. (...) O sea, yo quiero ser así como... ser un canterano que fue a Europa y regresó y sigue aquí.

Nos estamos preguntando con qué fútbol se identifican, qué imágenes circulan entre los futbolistas que hacen sentido y promueven su deseo de devenir profesionales. Lo primero que debemos decir, entonces, es que los testimonios no muestran tendencias claras, pero que sí encontramos elementos que muestran que una de las dimensiones preponderantes de las imágenes que observan en el fútbol son aquellas ligadas al espectáculo: mejores jugadas, ser "seguidores" de algunas biografías y, sobre todo, encontrar en las principales estrellas del fútbol mundial a sus referentes. Que ante la pregunta general sólo Miguel Layún y Eduardo Herrera hayan aparecido como referentes mexicanos para los jóvenes puede llevarnos a relativizar la idea de Pablo Alabarces de que no hay espectadores “globales" en América Latina. Dice este autor:

Los espectadores, aunque asisten con frecuencia a la exhibición del fútbol global (europeo), contrastan permanentemente ese relato con sus narrativas locales. No existe -o, con más precisión, no existe aún como dato sociológico para el análisis- el presunto espectador global en América Latina, aquel que se desentiende del fútbol local para regodearse en la exhibición del Manchester United o el Real Madrid (...)

Así, la circulación del fútbol europeo en nuestro continente sigue férreamente ordenado por la presencia o ausencia de las estrellas locales, devenidas globales: el espectador sigue a sus estrellas, no a las ajenas. Cristiano Ronaldo no es mercancía decisiva, sino marginal, porque es desplazado por los Neymar o Messi o Rafa Márquez -el jugador mexicano más exitoso de la última década,

${ }^{73}$ El testimonio también expone con claridad que la búsqueda de dinero no es la única motivación. Hay un factor ligado a la gloria deportiva y, desde mi punto de vista, a la ostentación de un modelo moral de ser deportista.

74 En el Anexo *7 se expone el discurso completo. 
luego del apogeo de Hugo Sánchez en los ochenta, antes del surgimiento de las televisoras globales-. (Alabarces 2014: 51)

Comparto con Alabarces que los futbolistas siguen siendo aficionados antes que nada de equipos de la liga local, pero a partir de los datos de las entrevistas se puede afirmar que la televisación global y sobre todo sus estrellas (que como vimos se difunden de muchas otras maneras no televisadas) funciona al menos a la par que el fútbol local. Con una particularidad: en México sólo la televisora Sky transmite los encuentros de la liga española ${ }^{75}$, y posiblemente no todos los jugadores tengan acceso a ella. Algo similar encontramos en Argentina y Francia, lo que por un lado confirma la mirada respecto de la globalización de los consumos del fútbol, y por otro lado obliga a profundizar sobre los análisis en recepción de medios para tener un diagnóstico más ajustado:

Como se puede observar, las respuestas son disímiles y es difícil encontrar representaciones claras sobre los modelos de jugadores a partir de los casos presentados. Observamos en Argentina la tendencia a destacar el sufrimiento como valor positivo, y en ambos equipos a aquellos jugadores que son referentes. Encontramos también que los jóvenes se identifican con numerosos futbolistas que no son estrictamente las figuras más importantes de cada equipo ni las que realizan más campañas publicitarias, aunque es indudable que la gran mayoría de ellos pertenece a las ligas europeas más importantes. También podemos mencionar que en muchos casos -no en todosestablecen una relación de identificación con ellos, es decir que buscan en sí mismos características similares a las de los jugadores que anhelan. No obstante, el dato más claro es el fracaso de ambos clubes por imponer sus figuras históricas como referentes de los jugadores. La influencia de los medios masivos de comunicación en este caso es indisimulable (Murzi \& Czesli 2014: 70).

Además de los medios de comunicación tradicionales, el trabajo expuso que hay otro dispositivo central en la relación de los jóvenes con el fútbol: las consolas de videojuegos Playstation o la Xbox y su juego FIFA, a tal punto que en broma podríamos decir que si este trabajo expone alguna tendencia clara, esa es la influencia estos dispositivos. Las encuestas en la categoría Sub17 expresan que de 23 chicos, 21 juegan, y en Sub13 juegan 23 sobre un total de $26^{76}$.

Una de los elementos que aparece al observar las entrevistas en profundidad es que el modo en que funcionan los equipos en la plataforma virtual es también constructor de imágenes o fantasías sobre ellos en el fútbol material: los chicos pueden no haber visto al equipo por TV ni saber si fue campeón, pero sí lo usan en sus juegos y encuentran que algunos jugadores se desempeñan bien allí, entonces pasan a sentirse atraídos por esos jugadores y equipos. Se produce una especie de camino en dos

75 En abril de 2016 el acceso costaba alrededor de 25 dólares.

76 La diferencia entre las preguntas de una y otra categoría responde a que en la Sub17 se buscó corregir la imprecisión que implica la formulación de la pregunta en Sub13. 
sentidos mediante el cual los jóvenes usan en la virtualidad los equipos de los que son aficionados en el plano material, y a la inversa. Observemos por ejemplo los siguientes dos testimonios:

- ¿Con qué equipo juegas?

-Pues me gusta mucho el Bayern [de Múnich] y el París.

-¿Por qué te gusta el Bayern?

- No pues en el Play porque tiene jugadores muy buenos. Muy rápidos pues.

(Entrevistado P3)

- Con Chelsea y Real Madrid. (...) Digamos que, o sea mi equipo, mi equipo favorito de Europa sería Real Madrid ¿no? Me gusta porque ps está Cristiano y...

- ¿Qué es lo que te gusta tanto de Cristiano Ronaldo?

-Ps, su manera de jugar, regates, goles...Saca tantas cosas que ps ni te imaginas, no sé. (...) Pues así chilenas, sus tiros, sus tiros libres, potencia te imaginas. Y el Chelsea pues porque pues, así, me gusta, no sé. Si yo jugara en un equipo de Europa sería en el Chelsea..." (Entrevistado P6)

En paralelo, un detalle sumamente interesante y que marca la pregnancia de este juego sobre las representaciones de los chicos al momento de jugar es la idea, confirmada no solamente en encuestas sino en las entrevistas en profundidad, de que intentan llevar al campo de juego, a su práctica, jugadas o movimientos que realizaron previamente en la pantalla. Es decir: la Play no sólo construye imágenes de heroicidad o jugadores sobresalientes; también transforma la manera en que los jóvenes pasan el balón, eluden a un adversario, imaginan un ataque, envían un centro, rematan una oportunidad de gol.

\begin{tabular}{|l|r|l|r|}
\hline \multicolumn{3}{|c|}{ Sub13 - ¿Cada cuánto juegas al FIFA en la Play/Xbox u otra? } \\
\hline 1 vez por semana & 12 & Muy seguido & 1 \\
\hline Día por medio & 3 & $\begin{array}{l}\text { Cuando puedo /Cada que } \\
\text { descanso }\end{array}$ & 2 \\
\hline 2 o 3 veces por semana & 1 & Cuando vienen mis primos & 1 \\
\hline Todos los días & 2 & No responde & 1 \\
\hline
\end{tabular}

\begin{tabular}{|l|l|}
\multicolumn{2}{|c|}{$\begin{array}{c}\text { Sub17 - Horas semanales que } \\
\text { juegan Playstation o Xbox }\end{array}$} \\
\hline $\mathbf{3 0}$ min a $\mathbf{2}$ hs. & 5 jugadores \\
\hline $\mathbf{3}$ a $\mathbf{6}$ hs. & 10 jugadores \\
\hline $\mathbf{9}$ y $\mathbf{1 0}$ hs & 3 jugadores \\
\hline $\mathbf{1 5}, \mathbf{1 8}$ y $\mathbf{2 4}$ hs & 3 jugadores \\
\hline
\end{tabular}

\begin{tabular}{|c|c|c|c|}
\hline \multicolumn{4}{|c|}{$\begin{array}{c}\text { Sub13 - ¿Intentas llevar al campo de juego } \\
\text { jugadas que haces en el FIFA? }\end{array}$} \\
\hline Bicicletas & 4 & Tiro con efecto & 2 \\
\hline $\begin{array}{l}\text { Barrerme y quitar el } \\
\text { balón }\end{array}$ & 3 & Caño & 2 \\
\hline Fintas & 2 & "Muchas" & 2 \\
\hline Tiros & 2 & Dribbles & 1 \\
\hline Rabona & 2 & Pase filtrado & 1 \\
\hline "Pegarle como CR7" & 1 & Ruleta & 1 \\
\hline Vuelta al mundo & 1 & No & 8 \\
\hline
\end{tabular}

\begin{tabular}{|c|c|c|c|}
\hline Bicicleta & 3 & $\begin{array}{l}\text { Las que hace Eden } \\
\text { Lazard }\end{array}$ & 1 \\
\hline $\begin{array}{l}\text { Tocar de primera / } \\
\text { Pases / pases } \\
\text { filtrados }\end{array}$ & 3 & “Jugar fácil” & 1 \\
\hline Fintas / gambetas & 3 & Caños, elásticas & 1 \\
\hline Tiros o dribles & 1 & "Jugadas individuales" & 1 \\
\hline Visión de juego & 1 & "Jugadas en conjunto" & 1 \\
\hline Diagonales & 1 & No & 7 \\
\hline
\end{tabular}


Los futbolistas saben que están jugando, que hay una pantalla y que allí sólo utilizan los dedos para manejar todo el equipo, pero las imágenes de todos modos pernean sobre la creatividad y la fantasía:

-...de hecho, el otro día estaba pensando que no sé si jugar [Playstation] también me ayudó como a ver de otra forma el fútbol. Jugar a la Playstation me habría ayudado a... no sé, los pases filtrados que hacía acá, la forma de moverse... es como verlo desde arriba y pues son opciones

- ¿Sientes que hay mucha diferencia o que es lo mismo?

-Sí, sí, hay diferencia. Para empezar la toma de decisiones es muy diferente ¿no? Aquí [por el mundo físico] creo que es más complicado tomar una decisión porque allá [por la virtual] ves el equipo completo y al final es un juego ¿no? Y aquí pues ya estás jugando y no alcanzas a veces a ver lo mismo ¿no? (Entrevistado P2) ${ }^{77}$

- ¿Tratas de hacer jugadas que haces en la Play acá? - A veces sí. Pues cuando agarro el balón y me meto por el medio, y alguna bicicleta, no sé, en una pared. Sí te da a veces un poco de ideas. (Entrevistado P3).

Las imágenes de éxito entonces también se construyen por estas vías, y esto impacta en los sueños de los futbolistas, en las aspiraciones para sus futuros. En Argentina y Francia encontrábamos por ejemplo que como el sueño se sostiene sobre el "llegar" (a Primera, a Europa) todo lo que sucede en presente parece un paso intermedio a alcanzarlo. Observamos además que la centralidad de las figuras del fútbol massmediático influía de tal manera que las motivaciones para desear ir a uno u otro equipo están ligadas a repetir las trayectorias de los jugadores que allí se desempeñan o desempeñaron. Es decir, no buscan formar parte de un equipo porque representa determinados valores o un estilo de juego, tampoco aparece con preponderancia el ser "hinchas" de ese club. Decíamos entonces que posiblemente lo que los chicos desean es reproducir la trayectoria de sus ídolos, devenir esos otros que admiran (Murzi \& Czesli 2014: 67).

Algo similar aparece en Pumas. Los dibujos expuestos en las entrevistas expresan que debutar en la Primera de Pumas, jugar en Europa y en la Selección son los tres anhelos más frecuentes, que se repiten en cinco jugadores. De los tres países estudiados, México es donde más jugadores desearon llegar a la Selección, ya que a esos cinco se suman dos que sueñan con jugar un Mundial, lo que da la pauta de una fuerte relación con lo comunitario nacional. Por el contrario, tres jugadores mencionan “jugar en Primera" (en Pumas o en otro club), lo que aquí muestra desapego respecto de las instituciones y de las comunidades. Sólo dos jugadores mencionaron "salir campeón con Pumas", lo

77 Otros testimonios: “-¿Tratas de plasmar acá alguna jugada que haces en la X-box? -Sí, algunas. Como una bicicleta, un sombrerito, algo así. Y este... pero a veces sale, a veces no. -¿A veces sale en el la X-box o acá? -Acá (Entrevistado P9); “¿Para ti es lo mismo, o es completamente distinto hacerlo en la cancha? -No. pues es un, digo que no es mucha diferencia porque pues tú los mueves con tus dedos. Pues entonces lo puedes hacer también con tus pies tú mismo. Nada más es cuestión de que lo practiques y te va a salir, como las jugadas nuevas que no te salen, pues lo practicas con tus pies y pues te puede salir" (Entrevistado P10). 
que expone que la imagen de gloria deportiva no es en absoluto potente. Otros dos jugadores dibujaron a sus familias junto a ellos, alentándolos en el debut, y un tercero graficó “ayudar a mis papás”. Otras representaciones individuales son "Tener una casa propia, familia e hijo", "Tener representante, mis tacos", “Jugar en Barcelona, la Champions", "Ganar el Balón de Oro" y "Regresar a Pumas [después de haber estado en Europa]".

Para cerrar este capítulo observemos la relación de los futbolistas con la imagen de fama. En el sexto capítulo observaremos cómo viven la fama ellos en sus presentes, pero en este momento -que seguimos rastreando el deseo- debemos ver es la relación que tienen con la fama "ajena", es decir, con la de las futbolistas consagrados. En ese sentido percibo que la fama se les presenta como aquello de lo que tienen que "tener cuidado" porque les puede arruinar la carrera; como si fuera muy fácil dejarse tentar por esos elementos y perder de vista que "lo importante" es ser disciplinado. Ya veíamos en Argentina y en Francia que el discurso de la humildad"8 y el esfuerzo físico se opone al de "echar relajo", y la fama es justamente el emblema de esa oposición, de ese riesgo: llegar, querer disfrutar "las mieles" y por eso perder todo. Ahora bien, creo que todas las respuestas a esta pregunta deben ser pensadas a partir de esa oposición, y observo que en esa oposición ellos se sienten obligados a decirme que son trabajadores, que no les gusta "la fiesta", que van a ser disciplinados por el resto de sus días para mantener una imagen de sí mismos ligada a la sencillez y humildad que se espera de un futbolista profesional:

- Sí, bueno, yo de los futbolistas siento que a veces, muchas veces se pierden ¿no? la fama se los come, son, no sé, se agrandan de más yo creo y este, no se cuidan, andan de fiesta en fiesta. Y se les sube, se les sube pues a la cabeza (...) siempre debes ser una persona humilde porque debes de acordarte de donde viniste ¿no?

- ¿Y en tu caso de donde viniste?

-Pues, yo ya soy una persona de barrio; ahora, si llego a, a estar en Primera División ya ganas muchísimo dinero. Pero siempre acordarte de dónde vienes, es lo más importante yo creo por que muchos se le, se les va al piso, no sé. (Entrevistado P3)

-¿Qué opinas de la fama?

- ¿De la fama? Pues creo que a todo mundo se le alborota, se siente en las nubes. Pero yo creo que está mal, porque siempre tienes que estar pensando en que no es lo mejor que das, sino que puedes dar más de lo que estas dando. Ya sea en Primera división, tú puedes ser el mejor.

-Y por ejemplo ¿tienes fantasías de ganar muchas chicas, o de ganar dinero, cosas así?

78 "Esto está ligado a que los jugadores inscriben su discurso en el de la "humildad", un valor que no sólo significa el esfuerzo diario, la ausencia de ego y de ostentación, sino que al mismo tiempo es un eufemismo para hablar de la pobreza económica. De esa manera, hacen propia la imagen del obrero para contraponerla con la imagen del futbolista afamado y rodeado de lujos.” (Murzi \& Czesli 2014: 85). 
-Este, pues no, yo pienso algo más serio de tener mi familia... más, más, más convivencia familiar, tener una esposa, 2 hijos. (Entrevistado P4) ${ }^{79}$

Por estos testimonios me resulta interesante que luego algunos de ellos mencionen sus fantasías ligadas a la fama. Fue en la última entrevista cuando creí encontrar, finalmente, el modo de indagarlo, porque si bien en algunos casos aparecían elementos, pequeños rastros de lo prohibido, era siempre debajo de la corrección política. Sin embargo, al preguntarle al Entrevistado P10 cómo se imaginaba su vida como profesional y le pedí que especificara la imagen de su casa, de su pareja, de su vida cotidiana, el joven me respondió que se imaginaba jugando en Barcelona, ganando 10 millones de dólares, con muchos autos y soltero. Mis notas tras la entrevista dicen lo siguiente ${ }^{80}$ :

...se imagina en una casa, una mansión de cinco pisos a la que llevaría a la madre, padre y al hermano a vivir allá. [Nota: sus padres están separados y el padre tiene nueva pareja e hijo, pero en su relato eso no estaba contemplado] (...) Con un departamento aparte para las mujeres, porque se imagina soltero y con muchas mujeres. Y dice que al jugar en Barcelona las relaciones cambian, que a las chicas las conocería en fiestas, en 'cócteles' y que algunas también por ejemplo de la prensa. Le pregunté qué chicas, cómo serían las mujeres, me dijo que serían modelos, o de prensa, como Sara Carbonero, mujer de Iker Casillas. Y agregó que una vez que estás en el Barcelona ya cambian tus relaciones sociales. También se imagina con muchos autos, habla de Lamborghini, de Ferrari; que esos serían autos que él manejaría cuando saldría con las mujeres; y otro un Rolls Royce, 'algo elegante' para ir al entrenamiento, con chofer.

Es el testimonio más paradigmático en este sentido, y las encuestas ${ }^{81}$ no exponen que sea una tendencia mayoritaria pero sí que son fantasías absolutamente presentes, que están "tapadas” por el deber ser "trabajador", “disciplinado", por la culpa de desearlo, por no olvidar "de dónde vienen". Sin embargo, es indudable que los futbolistas dialogan con la imagen de los profesionales que surge de los

79 Otro caso: “-¿Qué opinas de toda esa vida [pública] del jugador de fútbol? -Pues que es parte ¿no? Porque el fútbol sin los jugadores no sería nada y, y pues las empresas y eso buscan a los jugadores para, para verse ellos, porque ya toda la gente ve el fútbol. Yo pienso que ya es parte de, ya te tienes que acostumbrar a todo eso. Tienes que ser dentro y fuera de la cancha futbolista, en la calle eres futbolista, en donde sea, eres un futbolista siempre. Eres como embajador del club, lo que hagas, es como si lo hiciste aquí o así. - ¿Qué opinas de la vida de los jugadores fuera de la cancha? (...) Por ejemplo cuando ves en los diarios, las revistas, en la televisión digamos que están así con modelos o que se fueron de fiesta o, no sé, que visten la ropa de moda. ¿Qué sientes? -Pues hay diferentes jugadores ¿no?, como todo de que hay jugadores que son $100 \%$ profesionales, no se van de fiesta, no andan de parranda, desvelándose en la noche y hay jugadores que si ¿no? Que salen de fiesta, están con mujeres y pues hay jugadores que se pierden en eso ¿no?. Yo creo que se pierden en estar en el alcohol, en los vicios, en, se puede decir, en las mujeres ¿no? Se pierden muchos jugadores que están en Primera y desaparecen. (Entrevistado P7)

80 El grabador falló a los pocos minutos de iniciada la entrevista, de modo que se perdieron unos 15 minutos hasta que lo noté y comencé a grabar con un segundo dispositivo. Apenas culminó la entrevista grabé todo mi recuerdo en un audio a partir de las notas que había tomado mientras respondía. El párrafo presentado es un extracto de la transcripción de dicho audio.

81 Las respuestas de la encuesta, en el Anexo *8. 
medios masivos de comunicación. A veces relatado como chistes ${ }^{82}$ en la casa-club, a veces como algo que les pasa a otros, a veces por el rumor, las fantasías (también las de los consumos a los accederían al llegar al profesionalismo) ahí están presentes:

- Cuando piensas en tu vida como futbolista, ¿también piensas en la fama, en las mujeres, en el un auto, todo eso?

- No, pues creo que no; en auto, en la fama y eso sí ¿no?

- ¿De qué manera lo piensas?

- Pues que tengo para poder ser todo eso ¿no? Ser famoso, tener dinero, todo eso (...)

- ¿Cuando sentiste por primera vez que podías ser futbolista, inmediatamente también fantaseabas con la fama?

- Mm, en algunas veces si pensaba eso ¿no? Que pues, me quería ver yo acá, en, jugando, jugador profesional, jugar en estadios, autos, dinero y todo eso ¿no?

- [Asiente]

- Pues, para eso estoy luchando ¿no? (Entrevistado P9)

- ¿Por qué crees que todos quieren [ser futbolistas]?

- Porque pues, por lo mismo de que ves, ves que un futbolista tiene, es famoso es... Tiene la posibilidad de llegar a Europa, Selección, ser el ídolo de una institución. Pues también el dinero, también, todos se fijan mucho en el dinero.

- ¿Tú crees que tus compañeros se fijan mucho en el dinero?

- Ps, creo que sí ¿no?

- No sé, te pregunto ¿En la casa-club se habla mucho de eso?

- Mm, pues sí hablan de que vas a tener muchas viejas y [no se entiende] carrazo, 'yo quiero uno como ese', o así.

- ¿Pero ahí hablan de futbolistas profesionales o de los propios chicos de la casa club?

- Este, profesionales. También hay uno que ps está en Primera División (...)

- ¿Y aparecen con muchas viejas y un carro?

- No, no trae carro.

- Pero si muchas viejas ¿no? [risas]

- Sí.

Unas breves reflexiones para cerrar este capítulo. Hemos hecho un recorrido que comenzó con la primera infancia de los jugadores y culmina con los sueños a futuro de ellos mismos, ya adolescentes y encarando la adultez. El eje conductor fue buscar elementos para pensar cómo se constituye colectivamente el deseo de devenir futbolistas. Lo primero que observamos fueron elementos que permiten confirmar la influencia del pasado en la práctica presente a partir de juegos, de la emulación de la imagen adulta y de las familias que los llevaron a escuelas, pero también de ciertos mecanismos de coerción en casos en los que el chico no demostraba una "vocación" por este deporte y los padres insistieron hasta lograr su placer por el juego.

82 Un caso en Argentina: “-Ahora cuando vos pensás en tu futuro ¿estás pensando también en un poco en una idea como "los jugadores de fútbol siempre levantan las mejores minas"? Un autito lindo... -Eso cuando nos juntamos con los chicos en la pieza [la recámara de la casa-club] siempre hay uno que te lo dice, ponemos música en los parlantes y siempre se sienta en la cama y lo hace. -¿Qué es lo que hace? - Y, no sé, y pone la música y pone la manito así [imita el gesto de manejar el auto con una mano y llevar la izquierda apoyada en la ventana abierta]. Y eso es lo que piensan ellos, lo que quieren. (...) yo lo pienso pero más que nada pienso en familia primero.” (Entrevistado E3) 
En segundo término, que el deseo no es individual sino colectivo: los chicos muchas veces juegan por sus familias, acompañados por ellas pero también haciéndose cargo con los "beneficios" que surgirían de que ellos alcanzaran el profesionalismo. Sus carreras son colectivas, implican esfuerzos y apuestas familiares, económicas y organizativas, y sin ese apoyo no podrían continuar con sus carreras. Al mismo tiempo, observamos que en algunos casos dichas influencias implican un incremento del stress tal que perjudica su juego, y que sin embargo ellos perciben como "apoyo" las presiones de los familiares.

Encontramos también elementos para relativizar la idea de que son las condiciones de existencia las que generan devenires; si bien a partir del caso argentino podemos acompañar que son las representaciones de dichas condiciones las que motivan devenires, vimos al mismo tiempo que en Pumas no hay un relato, una narrativa clara que aglutine a los jugadores. Eso nos llevó a buscar otros anhelos, otras motivaciones, y en México las estaríamos encontrando en las imágenes que se construyen de las estrellas del fútbol internacional a través de canales massmediáticos. La televisión, el Instagram y las consolas de videojuegos parecen las plataformas más importantes en la construcción de la imagen del fútbol, y los chicos pueden estar buscando reproducir las trayectorias de los jugadores que admiran, desligados de las relaciones con la comunidad (excepto en el caso de la Selección Nacional, que en Pumas aparece preponderante).

Observamos el deseo y las aspiraciones futuras de los jugadores, pero para devenir futbolistas profesionales deben insertarse en organizaciones. Allí se encuentran con una estructura que los selecciona y clasifica, les propone normativas y un modo de actuar. En consecuencia, desde el próximo capitulo nos dedicaremos a las relaciones que se establecen al interior de la organización. 


\section{La estructura formativa}

Con el objetivo de exponer la estructura sobre la cual se materializa el deseo de los jóvenes de ser futbolistas y el marco general sobre el que se apoya el centro de formación como organización, en este apartado me referiré a la estructura del fútbol mexicano y de Pumas. En términos generales el fútbol profesional está monopolizado por una Federación Internacional, la FIFA, dentro de la cual se llevan a cabo los campeonatos internacionales y bajo cuya órbita se inscriben todos los "fichajes" de los futbolistas. Dentro de FIFA, el fútbol mexicano y Pumas en particular se enmarca en la Federación Mexicana de Fútbol Asociación A.C. (Femexfut), que a su vez forma parte de la Confederación Norte Centro Americana y del Caribe (Concacaf).

Pero tal como veíamos en el marco teórico, las organizaciones no están aisladas sino que están en relación con muchos otros actores, y el fútbol no es una excepción. Luiz Carlos Ribeiro propone una buena enumeración de los actores que influyen en el sistema organizacional del fútbol:

1. Los directores de las agencias oficiales del fútbol: los nacionales, como la CBF [la confederación brasileña]; las continentales, como la UEFA y la FIFA; 2. Los directores de los clubes, tanto de los pequeños y locales como los ricos y galácticos del fútbol europeo y su representación lobbysta, el denominado G14; 3. La comunidad compleja de jugadores, agentes y entrenadores; 4. El aficionado, desde el ciudadano que acompaña los partidos por televisión, pasando por los que van al estadio eventualmente hasta los hinchas fanáticos y organizados; 5. Los sponsors, desde las empresas locales hasta las multinacionales, como Coca-Cola, Nike o Adidas, entre otras; 6. Los medios, como sistema mundializado de comunicación y divulgación del deporte (televisión, periódicos, revistas, internet, etc.); 7. Los directores políticos nacionales y de la Unión Europea (UE), cada vez más implicados en las dimensiones sociales, económicas y culturales del fútbol; 8. La colectividad local que de manera directa o indirecta se involucra en las actividades deportivas. (Ribeiro 2008: 192. Original en francés, traducción propia) ${ }^{83}$.

Dentro de la FIFA los dieciocho equipos más ricos constituyeron en el año 2000 un grupo de presión -el G14- destinado a negociar el formato, los modos de afiliación y a imponer sus intereses al mundo del fútbol a partir de la incorporación de una lógica financiera, a tal punto que lograron cambiar la estructura tradicional de FIFA en desmedro del interés social del fútbol. Ribeiro menciona -y vale observar que su texto es de 2008 y no lo he actualizado- que este grupo logró una “democratización” de

83 Ciro Murayama también ofrece un resumen de los actores involucrados pero lo propone como un diagrama de flujo circular que voy a intentar transponer. Si ponemos el centro en los equipos y ligas, decimos que les venden derechos de transmisión a los medios y publicidad a las marcas deportivas. Tanto los medios como las marcas deportivas venden, a su vez, sus productos a los aficionados y consumidores (transmisiones en un caso, bienes ligados al club en el otro). Estos últimos colocan sus ahorros en el sector financiero (bancos, fondos de inversión y la bolsa), que realiza préstamos a los clubes de las ligas. Al mismo tiempo, los consumidores pagan impuestos a los Estados-nación, que regulan las ligas; lo mismo que las ligas, que también realizan aportes a los Estados. Las ligas venden entradas a los aficionados y hay una relación que no está clara en su modelo, que es el rol de los Jugadores, entrenadores y agentes de futbolistas. El autor los pone como "mercado de trabajo" (Murayama 2014: 27). 
las instancias internas de FIFA, que perdió cierta autonomía en la toma de decisiones y promoción de políticas en favor de los clubes más ricos.

En ese contexto general, América Latina se consolida como formador y exportador de futbolistas. Una enumeración de Wikipedia indica que México en las temporadas 2015-2016 cuenta con 42 futbolistas en el extranjero (8 en Guatemala, 7 en Estados Unidos, 5 en Portugal, 4 en España, 3 en Filipinas, entre otros datos) $)^{84}$. Esto marca una diferencia sustancial respecto de otros países formadores como Argentina y Brasil. Según el sitio especializado "Futbolistas argentinos por el mundo", el primero contaba con 1693 futbolistas en el exterior en noviembre de 201585, mientras que un artículo de Radio y Televisión Española de 2014 indica que los brasileños cuentan con más de 5000 compatriotas desempeñándose en tierras foráneas (Heras, 2 de julio de 2014), con un promedio de 1000 jugadores por año que parten al exterior para ganarse la vida con el balompié.

En ese contexto se inserta el fútbol mexicano. Su federación, Femexfut, cuenta con cuatro ligas afiliadas (Liga Mx, Ascenso Mx, Segunda División y Tercera División), y excepto Pumas milita en todas excepto Ascenso Mx. Entre 2006 y 2013 contó, inclusive, con el equipo Pumas Morelos en dicha categoría, pero tras el descenso del equipo en el Torneo Clausura 2013 la franquicia fue vendida a la empresa AMRH International Soccer, S.A. y poco tiempo después desapareció.

Las fuerzas básicas Sub20, Sub17 y Sub15 mantienen la lógica competitiva de la Liga Mx. Compuesta por 18 equipos que se desempeñan en dos torneos cortos, posee una primera etapa que consta de una rueda en la que juegan todos contra todos, tras la cual los mejores ocho pasan a una liguilla en la que compiten en duelos por eliminación directa hasta alcanzar una final. Los equipos son en su mayoría franquicias, lo que significa que son empresas que cumplen los requisitos de la Federación y piden afiliarse. A partir del capital con el que cuentan acceden a una categoría determinada, lo que suscita que numerosos ascensos se produzcan a partir de asociaciones ente clubes, mediante la compra de una franquicia por otra o que el mismo grupo inversor cuente con más de un

84 Jonatan Collazo enumera en mediotiempo.com 32 jugadores en 2014 (Collazo, 14 de marzo de 2014), y uno de terra.com ( $\sin$ autor) contabiliza 28, de modo que la cifra no es descabellada (terra.com, 3 de septiembre de 2015).

85 "Tenemos registrados jugadores argentinos en las seis confederaciones en las cuales se divide el futbol mundial. La UEFA (945) encabeza la lista; seguida por la CSF (442) [Confederación sudamericana o Conmebol] y cierra el podio la CONCACAF (231). La AFC (48) [Confederación Asiática] es la cuarta confederación y cierran esta clasificación la OFC (22) [Oceanía] y la CAF (2) [África]. En cuanto a los países donde juegan más argentinos el podio sigue igual: España lo lidera con 347. Lo sigue Italia con 264 y cierra el podio Chile con 155. El "Top Ten" lo completan: $4^{\circ}$ México (96), $5^{\circ}$ EE.UU. (80), $6^{\circ}$ Bolivia (73) , $7^{\circ}$ Perú (53), $8^{\circ}$ Grecia (48), $9^{\circ}$ Ecuador (40) y $10^{\circ}$ Alemania (38). Los mismos países que en la edición pasada; aunque con varios cambios de posición. El país, no americano ni europeo, con mayor cantidad de argentinos es Nueva Zelanda (22) que lidera este apartado por primera vez desde la publicación de este archivo. Lo siguen Australia (11) y Malasia (9)" (futbolistasaxem.com.ar, 4 de noviembre de 2015) 
club de fútbol. En estos movimientos muchas veces los clubes cambian de sede o de ciudad, lo que reduce también la identificación de los aficionados con algunas escuadras.

Una encuesta privada realizada por la consultora Mitofsky a comienzos de 2016 expuso una importante polarización entre los aficionados: el 24,5\% dice ser seguidor del Club América, un 17.2\% del Guadalajara (Chivas); el 12\% le va a Pumas, el 8,5\% a Cruz Azul y un 4,7\% a Tigres, último campeón ${ }^{86}$. Esto se condice con la mirada de Ciro Murayama, quien afirma que "Aunque hay millones de equipos de fútbol en el mundo, sólo unos cuantos de miles son profesionales, es decir, hay relativamente pocas empresas que producen ese servicio de entretenimiento que es el fútbol" (Murayama 2014: 28), y son incluso menos las empresas que distribuyen dicho servicio por televisión. Pero antes de ir a esos números veamos quiénes son los dueños de dichas franquicias. En el caso del América, desde 2012 cuenta con un Consejo Directivo presidido por Emilio Azcárraga Jean, presidente del grupo de medios Televisa, y con la Dirección General de Yon de Luisa, Director del Comité de Fútbol de Grupo Televisa; el Club Deportivo Guadalajara pertenece a Jorge Carlos Vergara Madrigal, empresario dedicado a rubros diversos; el Cruz Azul, por su parte, fue fundado y continúa perteneciendo a la empresa cementera Cooperativa Cruz Azul, del estado de Hidalgo, aunque desde 1971 compite como local en el Estadio Azteca de la Ciudad de México; y el Tigres de Nuevo León no sólo es el equipo oficial de la Universidad Autónoma de Nuevo León sino que desde 1997 cuenta con el respaldo y manejo administrativo de Sinergia Deportiva, empresa filial de la multinacional cementera CEMEX.

En el caso de Pumas hay dos partes fuertemente involucradas. Por un lado la Universidad Nacional Autónoma de México, considerada la Universidad más importante de América Latina y una institución sumamente honrosa para la población de Ciudad de México (Pumas, de hecho, genera identificación entre sus aficionados por ser el club "universitario"). El fútbol es sin embargo administrado y financiado por el "Patronato", una junta directiva que al momento de la etnografía era presidida por Jorge Borja Navarrete (Ingeniero Civil, consejero en la petrolera estatal Pemex y ex directivo de la empresa constructora ICA) y que cuenta entre sus miembros con Andrés Conesa Labastida (Director General del Grupo Aeroméxico), Alonso Quintana Kawage (Director General de la

86 No hay datos sobre el 35\% restante. La encuesta fue realizada sobre 1000 mexicanos mayores de 18 años (no hay datos sobre su género), de todo el país y con un margen de error del 3,1\%, según la propia consultora. Entre las conclusiones indican que "Los Tigres al lograr el campeonato, muestran incremento de aficionados y pasan del séptimo al quinto puesto rebasando al Monterrey y al Santos que en esta medición ocupan el sexto y séptimo puesto respectivamente, relegando al Toluca al octavo lugar". 
constructora ICA hasta febrero de 2016; ICA es también el principal patrocinador de Pumas); Paola Rojas Hinojosa (periodista de Televisa y esposa de Luis Roberto Alves, ex futbolista brasileño que jugó la mayor parte de su carrera en el América), y Carlos Slim Domit, presidente del Consejo de Administración de Telmex e hijo de Carlos Slim Helú, considerado el cuarto hombre más rico del mundo.

Un artículo del portal Contralínea indica que entre UNAM y Pumas existe un acuerdo por el cual la Universidad proporciona el Estadio Universitario y que existe un convenio de licencia de uso de marcas, "mediante el cual le confiere y otorga licencia exclusiva al Club para utilizar, explotar y sublicenciar las marcas consistentes en la Cara Estilizada del 'PUMA' y la palabra 'PUMAS' por sí mismo o a través de terceros (sic)", de acuerdo con la información proporcionada por la Universidad en respuesta a las solicitudes de información F8797 y F9463, presentadas por dicho semanario (Romero, 26 de noviembre de 2015). Según la misma fuente, en el caso de que el club arroje ganancias deberá cederlas a la Universidad; sin embargo, afirma que "Tras casi 4 décadas de la creación de la asociación, el número es categórico: ni 1 peso ha recibido la máxima casa de estudios"87, motivo por el cual el medio deduce que se está utilizando patrimonio público para realizar un negocio de privados.

Además de los ingresos por patrocinios, venta de tickets durante los días de partido y venta de jugadores, el fútbol como industria provee un espectáculo, y buena parte de este se difunde a través de medios masivos de comunicación. Para Murayama no es posible pensar al fútbol sin los ingresos por la televisación ${ }^{88}$; lo hace a partir del dato expresado por el informe Deloitte 2014, que indicaba que el $37 \%$ de los ingresos de los 20 clubes más importantes del fútbol mundial dependen en promedio de la venta de derechos de televisión. En el caso del Real Madrid, por ejemplo, los ingresos por televisación eran de 188,3 millones de euros, 119 correspondían a las taquillas y 211,6 a la comercialización de

87 El portal presenta documentos en los que el portal Transparencia y Acceso a la Información de la UNAM sostiene que el Club Universidad Nacional, está "constituida conforme a las disposiciones aplicables en la materia, esto implica que es una persona jurídica colectiva de carácter privado distinta a la Universidad Nacional Autónoma de México" (Romero, 26 de noviembre de 2015, citado en el original) y que dicha "privatización" sucedió el 5 de julio de 1977 cuando el entonces rector Soberón Acevedo aceptó la propuesta del ingeniero Bernardo Quintana Arrioja de separar a Pumas de la UNAM, bajo la promesa de absorber las perdidas monetarias en el caso que hubiera y aportar a la universidad en caso de superávit. Romero indica que el acuerdo consiste en una concesión por 99 años a la asociación encabezada por Bernardo Quintana Arrioja, quien pasó a ser apoderado y presidente del Consejo Directivo.

88 "Puede afirmarse que la televisión depende del deporte, que le ofrece unos niveles de audiencia que con dificultad alcanzan otros contenidos, y a la vez las ligas profesionales están supeditadas a los ingresos que de manera directa les proporciona la televisión y a los recursos indirectos que ésta genera, por ejemplo, vía difusión de productos vinculados con las ligas o los clubes. Por una parte, la televisión ha permitido que los principales torneos nacionales puedan ser seguidos prácticamente desde cualquier lugar del mundo donde se encuentre el aficionado; al mismo tiempo, los recursos que las cadenas mediáticas entregan a las ligas o equipos más importantes les permiten adquirir jugadores de fama global y a precios inconcebibles hasta hace pocos años..." (Murayama 2014: 60) 
otros productos. Ahora bien, el Atlético de Madrid, último en la lista de 20 pero tercero en ingresos por televisación en España, cobraba 52,5 millones de euros por televisación, lo que correspondía al 44\% de sus ingresos totales (120 millones de euros). Cada liga establece sus propias formas de negociación y distribución de ingresos entre los clubes. En España el torneo clausura 2016 -que se extiende hasta mediados de ese año- sería el último en el cual cada club negocia por separado sus ingresos por televisación, y a partir de la campaña 2016/2017 lo hará toda la liga en conjunto y esperan recibir 1500 millones de euros (El Mundo, 30 de abril de 2015), aunque no está claro cómo se repartirá entre los clubes. Hasta la escritura de la tesis el reparto expone una diferencia de 10 veces entre los más y menos poderosos.

Murayama también presenta el modelo alemán, sumamente distinto porque comercializa los derechos a través de una subsidiaria, DFL Sports Enterprises y de manera conjunta. En 2014 la Bundesliga lograba ingresos por 463 millones de euros y con un alto equilibrio entre los clubes más y menos poderosos: el Bayern Munich recibía 28 millones de euros, frente a 14 que percibía el Colonia. En Francia la liga vende a través de su federación los derechos de transmisión local, mientras que la internacional la realiza a través del canal qatarí Al Jazeera. Sus ingresos eran de 700 millones de euros y el reparto se realizaba de la siguiente manera: 50\% de forma igualitaria, 30\% por la clasificación de los equipos y 20\% por número de retransmisiones (Murayama 2014: 65). Finalmente, la liga europea que más ingresos percibe es la inglesa, que en 2014 alcanzaba los 770 millones de euros sólo por la transmisión nacional, mientras que la venta internacional adicionaba otros 542 millones. Sus ingresos se reparten: 50 por ciento de manera equitativa, 25 por ciento en función de la clasificación al finalizar la temporada y el cuarto restante en función del número de partidos televisados.

Todo esto muestra que la capacidad de generar espectáculo (y espectáculo mediatizado, entendido en puntos de rating) es central al fútbol profesional. Asimismo, diferencias tan grandes como la que se producían en España tienen consecuencias deportivas, en el sentido de que implica una perpetuación de las desigualdades entre los equipos porque dos (Barcelona y Real Madrid) cuentan con ganancias anuales que les permiten contratar jugadores estrella, mientras que el resto debe competir con muchos menos recursos. Por supuesto, en el campo de juego son once contra once y siempre puede haber excepciones, pero desde la temporada 2004-2005 campeón y subcampeón se dirimieron únicamente entre Barcelona (campeón 7 veces) y Real Madrid (4 ocasiones), mientras que sólo en la temporada 
2007 el Valencia alcanzó el subcampeonato y relegó al equipo catalán a la tercera posición, lo que marca la pauta de que la diferencia de ganancias repercute sobre los resultados.

¿Qué sucedía en Latinoamérica? Contamos con datos de Ribeiro, correspondientes a la temporadas 2005-2006. Allí lo primero que sale a la luz es que los derechos de televisación ocupan un porcentaje mucho menor que en Europa: en Argentina, aquel año el 50\% de los ingresos promedio eran por transferencias de jugadores mientras que la televisación alcanzaba el 22\%. En Brasil, 30\% correspondía a las transferencias y $20 \%$ a la televisación; y en México, el país más equilibrado de todos, el $15 \%$ correspondía a televisación, el $23 \%$ a transferencias, $37 \%$ a la comercialización de los días de partido y $25 \%$ a patrocinios y venta de licencias. Aquí el mercado de televisación está sumamente concentrado a favor de Televisa: desde julio de 2015 posee los derechos del $78 \%$ de los partidos de alta convocatoria, ya transmite al América, Guadalajara ${ }^{89}$, Cruz Azul, Pumas, Monterrey, Tigres, Toluca y Chiapas y a partir de ahí, de encuentros como Chivas-América o Pumas-Cruz Azul. Su principal competencia es Televisión Azteca, que transmite al Atlas, Veracruz, Santos, Tijuana, Querétaro y Morelia; en tercer lugar Fox Sports posee los derechos de León y Pachuca y finalmente TVC Deportes con los Dorados de Sinaloa (juanfutbol.com, 5 de julio de 2015).

Asimismo, la versión digital de Forbes indicaba en abril del mismo año que los ingresos por televisación habían pasado de 144 millones de dólares en 2013 a 398 en 2015, motivado sobre todo por el ingreso de nuevos actores interesados en la televisación. A esto se debe agregar un dato no menor: los canales de TV no sólo son difusoras del fútbol sino que son dueñas de equipos: "Seis de los equipos que compiten en la Liga MX pertenecen a medios de comunicación: Televisa es dueña del América, TV Azteca del Atlas y Morelia, Grupo Imagen de los Gallos Blancos y Grupo Pachuca-Carlos Slim (Claro Sports) del Pachuca y León" (Pérez, 10 de abril de 2015). Como se puede ver, la relación entre ambos sectores es central en el fútbol mexicano.

\subsection{Ligazón contractual entre club y futbolistas}

Una segunda cuestión estructural y que atañe a toda la formación es la relación que se establece entre los clubes y los futbolistas, algo completamente ligado a la dimensión productiva del club -en términos de producción de jugadores. Dos factores son centrales: si los futbolistas de cantera deben o

\footnotetext{
${ }^{89}$ Para el torneo Apertura 2016, el Club Guadalajara decidió cambiar el sistema de televisación y apostó por un sistema bajo demanda en el que la transmisión es a través de internet y cuenta con diversos planes de pago en función de los servicios que se contratan.
} 
no percibir una remuneración por su tarea cotidiana, y cómo hacen los centros de formación para que no les "roben" a los canteranos, teniendo en cuenta que la formación implica una inversión, que según datos de primera mano en Pumas y Olympique de Marsella oscila en torno de los 5 millones de dólares por año.

Respecto del primer asunto, los tres equipos estudiados resuelven la cuestión de distinta manera: en Estudiantes de la Plata ningún jugador cobra un solo peso por parte del club. Aquellos futbolistas que tienen representante (el 40 por ciento según las entrevistas), reciben por parte de estos unos 1500 pesos mensuales (aproximadamente 150 dólares al momento de hacer la etnografía), más indumentaria deportiva. Algún futbolista reconoció con agradecimiento que en cierta ocasión un entrenador le dio dinero de su propio bolsillo para que se pudiera costear los pasajes hasta el club, y si no tienen dinero para los zapatos se "bajan” desde la Primera, donde circulan patrocinios y más recursos. Pero allí se considera no sólo que pagarles sería un costo muy elevado para la institución sino que si los jugadores recibieran un salario "se relajarían" y mermarían su rendimiento. Por fuera de eso, el club se enorgullece -y los jugadores no disienten- que les "da todo": eso es alimentación, escuela y hogar a quienes provienen del interior. Vale destacar que se les cobra 600 pesos mensuales (USD60) por la escuela y otros 600 por la casa y comida, aunque imagino que si el joven no pudiera en absoluto costearlo y tuviera condiciones deportivas el club asumiría el costo. A quienes no poseen espacio en la casa-club el club les cubre la escolaridad y alimentación, pero viven en un hostel cercano, que deben pagar con fondos propios. Observaremos la idea de escasez en el próximo capítulo con un poco más de detenimiento. En relación a cómo evitan que otros clubes se los lleven, confían sobre todo en el registro ante la Federación Argentina (AFA) y la FIFA.

En Marsella la situación es opuesta, ya que los jugadores sí perciben un salario porque es un elemento central en el reclutamiento: si un joven tiene condiciones será tentado por varios clubes, y uno de los argumentos de peso es el contrato rentado. Así lo describimos en el trabajo conjunto escrito con Diego Murzi:

En Francia existen 2 grandes tipos de contratos: los de la Liga Profesional de Fútbol y los lazos Convention. Respecto de los primeros, se trata de contratos de trabajo que implican responsabilidades de ambas partes y determinan que el jugador es un asalariado del club. Dentro de estos hay tres categorías:

- Aspirant: es el contrato base que firman los jugadores que ingresan al Centro de Formación de un club. Puede ser firmado a partir de los 15 años y tiene una duración máxima de 3 años, es decir, hasta los 18 años. [entre EU262 y 374,5 en 2015]

- Stagiaire: Puede ser firmado a partir de los 17 años por 3 años (por 2 si el jugador tiene 18 años y por 1 año si tiene 19). [EU561,75 a EU636,65] 
- Elite: se firma a partir de los 18 años pero implica 2 años en el Centro de Formación más 3 años de primer contrato profesional. [desde EU898,8 hasta EU1722,7]

Por otro lado, existe un documento que oficializa la relación entre club y jugador pero no es un contrato de la Liga Profesional. Se denomina "Convention", y no implica retribución económica para los futbolistas. La Convention está registrada por la LFP [la Federación] y puede convertirse en un contrato durante la temporada. Es válida por un año y no puede extenderse dos veces, lo que significa que un jugador que esté bajo Convention necesariamente deberá firmar un contrato al año siguiente si el club desea mantenerlo en el CdF [centro de formación].

Para tener un panorama de cómo se distribuyen los contratos podemos observar datos de 2010, cuando había 1800 jugadores en los Centros de Formación franceses, de los cuales 1000 habían firmado un contrato y los otros 800 estaban bajo Convention.

(Murzi \& Czesli 2014: 31)

En consecuencia, en un mismo plantel conviven jugadores con diversos contratos en función de su proyección pero también de su edad, algo que también genera discrepancias al interior del cuerpo técnico porque no todos coinciden en que los salarios sean acorde a sus rendimientos. Cuando los balances no son tan positivos y el dinero presupuestado se reduce comienzan a evaluar, caso por caso, hasta qué punto el jugador está redituando en presente la inversión que por él se realiza. De los 37 jugadores de distintas categorías que viven en el club hay entre 20 y 25 que reciben salario, más aquellos que no viven en el club (es política del director del club que los jugadores de más de 18 años vivan en departamentos).

En México, finalmente, todos los jugadores registrados en Sub17 cobran algo más de 2400 pesos mensuales y sólo algunos viven en la casa-club. Pero en este caso me permito transcribir un largo fragmento de la entrevista realizada con el Abogado General de la institución (se omite su nombre por cuestiones de privacidad), ya que evita la mediación de mi lectura y expone la información de manera clara y contundente. La grabación comienza con una frase suya:

- ...todos los jugadores firman un contrato, a cualquier edad. Si son menores de edad el contrato va junto con una carta de sus papás en la que se los autoriza. Sobre todo a partir de los 13 años, que es cuando son registrados en Federación Mexicana de Fútbol. Firman un contrato y en ese contrato se establece que ceden sus derechos federativos al club y que el club es el dueño de esos registros federativos.

- ¿Qué implica un derecho federativo?

- Que se convierten en "propiedad" de Pumas. No es una propiedad como tus cosas, tu coche, tu casa. Pumas se vuelve dueño de sus derechos deportivos, de sus facultades para jugar... Si algún otro club los quiere tiene que negociar con nosotros, y ellos si se quieren ir a jugar a otro club tienen que negociar con nosotros.

- ¿Y si quiere dejar de jugar?

- También. Me avisa, me lo notificarán y haremos un documento formal donde asentamos que terminamos el contrato. Si un día el muchacho dice "ya no quiero jugar más futbol, ya me aburrí del futbol" me lo avisa y firmamos un contrato donde damos por terminada esa condición.

- ¿Y cómo evitas que después de la rescisión se registre en otro club?

- Para que se registre en otro club yo lo tengo que dar de baja. Entonces la Federación lo tiene controlado para que si me engañó y se va a otro club no lo pueda registrar. Yo como club tengo un inventario de jugadores, desde los 13 [años] para arriba, incluyendo al primer equipo. Tengo 
un inventario, si yo terminé mi contrato con cualquiera de estos jugadores pero sigue estando en mi inventario, hasta que yo no autorice que se vaya a otro equipo, seguirá estando dentro de mi inventario, no podrá registrarse en otro equipo.

- ¿Y el inventario tiene un plazo?

- No.

- O sea, imaginemos que se registró a los 13 años y que a los 20 años aparece en otro club...

- Ese otro club va a tener problemas a la hora que lo registre, porque la Federación ya tiene un número de identificación de jugador que ya lo liga, y es para toda su vida. El chico regresa a los 20 años con el Cruz Azul y quiere registrarse con Cruz Azul, les va a rebotar: este chico está registrado con Pumas: ¿qué dice Pumas al respecto? Este es un sistema que ha instalado la Federación de varios años atrás a la fecha... la Federación tiene un modelo de contrato y cada club puede tener su modelo interno. Pero al final de cuentas en el que lo registras es un formato de la Federación, para que sea parejo con todos.

- Entonces, en la Sub17, donde trabajé, muchos chicos vienen de otros clubes. A veces porque fueron dejados afuera por esos clubes... ¿Entonces ustedes están obligados a negociar con aquellos clubes?

- No, porque cuando llegan acá... puede ser de dos formas: o que te pongas a negociar con el club para que te lo preste o para que te lo transfieran de forma definitiva, o muchas veces el chico llega porque en ese club ya no lo quisieron. Aquí hay un tema muy subjetivo, como podrás ir dándote cuenta: para ti el jugador puede ser un crack y para mí no. Entonces si yo ya no lo quiero lo dejo libre... Tengo dos opciones: puedo dejarlo libre para que vaya a negociar con quien quiera, o jugarle un poco sucio al jugador, un poco chueco, mala leche al jugador: no darle contrato pero no liberarlo, para que entonces cuando ese jugador quiera entrar a otro club ese club va a tener que venir a negociar conmigo.

- ¿Y qué es lo que suele pasar?

- La costumbre aquí en Pumas es liberarlo. Liberarlo implica: cierras el contrato y yo lo libero, lo bajo de mi inventario y suerte. Lo mejor para ti en tu vida. Pero hay otros equipos que hacen lo contrario: simplemente no le dan su contrato pero sigue estando en su inventario para complicar la vida del muchacho, o para que el muchacho pague sus derechos, lo que sea.

- ...me imagino que te encuentras con las dos situaciones. ¿Cómo reacciona el club frente a una y otra?

- Con los chicos que vienen libres pues no hay ningún problema. Con los que vienen de otro club sí se valora si... se pone en contacto con la directiva del otro club, y sí se hace un trámite porque luego hay equipos que lo hacen sin saber, y que no lo bajaron de su inventario. "Oye por favor ¿puedes bajar a fulanito? Ah sí, pues ten, no hay problema”. Pero sí hay otros clubes que sí negocian y sí te venden al muchacho. Entonces pues aquí [vemos] lo que nos pide el área deportiva, el entrenador o José Luis Arce, si nos dicen "lo necesitamos, lo queremos, vale la pena" nos sentamos a hacer la negociación.

- ¿La negociación que se realiza es económica en presente o de derechos futuros en el caso de que se venda?

- Generalmente es económica en presente, como lo acabas de decir. Generalmente. No hay un límite para que sea de derechos a futuro, si a la hora que vendes al jugador le das un porcentaje, etcétera, lo que pasa es que eso está regulado en la figura de los derechos de formación, es una figura que regula FIFA.

- ¿Pero eso es el 7\% [del valor de venta], no?

- "Solidaridad" es el 5\% y "Formación" es en base a los años que estuvo capacitándose en tu club. Pero sí podría ser como tú dices: llévatelo pero si el muchacho debuta en Primera División y lo vendes, me das un porcentaje. No hay obstáculo para que no fuera de esa forma.

- ¿Solidaridad y Derechos Formativos es efectivamente lo que el club se lleva o se incluyen cláusulas aparte? En Argentina suele pasar que hay un contrato legal pero al mismo tiempo se firma uno paralelo: "no me alcanza con el 5 o 7\%, quiero el 15\%".

- Mira, regreso a lo mismo: aquí en Pumas lo hacemos con lo que establece Derechos de Formación y Solidaridad. No lucramos con esa parte. Por supuesto hay muchos clubes que firman cosas por abajo del agua y no son [no se entiende] a la Federación. Entonces sí es una costumbre en otros lados tener esos dobles contratos o esa situación oscura.

- ¿Y antes de los 13 años cómo funciona? 
- Antes de los 13 años lo registras en el sector amateur, no en el profesional, para tener un antecedente del muchacho. pero no hay un torneo oficialmente organizado, la Federación no se preocupa todavía por esos niños, son niños que llegan aquí de 10 años y entrenan a las tardes, está sujeto al calendario escolar. Por supuesto, ninguno recibe una remuneración.

- ¿Todos reciben 2400 pesos y monedas, no? ¿Desde qué edad?

- Eh... A partir de la Sub17.

- ¿La Sub20 cobra lo mismo?

- La 20 cobra un poquito más, pero a partir de la 20, y en Segunda División ya hay jugadores que pueden cobrar más dinero, sobre todos si están vinculados al Primer Equipo. Muchos que están en Sub20, y que ya jugaron algún partido con Primer Equipo pero regresan a Sub20 para cerrar su preparación tienen un poco más de dinero. Pero tampoco son "los" sueldos. Son 10 mil pesos.

- Aunque juegue un partido solamente...

- Lo que pasa es que hay que ver por qué lo jugaste ¿no? A lo mejor es si [no se entiende] entrenador o a lo mejor, vamos a ver, a lo mejor durante todo ese torneo te estuvo llevando. No jugaste pero estuviste en las concentraciones, fuiste a los viajes, etcétera. Pues sí tendrías elementos para que en tu siguiente renovación de contrato digas "Oye me están considerando para un poquito más". Pero son aumentos mínimos: 10, 12 mil, 15 mil pesos. No llegan a más. Y es mucho, a lo mejor debería ser 7 u 8 mil pesos, por ahí.

- Una pregunta que quedó pendiente: justamente una de las hipótesis que barajo es pensar el proceso de profesionalización como un proceso de mercantilización, es decir, la idea de que el chico se va convirtiendo en un producto de mercado y va adquiriendo un valor económico. Ahora bien, cuando les pregunto a los chicos cuánto creen que valen, no tienen ni idea. Pero sí veo que efectivamente es una variable que tú manejas. ¿Cuánto vale un jugador?

- El jugador se va valorando en base a muchas cosas. Por supuesto, lo primero es su rendimiento en los partidos. Que le genere resultados favorables al equipo. Después, si ese muchacho tiene algún llamado a Selección Nacional, eso cuenta mucho: ya está reconocido por otro entrenador, y que tengas un llamado a Selección Nacional, eso también ya impacta en tu monetización, por ponerlo así. Y por supuesto, tu desarrollo como futbolista. Es lo que te decía: que debutes en Primer Equipo eso ya da que de inicio tengas un poquito más de valor. Pero no hay una tabulación, una regla que te diga Sub13 vale tanto, Sub17 vale tanto, y por ser titular en toda la campaña tienes derecho a ganar tanto. No hay una regla, por lo menos aquí en Pumas no hay una regla que lo establezca.

- Pero no me refiero al salario de los chicos sino a su proyección hacia afuera, su "precio de venta", si se quiere.

- Es difícil contestarte eso porque tampoco lo hay realmente. Es a cómo percibas el jugador realmente. Si tu percibes que te está sirviendo, lo que menos piensas es en vender, lo piensas vender cuando llega a Primera División y cuando te resulte atractivo como negocio. Pero mientras, no piensas en venderlo: piensas en venderlo cuando ya no te sirve, cuando ya no te es útil. Entonces ahí lo que haces es ponerlo en una vitrina, el draft que se lleva a cabo dos veces al año: previo al inicio de la temporada y al finalizar el torneo apertura, es decir un draft muy pequeño en invierno. Diciembre y junio. $Y$ es un espacio que se aprovecha exclusivamente para jugadores de Primera División y Primera A, la liga de ascenso. Para esas dos, no entran otro tipo de jugadores.

- O sea que en lo que respecta al proceso formativo, ¿puede ser que haya como un valor implícito que se sabe que va creciendo pero que nunca se materializa?

- Es así.

- ¿Qué pasa si viene un club del exterior y te dice "me quiero llevar a este jugador”? ¿Pasa eso?

- Sí, no llegan tanto directamente con el club. Llegan con el jugador. Y le dicen "te quiero acá", quiero que te vengas con nosotros. Primero le venden la idea al jugador, lo encandilan, lo alborotan, le venden la idea de irse a otro club. Para ver la respuesta del jugador, si quiere o no quiere. Si el jugador demuestra un interés por irse entonces entraría a lo mejor el contacto con el club.

- ¿En los últimos años cuántas veces pasó eso?

- Mínima. Mínima, porque si son jugadores... el problema es que hoy en día todos los jugadores tienen el mismo sistema de Pumas, es decir, todos los equipos tienen sus fuerzas básicas, y todos los equipos están cubriéndose por todos lados para ver qué consigue por fuera de sus fuerzas 
básicas. Te vas a las escuelas, te vas a universidades, te vas a los campos llaneros, a las ligas amateurs, y ahí buscas jugadores, y si encuentras uno que te pueda servir lo jalas, lo traes, lo registras, lo primero que haces es registrarlo. Para que si alguien después lo quiere, ya por lo menos tengas algo con qué pelear, económica... federativamente hablando. Es decir, es poco que se da... a lo mejor me traigo un entrenador que estaba hace poco en Guadalajara. Me lo traigo aquí a Pumas. Y ese entrenador me dice "oye allá teníamos a un jugador que era así, así y así y me gustaría traerlo", pues a lo mejor haces un acercamiento para ver si te lo puedes traer... Pero lo más seguro es que Guadalajara no te lo suelte, a menos que el Guadalajara no lo esté ocupando, o no lo quiera, o a lo mejor Guadalajara tiene con quién suplirlo y ya te lo suelta, pero mientras, no. Ahora, se da algo muy curioso eh, lo platicamos hace un momento: para mí un jugador puede ser un crack y para ti no. Tú lo dejas ir, lo agarro yo y aquí brilla. Pasó algo muy curioso con un jugador hace como 6 o 7 meses. Hace como un año lo dejaron ir porque tenía una serie de calificativas bajas, no reaccionaba a determinadas cosas, su técnica era deficiente según determinadas personas. El chico se fue al América, y en América el entrenador anterior lo ve jugando en fuerzas básicas, lo ve en Sub17, lo sube y lo debuta en Primera División. ¿qué va a pasar con ese muchacho? No sabemos. Porque además el entrenador que lo debuta en América ya no está en América.

- ¿Y se mantuvo el chico o ya quedó?

- Aparentemente sí sigue jugando. Qué desarrollo trae ¿no? Entonces es cuando dices ¿por qué lo dejamos ir? Cuentan -cuentan, cuentan [aclara], como leyenda- que aquí vino a probarse Oribe Peralta y le dijeron que no, y después se fue a Torreón, y en Torreón fue la estrella, y de ahí fue al América, y ahora es el delantero de la Selección Nacional, y así. ¿Y por qué lo dejaron ir? Porque a lo mejor el día que vino a hacer su prueba se levantó con el pie izquierdo ¿no? No fue su mejor día.

- ¿Hay muchos representantes, muchos intermediarios?

- Sí.

- ¿Cómo es la relación con ellos?

- Los representantes son... un mal necesario. El representante lo que hace es buscar mejores condiciones para su jugador, pero eso muchas veces hace que se encarezca su costo. Hoy en día, a partir de abril de este año la FIFA cambió su reglamento respecto de los intermediarios para ponerles más reglas, que no sean tan abusivos [se refiere al "Nuevo reglamento FIFA de intermediarios", expuesto en la Circular 1417 del 30 de abril de 201490].

- ¿De qué manera eran abusivos?

- Antes no le respondían al jugador, obtenían una serie de comisiones mucho más altas, te encarecían... y lo que la FIFA buscó es que estos agentes que están participando como intermediarios estén muy delimitados, muy identificados, y sacar del fútbol a figuras que no tienen nada que ver con el futbol y lo encarecen. ¿Por qué? Porque el representante tenía una empresa y esa empresa compraba los derechos federativos y deportivos del jugador y entonces se lo vendía a otro país, pero lo vendía mucho más caro de lo que realmente valía, y entonces te encarecía, y eran agentes externos al club. Hoy día FIFA te pide que las negociaciones entre clubes se den directamente entre clubes, si quieres traerte un jugador de América, o de Boca Juniors o del Real Madrid contacta a la gente de Boca Juniors, contacta a la del Real Madrid.

- ¿Aunque venga y te lo ofrezca un tercero?

- Aunque venga y te lo ofrezca un tercero. O si va a venir a ofrecértelo un tercero, verifica que ese tercero esté registrado en la Federación a la cual está diciendo que pertenece. Aquí la federación mexicana tiene un registro de 12,15 representantes.

- Es muy poco.

- El problema es que alrededor de esos 12 o 15, 20 a lo mejor representantes, trabajan muchos, alrededor de ellos hay muchos girando y son los que tienen el contacto.

(...)

- Volviendo, antes habías dicho que los representantes son un mal necesario ¿por qué la parte de "necesario"?

- Porque son la forma de llegar a los jugadores. es una manera de llegar al jugador, una vía de contactarlo. Entonces, y es necesario también para el jugador propio. El jugador necesita también

${ }^{90}$ Disponible en http://es.fifa.com/governance/intermediaries/index.html 
que lo promuevan, que no se quede estancado, el jugador necesita alguien que vaya y lo oferte, que vaya y busque por su beneficio. Si la función del representante es también velar por su muchacho, el jugador necesita que alguien lo apure, alguien que conoce del mundo, de la materia, de los temas, alguien que tenga los contactos para promoverlo. Eso el jugador no los tiene.

(...)

- ¿Se producen casos de chicos que pese a todo sean comercializados a Europa o a otros países? ¿Casos de chicos que desaparecen de aquí y aparecen en Europa? Es algo que se menciona mucho pero por lo que me cuentas no sucede, y en Estudiantes de la Plata tampoco lo vi... ${ }^{91}$

- Sí pasa, y de hecho lo estamos ya siguiendo, pero ese muchacho tiene ya sus registros en Federación, entonces estamos por iniciar un proceso en FIFA para que el club que lo tiene nos pague Derechos de Formación y Solidaridad.

- ¿Un solo jugador?

- Uno en Europa y otro en Colombia.

- Bien, o sea que sucede en pocos casos pero sucede. Última pregunta: ¿Tienen algún otro mecanismo aparte de los derechos formativos para evitar que se los lleven?

- No, se firma un contrato y al final de cuentas el contrato se puede romper en cualquier momento ¿no? Con algunas consecuencias, por supuesto.

- ¿Qué consecuencias?

- Pues a lo mejor ¿te quieres ir? Ok, vete, sale, te rompo el contrato pero no te bajo del inventario, entonces al momento que otro club te quiera registrar, vas a aparecer... pues hay formas de que yo si quisiera te ponga el dedo...

\subsection{Pumas como organización}

Es hora de comenzar a presentar cómo se materializan los elementos que observábamos en el marco teórico, y el primer paso es describir el Centro de Formación. Para comenzar el abordaje expondré cómo está estructurada la organización tanto en términos de infraestructura como de relaciones sociales, porque es en ese espacio y no en otro en el que se produce el camino de los jugadores hacia el profesionalismo. Veremos además que la manera en que la organización está estructurada impacta sobre las posibilidades de formación de los jugadores.

En el marco teórico se resumió la concepción de la organización como un espacio que involucra relaciones formales e informales entre individuos en pos de un conjunto de metas colectivas e individuales, con una frontera relativamente identificable y un ambiente físico y social, un orden normativo, jerarquías, un sistema de comunicación, un sistema de incentivos y luchas de poder por el control y la dirección de la organización. Si bien no es únicamente la lucha lo que determina las dinámicas en el campo sino que también existe consenso y solidaridad entre los actores, a partir de la teoría de los campos podemos preguntarnos por los capitales económicos, culturales y simbólicos en pugna. En dichas relaciones los actores procuran alcanzar sus metas a través de "estrategias" que desde mi punto de vista son concebidas como producto del cálculo pero que están atravesadas por el habitus,

91 El único caso en los últimos tiempos fue el de Gonzalo Ireba, quien viajó al Real Sociedad de España (InferioresPlatenses.com.ar, 9 de septiembre de 2015) 
e involucran significantes colectivos y factores psicológicos individuales. Finalmente, dichas organizaciones y sus actores están en permanente transformación, no sólo por su dinámica interna sino por la necesidad de adaptarse a entornos cambiantes.

Por otra parte, y en línea con la concepción de representaciones que expusimos en el marco teórico, una organización es el resultado de valores, de una concepción de la formación, de lo que es un buen jugador y del tipo de deportistas que se consideran necesarios. Son todos elementos sedimentados y naturalizados, de modo que podríamos decir que al trabajar sobre ellos indagamos en aquello que por naturalizado "se desconoce", no se cuestiona. Por supuesto, el modo que asume una organización es también es el producto de la posibilidad: Pumas no cuenta, por ejemplo, con los mismos recursos económicos que el Pachuca, ni Estudiantes con los de Boca Juniors. Pero observaremos que las respuestas que generan para afrontar dicha "escasez" son producto de las concepciones y representaciones incorporadas, así como de las normativas que cada Federación impone.

Comencemos el abordaje por las instalaciones. Excepto la Sub 20 y la 1999, las fuerzas básicas entrenan en la "cantera oriente", un predio de 20 hectáreas en el sur de la ciudad de México que comenzó a construirse en 1995. El terreno solía ser una explotación minera a cielo abierto usufructuada durante 35 años por la Planta de Asfalto del Distrito Federal, actualmente pertenece a la UNAM y en su interior se encuentra la Reserva Ecológica del Pedregal San Ángel, de modo que se trata de un espacio con un microclima propio, un ojo de agua y cuatro lagos con profusa flora y fauna.

El ingreso al predio en la "superficie" está protegido por un muro de piedras. Un portón de metal, una puerta peatonal y un vidrio espejado impiden ver hacia adentro, y luego de golpear la puerta uno es recibido por guardias de seguridad privada. Si dan el visto bueno se puede pasar a una pequeña sala donde quienes no pertenecen a la institución deben dejar una carta de identidad a cambio de una tarjeta de visita que debe prenderse de las vestimentas. De ahí en más se debe caminar por un camino circular descendiente y atravesar un túnel de unos 300 metros hasta encontrar la cancha principal, detrás de un cartel imponente que reza "Territorio Puma" y bajo el cual hay otros guardias de seguridad que observan quién entra y quién sale. Esta forma de ingreso marca lo que en la definición mencionábamos como "frontera" y expone una primera distinción física entre los que pertenecen y no pertenecen a la organización. Puede lucir como un dato irrelevante, pero si observamos el ingreso a Estudiantes de la Plata podemos comprender su significación: allí el portón se encuentra permanentemente abierto, sólo flanqueado por un guardia de seguridad sin uniforme ni mucha capacidad de resistencia y dos vallas de 
plástico que obligan a los autos a zigzaguear y bajar la velocidad al ingresar. El campo de juego en el que los chicos entrenan está junto a la calle, sólo separada por una malla de alambre de mediana altura y púas en su tope, que dificulta pero no inhibe en absoluto ni la visibilidad ni un ingreso furtivo. Por supuesto, también les permite a los jugadores mirar hacia afuera, por ejemplo hacia una pintura en la pared de enfrente donde los aficionados escribieron "Orgullo de la ciudad" (en Anexo *9). Por otra parte, en sus 45 hectáreas también entrena el equipo profesional de fútbol y hay instalaciones de otros deportes como hockey y basquet, golf, piscinas y un restaurant. En el trabajo previo realizado con el Mg. Diego Murzi observábamos que

“...en el Country se permite la entrada de los socios del club, quienes pagan una cuota mensual para usar las instalaciones deportivas y sociales. En este sentido Estudiantes reproduce el modelo de los clubes de fútbol en Argentina, que son asociaciones civiles no solamente dedicadas al fútbol profesional sino que tienen una vida social, deportiva y asociativa importante y poseen lazos fuertes con la comunidad local (Frydenberg 2011). Por ende, si bien en su espacialidad son sitios parecidos, mientras que La Commanderie es sólo un centro deportivo de alto nivel dedicado al futbol profesional (y a su proceso de profesionalización), el Country es también un espacio de sociabilidad para la comunidad" (Murzi \& Czesli 2014: 17) ${ }^{92}$.

Una vez atravesado el túnel se encuentra la cancha principal, en la que se juegan los partidos oficiales de la Liga MX y esporádicamente entrena la Segunda División. Sobre uno de los laterales hay una tribuna para los espectadores, en el codo se encuentra el gimnasio "Renato Cesarini", sobre la cabecera los vestuarios local y visitante, las salas de utilería y de rehabilitación médica, y sobre el segundo lateral -frente a la tribuna- las oficinas administrativas y directivas. Un poco más alejados, un restaurant y una pequeña sala de cine donde se los entrenadores hacen su reunión semanal y otros encuentros como la charla de "coaching".

Detrás de las oficinas el predio continúa, pero en una segunda "terraza" ubicada 35 metros más abajo a la que se puede acceder por una escalera o mediante una rampa para automóviles. En esa segunda terraza se encuentra el campo de entrenamiento de césped natural y un segundo gimnasio denominado "Mario Velarde" en honor al ex jugador y entrenador de la institución y del seleccionado mexicano. Junto a la escalera que baja al campo existe un pequeño espacio al que denominan "el palco", un mirador (no hacia el horizonte sino hacia el campo de juego) que cuenta con dos bicicletas fijas, una mesa y dos sillas. Se trata sin ir más lejos de un espacio desde el que se puede observar el entrenamiento sin llamar la atención ${ }^{93}$.

\footnotetext{
92 Fotografías de los tres ingresos se pueden encontrar en el Anexo *10

${ }^{93}$ Fotografías del ingreso e instalaciones se pueden encontrar en el Anexo, en Anexo * 11
} 
Dado que el campo de entrenamiento es uno solo, las distintas categorías lo comparten. Si bien practican en horarios diferenciados, es común que se superpongan y deban dividir el campo por la mitad. Esto tiene dos consecuencias claras: por un lado el mal estado del terreno por exceso de uso, que incrementa el riesgo de lesiones y dificulta los trabajos de técnica con balón por tener pozos y montículos. En segundo lugar, que al compartir espacio los técnicos observan el trabajo de sus colegas, se saben observados y se incrementa la estructura de observación colectiva (volveremos sobre esto en el próximo capítulo).

Detrás de ese campo de juego se encuentra una segunda cancha de tierra donde entrenan los jugadores “a prueba" y una "jaula de definición”, inaugurada mientras realizaba mi segundo mes de trabajo de campo. La jaula es un sitio semi cerrado y con césped sintético que cuenta en un espacio reducido con dos porterías de tamaño profesional y el trazado de las áreas chicas, y que está diseñado para que los jugadores practiquen la definición a partir de poder golpear el balón a portería sin temor a que se vaya o sin perder tiempo por ir a buscarla lejos. Finalmente, ya detrás, los lagos y la reserva natural. En el exterior del predio se encuentran otros dos espacios: las canchas 5 y 8 de la Ciudad Universitaria (así se denomina al campus de la UNAM), que en ocasiones es utilizada por la Sub20, y la casa-club, el edificio en el que viven los jugadores que no pueden trasladarse a diario desde sus hogares hasta la cantera.

\subsection{Actores que constituyen la formación}

Otro de los elementos de una organización son los individuos que la constituyen, sus jerarquías y relaciones de poder. Las fuerzas básicas están estructuradas por “categorías”, que corresponden en parte a las edades de los futbolistas y en parte a las ligas en las que compiten. En cada país las categorías difieren y se organizan en función de las regulaciones de la Federación Nacional, pero existe una equivalencia que posibilita que puedan competir en campeonatos internacionales. Asimismo, si bien la Federación de cada país define su estructura general, las relaciones que se establecen al interior de cada equipo entre las categorías -y entre los cuerpos técnicos de cada una- condiciona las posibilidades de los jugadores en su camino al profesionalismo. El caso de Pumas es además sumamente interesante porque si bien existe una estructura "formal", las relaciones informales tienen un peso muy importante. El siguiente era el organigrama del fútbol en Pumas al momento de realizar el trabajo de campo: 


\section{Vicepresidente deportivo del club}

\section{Primera División}

\section{Coordinador deportivo}

\begin{tabular}{|c|c|c|c|}
\hline $\begin{array}{l}\text { Coordinación } \\
\text { académica }\end{array}$ & $\begin{array}{l}\text { Director General de } \\
\text { Fuerzas Básicas }\end{array}$ & $\begin{array}{l}\text { Coordinador de PF de } \\
\text { Fuerzas Básicas }\end{array}$ & Recursos Humanos \\
\hline \multicolumn{4}{|c|}{$\begin{array}{c}\text { Segunda División Premier } \\
\text { (Compite en Liga Premier, Segunda División, regional) }\end{array}$} \\
\hline \multicolumn{4}{|c|}{$\begin{array}{c}\text { Sub 20 } \\
\text { (Juega en la Liga MX) }\end{array}$} \\
\hline \multicolumn{4}{|c|}{$\begin{array}{c}\text { Sub17 } \\
\text { (Juega en la Liga MX) }\end{array}$} \\
\hline \multicolumn{4}{|c|}{$\begin{array}{c}\text { Pumas Tercera División } \\
\text { (Juega en Tercera División Profesional, regional) }\end{array}$} \\
\hline \multicolumn{4}{|c|}{$\begin{array}{c}1999 \\
\text { (Juega en el Torneo Premier de Fuerzas Básicas, regional) }\end{array}$} \\
\hline \multicolumn{4}{|c|}{$\begin{array}{c}\text { Sub15 } \\
\text { (Juega en la Liga MX con futbolistas nacidos en } 2000 \text { y 2001) }\end{array}$} \\
\hline \multicolumn{4}{|c|}{$\begin{array}{c}\text { Sub13 } \\
\text { (Juega en la Liga MX con futbolistas nacidos en 2002) }\end{array}$} \\
\hline \multicolumn{4}{|c|}{$\begin{array}{c}\mathbf{2 0 0 3} \\
\text { (12 años, compite en liga regional) }\end{array}$} \\
\hline \multicolumn{4}{|c|}{$\begin{array}{c}\mathbf{2 0 0 4} \\
\text { (11 años, compite en liga regional) }\end{array}$} \\
\hline
\end{tabular}

En términos formales las categorías cuentan con una estructura similar: un DT principal, un DT auxiliar y un preparador físico. Dos duplas de técnicos entrenan a cuatro categorías, dos cada una: los entrenadores de Segunda también lo hacen con los 2003 (en la 2003 el auxiliar de la Segunda es el DT), y los de Sub17 y Sub15 también intercambian roles, al menos en términos formales. Los preparadores físicos son cuatro y tienen dos categorías cada uno, hay tres entrenadores de arqueros -sólo uno tenía más de diez años en el club: los otros habían ingresado recientemente y por eso rotaban entre las distintas categorías para ir conociéndolas a todas- médicos responsables, y utileros. Excepto dos doctoras, la coordinadora académica y personal legal y administrativo, son todos varones.

Para ser entrenador es requisito haber aprobado el curso de director técnico que imparte la Federación Mexicana, y además percibo sumamente necesario haber sido futbolista porque aquí la técnica está intrínsecamente ligada a la práctica. Detalles como "retrocede con pasitos cortos y la cintura baja para poder girar más fácil si el delantero cambia la dirección" no se aprenden en libros ni 
en escuelas de fútbol sino en la práctica extendida en el tiempo. Sucede lo mismo con la capacidad para diagnosticar con velocidad si fue o no un buen control orientado de balón, si el golpeo fue con la parte del pie adecuada o si algo en la postura falló ("pon el piecito abajo y vas a ver cómo se levanta"), así como generar hipótesis sobre el buen o mal funcionamiento del equipo en un match. Se trata, entonces, de un conocimiento antes que nada empírico, de tener desarrollada la capacidad de observación. Por supuesto, eso no necesariamente los convierte en grandes estrategas, comunicadores o generadores de grupos, pero en la etapa formativa la observación y el conocimiento de la experiencia marcan una diferencia importante.

Los preparadores físicos $(\mathrm{PF})$, por su parte, deben poseer estudios universitarios y piensan a los futbolistas a partir de su motricidad y el "biotipo", observan la evolución de los indicadores de rendimiento de los jugadores y ponen en práctica una planificación en busca de promover un tipo de cuerpos específicos. En Pumas, el PF dijo que "en los papeles" buscan desarrollar la coordinación motriz, brindarles "fortaleza física" y, de ser posible, incorporar jugadores de más de 1,80 metros de altura para que puedan jugar en "la elite". Las polémicas entre los PF podrían ser eje de otro trabajo (y de hecho, lo son al interior del campo de la preparación física), pero en líneas generales podemos mencionar que actualmente se enfrentan dos modelos: uno "tradicional" que hace hincapié en desarrollar un trabajo físico intenso sin balón y que trabaja la técnica de manera compartimentada y en situación controlada -por ejemplo: realizar pases lineales hombre a hombre durante un tiempo determinado, o enviar un centro sin marca- y el "método español”, que adquirió legitimidad a partir del campeonato mundial conquistado por dicha selección en 2010, y que consiste en un entrenamiento físico con balón, prácticas de tiempo reducido y, sobre todo, la idea de que no tiene sentido realizar una práctica en situación controlada porque las condiciones de partido generan numerosos condicionamientos $^{94}$.

Mientras en Estudiantes de la Plata el coordinador de preparadores físicos Leandro de Rose está implementando el método español, en Pumas el preparador argentino Ariel González es un férreo crítico: le atribuye una merma en el rendimiento, un incremento en las lesiones y ser un conocimiento foráneo que no tiene efectos positivos en una geografía diversa como la mexicana, que obliga a los

94 A modo de ejemplo, desde esta concepción no tiene sentido practicar la carrera con balón dominado porque en un match no hay jugador que no corra con el balón sin algún defensor que lo ataca por alguno de sus laterales, que lo persigue o que lo espera de frente. Todos estos elementos le agregarían a quien corre distintos condicionantes que afectan su dominio de balón. 
futbolistas a desempeñarse en climas y altitudes completamente disímiles ${ }^{95}$. Pese a la diferencia entre el conocimiento empírico y el universitario, en Pumas no encontré un distanciamiento entre ambos grupos que fuera producto de su base de legitimación, algo que sí observé en Estudiantes de la Plata entre aquellos integrantes del equipo de preparadores físicos que se presentaban como renovadores a partir de las nuevas concepciones difundidas en espacios académicos y aquellos que -más grandes en edad- se sostenían sobre modos de entrenamiento tradicional. Técnicos y preparadores físicos, entonces, forman una suerte de grupo de poder que busca estar aliado para generar el mejor resultado de su equipo y sobre todo defenderse de las opiniones ajenas.

Además de los entrenadores están los médicos -que por trabajar en distintas categorías están menos ligados a cada plantel- y los utileros. Estos últimos son los encargados de todos los elementos materiales que implica el entrenamiento y de reunir todos los insumos cuando el equipo juega de visitante (balones, conos, pecheras, pizarra, el desayuno cuando los futbolistas deben hacerlo en el vehículo que los traslada, indumentaria, líquido para la hidratación de los jugadores) pero su rol -al menos el de algunos que conocí- también es importante porque circulan rumores: llevan y traen información, escuchan, ironizan y desprecian de manera solapada a los detractores del cuerpo técnico con el que trabajan.

Respecto de la organización de la cantera, a simple vista la estructura parece lineal y vertical y los jugadores se organizarían por edades, aunque en la práctica esto no es necesariamente así. Asimismo, si bien existen lineamientos generales desde la coordinación técnica actual para el desarrollo de cada equipo, en Pumas cada DT se maneja con autonomía en su categoría ${ }^{96}$. Y aunque los técnicos no se "reportan" unos a otros tienen más status a medida que se encuentran más cerca de la Primera División, de modo que las aspiraciones de casi todos ellos consisten en ir ascendiendo en el escalafón hasta tener,

95“Todo con pelota, como rezan los cánones áureos del fútbol español, del cual somos tan fieles seguidores en México, ha producido dos fenómenos singulares: - empeoró el rendimiento físico de los equipos con respecto a los equipos que corrían la cancha hace algunos años y, - técnicamente -si mis ojos no me engañan-, no se nota una diferencia sustancial. Por otra parte, los sistemas de entrenamiento como el core training y el entrenamiento funcional -que están tan de moda entre toda la población, y en nuestro medio futbolístico han tomado parte del exiguo tiempo de entrenamiento físico general, han provocado que se diluya la carga de entrenamiento en un sinfín de ejercicios intrascendentes, lo que sin lugar a dudas ha repercutido en el rendimiento de los jugadores. (...) México es México, y con esto quiero decir, un país con una población con características diferentes a las europeas, que entrena y juega en condiciones muy diferentes a las del viejo continente, con un fútbol que históricamente tampoco tiene mucho que ver con ese que pretenden vendernos. En síntesis, debemos retomar lo nuestro, lo que nos da seguridad y nos permite jugar el fútbol que nosotros 'podemos' jugar y nos hace altamente competitivos. Ese fútbol tiene que ver con lo que se juega en los llanos, con lo que sienten nuestros muchachos y los millones de mexicanos que los siguen" (González 2015).

96 Sucedía lo mismo en el Olympique de Marsella, pero no en Estudiantes de la Plata. Allí Hermes Desio, el coordinador general de fuerzas básicas, generaba directrices para todas las categorías, se hacía presente en las prácticas, hablaba con los jugadores e incluso, al finalizar un encuentro, los reprendió en presencia del cuerpo técnico, que había sido más benevolente en su evaluación del match. 
incluso, la posibilidad de llegar al primer equipo. Es válido destacar además que desde las categorías más jóvenes hasta la Sub15 se considera que el énfasis formativo es el más importante, mientras que desde Sub17 en adelante la practica comienza a ser de "alto rendimiento". Esto está ligado no sólo a que a esa edad cada jugador comienza a exponer con más claridad sus condiciones para devenir profesionales, sino que también -y por su etapa madurativa- comienzan a realizar ejercicios tácticos y estratégicos más complejos.

Entonces, ¿qué posibilita que un entrenador tome una de las categorías de fuerzas básicas? En primer lugar existe una tradición de incorporar técnicos pertenecientes a la institución: al menos seis integrantes de los cuerpos técnicos y la coordinación del fútbol fueron futbolistas profesionales de Pumas, a los que se puede agregar otros dos que pertenecieron a la cantera, no lograron consolidarse como profesionales y con poco más de veinte años comenzaron a desarrollarse como entrenadores dentro del club. Un segundo elemento está ligado a la capacidad de generar victorias, un elemento que sin dudas los legitima. A modo de ejemplo, durante la realización de la etnografía la Sub17 tuvo un mal campeonato que derivó en una pobre relación entre entrenadores y jugadores y esto, en la salida del DT

del equipo (que pasó primero a la 1999 y luego a la Tercera). En paralelo, el entrenador de Sub15 tuvo un muy buen campeonato, que no se capitalizó en un ascenso pero sí en las relaciones que se establecían entre los técnicos: nadie podía decirle nada ni otros entrenadores hacían comentarios "por atrás" sobre el juego de su equipo.

Pero existe un tercer elemento que determina que un entrenador acceda o no a una categoría: las afinidades personales y las "alianzas" entre los entrenadores. A continuación profundizaremos sobre este tema.

\subsection{La organización real y la pelea política}

Para comprender cómo funciona verdaderamente la cantera y en qué contexto se enmarca el camino al profesionalismo de los futbolistas es preciso hacer un poco de historia, un dato que también expone que una organización no sólo se rige en función de sus metas sino a partir de representaciones que vienen del pasado. Al momento de realizar nuestro estudio el Director Técnico del primer equipo era Guillermo Vázquez Herrera, hijo de Guillermo “el arquitecto” Vázquez Mejía, una figura 
emblemática de Pumas y del fútbol mexicano ${ }^{97}$. Vázquez Mejía fue Director de Fuerzas Básicas de Pumas hasta agosto de 2014, cuando se postuló a su hijo como DT del primer equipo y el entrante Presidente del Patronato, "el ingeniero" Jorge Borja Navarrete, puso como condición que Vázquez Mejía declinara su cargo. Según información periodística (LosPumasUnam.com 2014), entre los candidatos a suceder a Vázquez (padre) se encontraban Luis Alberto "Pato" Baeza"98 y Sergio Bernal"99. Sin embargo, el elegido para ocupar dicha posición fue José Luis Arce, conocido como “el doctor” por su profesión de odontólogo, y quien si bien había formado parte de la cantera Puma entre 1984 y 1994 venía de coordinar las fuerzas básicas del Club América, histórico adversario de Pumas en el "clásico capitalino" (a nivel nacional la rivalidad más importante es entre el Club Deportivo Guadalajara y el América).

Arce fue promovido por el Patronato y aparentemente con el acuerdo de Vázquez Mejía, pero al poco tiempo nació un antagonismo entre ambos. En paralelo, José Luis "Pato" Baeza asumió como Coordinador Deportivo de Pumas bajo la órbita de Memo Vázquez (h), comenzó a trabajar junto a la Primera División y entre sus roles pasó a encargarse de observar a los jugadores de fuerzas básicas con el objetivo de reclutarlos para la Primera División. Era, de alguna manera, el enlace entre la escuadra profesional y las fuerzas básicas, y a partir de dicha tarea coordinaba la tarea de los cuerpos técnicos de las categorías Sub20, Segunda y Sub17.

Mientras tanto, Vázquez Herrera comenzó su tarea como entrenador del primer equipo. Se trató de su segunda incursión en la dirección técnica de Pumas, ya que la primera se había producido entre 2006 y 2010 -como auxiliar técnico de Ricardo Ferreti- y desde 2010 ya como entrenador en reemplazo del Ferreti. En su segunda campaña consiguió el campeonato, el séptimo título de la institución. Pero desde ahí sus resultados empeoraron, lo que generó que tras el torneo Clausura 2012 renunciara a la dirección técnica del equipo. En agosto de 2014 regresó al banquillo universitario y logró llevar el equipo a cuartos de final., luego tuvo bajón futbolístico en el Torneo Clausura 2015 que puso en riesgo la permanencia del equipo en Primera División y en el Apertura 2015 fue líder durante la liguilla y

$97 \mathrm{Su}$ éxito deportivo consiste en que como jugador logró el ascenso a la Primera División en 1962 y luego fue auxiliar de Miguel Mejía Barón en el cuerpo técnico Nacional que logró el subcampeonato en la Copa América y el campeonato de la Copa de Oro en 1993, tras derrotar a Estados Unidos por 4 a 0 en el Estadio Azteca. Dicho cuerpo técnico, además, alcanzó los octavos de final en el Mundial de 1994 tras perder por penales frente a Bulgaria.

98 Ex-futbolista de Pumas e hijo de Alberto "Pato" Baeza, ídolo del Necaxa que en 1961 le ganó al Santos de Pelé. Además de su cargo actual en Pumas, Luis Alberto es propietario y director deportivo del equipo Pato Baeza F.C. que milita en tercera división y organizador de la Copa Pato Baeza, ambas en honor a su padre.

99 Se trata de un ex portero de Pumas entre 1988 y 1997, de modo que fue compañero de equipo de Vázquez Herrera y de David Patiño. 
llegó a la final, que perdió por penales ante el club Tigres de Nuevo León. Todo este recorrido nos permite observar que "Memo" Vázquez Herrera estaba legitimado como entrenador por haber hecho méritos al frente del equipo, por haber sido un jugador identificado con el club y por ser hijo de una figura emblemática del fútbol mexicano y "universitario".

Al seleccionar a José Luis Arce como coordinador de la cantera, considero que el Patronato buscó reducir la hegemonía de Memo Vázquez sobre la estructura futbolística, y promover más jugadores de cantera como producto de los serios problemas financieros en los que se encontraba la institución. Para establecer su base de poder, Arce incorporó personal: dos acompañantes de su confianza, un nuevo Jefe para el cuerpo de médicos (que a su vez renovó el plantel en el área) y dos colaboradores más jóvenes y con menos peso propio.

Como resultado, la cantera estaba partida y con dos líderes, Baeza y Arce, y lo dicho hasta aquí permite comprender con qué capitales contaba cada uno para definir su posición en el campo al interior de la organización. Los técnicos de las categorías Sub20 y Segunda se alinearon junto a Baeza y se desentendieron de algunas indicaciones y propuestas de Arce (o las efectuaron con resistencias), mientras que el cuerpo técnico de la Sub17 (con el que se realizó este trabajo) se vio en conflicto, ya que recibía indicaciones por parte de Baeza y al mismo tiempo tenía como auxiliar a la mano derecha de Arce. La Tercera y la 1999 contaban con personal ligado a Arce, y en Sub15 y las categorías menores se alinearon sin mayor dificultad. Es aquí donde se hace relevante que sus buenos resultados lo hicieron "intocable".

Ahora bien, después de todo: ¿qué se disputaba en el conflicto? Desde mi punto de vista se trataba centralmente de poder, de mantener una posición de status simbólico -dirigir una categoría importante de un club de prestigio- y beneficios asociados como que el club es una plataforma permanente para ser considerado en otras instituciones, quizás de menor importancia pero de mayor poder adquisitivo ${ }^{100}$. Dicha disputa se materializaba en pugnas como la estrategia de promoción de jugadores o concepciones sobre cuáles eran los más destacados (es decir que se disputaba por el capital “entrenador más destacado”). Sin embargo, una persona me dijo que también se trataba de dinero, y sobre el siguiente testimonio debo mencionar tres cosas: primero, que es un dato chequeado pero no confirmado fehacientemente. Lo que a continuación se manifiesta es verídico porque otras dos

100 Dos entrenadores me comentaron en una ocasión que en otros clubes podrían cobrar el doble, aunque en una conversación informal en la tribuna escuché a un visor de otro equipo indicar que en aquel club se cobraba un 25 por ciento más por mes pero sólo 10 meses al año y sin seguros sociales, mientras que en Pumas se cobra los doce meses y con seguros sociales agregados. 
personas $^{101}$ también lo mencionaron superficialmente, pero no tengo información irrefutable. En segundo lugar, que por tratarse de información no totalmente confirmada creo que debe ser considerada como dato indicador, como posibilidad, pero no como acontecimiento. Y tercero, que quien lo expresó no fue ninguno de los actores con los que trabajé a diario, y esto lo aclaro porque como mi trabajo fue con dos categorías, las sospechas podrían recalar en un pequeño número de personas con las que establecí un lazo de confianza y así ponerse en riesgo sus fuentes de trabajo. El dialogo aproximado fue el siguiente ${ }^{102}$ :

- ¿Por qué se produce la disputa?

- Por poder y por dinero.

- ¿Pero tanta diferencia hay en lo que cobran según categorías? [Yo imaginaba que a medida que ascendían en categorías aumentaba la escala salarial, y que se pugnaba por eso].

- No, pero cuando logras una posición de poder en la 17 o en la 15 se te acerca mucha gente que te dice 'pon a mi hijo a jugar', y a cambio del registro cobran 80 mil pesos. Entonces, y como ellos están encargados del registro, te registran y te cobran por entrenar ahí.

- ¿En serio pasa eso?

- Sí, en todos lados y acá también. Antes pasaba de manera más sutil y ahora es mucho más explícito.

- ¿Los chicos están al tanto de todo esto?

- Sí, fíjate en la Segunda: juega el hijo de [menciona a una figura de prestigio en el club].

- Bueno, pero no hay chance de que ese chico llegue a Primera, tiene por lo menos 10 kilos de más.

- Estás en México, todo es posible. ¿Crees que no? No es tan loco.

El conflicto duró más de seis meses, en marzo de 2016 continuaba aunque con algunos cambios en la jerarquía entre los entrenadores y en mayo hubo nuevas transformaciones cuando Borja Navarrete dejó de ser el presidente del Patronato y a partir de ahí se produjeron cambios en el cuerpo técnico del primer equipo, José Luis Arce fue promovido a vicepresidente deportivo del club y Sergio Egea fue incorporado como director de Fuerzas Básicas. Antes de este último cambio se había consolidado la partición de la cantera: Baeza tenía influencia hasta Sub17 mientras que de Tercera hacia abajo las decisiones recaían sobre Arce.

En la cotidianidad esta cuestión se traducía en una relación de cooperación y cordialidad profesional entre los técnicos, comentarios "a espaldas" y pocas críticas o sugerencias entre sí porque sentían que había "mucha susceptibilidad". Esto significa que los técnicos afrontaban conflictos menores entre sí o incluso el deseo de realizar sugerencias técnicas para mejorar un ejercicio de manera sumamente cautelosa por el temor a ofender al técnico al que se le hacía el comentario. Entre los

101 Una de ellas se lo mencionó a un tercero y yo lo escuché, alejado; en el segundo caso, en una conversación con un integrante del staff lo comenté dándolo por sentado, y la persona lo asumió y dijo "ni me recuerdes, ya sabes el desmadre que se armó".

102 El diálogo es aproximado porque no fue grabado. El método utilizado consistió en realizar una grabación propia con todas las ideas de la jornada apenas salí de la institución. 
técnicos compiten aunque tengan que colaborar, observan los ejercicios que hace uno y otro, los resultados de cada equipo y las actitudes que cada uno de ellos tiene respecto de sus jugadores.

Si pensamos estas dinámicas a partir de la definición de campo podemos pensar que el capital por el que pugnaban los entrenadores y coordinadores era el de entrenador/coordinador exitoso, y que ese capital entre los entrenadores se sostiene primero a partir de los resultados de su equipo, y en segundo término a partir de qué tanto logran instalar sus explicaciones sobre el mal rendimiento -en aquellos casos en que los resultados no aparecen.

Ahora bien, el tipo de alianzas que desarrollaron (el hecho de que las principales categorías se alinearan bajo la órbita de la Primera), los recursos que utilizaban para intentar socavar el poder del adversario (el rumor, hablar a espaldas, los valores que ponían en escena sobre lo que debía ser y no ser una "coordinación"), todo eso formaba parte de lo que los distintos actores especulaban que debía ser dicho a partir de las relaciones de poder que observaban y dicha especulación, creo yo, del conocimiento "nativo". ¿Podemos preguntarnos si esta informalidad está ligada con alcanzar sus metas, para pensar la cuestión a partir de la corriente institucionalista estadounidense? En parte, si pensamos que este reacomodamiento tenía como objetivo asegurar su puesto laboral y a lo sumo lograr una mejor posición una vez que el conflicto se resolviera a favor de una u otra parte ${ }^{103}$. Desde ese punto de vista, la ubicación de cada uno era también una apuesta en función de un resultado probable, aunque los modos en que se daba el conflicto involucraba numerosas cuestiones simbólicas (lo que se supone que debe ser un entrenador, un coordinador de cantera, etc.), significaciones que se sostenían sobre la imágenes tradicionales del club, significaciones ligadas a conocimientos académicos sobre el entrenamiento... Quizás esa pugna no fuera producto del habitus de los actores pero sin dudas se apoyaba sobre sus experiencias y sus pasados en la profesión, muchos de ellos sedimentados.

En ese contexto ¿qué lugar ocupaba yo como investigador? Mi ingreso fue a través de José Luis Arce, a quien contacté por ser coordinador de fuerzas básicas. Si bien me esforcé en dialogar con todos los actores por igual (y en que se notara que lo hacía), eso suscitó que mi perfil al interior del club estuviera asociada a su "parcialidad" y en consecuencia que algunas personas desconfiaran de mi persona. Por otra parte, en una situación como la descripta todos los actores regularon sus testimonios, en algunos casos respondieron de manera cortés pero superficial o se alejaron de mi persona para

\footnotetext{
${ }^{103}$ Si bien había culminado mi etnografía cuando en mayo de 2016 el Patronato cambió de presidente y se reacomodaron las piezas, observé que se beneficiaron actores que se habían opuesto al grupo vencedor. Habría que ver entonces si los antagonismos eran tan tajantes o si frente al cambio se reactivaron otras negociaciones.
} 
referirse a algunos temas, lo que generó alguna dificultad para profundizar en algunos aspectos e indagar en $\operatorname{otros}^{104}$.

Ahora bien, el relato de esta organización "informal" no es meramente descriptivo. Si nos interesa es sin dudas porque observamos que tiene consecuencias directas sobre la formación de los jugadores. Hacia allí nos dirigimos, pero para comprender cabalmente la situación es necesario dar un rodeo, explicar otros elementos centrales a la estructura formativa.

\section{5 "Todos tenemos un muerto en el closet"}

Contar con fuerzas básicas y que sus planteles participen en las ligas oficiales es un requisito que impone la Federación Mexicana a los equipos de Primera División. Si bien Pumas es un club tradicionalmente conocido por haber promovido algunos de los mejores futbolistas de la historia mexicana, el pasado reciente expresa lo contrario. Algunos integrantes del Centro deslizaron que en la compra y venta de jugadores se hacen numerosos negocios, y que ese es el motivo por el cual el modelo de equipo profesional estuvo más ligado a incorporar jugadores ya consolidados en Primera que a desarrollar un sistema de visorías y reclutamiento, formar jugadores a lo largo de ocho o nueve años y en el mejor de los casos exportarlos. Los datos indican que la plantilla 2016 del equipo profesional cuenta con diez jugadores extranjeros, y según un artículo del portal mediotiempo.com, de los jugadores registrados en el primer equipo nada menos que 17 salieron de las fuerzas básicas, aunque sólo ocho han sido tomados en cuenta para algunos partidos de la Liga y apenas cinco "tienen actividad constante en el 11 titular de Memo Vázquez” (Ibarra, 14 de septiembre de 2015). Además, vale destacar que según dicho medio ninguno de esos cinco debutó con Vázquez: el más reciente es de 2012, lo que da la pauta de que ningún jugador de cantera logró consolidarse en el equipo titular en los

\footnotetext{
${ }^{104}$ En el trabajo de campo encontré una tercera instancia de la relación entre los técnicos, y muy curiosa por cierto porque dejaba afuera la competitividad y las parcialidades. Se trata de la "compra" de gorras, un hecho que no fue aislado sino que se hizo presente de manera continua al menos entre julio de 2015 y febrero de 2016 . El hermano de uno de los técnicos trabajaba en una imprenta de calcomanías y afines. Entre ellas tenía unas con el logo de Pumas, y el técnico del club (que, dicho sea de paso, presenta una calvicie avanzada), como hobby se había impreso una estampa sobre una gorra para sí mismo. Cuando la llevó al club muchos otros técnicos, preparadores físicos, médicos e integrantes se interesaron y comenzaron a pedirle que hiciera más, primero para ellos, luego para familiares, finalmente para conocidos y allegados... En un momento todos pedían por cantidad, nadie quería quedarse sin la suya y, literalmente, nunca alcanzaban. Pregunté reiteradas veces a qué se debía tal interés y la respuesta más concreta fue que se trata de un objeto muy útil para el trabajo bajo el sol, que normalmente son muy caras y que éstas no sólo costaban 50 pesos sino que lucían muy bien. Los técnicos hablaban de combinaciones de colores de tela y de estampas, pensaban nuevos diseños y agregado de detalles... El técnico "productor", que en un comienzo las hizo casi por compromiso, pronto comenzó a preocuparse de que la noticia llegara al patrocinador. Otro técnico justificó: "Bueno, pero ellos deberían mandarnos ropa y no nos mandan". La historia continuaba hasta mi última visita al club. Y si bien no percibo aquí algún tipo de communitas -tampoco que haya afectado la formación de los jugadores- sin dudas se trató de un intercambio extendido en el tiempo en el que todas las diferencias y enemistades quedaron en suspenso.
} 
últimos 3 años $^{105}$. En paralelo, se debe reconocer que la cantera Puma continúa vigente y con nivel competitivo, al punto de que la Segunda División Premier fue campeona del torneo Clausura 2016.

Un centro de formación de futbolistas profesionales tiene dos etapas centrales: la selección de jugadores y su formación ${ }^{106}$. Los tres equipos observados tienen estructuras de selección diferente, y en todos los casos están atravesados por representaciones sobre el fútbol. Pumas no cuenta con "visores" personal destinado a recorrer el país, observar jugadores y reclutarlos para que vayan a jugar al clubpero sí con numerosas filiales distribuidas en todo el país. Estas son escuelas de fútbol con reconocimiento oficial que les cobran a los niños por formarlos, a menos que desde temprana edad expongan mucho talento. Un técnico, no obstante, mencionó que es muy difícil que de esas escuelas surja algún jugador con verdaderas condiciones.

Todos coinciden en que hoy Pumas está lejos de reclutar a los mejores jugadores, sostienen una y otra vez que "hacen lo mejor que pueden con lo que les llega", que "eligen lo menos peor de lo que dejan otros", y que eso está ligado a la inversión que realizan otros equipos en "barrer" el país para reclutar jugadores. Incluso tuvieron la mala experiencia de reclutar a un jugador que verdaderamente hacía diferencia, y al mismo tiempo que iniciaron los tramites de registro el club Pachuca lo buscó, le ofreció casa-club y 12 mil pesos de salario al jugador, y así se los quitó. "Una cosa es competir con los grandes equipos y otra cosa es hacer que compites. Y para competir realmente es necesario invertir en reclutamiento", expresó el coordinador José Luis Arce en una ocasión.

En consecuencia, el fuerte de Pumas son las "pruebas" que realizan en el predio mismo de la cantera, en un campo de juego de tierra. Todos los lunes y martes la oficina administrativa recibe solicitudes de niños que desean probarse en las tres convocatorias anuales. Reciben cincuenta por día, de modo que son 400 chicos por mes y unos 4800 por año. Además de esas fechas abiertas a todo aquel que esté interesado, el club permanentemente recibe y prueba jugadores acercados por personas allegadas.

Los jugadores a prueba en general deben concurrir al club una o dos veces por semana a lo largo de un promedio de dos a tres meses, pero ha habido casos de jugadores que estuvieron seis meses o

\footnotetext{
${ }^{105}$ Expresa el artículo: "De esa quinteta de jugadores, Josecarlos Van Rankin es el futbolista que menos años lleva en la institución, pues debutó el 18 de marzo del 2012. El resto de los elementos -con la excepción de Kevin Escamilla (2012)debutaron previo a la fecha citada: Alejandro Palacios en 2003, Luis Fuentes, Javier Cortés y David Cabrera en 2008, Alfredo Saldívar en 2010 y Eduardo Herrera en 2011" (Ibarra, 14 de septiembre de 2015).

106 Vale aclarar: la selección no es un requisito sino que es producto de que pese a todo en Pumas se aspira a generar jugadores profesionales, pero otras instituciones, por ejemplo, decidieron dejar de reclutar y comenzaron a cobrar a los jugadores por pertenecer a la cantera y ser formados en ella. En estos casos pueden continuar compitiendo en los torneos oficiales -con peores resultados- pero dejan de promover canteranos.
} 
incluso más sin una definición sobre su rendimiento ${ }^{107}$. La selección es ardua y extensa: en la categoría Sub17 a comienzos de 2015 se presentaron entre 250 y 300 jugadores, de los que después de tres meses quedaron cinco. Esos cinco junto a otros dos -acercados por directivos- pasaron otros dos meses entrenando a diario junto al equipo de Sub17, hasta que se decidió registrarlos a todos y recién ahí recibieron la indumentaria oficial y el salario de 2400 pesos mensuales. Hasta esa fecha debían ir vestidos íntegramente de blanco y costearse los gastos: en uno de los casos uno de los chicos viajaba desde Pachuca a diario y otros se pagaban un hotel. En enero de 2016, cuatro meses después de finalizada la etnografía, visité al plantel y ninguno de los cinco había conseguido ser titular en Sub17, tampoco estaban consolidados en ese plantel sino que se entrenaban con la Tercera y a uno lo habían expulsado, presuntamente por haber robado en la casa-club. Uno de los dos que había arribado a través de un directivo era suplente en el equipo de Sub17, el otro entrenaba alternativamente con Tercera o con la 1999. En abril del mismo año, 4 de los 5 a prueba habían sido separados del equipo. En ese momento la gerente de Recursos Humanos me dijo: "si nos pensamos como empresa, nuestro índice de rotación es muy muy alto".

La elección de jugadores se realiza sobre la base de valores o conceptos legitimados socialmente, hay algunas pautas consensuadas sobre el tipo de jugador que se busca y luego una elección que cada técnico presenta como individual. No es sencillo profundizar en esos valores porque implica sistematizar no sólo los discursos sino la observación de lo que luego realizan en la práctica, que está atravesada por la intuición y la consideración de detalles difícilmente verbalizables. La técnica es central e incluso Baeza en una reunión de técnicos así propuso la planificación a futuro:

Ahorita tenemos 12 jugadores de plazo inmediato, plazo corto. En el mediano plazo es la 17 y en el largo plazo, la 15. Para que ahí empecemos, que los chicos corran, luchen, que tengan una buena calidad, que ahorita nos guiemos mucho por la calidad que tengan los jugadores. La calidad técnica. Si les tenemos que enseñar técnica a los de 20 años perdemos el tiempo. Entonces esas dos categorías son super importantes. Ése va a ser nuestro semillero, para que no suframos que no tenemos jugadores y haya que buscar otra vez.

La condición física es siempre observada, pero en general no es determinante porque se puede desarrollar. Importa más la estatura que tienen o que pueden llegar a tener, porque para algunos puestos

107 Un técnico me comentó que pasan "a prueba" mucho tiempo por los "compromisos" de los directivos con el Patronato o con otros actores de poder, entonces puede suceder que el jugador no tenga nivel para competir por un lugar en el plantel pero que no les convenga dejarlo afuera. El técnico mencionaba que había hecho el informe en el que explicaba los motivos por los que recomendaba no incorporarlo (en todos los casos se realiza), pero que como el jugador al que se refería había llegado por "el Rector", cuando al rector le comentaron el informe su mensaje fue "ténganlo más tiempo". El joven pasó así un año, hasta que nuevamente hubo que hacer el informe y allí se repitió que "no le alcanza para ser incorporado". Entonces un tercero se quejó: por qué estuvo tanto tiempo si finalmente no quedó. 
como la defensa central la concepción actual y el mercado internacional especifican que necesita altura, porte, y si el jugador carece de eso difícilmente pueda ser transferido. Entonces si defiende bien pero es bajo en estatura deberá ser veloz para jugar por los laterales o se lo probará como "contención”, es decir como un mediocampista defensivo por el centro. Los entrenadores de porteros saben que si mide menos de 1,85 difícilmente puede aspirar a las ligas europeas o a la Selección ${ }^{108}$. Tampoco es lo mismo si quien observa fue defensor, volante o delantero en su carrera como jugador: "uno siempre busca jugadores parecidos a uno", admitió un entrenador ${ }^{109}$.

De una manera u otra, lo que aquí es relevante es que la observación es absolutamente central a la cantera, que es el resultado de procesos colectivos pero que esos procesos se ponen en práctica a través de la subjetividad de los técnicos. Un entrenador que observa a los niños de entre 10 y 12 años que se encuentran a prueba me comentó que lo que observaba era que sus movimientos fueran "fluidos", que al recibir el balón o golpearlo hubiera una continuidad y su cuerpo no hiciera el movimiento de manera rígida. Entonces, si bien la fluidez del jugador es una representación socialmente legitimada (por eso no sentía vergüenza al decirlo), cuándo un jugador representa esa fluidez es algo que sólo el entrenador que lo mencionó puede poner en práctica y que cualquier otro entrenador materializaría de distinta manera. Es este uno de los espacios donde se justifica el trabajo teórico que hicimos sobre las representaciones y afirmamos que son sociales y no individuales: la percepción es resultado de esas relaciones, los técnicos no arman su equipo de manera independiente y a partir de su propia concepción del juego sino que toda la estructura condiciona su accionar.

La selección no se trata exclusivamente del reclutamiento de jugadores sino que existe una clasificación permanente para buscar aquellos que mejor se desempeñan. Hay fechas donde las elecciones se tornan tajantes: al final de cada campeonato los planteles desestiman aquellos jugadores que no estuvieron a la altura de las exigencias y que, se estima, en el futuro no podrán alcanzar el nivel necesario.

108 Estas representaciones influyen aunque Jorge Campos, uno de los porteros más importantes de la selección mexicana, midiera tan sólo 1,70 metros, o que el considerado mejor lateral izquierdo de la historia, el brasileño Roberto Carlos, contara con una altura de 1,68 .

109 De los tres equipos analizados, el Olympique de Marsella es el único que además de observar las condiciones del jugador dice estudiar el contexto social del cual proviene: "Nosotros cuando hacemos entrar a un jugador al CdF tenemos un doble o triple proyecto: esta la parte deportiva, la escolar y lo social también, porque nosotros formamos hombres también ¿eh? No es solo el futbolista, si bien el futbolista es lo más importante hay que tener en cuenta también la escolaridad y el lado social también. Porque los padres nos dejan a sus hijos así que nosotros reemplazamos, de alguna manera a los padres, por lo que tenemos que transmitirles valores. Y está la parte escolar, ya que son muy pocos los jugadores que pasan por el CdF que llegan a ser profesionales". (Testimonio de Paul Ruiz en entrevista con Diego Murzi) 
Pero, nuevamente, la selección implica observar y ponderar detalles: de un muy buen defensor pero con baja estatura dos técnicos discrepaban: uno creía que no iba a crecer en altura y que había que hacerlo jugar por el lateral; el otro, que era más competitivo y con mejor técnica que los centrales y que en consecuencia había que ubicarlo ahí. Otro debate era entre dos defensores: uno con mucha técnica pero "poco corazón" (poca motivación natural por competir) y el otro con menos técnica pero con mucho más temperamento, y nuevamente los técnicos discrepaban sobre quién debía ser el titular. Además, al segundo, por su poca técnica sus compañeros no lo respetaban y no seguían sus indicaciones para ordenar la línea defensiva. De un lateral con mucha capacidad técnica se criticaba que jugaba "para la tribuna", que hacía más lujos que los adecuados y que se desordenaba con facilidad; claro que los hacía dudar cuando enviaba centros con mucha calidad o sacaba remates dirigidos al ángulo; de un delantero central se debatía si por su bajo porte convenía ubicarlo por las bandas; dos jugadores que a la vista impresionaban por sus gambetas también hacían dudar por su dificultad para concretar jugadas, para darles claridad a los movimientos del equipo. En términos de representaciones, acá vemos con mucha claridad que la idea de qué es un buen jugador es un espacio de lucha entre distintos actores y de cada uno de los entrenadores con las ideas legitimadas. Entonces, a menos que el jugador marque una diferencia sustancial respecto de sus compañeros y de los rivales, estará bajo la vara de la observación y la pugna entre distintas miradas.

Se podría decir incluso que el éxito de un centro de formación depende antes que nada de la capacidad de sus observadores de seleccionar a los jugadores más adecuados para su proyecto deportivo. Por eso en Estudiantes dijeron que "todos tenemos un muerto en el placard [closet]": todo entrenador, toda cantera, en algún momento de su trayectoria dejó "libre" o desestimó un jugador que luego otro club supo observar, potenciar sus capacidades y vender por una suma millonaria.

Para evitar volver a perder un jugador, en Estudiantes de la Plata intentaron sistematizar la selección de futbolistas. Idearon un esquema que consistía en describir todas las características de los jugadores, técnicas y las ligadas a la personalidad, de la manera más pormenorizada posible ${ }^{110}$. Al momento de reducir el plantel, los dos técnicos de cada categoría -DT y auxiliar- debían calificar por separado a todos los jugadores y en todos los aspectos, de 1 a 5 puntos. Luego se reunían con el coordinador de la cantera (de quien decíamos que pasa mucho tiempo observando a todas las categorías), y analizaban caso por caso. No comparaban calificación contra calificación sino que

110 Algunas de ellas eran pase con pierna izquierda y derecha, remate, cabezazo, capacidad defensiva, visión de campo y capacidad de autosuperación. 
realizaban un análisis en función de la posición que el jugador ocupa en el equipo o desean que ocupe. Entonces, un volante central con buena técnica pero sin "orden" o "visión de campo" difícilmente pueda desarrollarse en esa posición: o se lo cambia de ubicación en el campo de juego o se prescinde de él. El método procura reducir el margen de subjetividad de decisiones que pueden costar millones, darle cierto sostén a la observación e incrementar la transparencia hacia el interior del club.

Ahora bien, permítaseme un párrafo para dirigirme a los entrenadores y coordinadores. Lo primero: que si dejaron pasar a un jugador no fue por una falta de capacidad de observación individual, porque deben saber que su manera de observar estaba atravesada por una (varias) miradas ajenas, un contexto social "superior" en términos de relaciones de poder que les decía que ese jugador no valía la pena, que era mejor fijarse en otros. Por eso el método propuesto en Estudiantes tampoco va a evitar que cometan errores, porque aunque los entrenadores califiquen y clasifiquen a los futbolistas por su cuenta y sin tomar conocimiento de la mirada del otro técnico, ambos están condicionados por lo que saben o intuyen que otros piensan de ese jugador. Nunca va a haber grandes discrepancias entre ellos por el miedo de quedar como tontos ante sus pares si califican con 5 puntos a un jugador que el contexto social calificaría con un 1 o un 2, porque si eso sucediera se deslegitimarían como entrenadores. Si lo hicieran se pondrían en riesgo: comprometen su carrera a cambio de darle espacio a un jugador del que tampoco están del todo seguros (porque nadie escapa a la mirada social).

Mi propuesta para que los clubes eviten dejar pasar a un jugador valioso es el camino opuesto: sugiero no generar mecanismos que reduzcan la multiplicidad de miradas sino fomentarlas, reducir las relaciones de poder entre los entrenadores para que el club pueda aprovechar todas las percepciones e incluso contratar, en las épocas previas a la selección de jugadores, a un pequeño grupo de entrenadores externos al club -desligados de las relaciones de poder- para que también los califiquen y posibiliten miradas que al interior del club no están siendo consideradas.

Aquí los coordinadores de cantera tienen una responsabilidad mayor, porque por su posición de poder son quienes pueden promover condiciones para que los técnicos se sientan con entera libertad para calificar a los jugadores como les plazca, sin temor a represalias. A los técnicos, por su parte, les cabe intentar olvidar todo lo que piensan de un jugador, tratar de desligarse de miradas ajenas, imaginar que no lo conocen y que lo observan por primera vez y recién ahí intentar calificar sus fortalezas y debilidades. Animarse a tener ideas ridículas. 
Esto está relacionado con otro elemento que mencionamos en el marco teórico: las representaciones se sedimentan y se van construyendo progresivamente como verdades. A partir de las relaciones, de las opiniones sobre los jugadores, se va construyendo una mirada que se va perpetuando: de algunos dirán que están legitimados y otros lentamente perderán esa legitimidad, se irán construyendo como suplentes, como prescindibles, se irá "esencializando" una representación sobre ellos que no es sino arbitraria. En resumen, entonces, la observación de los jugadores no es subjetiva sino que está atravesada por las relaciones sociales y de poder que se establecen entre los técnicos.

\subsection{El conflicto entre formación y competitividad}

Sigamos dando un rodeo para comprender cómo la estructura informal impacta sobre el devenir de los jugadores. En Pumas los futbolistas pertenecen oficialmente a una categoría, pero en función de su desempeño pueden sumarse a planteles de mayor nivel (o fortalecer con su presencia los de menor nivel). Cuando expreso "en función de su desempeño" me refiero a dos cosas: a que este depende de la observación por parte de los técnicos, y a que los futbolistas pueden jugar para distintas categorías a lo largo de un campeonato, incluso durante la misma semana (esto también está ligado a un sistema de premios y castigos al que me referiré en el próximo capítulo, aquí sólo observaremos los efectos de la disputa). Estos movimientos también están institucionalizados por la Federación Mexicana, que como un modo de promover el desarrollo de los futbolistas reglamentó que en cada campeonato jugadores de una categoría menor deben sumar al menos 800 minutos en alguna categoría superior.

Promover el desarrollo significa priorizar la formación a la competitividad. En mayor o menor medida, el conflicto entre formación y competitividad es una dimensión presente en todas las fuerzas básicas, y de manera resumida consiste en que la misión fundamental de un Centro de Formación (y en consecuencia, de cada uno de los técnicos) es educar a los jugadores de tal manera que la mayor cantidad de futbolistas esté en condiciones de pelear un lugar en el equipo profesional. He aquí, entonces, el elemento "meta" al que nos referíamos en la definición de organización. Ahora bien, para educar a un jugador en términos futbolísticos se necesitan recursos y entrenamiento (técnico, táctico y físico), pero además un tercer elemento: que el futbolista "juegue", que tenga minutos de competencia, que se enfrente a rivales, que ponga en práctica lo trabajado y que aprenda a manejar la presión de jugar "por puntos" y con la presencia de público, un factor que sin dudas condiciona el rendimiento. Que incremente su temperamento: que se equivoque muchas veces y aprenda a recuperarse. 
Hay jugadores que por talento deportivo, por capacidad física o por personalidad resuelven mejor que otros las situaciones de juego en su etapa formativa. Pero eso no asegura -dicen- que suceda lo mismo en toda su carrera: a medida que crece puede comenzar a flaquear, puede perder el interés o incluso capacidad frente a rivales de mayor calidad. No olvidemos que son adolescentes que atraviesan todo tipo de transformaciones. De manera inversa, un deportista que a los 13 años no muestra todo su potencial sí puede hacerlo a los 15, a los 17 o incluso más grande. Entonces apostar a la formación y no a la competitividad significa darles espacio a todos (o a la gran mayoría), que los técnicos incrementen el riesgo de que el equipo sea derrotado a cambio de utilizar un mayor número de jugadores en los partidos oficiales. Por ese motivo, en fuerzas básicas los técnicos pueden realizar seis cambios por encuentro, a diferencia de los tres que se pueden hacer en Primera.

En Pumas este conflicto es inseparable de otro factor: la cantidad de jugadores que tiene Pumas en tres categorías con similares rangos de edad. En términos comparativos: la categoría U17 del Olympique de Marseille trabaja con 38 jugadores $^{111}$, con los que compiten en dos campeonatos -el Nacional y el "DH", regional- y ceden algunos a la categoría superior, ya sea la U19 o incluso la Primera. Estudiantes, por su parte, cuenta con unos 35 jugadores para la categoría "séptima" (nacidos en 1999) y otro tanto para "la octava" (en 2000), pero aquí debemos tener en cuenta que cada categoría juega dos campeonatos, uno correspondiente a la Asociación del Fútbol Argentino y otro a la Liga Metropolitana, regional. En consecuencia, cuentan con unos 70 jugadores que compiten en cuatro torneos. A esto debemos agregar que al pasar a "sexta" (un año más grandes) sólo compiten en un certamen, motivo por el cual el plantel de la categoría se reduce a unos 25 futbolistas.

En Pumas es más complejo. Existen tres categorías: la Sub17, que como veíamos en el organigrama compite en la Liga MX (la liga de fútbol profesional más importante de México) y que no puede contar con jugadores que excedan los 17 años. En segundo término se encuentra la Tercera, que compite en la "Tercera División Profesional”, una liga regional y de menor jerarquía en la que el límite de edad es de 19 años. Aquí Pumas decide dar ventaja en términos corporales para propiciar el desarrollo de sus jugadores, ya que la función “original” de participar en esta competencia consistía en

\footnotetext{
${ }^{111}$ Durante la etnografía correspondía a nacidos en 1999 y 2000, eran en promedio 19 jugadores por año, a los que se puede sumar algunos pocos 2001. A los del año 1999 se les dice "U17 primer año", y a los otros, "U17 segundo año", y se entiende que los de segundo año se están adaptando a la categoría y que hay que incorporarlos lentamente. En general son los jugadores 1999 los que juegan en el Nacional, excepto si un 2000 los supera en rendimiento. El equipo regional se compone entonces de los 1999 que no han jugado en el Nacional y de los mejores 2000, más algunos U15 promovidos o incorporados para completar el equipo. Al equipo Nacional lo dirige el Director Técnico, y al regional su auxiliar, prácticamente sin intervención del DT.
} 
que aquellos jugadores con proyección pudieran medirse con rivales de mayor porte físico (para un chico de 15 años, enfrentarse a uno de 18 o 19 implica una diferencia corporal importante) y en campos de juego en no tan buen estado porque los rivales son en su mayoría regionales y de menores recursos. Se considera entonces que así se incrementa su temple.

Finalmente, la categoría 1999 congrega a un tercer plantel de jugadores que han sido registrados pero que no se desempeñan en ninguna de las otras dos ligas. Aquí compiten en otra liga regional -la "Liga Mexicana"- incluso de menor jerarquía que la Tercera. Como consecuencia Pumas cuenta con unos 45 jugadores entre los 16 y 17 años que se desempeñan en tres campeonatos, de los cuales solo uno parece tener verdadera relevancia en la actualidad.

En términos numéricos no parece mucho (15 jugadores por torneo, menos que los 17,5 de Estudiantes y que los 19 de Olympique de Marsella), pero ¿cuál es el inconveniente que observo? Que por la pelea política todos los directores técnicos buscan legitimarse frente a sus pares mediante la exposición de que sus equipos ganan -y de que ellos como técnicos son exitosos. Sin reglas de juego claras por parte de los dirigentes por efecto de la existencia de dos parcialidades, todos priorizan la competitividad a la formación y en consecuencia terminan utilizando prácticamente los mismos jugadores. Aquí se puede aplicar la relación costo-beneficio: por la necesidad de mantener e incrementar su legitimidad, para los entrenadores es más riesgoso apostar a la formación y poner en el campo de juego futbolistas no tan asentados que incluir en el once inicial a aquellos que consideran más formados. Priorizan su propia carrera y estabilidad laboral a promover un colectivo más amplio de jugadores. Como consecuencia, existen unos 25 futbolistas que pueden estar jugando dos o incluso tres, ocasionalmente, partidos por semana (algo que incrementa los riesgos de lesión por sobrecarga física) y otros que no juegan nunca, con lo cual ven acotadas sus posibilidades. Esto nos lleva al próximo apartado.

\subsection{Impacto de la estructura informal sobre el camino al profesionalismo}

Hasta aquí observamos que pese a la existencia de una estructura formal son sumamente relevantes las relaciones que se establecen entre los integrantes de la cantera a partir de un liderazgo bicéfalo. Encontramos además que toda la selección de jugadores se sostiene sobre la observación, que esta es producto de las relaciones de poder entre los técnicos y que a partir de ella se realiza una selección constante. Nos detuvimos sobre la cantidad de jugadores que posee Pumas en una franja 
etaria reducida, observamos el conflicto entre formación y competitividad, entre la misión de formar y apostar a la mayor cantidad posible de jugadores y la búsqueda de la victoria como parte del aprendizaje, y encontramos que esa necesidad de ganar está acrecentada por la fractura al interior de la cantera, a tal punto que los partidos como perdían terreno espacio formativo y muchos futbolistas quedaban sin jugar.

A partir de todo esto, la estructura informal impacta de dos maneras: la primera es que la informalidad pone un límite al discurso del esfuerzo personal como camino al "éxito" que pregonan los clubes, entre ellos Pumas. En el próximo capítulo profundizaremos sobre esta cuestión, pero podemos anticipar que uno de los "argumentos" presentes sobre todo en Pumas y en Estudiantes de la Plata para motivar a los jugadores es la inducción de que sólo van a llegar a Primera si "dejan todo" en cada entrenamiento y en cada partido. Pero el trabajo etnográfico expuso que es una creencia que puede ser relativizada. El esfuerzo es, en efecto, una de las pocas variables que el jugador puede poner en funcionamiento de manera individual, pero eso no garantiza nada, en gran parte porque la observación es colectiva y sedimentada: he encontrado casos de jugadores que se entrenaban por su cuenta a la tarde, en doble turno, que eran sumamente ordenados con sus comidas y sus deberes, que en cada entrenamiento se proponían dejar todo, y que pese a todo eso, pese a hacer las cosas bien, eran relegados a ser suplentes o a jugar en Tercera por la imagen que de él tenían algunos técnicos. Entonces, mientras no se genere desde el lado de los entrenadores una apertura que posibilite incorporar a estos jugadores, el esfuerzo como camino de desarrollo no se materializa en la práctica.

Por otra parte, los que sí juegan se transforman en una especie de elemento en disputa por los técnicos. Estos acuerdan en la reunión semanal que para que el chico pueda jugar en las diversas categorías no lo va a hacer durante los noventa minutos de cada partido: jugará, por ejemplo, el primer tiempo del partido del viernes y el primer tiempo el partido del sábado. Pero luego el DT del viernes ve en riesgo su resultado y lo deja en el campo de juego 75 minutos, y con pocas horas de descanso los jóvenes deben presentarse a jugar con el otro equipo (y no se trata exclusivamente de un esfuerzo físico sino también mental porque prepararse para un partido implica una predisposición, estar concentrados).

Así se incrementa el riesgo físico -he visto jugadores lesionados por sobrecarga muscular- y el riesgo de que mermar en su rendimiento, en el partido o en el entrenamiento. Tienen el derecho a decir que están cansados, pero en la práctica no se realiza: pueden inventarse una lesión o una enfermedad, pero no rechazan jugar. Uno de los doctores me comentaba que muchas veces van a la consulta con 
dolores y él se da cuenta de que no tienen nada físico, que a veces están cansados mentalmente, estresados, o que sólo necesitan cambiar la rutina un par de días.

Dice que a veces entran en períodos de depresiones livianas. Le pregunto cuáles son los síntomas y me dice "Apatía, tristeza... A veces se inventan lesiones. Vienen al consultorio con un dolor y lo estudias y ves que físico no es, que es algo más. A veces sólo necesitan ir al hospital para salir un rato, cambiar la rutina.

(Diario de campo, 30 de julio de 2015)

Luego los manda a rehabilitación y no van, o les pregunta si tomaron la medicación y no lo hicieron. En paralelo, para muchos otros no hay oportunidad de jugar, de pelear por un puesto ni de irse a otro club hasta que queden "en libertad de acción" y vuelvan a tener la transferencia en su poder.

En segundo término, la estructura informal también impacta sobre los jugadores porque prioriza a aquellos que llegan con capital social. Los espacios que estos ocupan en la plantilla, en la casa-club o en el once inicial son espacios que un jugador sin dicho capital pierde la posibilidad de ocupar, e incluso sin indicaciones claras que propicien su inclusión los entrenadores no se afirman en su opinión cuando es contraria al jugador sino que prefieren mantener su posición laboral y los incluyen en el equipo o en las listas de registros.

A modo de ejemplo, ya se mencionó que en la Segunda se desempeña el hijo de una figura muy importante del club y que si no fuera por su apellido no tendría posibilidad de mantenerse en el equipo. Pues bien, en una ocasión yo miraba un partido de la Segunda cuando apareció otra figura importante, abuelo de este jugador y que había sido coordinador de la cantera. Todo el mundo lo saludaba y algunos directivos y técnicos se acercaron a recibirlo. El joven había estado como suplente todo el partido y, por suerte para el entrenador, el equipo ganaba 2-0. Pero cinco minutos después de la aparición de esta figura, y a falta de 10 minutos para que finalizara el encuentro, el joven se alistó para ingresar.

Otro DT expresó que cuando lo tuvo como jugador y el abuelo era coordinador general de la cantera, éste le indicaba que tenía que incluirlo, que tenía que jugar. Si él como entrenador lo incorporaba en el segundo tiempo por motu propio, el coordinador le pidió que jugara desde el inicio.

En mis notas de campo registré lo siguiente:

Me cuenta que esto le generaba problemas con los otros jugadores y que él trataba de explicarles, que no se enojaran. Porque era como jugar con uno menos. Y él les decía 'a meterle, siempre jugamos con 10'. Pero que en una ocasión estaban en la final de un torneo internacional y el coordinador le pidió que además de su nieto pusiera a otro jugador a quien también amparaba. Ese chico hoy está jugando en Segunda y juega mucho mejor pero en aquel momento era flojo. Y el coordinador le dijo que lo pusiera y los otros jugadores se enojaron, le dijeron 'con 10 está bien, pero ¿con 9?' y él les respondía 'Entiendan, entiendan'. El partido lo perdieron 2-0, yo le dije que me parecía que quedaba claro que el señor priorizaba a su nieto por encima del equipo (...) Le pregunté si cree que el chico puede llegar a Primera. Me dice que no cree, que no cree que hagan 
tan explícito todo lo que implica, e interpreto: que llegó amparado por ellos y no por mérito propio".

(Nota de Diario de Campo, 21 de agosto)

Este DT me mencionaba que en un momento el chico quiso dejar el fútbol y que el abuelo le pidió que lo convenciera de seguir; que otra semana llegó a un entrenamiento recién el jueves (es decir que no asistió entre lunes y miércoles), y que él hablaba con el joven pero nada cambiaba. Otro técnico que lo tuvo expresó prácticamente lo mismo: que sufría, que tenía que hablar con los jugadores de su equipo y todos sabían que lo incorporaba al plantel desde el inicio por presiones; el DT agregó que les hablaba desde la resignación, les decía que no podía hacer nada pero que había que meterle y tratar de sacar los partidos adelante. Lo interesante es que absolutamente todo el mundo conoce la situación pero nadie se anima a sacarlo del equipo o a no convocarlo, y que hay al menos tres casos más de niños que pertenecen a la cantera estrictamente por su apellido. En la categoría 2003, con futbolistas de 12 años, pocos días antes de realizar el primer registro de jugadores apareció un chico tímido, pequeño en altura y que no se destacaba por su técnica: se lo registró porque era el hijo de una de las autoridades más importantes del club, lo que significó que algunos de los otros niños que tenían más ritmo y jugaban desde el año pasado se quedaran sin registro.

Es decir que desde los 12 años los futbolistas de Pumas saben que las posibilidades no son iguales para todos, que el fútbol es un espacio donde ser "familiar de" o "amigo de" genera una ventaja que simplifica el camino al profesionalismo y que si quieren "llegar" puede ser una opción apelar a estos recursos. Esto conforma una suerte de habitus -más efecto de la experiencia que del pasado o las condiciones de existencia sedimentadas- con la que luego operan en los distintos equipos por los que pasen. Porque no podemos pensar en los jóvenes futbolistas como un actor pasivo y que acepta llanamente la normativa (formal e informal) que se le propone desde la organización. Veremos en las conclusiones que parte de su agencia se pone de manifiesto al intentar poner bajo su control su carrera a través de los representantes.

Claro que también puede jugar en contra: los jugadores a prueba que vienen referidos por un directivo son vistos con algo menos de aprecio por parte de los técnicos, casi una forma de resistencia solapada. He visto que no les siguieran la carrera o la evolución, ni que fueran la primera opción al momento de buscar alternativas. Pero en general, quien viene sostenido por un directivo o allegado tiene un peso extra porque el DT no se anima a negarle el registro al directivo, así como el directivo no se lo negaría a los patrocinadores o a la Junta Directiva del Patronato. 
Para concluir, una aclaración: no se trata aquí de criticar el modo en que las fuerzas básicas de Pumas organizan sus relaciones con otros actores, no es una tarea que me corresponda sino que intento comprender cómo funciona una sociedad a partir de una organización. Ahora bien, sí me corresponde afirmar que el efecto de estas relaciones (la estructura social como funciona en la práctica y no en su discurso) contradice la idea de que todos los jugadores tienen las mismas posibilidades de ocupar una posición en el once inicial, así como la idea de que es el esfuerzo el mecanismo primordial para alcanzarlo ${ }^{112}$.

Por otra parte, queda claro que una normativa no sólo se transmite a partir de lo que ella dice y construye de sí misma sino que en la práctica operan muchos otros elementos. Concretamente, en la práctica cotidiana imágenes sagradas como la asociación con la Universidad Nacional, la identificación que a partir de allí se construye con ideas como el desarrollo de una sociedad a partir de la producción de conocimientos, la ausencia de la corrupción, la UNAM como actor social y político o incluso un estilo de juego asociado con "la garra Puma", quedan en un segundo plano cuando los chicos observan desde sus primeros pasos en la institución que quienes avanzan en la institución muchas veces lo hacen gracias a otras vías y mecanismos o cuando se rumorea que algunos compañeros están como producto de un soborno ${ }^{113}$.

Para cerrar, dos ideas: lo primero es que no hay deseo que pueda materializarse sin que pase a “jugar” en el marco de una organización y se vaya transformando a partir de las relaciones sociales que allí se desenvuelven. Conseguirlo no depende únicamente del individuo y su voluntad sino del espacio en el que se va insertando para llevarlo a cabo. En segundo término, la propuesta institucional se transmite por múltiples vías, y que muchos de los conflictos al interior de los equipos -la tan repetida "falta de comunicación" o el modo en que interpretan las críticas de los entrenadores, por ejemplo-

112 Por supuesto, además pone a la formación en un contexto de rumores, de decisiones poco claras, de desconfianzas... Todos estos efectos incrementan los costos, perjudican el clima laboral, reducen la permanencia del personal en la institución, aumentan el oportunismo... Los efectos "nocivos" son múltiples, pero no los abordamos en detalle porque en este trabajo el foco es analizar el camino de los futbolistas hacia el profesionalismo y no la operativa de la organización.

113 El caso de Estudiantes es prácticamente opuesto en este sentido: allí dicen ser "una familia", y materializan la idea en espacios de contención que colaboran para menguar el destierro que sufren los jugadores. Esto repercute positivamente entre estos últimos, y posibilita testimonios como los siguientes: "Me encontré con un club que es muy familiar, y eso es lo mejor que podés encontrar en un club, porque al estar lejos de tu familia creo que es lo que más te ayuda ¿no? En el trato, en los chicos que están en pensión [casa-club] con vos, en los entrenamientos, las chicas, las cocineras, los técnicos. Todos, todos te están apoyando constantemente" (Entrevistado E5); "En los que yo me apoyé mucho fue en el trato con los cocineros, cuando yo tenía problemas hablaba mucho con Oscar y Cata, acá en la cantina, ellos fueron los que hicieron de mamá y de papá cuando yo lo necesitaba" (Entrevistado E2). Los jugadores añadían que gracias a estos espacios y a esta forma de relacionarse ellos sentían "deberse" al club con más fuerza, "defender los colores" de aquellos que están apostando por su juego, que generan formas que les hacen la vida cotidiana más llevadera y reducen la sensación de ser "utilizados" por el club para alcanzar el máximo rendimiento. 
tienen como origen no cuestiones deportivas sino asuntos ligados a las relaciones que se establecen al interior del club. Si las esperanzas de crecer como futbolistas están condicionadas no sólo por el esfuerzo que puedan realizar sino por las relaciones sociales que puedan establecer o el capital social con el que cuenten, seguramente se sientan menos motivados a entrenar en profundidad, o a hacer un pase-gol si pueden definir ellos la jugada. Toda la normativa institucional contribuye, en consecuencia, con lo que sucede al momento de salir al campo de juego e incrementa o disminuye la motivación por "defender los colores" del club. 


\section{El deseo, el poder, el placer}

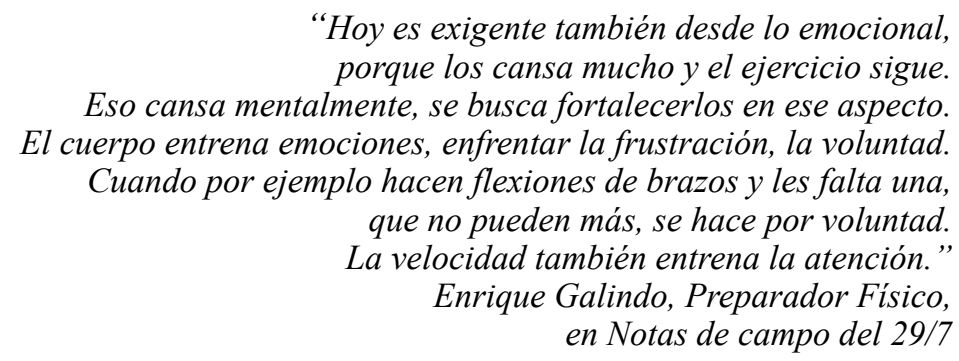

La Sub17 de Pumas entrena de lunes a viernes, de 9:30 a 12 o 12:30 horas. La Sub13 hace lo propio de 16 a 18, cuatro veces por semana para no exigir tanto a los niños. Los mayores comienzan con 45 minutos de trabajos físicos, en gimnasio o al aire libre bajo la coordinación del Preparador Físico (PF); una vez por semana -en general los miércoles- se realiza un trabajo intensivo. Además, aquellos jugadores que deben fortalecer algún aspecto se quedan entrenando en el gimnasio después de las 12:30, también bajo la coordinación del PF.

Dado que antes de los 17 años el desarrollo corporal de un joven -la "osificación”, explican los preparadores- no está terminada, es común que haya contexturas físicas desparejas, que compitan todos por igual entre sí y también contra equipos contrarios. Como decíamos en el capítulo anterior, los preparadores físicos y los técnicos saben que a los chicos "hay que esperarlos", que quienes hoy no expresan su plenitud física o deportiva mañana sí pueden hacerlo, pero al mismo tiempo se debaten permanentemente "cuánto tiempo los esperamos". Entre esos márgenes oscila la apuesta deportiva y la inversión económica del club.

Una vez concluida la parte física comienzan los ejercicios con pelota, cuando se practican las distintas aristas del juego. En general lo que se busca es comenzar con un ejercicio sencillo e ir complejizándolo hasta llegar a una situación que simule un partido. A la par de los ejercicios los técnicos los observan y los estimulan: "Compromiso con el balón”, "En cuanto la rifa es mía"; "Que se cague, que voy por él" son sólo ejemplos entre un mar de frases que también manifiestan numerosos valores. Los ejercicios, además, tienen una introducción a cargo del técnico y una breve charla a su término -o durante el ejercicio- en la que se busca que los jugadores comprendan la problemática que están ensayando.

De modo que una de las maneras en que se transmiten los modos de actuar es a través de la práctica deportiva. En la teoría de Michel Foucault el cuerpo es central, ya que postula que una de las formas centrales a través de las cuales el poder se ejerce es la gimnasia, los ejercicios, el desarrollo 
muscular, la desnudez, las concepciones de belleza corporal y de salud. Se pregunta además qué tipo de cuerpos necesita la sociedad capitalista a la que pertenecía, y responde que -contra lo que podía pensarse- no eran necesarias estructuras corporales "pesadas", "macizas", "constantes" como los disciplinamientos de las escuelas, los hospitales, los talleres o el ejército sino que dicho poder podía ser más relajado y multiforme.

Propone entonces dos cuestiones: que no hay introducción del poder sobre el cuerpo que no genere una resistencia, y que ante la sublevación el poder no se ejerce mediante coerción sino a través de la estimulación"114. El concepto clave es "el cuerpo dócil", "un cuerpo que puede ser sometido, que puede ser utilizado, que puede ser trasformado y perfeccionado" (Foucault 1980: 140). Desde su perspectiva, desde el siglo XVIII este poder se ejerce a través de una "escala de control", que implica que el cuerpo no es una unidad indisociable sino que es trabajado en sus partes, "de ejercer sobre él una coerción débil, de asegurar presas al nivel mismo de la mecánica: movimientos, gestos, actitudes, rapidez; poder infinitesimal sobre el cuerpo activo" (1980: 140). Por eso habla de una "microfísica del poder", porque es en esos pequeños detalles o "acondicionamientos" que los dispositivos producen las coerciones.

El foco de este movimiento de poder sería ya no el resultado sino la atención al proceso, un control minucioso y permanente sobre sus operaciones. A diferencia de la esclavitud no implica una apropiación de los cuerpos; a diferencia de la domesticidad, no implica una dominación bajo la voluntad de un amo; a diferencia del vasallaje, no implica una sumisión codificada; lo mismo con el ascetismo, de la que se diferencia porque no busca el dominio de cada cual sobre su propio cuerpo.

El cuerpo es entonces objeto de control, y para ello las instituciones (en nuestro caso, los clubes) establecen diversos métodos a los que Foucault denomina "disciplina", tendientes a incrementar la fuerza del cuerpo "en términos de utilidad" pero a disminuir sus fuerzas "en términos políticos de obediencia" (1980; 141). Es decir, cuerpos fuertes "pero" sumisos. En Pumas están lejos de ser tan estrictos, pero existen otras instituciones mexicanas como el Pachuca donde el sistema es de internado (el 95\% de sus jugadores vive, entrena, estudia y duerme en el club) y allí sí se aplica un sistema de clausura, una división del espacio en zonas o una temporalidad: a determinada hora se despiertan, estudian, almuerzan, duermen. Tanto en el Olympique de Marsella como en Estudiantes de la Plata,

114 En la sexualidad, tema que él trabaja, observa que el poder responde "por medio de una explotación económica (y quizás ideológica) de la erotización, desde los productos de bronceado hasta las películas porno... En respuesta también a la sublevación del cuerpo, encontraréis una nueva inversión que no se presenta ya bajo la forma de control-represión, sino bajo la de control-estimulación: «iPonte desnudo... pero sé delgado, hermoso, bronceado!»» (Foucault 1980: 105). 
aquellos jugadores que viven en la casa-club -entre un 20 y 30 por ciento de las categorías analizadasse regían bajo este sistema. En Marsella la escuela estaba afuera del Centro y en Estudiantes al interior del predio, de modo que en este último club los chicos terminan saliendo una vez por semana, previa autorización de los padres.

Ya se mencionó en el marco teórico que pienso las representaciones de manera corporal, que no se trata de una perspectiva mentalista. Y Pierre Bourdieu amplía esta mirada: para él el habitus, al que ya nos referimos en el marco teórico, es definido como un "estado de cuerpo", en oposición a ideas como que decidimos adherirnos a un cuerpo de dogmas o doctrinas (Bourdieu 2010: 111).

Para Bourdieu es posible "inculcar toda una cosmología, una ética, una metafísica, una política, a través de mandatos tan insignificantes como 'estate derecho' o 'no sostengas el cuchillo en la mano izquierda'...”. (ídem: 112) Esto significa que a partir de detalles sobre la postura corporal o la forma del vestir se inscribiría la arbitrariedad cultural sin tener que apelar a la conciencia o a la explicitación. Finalmente, y casi en línea con Durkheim, propone que "Es todo el grupo el que se interpone entre el niño y el mundo, no solamente por medio de sus advertencias (warnings) adecuadas para inculcar el temor a los peligros sobrenaturales, sino a través de todo el universo de prácticas rituales y discursos que lo pueblan de significaciones estructuradas conforme a los principios del habitus adecuado" (ídem: 124).

Decidí incorporar todo lo dicho hasta aquí porque comparto la mirada de que el cuerpo es objeto de relaciones de poder, y en consecuencia que los ejercicios físicos que realizan a diario también pueden ser leídos en esa tónica; es decir que la dimensión política es una de las que atraviesa al cuerpo. Pero también lo incorporo para aclarar que aunque sé que es relevante, no es un tema que voy a analizar. Si bien recopilé buena parte de los trabajos que realizaron en los tres países y comentarios de los técnicos mientras los practicaban, no tengo los conocimientos de fútbol suficientes para interpretar a partir de los ejercicios formas de concebir el deporte y de observar relaciones de poder. No obstante, en este capítulo sí me voy a dedicar a otras formas de poder que se implementan desde la organización con el objetivo de maximizar el rendimiento de sus jugadores, algo que consideran ligado al deseo, al convencimiento que tienen al entrenar y al jugar.

Por supuesto, no siempre se trata de mecanismos que se realizan adrede ni de manera intencionada y estratégica, pero sí son representaciones que circulan en la organización, y que tienen como propósito que los jugadores se motiven a diario. Tampoco son relaciones de poder que respondan 
a un sentido último ("la reproducción del capitalismo"; "la dominación de la burguesía", por mencionar los que el propio Foucault utiliza para ejemplificar), sino que llevan la autonomía de la propia institución. Sin embargo, me animo a decir que no contradicen la estructura social en la que están inmersos y tengo la presunción -presumo- de que podríamos encontrar las mismas formas en muchos otros espacios. Si así fuera, si estos mecanismos de poder fueran regulares (corresponde realizar otro trabajo para comprobarlo), podríamos estar hablando de que en nuestra época estas son algunas de las formas de poder predominantes.

En el marco teórico observamos que en Foucault el poder precisa de un soporte institucional a partir del cual se distribuye, y encontramos que en su teoría está ligado sobre todo a la "voluntad de verdad" (la construcción de representaciones de lo que es verdadero y lo que es falso, lo que es racional y lo que es "loco"), y la construcción del saber: qué conocimiento se valoriza y que posibilita que algunos actores definan lo que es verdadero. Pues bien, recuperemos algunas ideas más de su teoría para condensar de qué manera propongo observar las siguientes representaciones:

Hay efectos de verdad que una sociedad como la occidental -y ahora podemos decir la sociedad mundial- produce a cada instante. Se produce la verdad. Esas producciones de verdades no pueden disociarse del poder y de los mecanismos de poder, porque estos últimos hacen posibles, inducen esas producciones de verdades $\mathrm{y}$, a la vez, porque estas mismas tienen efectos de poder que nos ligan, nos atan. Lo que me preocupa son esas relaciones verdad/poder, saber/poder. (Foucault, 2012: 73)

A partir de allí, como indica su entrevistador, el poder no es "ni una institución, ni una estructura, ni un poder estatal, sino un lugar estratégico donde se encuentran todas las relaciones de fuerzas poder/ saber" (ídem: 75).

Hay relaciones de poder entre un hombre y una mujer, entre el que sabe y el que no sabe, entre los padres y los hijos, en la familia. En la sociedad hay millares y millares de relaciones de poder y, por consiguiente, de relaciones de fuerzas, y por tanto de pequeños enfrentamientos, microluchas, por llamarlas de algún modo. Si bien es cierto que esas pequeñas relaciones de poder son muchas veces regidas, inducidas desde arriba por los grandes poderes del Estado o las grandes dominaciones de clase, hay que decir además que, en sentido inverso, una dominación de clase o una estructura de Estado sólo pueden funcionar bien si en la base existen esas pequeñas relaciones de poder. ¿Qué sería del poder del Estado, el poder que impone el servicio militar, por ejemplo, si en torno de cada individuo no hubiese todo un haz de relaciones de poder que lo ligan a sus a sus padres, a su empleador, a su maestro: al que sabe, al que le ha metido en la cabeza tal o cual idea? (Foucault, 2012: 76)

Si con Althusser decíamos que no importan las condiciones de existencia de un colectivo sino las representaciones que ese colectivo tiene de sus condiciones, creo que lo que a continuación presento es un conjunto de representaciones que construyen imaginarios de los recursos con los que cuentan los individuos para desarrollarse, representaciones del lugar que ocupan al interior del club (un lugar frágil, 
que pueden perder en cualquier momento), representaciones de lo que deben hacer para materializar sus deseos (son representaciones que promueven prácticas) y representaciones que generan placeres porque los hacen sentir poseedores de valores legitimados socialmente ${ }^{115}$.

\subsection{La estructura de observación y la oportunidad}

Como vimos en el capítulo anterior, la estructura formativa se sostiene sobre la observación y la selección de jugadores. Dijimos que la observación es colectiva y está atravesada por las relaciones de poder, que hay algunas ideas consensuadas sobre el tipo de jugador que buscan y al mismo tiempo, que hay una percepción que se presenta y tiene algunos elementos de subjetividad. Expresamos también que la selección no afecta únicamente al reclutamiento sino que consiste antes que nada en observar a aquellos que van demostrando más condiciones para devenir profesionales en Pumas, es decir que la selección es permanente.

Esto tiene una contraparte por parte de los jugadores, que consiste en "mostrarse", "demostrar" que tienen las condiciones necesarias para formar parte del equipo y de llegar a la Primera, que tienen elementos para ser "promesa"116. Observemos a modo de ejemplo la siguiente situación:

Ayer registraron a todos los chicos que están a prueba. Cuando termina el entrenamiento Salas los llama un momento aparte y les dice

-Bueno chicos, ahora no se relajen por haber conseguido el registro. A meterle eh. Las oportunidades aparecen, ya ven que a Javier, a Gustavo los llaman y se abren posibilidades. No se sabe cuándo aparecen, pero aparecen. Así que ahora a...

-(Un jugador se anticipa): A demostrar.

-Sí, pero también a jugar, a meter, a correr

Luego les recomienda que miren la película "Invincible" [2006, Dir. Ericson Core], que fue la que pasó la vez pasada en el micro [autobús]. Les dice que es central para los que están a prueba porque es un muchacho que va a una prueba y queda y etc etc.

Diario de campo, 21 de agosto

Esta estructura de observación en la que los jugadores se saben observados tiene dos "caras": por un lado desean ser observados (porque eso habilita la posibilidad de desarrollarse) y al mismo tiempo se incrementa la presión y el stress, porque en los días de partido deben "demostrar". En todos los

\footnotetext{
115 “...entonces todos los días pregúntense por qué estoy aquí. Se los digo porque los veo cansados, sin ganas. Entonces encuéntrenle el placer a estar aquí. El solo hecho de estar aquí es un privilegio. Es un gusto”. Charla del preparador físico a los jugadores de Sub17, 29 de julio de 2015. Dicha prédica expone una paradoja: si fuera un placer no sería necesario que lo dijera: podríamos traducir su mensaje como "sean felices, tienen algo que muchos anhelan, respondan a eso que se supone que debe ser dando todo de sí". Los placeres se construyen, y él les está "recordando" que están en un lugar de privilegio.

116 “ $¿$ Y ahora cómo te sientes? - Pues, se podría decir con, con satisfacción ¿no?, satisfacción y con responsabilidad de corresponderle al técnico y al club ¿no? Que te está brindando la oportunidad de pertenecer. Y más que nada la responsabilidad de salir adelante y demostrarles a los profes y a mí mismo que puedo dar esto y puedo dar más". (Entrevistado P8)
} 
clubes opera la misma estructura, pero en algunos la presión es mayor que en otras ${ }^{117}$. En el trabajo escrito con Diego Murzi describíamos lo siguiente:

Podemos observar entonces que la observación por parte de técnicos y dirigentes tiene doble cara: si se juega bien abre la posibilidad de crecer y ser considerado para una categoría superior; pero si se cometen errores puede condenar el futuro, y por eso los chicos no sólo quieren mostrarse: también juegan con miedo. Como en Estudiantes, además, el pasaje de la categoría séptima a la sexta implica la rescisión de la relación con casi el 30 por ciento de los jugadores, la competencia se hace más intensa ${ }^{118}$ (Murzi \& Czesli 2014: 80).

Si bien en la práctica los jugadores suelen contar con diversas oportunidades para exponer su rendimiento, en términos de representaciones la estructura de observación funciona como mecanismo de poder porque promueve que los futbolistas están permanentemente bajo la idea de ser observados, evaluados y que su futuro puede definirse en cualquier momento, tanto "para arriba" como "para abajo". Por eso es central otra noción entre los jugadores, la idea de oportunidad: para "llegar" se necesita "tener la oportunidad" y "aprovechar la oportunidad”. Este valor circula con muchísima fuerza en los distintos sectores de Pumas, como por ejemplo en la reunión de técnicos donde Pato Baeza expresó lo siguiente:

...el [nombra a un jugador] si me hubieran dicho a mí también, no me hubiera imaginado que iba a estar donde está hoy. Pero se le apareció la oportunidad, el cabrón la aprovechó, [nombre del jugador] no fue gracias a Dios... apareció la oportunidad pero el tipo estaba preparado para aprovecharla. ¿Cuándo llega la oportunidad? No tengo ni idea, pero que va a llegar, va a llegar, y tienes que estar preparadísimo para cuando te digan "vas". Y creo que ese es un ejemplo clarísimo. El tipo cómo terminó la Sub17, cómo está ahora entrenando, yo creo... En 5 minutos les llenó las pupilas, tuvo 5 minutos y los aprovechó. Pero para ese momento hay que trabajar. Hay que hacer conscientes a los chavos de que un día les va a llegar la oportunidad, un día les va a llegar. Para esos 5 minutos que tienen, y llenarle las pupilas al técnico.

Diario de campo, 31 de julio de 2015

Un día después de la primera reunión de coaching, el DT de la Sub17 les preguntaba a los chicos qué pensaban de la reunión de ayer:

- ¿Qué más, qué opinan de la reunión?

- [Un chico responde] Que es una oportunidad muy grande para crecer.

- Sí, lo hemos platicado. Cualquier situación son oportunidades para algo, cabrón. Una fiesta, para cambiar de novia o para tener novia, una escuela, para conocer más; un viaje, para aprender una cultura, estar en un avión, cómo comportarse. Todo son oportunidades.

Diario de campo, 7 de agosto

117 De los clubes estudiados, fue en Estudiantes de la Plata donde la estructura se presentaba como más potente y donde generaba más conflictos, porque muchas veces los futbolistas tienden a jugar de manera individual antes que colectiva, a hacer lujos que llamaran la atención. Creo que así sucedía porque quienes observaban no eran únicamente los técnicos de la categoría sino el coordinador de la cantera, una figura muy presente y de personalidad vehemente, el Secretario Técnico y el Presidente del club, Juan Sebastián Verón, ex figura del club y de la Selección Nacional.

118 “¿¿Ante quién se quieren mostrar? - Y, acá de local te están viendo todos, te está viendo Verón, el otro día estaba Verón... Verón, Hernán, Alayes, los técnicos... todos te ven, y vos te querés mostrar, obvio. Individualmente tampoco es la forma, por ahí si hacés una o dos. Pero como dicen todos, si vos jugás en grupo, las individuales salen solas, y es verdad..." (Entrevistado E9). Otros testimonios en el Anexo *12. 
Entre los futbolistas también un concepto central: en las 10 entrevistas en profundidad la palabra “oportunidad" aparece 69 veces. Tiene dos dimensiones, una material, por ponerle un nombre, y otra simbólica. La material consiste en que el club debe generar espacios en los equipos superiores -sobre todo en el primer equipo- para que aquellos jugadores que son talentosos puedan continuar desarrollándose. Si no hay espacio en la Primera, prácticamente todo el trabajo que se realiza en fuerzas básicas pierde sentido, porque llega un momento en que Pumas está obligado o a firmar un contrato profesional o a otorgarle al jugador la libertad de acción. En general los jóvenes quedan "libres” y no continúan con la carrera deportiva. Por eso el Coordinador de Fuerzas Básicas expresaba durante el trabajo de campo que el problema principal del club es que los jugadores están "tapados", que no se generan los espacios ni se les da el tiempo y la confianza para que se adapten al equipo profesional. Cuando se abre un espacio en Primera, el jugador de la categoría menor tiene espacio para ocuparlo, y así libera su propio espacio para un jugador que viene "de abajo" y así se produce una cadena de espacios que propician el desarrollo. Pese a la mirada de Arce, el Entrevistado P1 expone que sí hay oportunidades:

- ¿Qué es lo que más te gusta de Pumas?

- La forma en cómo te apoya y que están dando mucha oportunidad a los... a los chavos (...) Por ejemplo ahorita cómo nos están enseñando lo del coaching y este... las instalaciones, los profesores, que aparte esos profesores son muy buenas personas, te apoyan, te entienden, te comprenden, este... que a veces te regañan y te... pero es parte de esto, y pues la oportunidad es que si tú haces las cosas bien, si tú haces lo que te piden ellos, o sea tú estas seguro que vas a cumplir ese sueño que es debutar que es estar en primer equipo, porque por ejemplo en los demás clubes, si es hasta en América, pero pos América contrata puro extranjero pero los chavos...

(Entrevistado P1)

La dimensión simbólica sin dudas está ligada con la posibilidad de jugar, pero tiene que ver con la oportunidad de crecer, de mostrarse, la posibilidad de acercarse al sueño. Se puede entrenar con toda la energía, pero si no se les da la chance de ser vistos y considerados no hay futuro posible. Esta oportunidad es la que esperan todos los chicos que no forman parte del "once inicial", de los titulares; es la oportunidad la que sostiene la motivación y el deseo y, como se puede ver en el siguiente testimonio, el "sueño" de hacer una jugada que los ponga en consideración:

- ¿En qué piensas cuando las cosas no te salen?

- Bueno, siempre trato de ser positivo al decir, se me va a dar, se me va a dar, y tratar de hacer, nunca desanimarme.

- ¿Qué es lo que se te va a dar?

- Pues la oportunidad de jugar tal vez, de hacer una jugada, de meter gol...

(Entrevistado P4) 
- Pues mi sueño futbolístico siempre ha sido llegar a Primera División con el Club Universidad. Porque es mi club de mis amores, por así decirlo, siempre he sido aficionado al club y si se me da la oportunidad de jugar para él ¿qué mejor? Más por lo que representa para mí, por decirlo. Y pues jugar en el estadio de C.U. sería para mí un sueño hecho realidad (...) Sí y de ahí mi, sí, mi sueño es realizarme en el Club Universidad y llegar a Selección Nacional y poder demostrar lo que sé, por decirlo así, lo que podré llegar a aprender y si se da la oportunidad de llegar a Europa, que, donde sea je, en Europa sería de lo mejor, el sueño realizado para cualquier joven futbolista que quiera llegar.

- ¿En cualquier club de Europa?

- Si, en cualquiera, je, mientras se dé la oportunidad uno sabrá cómo aprovecharla o desaprovecharla.

(Entrevistado P5) 119

Como una manera de reducir la presión que significaría "no aprovechar" la oportunidad, el DT de

Sub17 solía insistir en que equivocarse es lícito pero que lo que no se puede es dejar de intentar avanzar, hacer jugadas, pegarle al arco. También circulan ideas como que "al jugador se lo valora por la intención", que si su ejecución luego es mala se puede corregir pero que hay que observar la intención. No obstante, la noción de oportunidad, desde la perspectiva de los jugadores expone dos cuestiones en concreto: en principio, que no alcanza con el esfuerzo sino que se precisa una dosis de suerte: que la oportunidad se dé; y finalmente, que una vez que se da, depende del individuo poder o no aprovecharla.

\subsection{La pedagogía aspiracional y la escasez}

Mañana otra vez tenemos un poquito de fútbol para seguirlos viendo, los de allá arriba quienes no los conocen, que a mí me digan 'sabes qué, este sí, este no, mira lo bueno que hace este...' Sólo quiero que sepan que no hay lugares seguros. Nadie está seguro acá, todos tienen que ganarse su lugar, ¿sí? Y ahorita sólo tenemos 16 lugares: 2 porteros y 14 jugadores. Entonces, la lista ya les diré después cuál es esa primer lista, y espero que me abran más registros para poder registrar a más gente porque tenemos pensado que se registre más gente. Entonces, sí, puede ser triste no aparecer en la primer lista, pero si me desanimo ya no voy a aparecer ni en la segunda ni en la tercera eh. Entonces si realmente quieren estar es trabajar y trabajar y trabajar y trabajar hasta que algún día se presente la oportunidad. ¿Estamos? Bien trabajado, nos vemos mañana 4 de la tarde, acá abajo iniciamos.

Diario de campo, 13 de septiembre

119 Otros testimonios: "-Pues, en primero dibujé en el estadio en C.U., que es, pues estar dentro de la cancha y que se me dé la oportunidad de debutar ¿no? Entrar al terreno de juego, pues mostrarme ¿no?, lo que siempre he querido lograr. Y pues el segundo dibujo fue el llamado a selección mexicana ¿no? Recibir la nota que siempre te dan en una hoja de papel, que bueno, te dan y te dicen que ya estas convocado ¿no? Y hacer una concentración o un partido. Y pues ya, por último sería jugar en Europa ¿no? Ir viajando y pues que se me dé la oportunidad de jugar en un equipo allá y mostrar de qué estoy hecho. (Entrevistado P8); “-¿Cada cuánto venías? -Cada vez que me citaban pues, cada, si a veces era una semana, a veces pasaban 2 días y tenía que estar aquí pues. Estuve un mes, gracias a dios me dieron la oportunidad de llegar al club, me dieron las cosas y pues siempre como llegué quiero seguir haciéndolo ¿no? Con mucha garra, intensidad, mucho esfuerzo que he hecho pues" (Entrevistado P8); -¿Qué es lo que más te gusta de Pumas? - Pues que trabajan muy bien la cantera yo pienso que sí impulsan a los chavos, que si haces bien las cosas estando en la Sub20 o en donde estés te puedes subir a primera. Y estando en Primera tienes que aprovecharlo porque no hay segundas oportunidades. -¿Por qué tienes esa idea? Porque [menciona un jugador], un compañero debutó en Copa y lo hizo mal y ya desde ahí ya ni si quiera juega en 20 ni nada, sí sí sí” (Entrevistado P7). 
Con esas palabras el entrenador de la categoría Sub13 les contó a los jugadores, de 12 años, que al día siguiente se realizaría la primera selección de jugadores, a quienes se les darían los primeros 16 registros. Como se pudo leer a lo largo de todo el texto, prácticamente no utilicé el material que surgió del trabajo de campo realizado con esta categoría, pero en este caso decidí incorporarlo porque fue este hecho el que me mostró con claridad una lógica que está presente en todas las etapas de la formación. Me pregunté por qué registraban sólo a 16 jugadores, por qué se perdían la posibilidad de sumar chicos que ya habían conformado un equipo el año anterior. ¿Era por cuestiones económicas? Difícilmente, cada registro cuesta sólo 250 pesos al club (aproximadamente USD14). El registro también implica que a cada jugador le entreguen indumentaria oficial del club, pero eso tampoco involucra un costo económico, porque por ocho chicos (¿24 conjuntos, tres por jugador?) ninguna empresa de indumentaria pondría en duda su acuerdo con el club. Y toda la situación generaba nerviosismo entre chicos que a los 12 años difícilmente cuentan con las herramientas para afrontarlo, y malestar entre los jugadores porque entre los registrados había al menos dos elegidos por sus apellidos y uno de ellos había ingresado hacía dos semanas y aún estaba por debajo del promedio.

Pero a mismo tiempo, en un contexto en el que a Pumas le cuesta conseguir jugadores que hagan una diferencia ¿por qué asumen el riesgo de no registrar a un jugador que un año después puede comenzar a marcar una diferencia? ¿Qué ganaban al dejar de registrar a algunos jugadores si el registro no les costaba nada?

En una conversación posterior con el coordinador de la cantera lo pregunté, y ahí me habló de "lo aspiracional". A continuación transcribo mis notas a partir de la explicación que me dio:

La selección siempre es cruel, y esto no es como una escuela primaria donde llega fin de año y todo el mundo pasa, sino que se generan esos sistemas para promover que los chicos quieran formar parte del once inicial o de los siete suplentes. Tenemos que buscar que esos chicos quieran estar ahí, y muchas veces pasa que aquellos que comienzan sin estar registrados terminan siendo titulares por ese esfuerzo que dan para tratar de pertenecer.

Diario de campo, 22 de diciembre

Entonces observé que este mecanismo era estructural a la organización y que la escasez (la escasez de registros, por ejemplo) es promovida para propiciar el esfuerzo entre los distintos individuos. A mayor escasez, también más ajustada debe ser la observación que realizan los técnicos.

Comprendí que la existencia de sólo 18 camas en la casa-club también está ligado a eso. Se me podrá argumentar que hasta hace un año Pumas tenía una segunda casa donde vivían los Sub20, y que por cuestiones presupuestarias decidieron reducirla. Se podrá argumentar que tienen en proyecto una nueva casa-club, con 40 camas fijas y veinte rotativas entre chicos a prueba. Es posible, pero en 
Estudiantes de la Plata las camas no superan las 55, y en Olympique de Marsella -donde definitivamente no faltan recursos- la cifra es la misma (con más comodidades para quienes viven en las instalaciones, pero una cifra igual). Ahí pensé que la escasez es necesaria.

En Marsella lo aspiracional aparece a través del salario: como ya observamos, en un mismo equipo hay distintas escalas en función del rendimiento, y se espera que quienes están en la casa-club formen parte del once inicial. Pero el coordinador de cantera tenía estudiado que esto en la práctica no sucedía, de modo que al finalizar la temporada posiblemente corriera a los jugadores de la casa-club para brindarles espacios a quienes sí estaban siendo titulares o a otros nuevos que pudieran serlo. En Estudiantes se producía exactamente lo mismo: los jugadores de "pensión” debían destacarse del resto: destacarse en términos futbolísticos pero también en su conducta. Esto generaba que los jugadores de pensión — que además estaban alejados de sus familias - se encontraran permanentemente bajo observación y debiendo "demostrar".

En Estudiantes, además, ningún jugador cobra un salario porque se considera que si "además de todo" se les diera un salario a los jugadores, se "relajarían", dejarían de esforzarse como lo hacen hasta ese momento. Es decir, en Argentina lo aspiracional tiene como meta alcanzar el salario. Sin embargo, en Pumas y en Marsella los jugadores sí perciben un salario y no hay elementos que permitan inferir que sean ligas de menor competitividad ni que los jugadores se esfuercen menos.

En Estudiantes la escasez también se promueve a través de la entrega y quita de beneficios materiales. El más claro es la ropa oficial para los partidos, que el club entrega los viernes y los jugadores devuelven los lunes, de modo que los chicos nunca "capitalizan" la posesión de las vestimentas. Tampoco cuentan con un casillero (locker) propio en el vestuario en el que puedan dejar sus cosas. En Marsella, por el contrario, cada jugador posee su propio espacio, con nombre y foto, donde pueden dejar guardado lo que deseen con total tranquilidad.

Queda claro entonces que se considera que de esta manera se consiguen no sólo mejores rendimientos por parte de los jugadores sino una selección más adecuada porque se incrementa el nivel de exigencia. Sin embargo, al mismo tiempo vimos que en los tres centros de formación la misma lógica se aplica de manera distinta, y lo que en un país se considera que afecta al rendimiento, en el otro no. Entonces, ¿hay verdaderos elementos que permitan sostenerla? 


\subsection{Premios y castigos, temor y esperanza}

Casi como una derivación de lo "aspiracional" se encuentra el sistema de premios y castigos en función del rendimiento. La amenaza siempre latente, la que se supone que a todo jugador aterra, es ser excluido del plantel, y para muchos jugadores sin una estabilidad económica puede significar tener que dedicarse al estudio o al trabajo, y seguramente abandonar los sueños de gloria, fama, dinero y tranquilidad económica. Al día siguiente de una derrota 3 a 0 , un integrante del cuerpo técnico de Sub17 les dijo lo siguiente a los jugadores:

Abajo está la calle. Arriba está la Primera. Estamos acá [y se señala por abajo de su cintura]. No pueden hacer cosas que vayan para abajo. Tienen que ir paso a paso acercándose a Primera.

Diario de campo, 27 de julio

El club les da muestras de que eso les puede suceder. El gesto más claro es que si tuvieron un mal partido los excluyen del once inicial; si tuvieron un partido pésimo el fin de semana siguiente juegan ya no en Sub17 sino en Tercera. Se podría pensar que la idea es que el técnico, al fin de semana siguiente, no quiere volver a sufrir una derrota y en consecuencia realiza cambios para mejorar el equipo, pero al sacar al jugador del equipo lo que se busca es afectar su orgullo y promover en consecuencia que se esfuercen más por volver al once inicial, generarle la sensación de que si la selección de jugadores fuera esa semana, quedarían afuera de Pumas, que no tiene su lugar asegurado, que hay otros que le compiten el puesto.

Claro que esto no siempre sucede. Los chicos no necesariamente sienten un profundo orgullo por pertenecer al once inicial, ni están completamente compenetrados con el objetivo de llegar a Primera. A veces como efecto de la etapa adolescente, a veces porque están cansados de un régimen físico y psicológico tan duro, a veces porque tienen problemas en sus casas y están pensando en otras cosas.

Luego [el DT] comenta con su auxiliar que ayer mostró las pecheras titulares y suplentes, y que cuando a [nombre del jugador] le dio la suplente, el jugador se rió. El DT le preguntó: ¿Por qué te ríes? ¿Qué te genera? "Nada" - ¿En serio no te genera nada? "No". El auxiliar acota: "Yo estaría encabronadísimo, a mí no me eches con los suplentes cabrón". Un tercero agrega: Por pendejaditas así, por soberbios...

El DT añade: Sí pero... nosotros comentamos. Yo un día le digo a él [al jugador]. Le digo "Puta guey, siento que yo estoy más preocupado por mejorar que tú cabrón, a veces pienso que a mí me preocupa más que a ti que llegues a Primera". Y me responde "No, no no sí sí sí..." pero le duele menos...

Diario de campo, 9 de agosto

En otros casos, los jugadores se enojan tanto si los sacan del once inicial que cuando los reincorporan al equipo no quieren jugar porque sienten que previamente no valoraron su esfuerzo. Este sistema también genera debates, porque a veces quienes no rinden y son "castigados" son aquellos 
jugadores de categorías inferiores que habían sido promovidos, entonces la polémica se suscita porque se supone que al futbolista hay que "darle tiempo" para que se acomode a la nueva categoría. Y porque hay algunos técnicos que son tajantes con sus decisiones, convocan futbolistas para sus categorías y a los 15, 20 o 25 minutos de iniciado el partido los cambian porque sienten que no rinden. Eso afecta la moral del jugador, lo expone ante el público presente, privilegia la competitividad sobre su desarrollo. Aunque no se lo digan al entrenador en persona, "por atrás" se coincide en que es una falla.

El gesto opuesto al castigo es premiar a los jugadores "acercándolos" a la Primera, subiéndolos de categoría o enviándolos a entrenar como sparrings ${ }^{120}$ junto al primer equipo. De esa forma el futbolista debe adaptarse a una categoría superior, competir con compañeros de mayor talla física, tratar de probar que puede mantener el nivel pese a estar en desventaja pero, sobre todo, mostrarse ante los entrenadores de las categorías superiores. Si el técnico observa que rinde bien lo tendrá en cuenta.

Vale aclarar que el premio no es el único motivo que lleva a "subir" jugadores sino que -como ya lo explicamos- también depende de los espacios que se van generando y de las relaciones entre los entrenadores y los jugadores. Por ejemplo, un mediocampista fue promovido a Sub20 y luego al primer equipo para un partido por la Copa $\mathrm{Mx}^{121}$ porque quienes allí debían desempeñarse no estaban rindiendo de la manera esperada. Lo particular es que este joven se estaba desempeñando de manera pobre en su propia categoría; no obstante, como cuando había sido sparring había dejado una buena imagen, fue convocado. En resumen, su caso expone que estaba "llegando a Primera" no tanto por condiciones propias sino por la ausencia de alguien mejor. Eso no significa que lograra mantenerse en el puesto, pero no todo jugador tiene la "oportunidad" de jugar en el primer equipo. De hecho, sólo por haber jugado su cotización se incrementaba.

Subir a los jugadores implica incrementar su esperanza de "llegar". Por eso, por esta oposición entre el temor y la esperanza es que me interesa mencionar otra forma de incrementarla, que no es un premio porque no es individual pero que sin dudas les da a los futbolistas la sensación de "estar cerca", de llevar una vida de profesionales. Se trata de los viajes al exterior a competir en torneos internacionales.

Todos los años, en las tres instituciones todas las categorías mayores viajan al exterior. En 2016 los Sub17 viajaron a Dallas, en Estados Unidos, y a Viareggio, en Italia, y en años anteriores habían

\footnotetext{
${ }^{120}$ Son jugadores que entrenan con un equipo profesional como adversarios o para completar un puesto vacío: si tienen que ensayar el ataque, por ejemplo, se arma un equipo de sparrings que le permite al primero ponerse a prueba.

${ }^{121}$ Se trata de un campeonato paralelo a la Liga Mx (la más importante) en el que todos los equipos compiten entre sí más allá de la categoría en la que militen.
} 
viajado a Uruguay y Argentina, Qatar o Praga, por ejemplo ${ }^{122}$. Actualmente, en Sub17 los chicos no deben pagar nada por viajar, de modo que implica una inversión para la institución (y también vemos cómo la idea de escasez tiene sus bemoles: se invierte donde es simbólicamente importante). No todos los clubes viajan porque dicen que se necesita cierto prestigio para participar de estos campeonatos y posiblemente algunos contactos: en Estudiantes, por ejemplo, comenzaron a viajar cuando Hermes Desio asumió como coordinador de las fuerzas básicas y los técnicos consideraban que se debía a su intervención.

Tampoco viajan todos los jugadores: se hace un "selectivo" con los que los entrenadores consideran que son los mejores jugadores, de modo que en los meses previos se intensifica la competencia entre los jugadores por vivir dicha experiencia. Desde el club se dice que se viaja porque allí se conoce mejor a los jugadores gracias a que pasan todo el día concentrados en el hotel o en el entrenamiento; posiblemente también se lo justifique a partir de esa competencia previa y la unión del grupo que se genera al viajar todos juntos. No obstante, desde mi punto de vista es antes que nada un ritual en el que los jugadores “viajan al exterior”. Viajar al exterior es central entre las representaciones de los futbolistas por diversos motivos. En primer término es sumamente relevante para aquellos jugadores que vienen de familias vulnerables y que difícilmente tengan la "oportunidad" de salir del país. El Entrevistado P4, por ejemplo, mencionó que con su primer salario como profesional le regalaría un viaje al exterior a su familia:

- ¿El primer salario? Pues, a mi familia, llevarla a un lugar deseado que ellos quisieran, a la playa, ir a otro país, como ellos nunca les ha dado la oportunidad de salir a otro país, si me gustaría que...

- ¿Nunca tuvieron esa oportunidad?

\footnotetext{
122 Aún no tengo elementos para comprender cómo es el negocio de los torneos internacionales. El de Praga (http:// www.allstarscup.cz/), por ejemplo, es organizado por la All Stars Team, una agencia de marketing que tiene licencia de FIFA como intermediario oficial (www.allstarsteam.cz) y que tiene a My Footbal World (http:// www.myfootballworld.com.mx/ ) como representante exclusivo para América. En su sitio web, esta empresa afirma que se dedica al Turismo Deportivo y que "gestiona giras y torneos internacionales para jugadores de fútbol soccer, con el objetivo de que crezcan personal y futbolísticamente por medio de la superación de desafíos impuestos y de la adquisición de habilidades". Sé que a estos torneos suelen asistir visionadores de clubes europeos para observar potenciales jugadores y gestionar contratos o precontratos, con o sin la anuencia de su club; sé que en estos torneos suelen estar involucrados patrocinadores como Nike o Adidas, pero desconozco cómo se recupera la fuerte inversión que implica. Sin datos no corresponde que lo diga, pero me pregunto si está ligado a una tendencia reciente que consiste en que muchos futbolistas ya no se forman en clubes de fútbol sino que son formados por empresas de intermediarios, que cuentan con infraestructura propia y deciden contratar entrenadores y preparadores físicos para formar a los jugadores hasta, finalmente, venderlos o colocarlos en un club hasta lograr su transferencia. El coordinador de preparadores físicos de Estudiantes, por ejemplo, trabaja al mismo tiempo en CNSports (cnsports.com.ar). Para Estudiantes esto no parece ser en absoluto conflictivo, ya que de hecho sus equipos compitieron en la copa "CNSports".
} 
- No. Me gustaría llevarlos a alguna parte así. ${ }^{123}$

Entonces salir del país -y salir del país sin pagar- para los chicos también implica una separación respecto de sus familias y pares. En segundo término es simbólicamente importante porque la idea de "competencia internacional" implica prestigio, calidad, competir en terreno desconocido y contra jugadores desconocidos. En dichas competencias compiten contra equipos de la primera plana internacional como el Inter, el Celtic Glasgow, el Real Madrid o el París Saint-Germain y no sólo representan al club sino también "a su país". Pero desde mi punto de vista este ritual contribuye a generarles a los jugadores la sensación de que "ya están ahí", que ya viven experiencias de futbolistas profesionales, ya hacen carne el sueño anhelado. Para sostener la esperanza y la motivación de llegar se necesitan pequeñas concreciones, pequeños anticipos de lo que se podría experimentar en el profesionalismo. Esto nos permite pasar al cuarto dispositivo de poder.

\subsection{Pertenecer tiene sus privilegios}

El subtítulo lo robé de un libro de José Garriga Zucal (2007) sobre la violencia en el fútbol. Se trata de una etnografía en la porra de fútbol ${ }^{124}$ del Club Atlético Huracán, de la Ciudad de Buenos Aires. En dicho apartado Garriga expone cómo la constitución de grupos "violentos" y el deseo de pertenencia está asociado no sólo a la posibilidad de constituir un "nosotros" sino también a satisfacer la necesidad de prestigio y renombre, de honor, de reputación, a acceder a recursos y a desarrollar vínculos de solidaridad.

De manera similar, sólo por formar parte de las fuerzas básicas de Pumas los jóvenes acceden a una posición de status social porque mientras pertenecen tienen el derecho de detentar el ser "promesa" del fútbol, la posibilidad abierta de llegar a Europa y materializar todos los capitales que ya observamos. Esto se expone por ejemplo en las redes sociales: en Facebook, Twitter o Instagram los chicos se presentan a sí mismos como jugadores de Pumas, publican fotos de sí mismos en la práctica o disfrutando la vida del futbolista (es común ver escenas de "hermandad" con sus compañeros de casa-

123 Sólo para graficar lo que implica un viaje para un chico en esta situación me permito incorporar un testimonio de Estudiantes de la Plata: "Conocés gente, a los ídolos de Racing [su club anterior]. Íbamos a la cancha, nos llevaron al zoológico, a un museo, a la Legislatura Porteña creo que fue, todas esas cosas. (...) También fuimos a un teatro en Capital, habíamos ido a ver Metegol [un film animado] y también habíamos ido a ver una obra, estuvo muy bueno. Conocí cosas que yo pensé que jamás iba a conocer, que yo pensé que me iba a quedar a jugar al futbol ahí, que no iba a salir de mi casa, conocer Buenos Aires, La Plata, o distintos clubes. Jamás lo pensé así”. (Entrevistado E8).

${ }^{124} \mathrm{Se}$ trata de un grupo de aficionados semi-organizados que hacen de la violencia física una marca de pertenencia. En términos nativos, "barra brava" o "hinchada". 
club), mensajes motivacionales y videos de los consagrados, de modo que ese es un espacio en construyen de manera "pública" su identificación con las estrellas del fútbol.

Esto se sostiene sobre el acceso a algunos beneficios materiales: además del salario mensual -un dato no menor, porque marca una diferencia respecto de sus pares no futbolistas-, un claro beneficio que incrementa el status es contar con la indumentaria oficial de la institución. A tal punto es así que los jugadores a prueba no registrados deben asistir a los entrenamientos vestidos de blanco, de pies a cabeza, de modo que no pueden utilizar ni la playera del club ni la de cualquier club del extranjero. En el club lo justificaron con la idea de que la vestimenta blanca es la más fácil de conseguir, pero las implicancias simbólicas son ineludibles.

Pero también tiene que ver con otros accesos: en el Olympique de Marsella -cuya principal accionista es Margarita Dreyfus, viuda de Robert-Louis Dreyfus, ex CEO de Adidas-Saatchi- la empresa de indumentaria distribuyó con fines publicitarios y para todas las categorías 1500 pares de zapatos último modelo ( 3 o 4 pares por jugador, si por ejemplo descontamos los que se destinan a los entrenadores), incluso cuando los zapatos no pertenecen al acuerdo entre ambas instituciones porque los chicos queden utilizar el calzado que deseen (y de hecho, muchos entrenaban pese a todo con la marca Nike, su competencia) ${ }^{125}$.

"Pertenecer" implica diferenciarse. Al interior de la plantilla también se producen distinciones: hay jugadores que tienen patrocinios y otros que tienen representantes. En Sub17 dos jóvenes cuentan con patrocinios: un portero el de la empresa de indumentaria Voigt, y un mediocampista el de las bebidas Gatorade (en youtube se puede encontrar la publicidad que a los 15 años el chico filmó bajo el título "Future of soccer"). Ambos cuentan con indumentaria y en el segundo caso con su propio "equipo" de bebidas, que se distingue del de sus compañeros. Además, al menos un jugador tiene representante que le provee el último modelo de zapatos, el que -dicho sea de paso- fue promocionado por Cristiano Ronaldo. A través de esos gestos, la representación de ellos como individuos comienza a implicar una diferenciación respecto quienes hasta ese momento eran sus pares.

En el mismo sentido funcionan las entrevistas periodísticas. El sitio vamosdeportes.com cubre todos los partidos de la categoría y al finalizar incluyen una entrevista a un jugador, a lo que se suma algunas que esporádicamente hacen en los entrenamientos (esto no sólo sucede en Pumas sino que al menos en Estudiantes también hay portales dedicados exclusivamente a las fuerzas básicas de la

\footnotetext{
${ }^{125}$ En México, cada par cuesta entre 4 mil y 5 mil pesos (un poco más de 300 dólares).
} 
institución ${ }^{126}$ ). Si bien no se trata de un medio importante en el plano nacional, percibí que los chicos sí le dan relevancia a las entrevistas, que en algunos casos se ponen nerviosos, que disfrutan ser filmados. A la cobertura audiovisual y periodística que realiza este sitio se suman las notas que hacen los suplementos deportivos de periódicos como Milenio en las que se refieren a los jugadores que se destacan en fuerzas básicas ${ }^{127}$, de modo que hay un contexto general que los va ubicando, progresivamente, en el lugar de profesionales, les van permitiendo imaginarse en ese lugar y sobre todo ser interpelados por su entorno y por sus relaciones sociales de esa manera.

Por otra parte, como el horario de los entrenamientos implica cambiarse de escuela (muchos utilizan un modelo de escuela "virtual" desde sus casas), y porque por el fútbol dejan de salir, de beber o de experimentar prácticas de la vida adolescente, en algunos casos los chicos pierden relación con sus compañeros y amigos del barrio ${ }^{128}$. Pero muchos viven un trato distinto, que por ejemplo se materializa de dos formas: los nuevos amigos y la facilidad para conquistar mujeres.

- ¿Crees que ser futbolista ayuda para conseguir pareja?

- Pues sí [risas] Pues sí, sí pasa.

- Esa también es otra fama

- A menor escala, pero también, y hay que también saberlo manejar ¿no?

- ¿Por qué? ¿Qué conflictos genera?

- Pues sí... ahora que esto se hace más importante y que ya tiene mayor importancia cuando dices que estás en una Sub17 pues sí pasa que te aparecen amigos que no siempre estuvieron ahí contigo ¿no?

- ¿Qué te dicen o qué quieren?

- Pues ya se empiezan a juntar más contigo, y 'Oye vamos a tal lado, e invítanos al estadio'... Sí pasa, entonces hay que tener cuidado también con eso. (...) Pero sí se te acerca gente... no sé si por conveniencia.

- ¿Adultos también?

- Pues sí. Menos, pero también.

- ¿Como quién?

- Igual, amigos de mis papás, que antes no le daban mucha importancia. Antes decían "¿Sigues yendo a la escuela esa a la que vas?" Y ahora te tratan diferente.

- ¿Hablas siempre de conveniencia o sientes que te respetan más?

- Pues yo creo que te respetan más y te ven diferente.

\footnotetext{
126 Los dos más importantes son www.lacanterapincha.com.ar o www.inferioresplatenses.com.ar

${ }^{127}$ A modo de ejemplo, ver Guerrero Atiliano, R, 1 de marzo de 2016 y Guerrero Atiliano, R, 1 de enero de 2016.

128 “- Pero por ejemplo ¿de la escuela, del barrio? ¿No te quedaron amigos? - De la escuela tengo... estoy a distancia, entonces la hago en mi casa. Te digo, en mi casa nada más tengo 2 [amigos], y ese chivato toma y toda la cosa. - ¿Hay otro chico que va a tu casa que va hacer la misma cosa? -No, ósea... yo estoy en mi casa y cuando estaba en la secundaria fue el único amigo que tuve, pero él desde chiquito le gusto tomar, fumar y todo eso, entonces haz de cuenta que él no es de esos chavos que me dicen 'Ay tómale güey', o sea él es así más... le da gusto lo que hago: 'Nah es que estás loco, ¿quién se levanta a las 5 de la mañana a entrenar? Yo no lo haría, yo a esta hora voy regresando de las fiestas’. (...) O sea no soy así de... nah no tengo amigos, eso ya. Sí le hablo a todo el mundo y así, pero... yo he dicho que los amigos son los que le confías todo y pos te pueden ayudar, y te digo... lo único que tengo es mi papa". (Entrevistado P1)
} 
- ¿Es más fácil con las chicas siendo jugador de fútbol?

- Pues yo pienso que sí ¿no? Que el escudo... [risas] Pues, ay no, qué puedo decir, a veces [risas]. Es que hay muchas, a mí me ha pasado pues que no me hablaban antes, y ahorita... ¿no? Cuando estaba en Chivas y me corrieron, perdí el 50\% de mis amigas [risas]. No, te lo juro, así el 50\% y ya, estuve en Vaqueros y aumentó como un 20. Ya estoy aquí y ya ni las conozco, ni sé, pero ya me hablan más y así. Sí, así es.

- ¿Y dónde las conocen? ¿Es todo por Facebook, cosas así, o salen con los chicos de la casa club?

- Pues sí, a veces salimos de la casa club y así, que nos invitan, que la otra vez fuimos a Xochimilco con unas compañeras de un amigo y sí, nos invitan así a lugares, ahí es donde las conocemos. Y nos siguen invitando y así. Sí, sí, sí. Pero pues yo pienso que si no jugaras en un club, si sólo estudiaras, yo pienso que no sería lo mismo, no consiguieras ni el $20 \%$ yo pienso.

(Entrevistado P7)

Lo que me interesa destacar, en resumen, es que los chicos experimentan la fama no como una fantasía o un problema futuro, algo que podría sucederles en el caso de convertirse en profesionales, sino que la viven en tiempo presente. Es decir que establecen relaciones con actores de todo tipo familiares, conocidos adultos, vecinos, amigos de su edad- a partir de su pertenencia al club, y son reconocidos como tales por personas que no necesariamente pertenecen al ámbito futbolístico. Y eso es percibido como sumamente placentero y como un producto de pertenecer a Pumas. Por eso, desde mi punto de vista aquí y en los premios observamos con claridad que el poder se ejerce no sólo mediante constricciones o coerciones sino también a partir de la promoción de placeres.

\footnotetext{
${ }^{129}$ En otro segmento, el mismo jugador amplía: “-¿Y tus compañeros de la escuela qué opinan? - Pues, yo sí siento que me ven así como... porque aparte en la escuela según y soy así, igual... trabajo y soy responsable entonces, pues sí creo que... aparte de que igual me apoyan mucho y muchas veces vienen a ver los partidos, pues sí me ven como, no sé es una sensación extraña. -¿Extraña de qué manera? -Muchos me han dicho 'quisiera estar donde tu estas', entonces se siente bien que te lo digan. Y así es también su forma de apoyarme" (Entrevistado P2); Otros testimonios: -¿Parte por tu deseo por llegar a Primera tiene que ver por ejemplo con el dinero, con las mujeres, con todo eso? -No, la verdad no, pero o sea, en cuanto a la fama, la verdad a mí nunca me ha gustado, no se me hace lo esencial, por así decirlo, ni el dinero y mi principal objetivo para jugar al fútbol es de que me gusta. Pero en cuanto a la fama, el dinero y eso no. -¿No hacen chistes por ejemplo de vez en cuando con amigos: 'Eh voy a llegar a primera y te voy a pasar a buscar con la Ferrari', algo así? -No, ellos sí, de repente te comentan, pero a mi no. (...) Mis amigos de la escuela, aja, de la calle. Sí, no 'Ya cuando juegues, que no se que, nos vas a sacar de pobres' y eso, si” (Entrevistado P5).

${ }^{130}$ Otros testimonios: “-¿Qué dicen tus compañeros de la escuela? -No, pues hay chavos que les gusta el fútbol y pues luego hasta se emocionan ¿no? (...) Y así es como las otras personas como sorprendente, como que te ven diferente. - ¿Y tú cómo te sientes? -Pues se siente bonito, sí, te sientes como, nada agrandado ni nada pero si como que te elevan" (Entrevistado P3). "-¿Con las chicas es mas fácil siendo jugador? - Yo creo que sí, sí [risas]. - ¿Qué me puedes decir al respecto? - Pues no se porqué... Tan sólo escuchar el nombre de Pumas... Pues ya te, por decirlo así, un imaginario... Te ponen un... en un escalón más arriba. - ¿Pero cómo haces? ¿Te presentas y decís, ‘hola, soy el contención de Pumas'? - No, pero por ejemplo así entre amigos ya empiezan a comentar, entre las chicas te empiezan a decir... - ¿Qué es lo que se suele decir? ¿Qué chistes aparecen? - No, pues sí, dicen "es jugador de Pumas y que ya va a ganar dinero"... Pero así, aparte 'es jugador de Pumas, está fuerte', empiezan a decir también. 'Es atlético, le gusta el deporte'”. (Entrevistado P5). Otro caso es el del Entrevistado P10, quien me comentó que desde que lo citaron para selección se le acercó gente con mucho dinero, jóvenes y adultos, que uno de los jóvenes es por ejemplo el sobrino del presidente Enrique Peña Nieto y que se le acercó y que lo respetan.
} 


\title{
6.5. El esfuerzo y la posibilidad siempre está
}

\author{
"Competir es como ir a rendir un examen. \\ Si estudiaste vas y respondes; si no estudiaste, \\ dudas, no entiendes la pregunta". \\ Miguel Salas, DT de Pumas Sub17
}

Para cerrar este capítulo dedicado a los mecanismos a través de los cuales se sostiene e incrementa el deseo de devenir futbolista voy a mencionar dos creencias que acompañan los entrenamientos cotidianos y que son repetidas al interior de los centros de formación. Creo que el modo en que ambas se presentan en el centro de formación corresponde con lo que Foucault denomina "el comentario", y que ya se expuso en el marco teórico: aquellos relatos que se cuentan, se repiten y se cambian, concepciones ritualizadas de discursos, relatos que están "en el origen de un cierto número de actos nuevos de palabras que los reanudan, los transforman o hablan de ellos..." (Foucault 1973: 21)

El primero de ellos es la idea de que con esfuerzo todos "llegan", y el segundo, las historias de aquellos jugadores que no eran considerados en sus equipos y que de golpe lograron demostrar su juego y ser observados y fueron promovidos y llegaron a Primera; es decir, que en cualquier momento "se puede dar" pese a todo.

Hemos hablado mucho toda la puta semana y la semana pasada. Y hay que meter las manos cabrón, hay que meter las pinches manitas y meter el corazón y todo lo que haya que meter hay que meterlo. No hay otra, no hay otra opción. Sí, nos podemos equivocar, pero también vamos a acertar. También nos tenemos que dar cuenta de lo que hemos dejado de hacer: hoy hay que meter las manos, hoy es a huevo, no hay otra opción, los que estén dentro y los que estén fuera. Los que les toque jugar y los que no. Y sufran los de adentro y sufran los de afuera. Necesitamos más sangre, necesitamos más corazón, más huevos, más coraje.

Charla técnica pre-partido, 9 de agosto de 2015

Como se puede observar en esta cita, el entrenador les pide a los jugadores que para ganar el partido metan corazón, manos, huevos, sangre, coraje y "todo lo que haya que meter". Para salir adelante en un momento de adversidad les propone hacer un esfuerzo completo al punto de sufrir el partido. Esto tiene diversas significaciones asociadas, voy a comentar brevemente dos y luego me voy a concentrar en la que me parece más relevante, que es el mito de la igualación de posibilidades a partir del esfuerzo.

Antes un dato necesario: el fútbol es un deporte físico y de contacto, donde el partido se gana no sólo con habilidad y buen juego colectivo sino que también se gana con temperamento, poniendo el cuerpo (superar el temor de lesionarse por ir al choque), sin dejarse superar, anticipar ni atemorizar por el adversario. No lo habíamos mencionado hasta aquí pero en paralelo a sus carreras como futbolistas también atraviesan la adolescencia y se convierten en "hombres", y uno de sentidos a los que se asocia 
la masculinidad es a la figura del hombre que apela a su fuerza y temperamento para resolver una situación de conflicto.

Dicho esto dediquémonos al eje de este apartado: que el valor principal en Pumas es que para llegar a Primera se necesita esfuerzo, y que al depender de este se construye la idea de que todos los jugadores tienen las mismas posibilidades. En Argentina sucede lo mismo -ya vimos que el esfuerzo se asocia al sacrificio, y este a la "humildad"-, y la observación en Marsella nos da la pauta de que se concibe la formación como un proceso de superación de los obstáculos más que de dejar todo permanentemente. Allí se habla de desarrollar "lo mental". Pero desde mi punto de vista es posible relativizar esta idea que llegar dependa antes que nada del esfuerzo, y es igualmente relativo que todos los chicos tengan las mismas posibilidades. Observemos primero cómo se sostiene este valor y luego expondré por qué creo que no es del todo verdadero.

Partimos nuevamente de las encuestas. Cuando les pedí que relataran consejos que recibieron en general, las encuestas expusieron que los ligados al esfuerzo fueron largamente mayoritarios con 30 menciones, aparecieron 8 que también fueron motivadores pero de otro tipo (“tú puedes”, por ejemplo), 6 consejos enfocados en el placer ("que haga lo que me gusta"), 2 ligados a lo religioso y seis de otro tipo (el cuadro con el análisis de los consejos se puede encontrar en el Anexo *13). Esto se confirma en las entrevistas en profundidad, donde un rápido conteo enumera que el concepto "ganas" aparece 53 veces, casi siempre asociado a "echarle ganas"131. Desde mi perspectiva, los datos exponen que si partimos de los consejos familiares la entrega y el esfuerzo son representaciones absolutamente centrales.

Pero esto no nos habla de lo que sucede al interior de la institución. Entonces pregunté algo similar respecto de los consejos de los entrenadores, y allí nuevamente encontramos que incluso en una pregunta abierta los consejos ligados al esfuerzo son centrales y mayoritarios. Ahora bien, cuando observamos las entrevistas en profundidad y específicamente la pregunta ¿Qué hay que hacer para llegar a Primera? vemos que este discurso está completamente asumido.

- ¿Qué crees que tienes que hacer para llegar a Primera?

131 Sólo a modo de ejemplo presento dos casos: “...y que pues toda mi familia igual me da aliento ¿no? Que yo le eche ganas, que me quieren ver acá ¿no? (...) No, pues gracias a Dios ya me han pedido mis papeles y ya gracias a Dios en esta semana queda lo de mi registro. $\mathrm{Y}$ este pues a echarle ganas porque para estar ahí pues tengo que estar trabajando al 100 para poder ganarme un lugar porque ya el profe tiene su, sus 11 y yo quiero estar en uno de, en el 11 inicial de él ¿no?. Y pues hay que seguir trabajando para eso" (Entrevistado P9); "¿Y después te dan consejos, te dicen alguna cosa o alguna otra? -Mi papá más que nada (...) Pues, cómo ve, que si me vio mal o me vio bien, me dice que le eche ganas (...) a mí en lo personal me gusta mucho mucho que vengan a verme. Lo siento así como más apoyado, con mucha más seguridad. Y este, y hasta es un motivo como para echarle más ganas ¿no? Trabajar más por ellos” (Entrevistado P3). 
- Pues más que nada seguir trabajando siempre, no desesperarse y siempre dar lo mejor de ti en los entrenamientos, darte (...) este, no se, siento que, pus eso, muchas veces la entrega es lo que te puede llevar. (Entrevistado P3)

- ¿Qué creo? Pues seguir trabajando como estoy ahorita porque por algo estoy aquí, por algo, porque creo que sí puedo llegar. Y pues, nada mas seguir trabajando, trabajando y trabajando, esa es mi palabra, trabajar, al día al día al día al día. Si, en el día a día hacer mejor cada vez y para buscar una oportunidad y quedarte ahí... (Entrevistado P7)

-...Hacer algo más que lo demás ¿no? Quedarme a entrenar extra, mejorar mis deficiencias, y ps, seguir trabajando ¿no? En el entrenamiento matarme, matarme en cada jugada, no dar ningún balón por perdido y como te repito, de quedarme a entrenar horas extras. Que sea dominar el balón, mandar centros, cosas que hace mi posición pues, de lateral. (Entrevistado P8)

- Tener mi mentalidad 100\% que sí puedo llegar, este, trabajar al 100\%, hacer lo que el profe pida y darle, dar todo en los entrenamientos. Jugar bien, estar todo, todo al $100 \%$ ¿no? Para poder estar allá. (Entrevistado P9) ${ }^{132}$

Hasta aquí expuse los elementos que me permiten sostener que un relato central al interior del club es que a Primera se llega a través del esfuerzo. Para que quede claro que se trata de una idea arbitraria, en otros contextos culturales un colectivo de jugadores podría haber dicho que para llegar a Primera se necesita puro talento, contar con gracia divina, dinero, ser líder, hacer jugadas nunca vistas que alimenten el espectáculo o por qué no "cambiar las reglas del juego" como se dice en el marketing, ser estéticamente bellos (el tenis femenino, sin ir más lejos, estuvo largamente influenciado por la apariencia de sus estrellas), o ser un buen comunicador en la cancha para lograr un buen juego asociado $^{133}$. Si retomamos la comparación que hice en el exordio, ¿es esfuerzo lo que se necesita antes que nada, por ejemplo, para ser investigador del Sistema Nacional de Investigadores?

No lo niego, seguramente se necesita de todo: talento, esfuerzo, comunicación, dinero, ser un rupturista, hacer jugadas nunca vistas e incluso, por qué no, un poco de gracia divina y de buena imagen estética (algo que explica que muchos jugadores profesionales cuenten con asesores de

132 Otros testimonios ligados pero no tan claros: “...- Pues ser constante y ser constante con el trabajo y tener los pies bien en la tierra, por decirlo así. - ¿Qué significa tener los pies bien en la tierra - Pues, que cuando subes un escalón, por así decirlo, de subir de categoría, así no, no sentirte el mejor, ni el peor, como luego no dicen. Porque cuando te empiezas a creer el mejor muchas veces empiezas a caer más abajo, por decirlo así. (...) Y pues siempre tienes que mantenerte constante con lo que haces, con tu trabajo, sí, pues yo digo que eso es lo mas importante para llegar, la constancia. (Entrevistado P5)"; - Destacar, en la categoría. -¿Qué significa destacar? - Como soy delantero meter goles. O sea, dar asistencias, apoyar al equipo, pues... Y mas aún si somos campeones. Es cuando nos voltean a ver los de Primera y tenemos oportunidad. (...) - De vez en cuando, para destacar ¿haces otras cosas? -Por ejemplo, hago gimnasio, gimnasio o sea, en la casa el administrador tiene barras y hacemos si. Él me ayuda también porque él también es, este, sabe de esto, de músculos y qué músculos trabajar. Ayer por ejemplo que tuvimos descanso, este, salí a correr. Y en las tardes pues me pongo a patear el balón ahí en mi cuarto, con la pared y así. (...) Y por ejemplo ahorita que hicimos gimnasio hoy, este, yo creo que mañana, mañana siempre los, siempre yo le meto los martes y jueves, porque tenemos un profe en la 17 que nos pone trabos para pierna, pues con él, con él es que con él que me voy a hacer pierna. (Entrevistado P6)

133 Y menciono la comunicación porque fue uno de los elementos que más buscó desarrollar el cuerpo técnico: para ser defensor central, por ejemplo, es sumamente relevante "gritarles" a los compañeros y lograr ser escuchado por ellos para que la defensa no se desarme. 
Sub 17 - ¿De todos los profesores y técnicos que tuviste hasta ahora, ¿qué consejos te quedaron grabados?

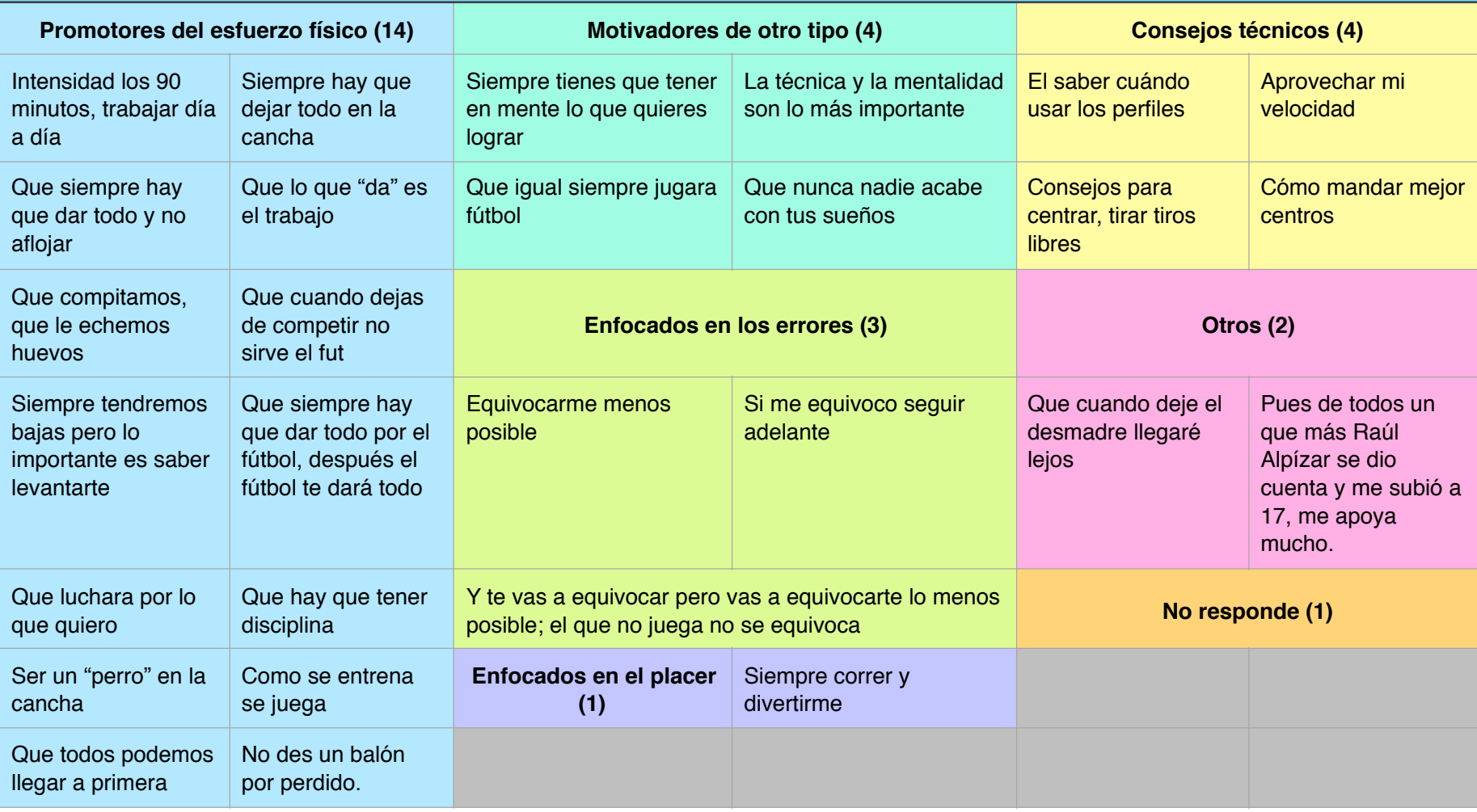

imagen). Pero de todos ellos, en el club se promueve y los jugadores coinciden en que lo central es el esfuerzo físico, trabajar más que los pares. Creo que este relato construye al fútbol como un espacio que permite aglutinar a individuos de sectores económicos diversos y construir la creencia de que todos tienen las mismas posibilidades. Y esto nos da una pauta de la importancia de los mitos y creencias en la reproducción de lo social: no importa dónde naciste, lo que importan son las representaciones que tienes de esas condiciones de existencia -tu relación con ellas- y lo que afirmo entonces es que el fútbol les está diciendo a los chicos que tienen "el futuro en sus manos", que sólo depende de su esfuerzo para llegar a donde quieran llegar. Afirmo, nuevamente, que esto se puede relativizar.

¿Tienen que esforzarse? Sí, por supuesto, y mucho. Y sin dudas ese esfuerzo permite mejorar el desempeño de algunos aspectos del juego (aunque no de otros, como los ligados al juego colectivo, la visión de campo o el desarrollo corporal que necesita la el fútbol profesional) ${ }^{134}$. En segundo término, ¿es el esfuerzo físico una de las pocas variables que los jugadores pueden manejar? En parte sí: el trabajo de campo realizado muestra que los jugadores no son individuos aislados que sólo cuentan con su cuerpo y su esfuerzo para avanzar. Sus trayectorias dependen, en primer término, de que los

\footnotetext{
${ }^{134}$ Por otra parte, los técnicos deberían admitir que en la práctica el esfuerzo permanente y exhaustivo no se produce seguramente porque nadie puede entrenar "al cien" seis veces por semana durante al menos 8 años sin que se convierta en una rutina- y que pese a eso mantienen un nivel de competitividad.
} 
entrenadores estén de acuerdo con su juego y no les moleste su personalidad ${ }^{135}$. Ya vimos en el capítulo 2 que las representaciones de los jugadores se sedimentan y aunque éstos se esfuercen por cambiar puede no ser percibido por los entrenadores.

También vimos que muchos jugadores cuentan con apellidos o avales económicos que les permiten incorporarse a la institución o mantenerse cuando ya "no dan el ancho". Y cada espacio que un jugador con esas condiciones ocupa es un espacio que otro que no cuenta ni con capital social ni económico puede ocupar ${ }^{136}$. Un entrenador de Sub13 me lo dijo con claridad cuando le pregunté si habían recibido alguna indicación de registrar a los chicos que portaban apellido que "son cosas que no te las dicen directamente pero uno no se arriesga". Así funciona la organización informal, sin manuales ni discursos, con lo sabido, con el temor a perder el trabajo, dando por sentado cómo actuar sin decir nada.

Otro ejemplo que permite relativizar la igualdad de condiciones es la casa-club, donde hay solo 18 espacios para aproximadamente 250 jugadores, de modo que aquellos que no viven cerca de la institución o no cuentan con una familia que les pague un hotel no pueden continuar con sus carreras, al menos en Pumas. Veíamos además que las pruebas pueden llevar entre dos y tres meses hasta ser aceptados por la institución y lograr un registro que les permita tener ingresos económicos, de modo que es un tiempo que los futbolistas y sus familias deben costear.

Hay un elemento más: postular que para llegar a Primera sólo se precisa de esfuerzo es considerar que el individuo es dueño de sí mismo, y no es así: no todos los jugadores atraviesan de igual manera el período adolescente, alejarse de sus familias y afrontar el destierro, relacionarse con pares o con jugadores de más edad en la casa-club, manejar la fama, conocer su objeto de deseo sexual. Y vale agregar -esto quedará para otro trabajo- que algunas respuestas de los jugadores en las entrevistas en

\footnotetext{
135 Un claro ejemplo: un jugador de Sub17 no podía pasar a la categoría superior porque dicho entrenador no le caía bien ("le caga su actitud" era la frase textual), de modo que cuando tuvo la posibilidad saltó la categoría inmediatamente superior y pasó a Sub20, donde en su juego daba más ventaja. Otro caso es el del Entrevistado P7, que relató que en un club previo donde era titular le respondió a un entrenador que le hizo una crítica que no consideraba válida y lo dejó sin jugar diez partidos, hasta que necesitó incorporarlo por no tener una alternativa.

136 Vale recordar que la etnografía se realizó en una institución de Primera categoría, donde todos los entrenadores cobran salarios que les permiten llevar un estilo de vida aceptable (en Estudiantes, por ejemplo, un entrenador tenía por las tardes un trabajo como empleado administrativo para completar su salario), y que Pumas es un club simbólicamente asociado a la UNAM, la universidad más importante de América Latina y una institución prácticamente "sagrada" para la población mexicana. Imaginemos entonces qué relaciones se pueden establecer en clubes menores, donde los entrenadores no tienen seguridad salarial y, posiblemente, el factor "oportunismo" se incrementa.
} 
profundidad exponen que muchos de ellos se sienten desamparados por Pumas ${ }^{137}$. En resumen, lo que observo con claridad es que llegar a Primera no depende únicamente del esfuerzo sino de muchos otros factores, que el jugador no es un individuo aislado y que su desempeño ni sus capacidades son resultado de su voluntad.

En segundo término otro relato falaz: que la posibilidad de llegar "siempre está", aunque no seas considerado por el entrenador de tu categoría, aunque no te estés desempeñando bien. Circulan por Pumas y también por Estudiantes las historias de jugadores que no eran considerados y de repente jugaron muy bien un partido, llamaron la atención de los técnicos de un categoría superior, lograron mantener el nivel y en poco tiempo fueron creciendo hasta alcanzar la Primera.

Encontré en mis notas la misma historia atribuida a tres jugadores distintos, aunque aún no logré saber si es que la historia circulaba con distintos nombres o que mi escucha y anotación fue mala. Observemos un testimonio:

- ¿Qué jugadores de cantera ves que llegan a la Primera?

- Omar Islas, o sea él apenas está empezando pero... O sea yo estuve con Omar y... fue hace un año, y a mí me subieron a 17 y yo era así como que "wow me subieron a 17" y él me decía "No güey pos muchas felicidades, y qué padre, y no pos yo voy a pedir mi baja, porque yo veo que ya no me quieren aquí".

-¿Él estaba en Segunda?

- No, ni en Segunda, ya no lo querían en ninguna, y yo le dije "Pos vete a Segunda güey", y dijo "Voy a pedirme un chance" (...) él era más grande que yo, pero la Sub17 fue a Austria y cuando regresaron ellos, empezaron así que a correr a los que no habían hecho un buen trabajo, entonces era mi compañero, pero él era una categoría más arriba. Y fue cuando le dije que se fuera a Segunda y él me dijo que iba a pedir chance, entonces fue a segunda, tuvo 2 partidos buenos, metió gol y ya se quedó en Primera...

(Entrevistado P1)

En Argentina se repetían frases como "nunca se sabe", "el fútbol es así". La historia más reciente era la de dos porteros, Gerónimo Rulli y Agustin Silva. El primero siempre como suplente del segundo, que era el candidato a ser titular del primer equipo. Sin embargo, Silva nunca se consolidó y después de

137 Dos ejemplos: Un jugador que entrena horas extras -es decir, que intenta incrementar su esfuerzo- me cuenta que ya no se siente tan hábil como antes. Entonces le pregunto si lo pudo hablar con [un integrante del cuerpo técnico], y por la respuesta que dicho integrante le habría dado podemos observar que el jugador no se siente acompañado en su esfuerzo: "Sí, hable con él pues de mis, de que yo sentía mi problema ¿no? Digamos que ya no me siento tan hábil, me sentía así. El lo único que me decía pues era que me sacara toda la mierda que tenía en la cabeza pues". Otro jugador, por caso, siente que precisa enviar parte del dinero que cobra a su familia. El conflicto es que para estar en Pumas debe continuar estudiando, y que para hacerlo y que no se le crucen los horarios con el entrenamiento debe ir a una escuela de paga. Como se puede ver en su testimonio, está afrontando un conflicto que no sabe cómo resolver, y es el último día de inscripción: "Y no, no estoy trabajando porque aquí te piden ya que estudies y ahorita veo la forma de conseguir plata para, para poder entrar a la escuela, hoy es el último día que me pidieron para entrar a la escuela (...) - ¿Y crees que vas a poder conseguir esa plata, o con el registro, o cómo vas a hacer? -Pues yo voy a ver la manera de buscarle ¿no? Para poder estar ahí en la escuela y... Es que creo que si te la hacen aquí, te hacen problemas si no entras a la escuela. Tienes que traer el comprobante de donde, de pago y de calificaciones. - ¿Y tú le comentaste tu situación a Magdalena, la encargada? - Sí, pero no he hablado con ella sobre eso. Pero pues sí, hoy es el último día creo. - ¿Y por qué no hablas? -No he ido a hablar pero yo digo que sí voy a conseguir para, para ir". 
una lesión perdió el puesto en manos de Rulli, quien no sólo se quedó con la portería sino que alcanzó el récord de 588 minutos sin recibir goles. A partir de allí logró muy buenas actuaciones durante tres torneos y en junio de 2014 un grupo inversor compró el 80 por ciento de su pase en 4 millones de dólares para transferirlo a la Real Sociedad, donde continúa desempeñándose como titular. Agustín Silva, por su parte, fue relegado del club platense incluso después de pedir explícitamente que lo mantuvieran, y según las últimas informaciones se encuentra entrenando con la cuarta categoría y sin club al cual irse a préstamo.

Desde mi punto de vista, si bien puede haber trayectorias que "confirmen" que hubo jugadores que no eran considerados y subrepticiamente lograron alcanzar el profesionalismo, son nimias. No obstante los relatos circulan, y desde mi punto de vista como promotores de la motivación de los jugadores, ya que si en el primer caso se sostiene que llegar es un asunto de esfuerzo, en el segundo convoca a no perder las esperanzas, a continuar esforzándose al máximo aunque nada muestre que haya posibilidades de desarrollarse en la institución. 


\section{Conclusiones}

Señor: en este partido de fútbol

Daré mi mejor esfuerzo.

Pondré todo mi cuidado y entusiasmo, para lograr la victoria. En tus manos pongo el resultado. No permitas que ninguno de nosotros, ni de ellos se lastime. Si por momentos me olvido de ti, tú nunca te olvides de mí. Amén.

Plegaria de los jugadores, previa al inicio de un partido

En la introducción a este trabajo expliqué que el objetivo consistió en analizar el proceso de profesionalización de jugadores de fútbol a partir de la dimensión del deseo, y que pensar el profesionalismo desde esa lógica me implica observar cómo surgen nuevos aspirantes a futbolistas y de qué manera las instituciones sostienen y desarrollan sus deseos.

Esto me llevó por dos caminos: qué impulsa a un chico a querer ser futbolista profesional y a pensar que es posible concretarlo (entendiendo el deseo como efecto de la promoción de representaciones colectivas y como uno de los factores posibles para impulsarlo) y cómo es materialmente ese proceso: qué sucede cuando ingresan a una cantera. Entonces fui a buscar en el centro de formación de jugadores de fútbol, trabajé con las relaciones que se establecen en los entrenamientos y con los individuos de manera particular a través de entrevistas. Hubo además tres preguntas a lo largo de todo el trabajo: qué motivaciones llevan a los niños a desear convertirse en futbolistas y cómo se sostiene dicho deseo, qué estructura encuentran al ingresar a la institución y qué representaciones se promueven por parte de esta en la dinámica social que se produce al interior e la organización. Trataré ahora de sintetizar los hallazgos observados y de pensar dónde nos dejan parados de cara al futuro.

Comencemos entonces por la construcción del deseo: vimos que entre los chicos Sub13 las encuestas expusieron que la mayoría comienza entre los 3 y 5 años; y que los Sub17, entre los 4 y los 6 . Más allá de la diferencia me parece que es clara la tendencia, y que en términos generales ese rango de edad aparece como central en la constitución de deseos y aspiraciones. Entre ambas categorías habría una caída del barrio como espacio de juego (que en los Sub17 aparece como la principal) y un incremento de los espacios privados: la escuelita de fútbol y las filiales de otros clubes, más una mayor presencia de la escuela primaria como espacio donde se dan clases de fútbol. Afirmarlo con certeza es no obstante prematuro porque entre ambas sólo existe una distancia de cuatro años, y difícilmente haya cambiado tanto la sociedad en ese período como para que aparezca de manera tan radical. 
También resulta interesante haber encontrado que los relatos no se asientan sobre una suerte de "talento" natural que marcaba una diferencia desde el comienzo, y que eso -desarrollado- fue lo que los llevó a la cantera. Lejos de eso, la influencia familiar y paterna aparece como central, y un elemento particular es haber observado que algunos padres no sólo juegan con sus hijos sino que ya desde la primera infancia los entrenaban: según el relato de los entrevistados, el "juego" consistía en pasarse sistemáticamente el balón, luego en hacer golpeos, luego otros movimientos. Además de ello, la presencia de familiares que se dedicaron al fútbol profesional (nada menos que el $80 \%$ dijo tener familiares) también es importante: la admiración suscita deseo y la cercanía familiar, la idea de que es posible. Lo indicaba en el capítulo 4: "hay deseos y formas de devenir adulto que se repiten a través de las generaciones (...) placeres e imágenes que buscan reproducirse". A tal punto que cuando no parecía haber una tendencia o un placer natural, un 30\% de padres parece haber sido lo suficientemente insistente como para lograr cambiar dicho perfil y que los chicos hoy se sientan convencidos de querer dedicarse al fútbol.

Todo esto -sobre todo las formas no coercitivas- está directamente ligado a la identificación simbólica e imaginaria a las que se refería Slavoj Zizek (recordemos brevemente: significa que promovemos determinadas trayectorias porque especulamos que allí recibiremos amor, y que para construir nuestra propia identidad nos identificamos con un Otro que nos gustaría ser). Pero cuidado, porque si nos quedamos con esto caemos en una mirada psicologista y no es esa la perspectiva que adoptamos a lo largo de todo el trabajo. Lo particular es que este deseo aparece extendido en numerosos chicos, de modo que se están poniendo en escena mecanismos promotores de deseos colectivos. A estos elementos nos referíamos cuando en el marco teórico mencionamos a Serge Moscovici y su pregunta por lo individual/social: "cómo el individuo se integra a las colectividades, por imitación y conformidad, por las presiones a la uniformidad ejercida por las masas y los grupos, por la diseminación de estereotipos y la necesidad de reducir la disonancia entre las presiones externas y las creencias y deseos internos" (Moscovici 2004: 19).

Los chicos que se reúnen en las fuerzas básicas estudiadas no son la coincidencia de muchas individualidades que "casualmente" encontraron en sus padres a unos promotores del fútbol sino que hay un proceso colectivo que lo fomenta en parte por vía familiar en un contexto cultural en el que el fútbol es un símbolo dominante, prácticamente omnipresente y que influye sobre numerosos otros espacios. Ahora bien, al estudiar una cantera trabajamos con individuos que ya aspiran a ser futbolistas, 
de modo que indagar en sus representaciones no nos dice qué tan extendido está dicho deseo en relación con otras profesiones. Un trabajo posterior deberá ir a un espacio "neutral" e indagar, como hizo Arlei Damo en escuelas primarias de Brasil, qué tan extendido está el fútbol como aspiración (Damo 2005: 179). Eso nos permitiría poner al fútbol en una ubicación más adecuada en el "campo de los deseos" de los niños mexicanos contemporáneos.

Si hasta ahora vimos la centralidad de la familia, de la escuela y el barrio, la búsqueda de procesos colectivos me llevó a indagar en los medios de comunicación. Hay que admitir que faltó trabajar en profundidad la relación con los medios que se produce en la infancia (me detuve en la relación presente), pero unos pocos relatos surgidos espontáneamente -un niño que veía a su padre por TV, otro que vio a Ronaldo, un tercero que en el Mundial de Brasil dijo "yo quiero estar ahí"- dan la pauta de que las imágenes televisadas en la infancia pueden ser otro elemento importante en la constitución del deseo, a confirmar en un estudio posterior. Si se confirmara, la familia, el barrio, la escuela y la TV parecen ser los espacios de propagación de los anhelos.

¿Qué nos dice lo visto hasta aquí de la noción de habitus de Bourdieu? Que la presencia de la familia como pasado social nos da la pauta de que estar en el mundo no es aleatorio sino condicionado, que sin dudas se expresa un abanico de posibilidades e imposibilidades, de lo razonable y lo irracional, de lo que "es para mí" y lo que no es. Pero tengo que marcar dos distancias: la primera la pregunta sobre si son las condiciones de existencia lo que produce el habitus: si en efecto la familia, el barrio, la escuela y la TV son los espacios que motivan la práctica, podemos preguntarnos si el fútbol circula en ellas de igual manera más allá de las condiciones materiales; si la recepción que hacen los niños del fútbol es similar en los distintos estratos sociales.

Podemos anticipar una respuesta negativa al observar el trabajo de Arlei Damo, quien observó claras diferencias entre la recepción que se hace del fútbol en escuelas primarias públicas y de paga, lo que permite pensar que el estrato social también influye sobre los modos de recepción:

...el prestigio de la profesión del futbolista posee un nítido recorte de dinero y de clase social, como puede observarse en el cuadro a continuación, en el que fueron seleccionadas las 10 indicaciones más frecuentes para la siguiente pregunta: "En su opinión, ¿cuáles son las profesiones más valorizadas en nuestra sociedad?" (...) De los 123 cuestionarios de niños en escuela pública, 44 indicaron que la profesión del futbolista es prestigiosa, prácticamente $1 / 3$ de la muestra. En paralelo, entre los 78 chicos de escuelas privadas, apenas 14 de ellos dieron crédito a los futbolistas, menos de 1/5 en consecuencia. (Damo 2005: 177. Original en portugués, traducción propia)

En este sentido, en un futuro también podríamos partir de la propuesta de García Canclini de pensar la clase a partir del consumo. Pero amerita una lectura más profunda de La distinción -el libro 
de Bourdieu sobre el que trabaja Canclini- y de la interpretación de Canclini mismo para luego poder aplicarla al presente trabajo. Si hubiera recepciones diferentes a partir de las condiciones de existencia, observar los mecanismos que entran en juego será sin dudas una cuenta pendiente, así como pensar al fútbol como Aparato Ideológico del Estado en línea althusseriana.

La segunda distancia que no se puede omitir es que para Bourdieu el habitus es un "estado de cuerpo": el pasado está corporalmente sedimentado, y se está y se actúa en el mundo primero corporalmente. Salir de la propuesta teórica y hacer de ella un estudio no es tan sencillo como parece, porque como investigador uno debería aprender a observar la corporalidad del modo que lo hacen los actores del fútbol. Un punto intermedio y al que sí nos aproximamos es el registro de las indicaciones verbalizadas que aparecieron en el entrenamiento, pero como expuse en el inicio del capitulo 6 no es tan sencillo de sistematizar.

En paralelo, mi trabajo parece exponer la centralidad de las representaciones en la reproducción de lo social, desglosadas en al menos cuatro formas: el comentario, el relato, la fantasía y la creencia. Todas ellas también están ligadas a la segunda pregunta-eje: cómo se sostiene el deseo a lo largo del tiempo. Uno de los primeros elementos que observamos es que las relaciones parentales continúan siendo relevantes en su adolescencia y en su práctica de diversas maneras. Además de las formas de contención observamos en algunos casos presiones, a veces disimuladas bajo la forma del "apoyo" o de la mirada que opina sobre el desempeño del jugador. No obstante, también encontramos que la apuesta del joven por ser futbolista motiva movimientos en toda la familia, que a veces cambia sus rutinas para que el chico pueda asistir a los entrenamientos, o que los acompañan hasta el club dos horas de ida, otro tanto de vuelta y dejan de lado sus actividades. El fútbol se transforma así, a veces, en una actividad familiar, y esto también motiva que los chicos no jueguen para sí sino también para esos otros "que se sacrificaron por ellos", que los acompañaron. Observamos que en 4 de las 10 entrevistas las familias aparecían en los dibujos, en las imágenes de éxito. En paralelo, el caso argentino expuso que aún en ausencia la familia está sumamente presente, y que allí se liga al sufrimiento, a cierta construcción de mártir sobre la que se asienta la práctica: jugador y sus familias sufriendo a distancia por cumplir un sueño.

El deseo formado en la infancia se iría encabalgando sobre relatos (uno es "hacerlo por otros", sin ir más lejos), aunque no encontré en México uno con claridad, como sí sucedía en Argentina, donde la noción de sacrificio, asociada a la humildad y a salir de la pobreza estaban presentes. Esto no significa 
que todos los futbolistas argentinos estén atravesados por dicho relato, ni que entre los futbolistas mexicanos no haya ninguno; lo que no encontré es uno regular, que sea preponderante y marque tendencia. Desde mi punto de vista estas narrativas sobre la práctica cotidiana son centrales porque enmarcan toda la práctica (el esfuerzo físico, la disciplina, hacer de la competitividad deportiva un gesto cotidiano, concentración mental, cambiar horarios, alejarse de los amigos y de hábitos y experimentaciones adolescentes), en pos de un "algo" que tiene que ser socialmente lógico, racional, entendible, creíble. Como decía Castaingts Teillery, son relatos que le permiten estructurar creencias y orientar la acción, de modo que son respuestas que los futbolistas se dan a sí mismos y a sus pares (mejor dicho: necesitan darse a sí mismos y a sus pares), y que les permiten sostener el fútbol a diario. Zizek les daba el nombre de "creencias" y afirmaba que sostienen la fantasía que regula la realidad social en el decir y hacer social. Lo que observamos, entonces, es que toda la trama social aparece sostenida sobre dichos relatos: como dos caras de una moneda, los procesos materiales tienen una contraparte narrativa (y que las narrativas se asientan sobre procesos materiales).

Las estrellas del fútbol profesional también aparecen como una representación que sostiene el deseo, porque expresan la fantasía de lo que puede resultar a futuro. Esto se expresa de dos maneras: como acceso a bienes materiales (aquel testimonio que imaginaba que la vida de Cristiano Ronaldo sin dudas debía ser perfecta) o como la consagración de un modelo moral: los futbolistas no se expresan únicamente por sus condiciones deportivas sino por lo que representan en ese campo de posiciones simbólicas. A veces significan por sus historias, por su capacidad de autosuperación o su disciplina (es el caso de Cristiano Ronaldo, quien pese a tener fama de soberbio se distingue de Lionel Messi por compensar su menor talento con esfuerzo), y en otras ocasiones por el modo en que aparecen públicamente: su sencillez y humildad para manejar la fama (por mencionar el caso de Xavi e Iniesta relatado por uno de los entrevistados). Los futbolistas consagrados pasan, entonces, a ser considerados ejemplos de vida, y a partir de esos relatos que buscan ser imitados es que se promueven formas de accionar en el mundo.

En este sentido, el trabajo expuso que las consolas de videojuegos son también un elemento significante absolutamente presente, y que los futbolistas estrella también se construyen por esa vía (aunque en las consolas lo que aparece fuertemente es su desempeño deportivo, su imagen física y algunos gestos propias). Desde mi punto de vista, la preponderancia de la consola Playstation y de Instagram como plataforma de reproducción de imágenes y pequeños videos a través del celular 
marcan también que en Pumas los jugadores se relacionan antes que nada con un fútbol "fragmentado", un fútbol de jugadas descomunales, de recopilaciones editadas de movimientos particulares, de trastiendas de los partidos, de curiosidades. Miran televisión, miran futbol y también relatan observar a los jugadores de sus puestos, pero mi percepción es que se relacionan sobre todo es con ese fútbol postproducido ${ }^{138}$ y editado por agencias de publicidad. Como efecto de esta relación con el fútbol, la fama está sumamente presente. Aparece solapada, a veces de manera humorística y la mayoría de las veces como aquello de lo que hay que cuidarse, lo que puede arruinar una carrera e -interpreto- que se opone a la moral trabajadora y asceta. Pero está presente y sostiene la motivación: en algunos casos los chicos admiten que la desean y en otros sólo el bienestar que viene asociado al profesionalismo, pero en ambos casos suscita fantasías.

Todo lo visto hasta aquí nos da algunas respuestas al postulado de Víctor Turner, quien pensó la dinámica social como un "proceso de reordenamiento de la acción y de las relaciones respecto a fines socialmente dados, en términos de ajustes que resultan del ejercicio de elección por parte de los miembros de la sociedad" (Turner 2002: 45). El antropólogo escocés daba relevancia a factores como la voluntad y las vías de motivación que se ponen en juego en pos de metas sociales, pero entendidos como "estructuras atemporales", "modelos y metáforas" que los actores tienen en la mente (ídem: 48). La relación con el fútbol en la infancia, el contexto familiar, los relatos que circulan en torno de la práctica, los relatos massmediáticos, los modelos morales, las fantasías, los discursos de poder, todas operan y se ponen en funcionamiento en estos procesos sociales. No voy a afirmar que existen "para" alcanzar las metas porque implicaría una mirada funcionalista que por el momento no observo con claridad, pero sí que están presentes y sí que sostienen aspiraciones, condicionan devenires y promueven modos de actuar.

El capítulo 5 expuso que las organizaciones tienen normativas y formas de operar medianamente autónomas, que no necesariamente se condicen con los relatos del fútbol que circulan en otros ámbitos y que condicionan el camino de los jugadores en pos de su objetivo. La institución es también, entonces, promotora de algunas significaciones. En esta línea, el capítulo 6 expuso otras cinco representaciones que son promovidas desde el club y que son consideradas verdaderas. He aquí entonces el poder operando a través de representaciones. La primera es "tener la oportunidad y aprovechar la oportunidad", ligada a una organización estructurada en torno de la observación. De aquí

${ }^{138}$ Googleo "instagram fútbol” y aparecen dos ejemplos claros: https://www.instagram.com/futbolsport/?hl=es; https:// www.instagram.com/bestoffootball// 
se desprende una coerción del esfuerzo, ya que "te están mirando todo el tiempo, todo el tiempo te tienes que destacar", y si te has esforzado lo suficiente tendrás la "oportunidad" de jugar en el once inicial, y si eso sucede deberás dejar todo (nadie habla de la suerte) para que el entrenador confirme que hizo una buena elección.

Lo paradójico de este caso es que al menos en Pumas los chicos de la Sub17 están lejos de estar profundamente concentrados, de entregarse enteramente en cada balón. La única respuesta que hoy puedo brindar a esta situación es que, como vimos en el capitulo 5, la promoción de una normativa no se transmite únicamente de manera oral, a través de las "intenciones" de los directivos y entrenadores, sino que es el resultado de muchos movimientos en los que también influyen las relaciones informales: el modo en que realizan las elecciones de los jugadores, el modo en que viven en casa-club, el tipo de vocabulario que utilizan para dirigirse a los jugadores, detalles como que no haya una indicación de bañarse al finalizar los entrenamientos... Existe un conjunto de elementos que desde mi punto de vista relativizan los esfuerzos que se hacen desde los entrenadores por promover un esfuerzo y una disciplina constantes. Los futbolistas pueden repetir ese discurso en las entrevistas, saben lo que se supone "debe hacer”, pero en la práctica juegan en la dinámica colectiva que se les presenta.

En segundo lugar hablamos de lo aspiracional: aquí el deseo se construye a partir del temor de quedar afuera. El mensaje es "no hay lugar para todos, esfuérzate porque puedes quedar afuera". Es interesante que el club considera que no alcanza con el sueño de "llegar" para que los chicos dejen todo sino que tienen que generarles la sensación permanente de que no lo están consiguiendo, que en breve pueden no conseguirlo. A partir de lo observado, esta metodología incrementa el stress y la inseguridad de algunos jugadores (no opera en todos igual) y reduce el juego asociado, pero son elementos que no son considerados por los directivos.

Asociado al temor vimos la construcción de la esperanza a partir de la propiciar una imagen de cercanía con el profesionalismo: subirlos de categoría no es únicamente ofrecerle al jugador la "oportunidad" de incrementar el nivel de desafío, ni los viajes son únicamente espacios donde los equipos se enfrentan a rivales de mayor peso, donde los entrenadores pueden conocerlos mejor por pasar días completos con ellos, ni experiencias que promueven la cohesión del grupo. Son eso pero también un ritual en el que se construye la cercanía con el profesionalismo y donde se marca una separación respecto de sus pares no futbolistas, la familia y los amigos del barrio o de la escuela. Si, como vimos, mientras los jugadores "pertenecen" a Pumas son "promesa" de otra cosa, de otro estilo 
de vida, de mayores niveles de éxito, de mayor bienestar, dinero y mujeres, al mismo tiempo se encuentran en una instancia en la que aún no lo son. El club les ofrece, mientras tanto, elementos para que vayan saboreando lo que se puede venir, y marca así una separación respecto de sus orígenes. Viajar al exterior (y me animo a decir: viajar "al exterior" en un mundo global, proviniendo de un país periférico hacia un país central en términos económicos o geopolíticos) tiene una carga simbólica que excede lo instrumental. Un trabajo posterior debería indagar la relación entre los viajes al exterior (o cualquier otro premio simbólico) y el "éxito" como construcción social.

Esto nos conecta con el cuarto dispositivo de poder al que me referí en el apartado 6.4, la “pertenencia". Como se puede ver, la clasificación es sobre todo con fines explicativos pero hay continuidades y puntos de contacto entre ellos. Podrían haber sido tres, podrían ser seis, lo que importa es que hay representaciones con carga política circulando al interior del club y que ellas propician un incremento de la autoexigencia del jugador. Entonces la pertenencia también está ligada a vivir la fama y el status social en tiempo presente. Ambos también generan beneficios que motivan placeres: el poder no sólo es coercitivo, decía Foucault, sino que promueve placeres, saberes, la posibilidad de acceder a nuevas relaciones sociales, ser "reconocido" por personas que de otro modo no lo harían. El poder aquí opera con el siguiente mensaje: "mira a todo lo que accedes por pertenecer, haz lo necesario para mantenerlo".

Y para cerrar, el discurso de la democratización: todos pueden, sólo se necesita esfuerzo físico. Escribía allí que sin dudas se necesita talento y otros factores (de ahí que el reclutamiento sea tan importante), pero a la hora de buscar el desarrollo de los futbolistas el club promueve el esfuerzo físico como valor, y que esto permite simular su igualación más allá de los estratos sociales: no importa dónde naciste sino "lo que des de ti" para alcanzar tus objetivos. Aquí es donde aparece Foucault con todo su peso, porque nos permite pensar el poder (lograr que los chicos continúen trabajando) a partir de la construcción de esos discursos de verdad.

Por todo esto, lo que posibilita o no un devenir no son sólo las condiciones de existencia en sí, que deben presentar un contexto donde el fútbol apareciera como opción más los capitales económicos y sociales que les permitieran ir a las pruebas de Pumas, sino también la relación -las representacionesque los individuos tienen con esas condiciones de existencia. Lo que hace verosímil que eso devenga una trayectoria son las representaciones, y el fútbol les dice a los jugadores que el principal recurso con el que cuentan para alcanzar sus deseos (el que se les ocurra, porque el fútbol que los chicos imaginan 
es un fútbol "con todo": con la pareja que quieran, con la casa y los autos que quieran, con el bienestar que quieran) es el esfuerzo físico. Y en el capitulo 6 ya vimos que se puede relativizar. El otro relato, central al camino al profesionalismo, es que la oportunidad está siempre presente. Mientras pertenezcas a Pumas, la posibilidad está abierta, una verdad que se sostiene sobre los relatos de "casos reales", chicos que perdían toda expectativa y en un golpe de suerte se ganaron la oportunidad y la aprovecharon. En términos de motivación de deseos, estos relatos sostienen la esperanza (sostiene el esfuerzo) aún cuando todo indica que no hay posibilidades de conseguirlo.

En resumen, páginas atrás anticipaba que lo que mi trabajo parece exponer es la importantísima influencia de los comentarios, relatos, creencias y fantasías. A todas ellas las concibo como diversas formas de las representaciones sociales y constitutivas tanto de la reproducción como de la transformación a partir de la promoción de aspiraciones y devenires. En el presente estudio las cuatro aparecieron un poco mezcladas y bajo las mismas definiciones, pero a futuro será nodal abordar cada una por separado y hacer una adecuada clasificación.

No obstante, si me aventuro a partir de lo que surgió en este trabajo haría una primera definición de la siguiente manera: 1) los "comentarios" como los presenta Foucault: aquellos relatos que vienen del pasado y que median nuestra relación con el mundo, relatos míticos o ancestrales que motivan nuevos relatos, relatos que condensan muchos otros en circulación, puntos narrativos nodales de la significación social; 2) las "creencias" como efectos de la voluntad de verdad, y específicamente aquellas creencias que nos ponen en relación con nuestras condiciones de existencia y a partir de ellas definen mecanismos de acción porque construyen los recursos con los que contamos; 3) los relatos: las historias "de éxito" que nos permiten explicarnos, en tiempo presente, aquello a lo que nos entregamos diariamente; 4) las fantasías como representaciones a futuro, como materialización de lo deseable y lo posible (y de lo deseable y que se siente posible aunque no haya oportunidades sensatas de que suceda).

Una de las críticas que se le podría realizar a este trabajo es la ausencia de la voluntad y capacidad de decisión de los individuos. Con sólo mirar el índice encontramos un capítulo dedicado a los deseos (en gran parte como producto de la influencia de "otros"), un segundo capitulo dedicado a las lógica de la organización en la que se incorporan, y un tercero en el que se observan los dispositivos de poder que se ponen en práctica sobre los futbolistas. En ese marco, ¿dónde están los jugadores? La teoría de la estructuración de Anthony Giddens buscó relativizar la mirada reproductivista, la idea de 
que lo que hacemos es sólo producto de los condicionamientos del pasado -ya sea incorporado al inconsciente o ley interior hecha cuerpo, como venimos viendo- y expresó que los actores tienen capacidad de "hacer cosas", eventos en los cuales un individuo es un autor porque podría haber actuado de manera diferente" (1995: 49). Esto no significa necesariamente que el individuo opere a partir de intenciones sino su capacidad de hacerlo. No implica intenciones porque las acciones no necesariamente se condicen con lo que efectivamente se hace, y porque si bien sólo excepcionalmente se preguntan las razones o intenciones de su conducta, sí mantienen una comprensión respecto de sus actos. A esto lo denomina una "conciencia práctica": el modo en que los actores saben cómo operar en la vida cotidiana. A diferencia de la teoría bourdieana, aquí los individuos tienen una comprensión respecto de su accionar ${ }^{139}$.

En este trabajo se han expuesto algunas representaciones que les permiten a los individuos comprender sus acciones y experiencias, aunque la concepción a lo largo del trabajo es que tales son naturalizadas y que con ellas no se tiene una relación de distanciamiento. Respecto de la capacidad de los actores de "hacer cosas", de actuar de distinta manera, diría en principio que la etnografía no expuso -o no supe ver- elementos en una magnitud tal que me permitieran esbozar al menos un apartado.

Los chicos saben, afirman permanentemente que la escuela es una suerte de camino seguro y que si bien en el fútbol tienen todas las posibilidades de perder, si acaso "ganan" se llevan "ganancias extraordinarias", por ponerle un nombre. Al mismo tiempo, la apuesta por el fútbol no contradice preceptos familiares ni sociales -de hecho, cuenta con el apoyo del entorno-, de modo que aún como decisión podríamos pensar que es efecto del pasado sedimentado, hecho cuerpo. No tengo una respuesta clara al respecto: problematizar teóricamente y a partir de lo que indica el material de campo la relación entre reproducción y transformación, influencia pasada y libertad de actuar, y la capacidad del individuo de romper con lo sedimentado o lo inconsciente será central en un trabajo futuro.

Me interesa sin embargo presentar dos situaciones en las que encontré decisiones por parte de los jugadores en relación a sus carreras. La primera se dio en Argentina, tiene que ver con los representantes comerciales (los "managers") y permite relativizar que la capacidad de agencia se dé

\footnotetext{
${ }^{139}$ En su teoría, la acción es pensada desde una óptica dinámica -es decir, no una sumatoria de acciones individuales- y argumenta que las actividades sociales "son recursivas", idea que define de la siguiente manera: "Equivale a decir que actores sociales no les dan nacimiento sino que las recrean de continuo a través de los mismos medios por los cuales ellos se expresan en tanto actores. En sus actividades, y por ellas, los agentes reproducen las condiciones que hacen posibles esas actividades" (Giddens 1995: 40).
} 
exclusivamente bajo los carriles "institucionales", bajo las normas que la sociedad promueve. En el país sudamericano veíamos que los chicos no cobran dinero por parte del club por jugar en fuerzas básicas, que en la mayoría de los casos se encuentran desterrados de sus pueblos o ciudades de origen, y que 4 de 10 chicos entrevistados dijeron contar con un representante. No fue abordado en este trabajo pero también se observó que en el camino entre sus ciudades y Estudiantes de la Plata muchas veces los caminos eran zigzagueantes, pasaban en promedio por 4 o 5 clubes y lo hacían de la mano de entrenadores, representantes, familiares que los ubicaban y reubicaban buscando su máximo desarrollo. Como consecuencia, los chicos aprenden que el camino hacia el profesionalismo está atravesado por todos esos factores, y a partir de esas representaciones de lo que es el fútbol es que recurren a los representantes. Además de darles dinero, el representante provee acompañamiento y apoyo, pero sobre todo -y aquí es donde veo la agencia- es una figura con contactos que le permite al jugador contar con una alternativa en el caso de que en el club en el que juega deseen prescindir de sus servicios. Es decir que los jugadores buscan (a veces con sus padres) llegar a Primera no sólo por los carriles de la organización a la que pertenecen sino que hacen sus propias búsquedas, sus propios intentos, apuestas y especulaciones.

En segundo lugar se puede mencionar el caso de un jugador de la Sub17 de Pumas con talento y proyección que a comienzos de septiembre de 2015 decidió dejar de jugar. Lo mencionaré brevemente porque tengo diversos testimonios pero no el del jugador, de modo que sería injusto hacerlo en profundidad. La historia cuenta que el chico un día no fue, al día siguiente tampoco y ahí el entrenador se preocupó, le preguntó a uno de sus mejores amigos en el equipo y el amigo le contó que se había ido de la casa paterna porque el padre no quería que fuera a entrenar porque no competía ni le ponía ganas. Que el chico se habría enojado, le habría respondido mal y que el padre lo echó de la casa. En ese momento aún no se sabía dónde estaba durmiendo pero había dejado toda su ropa de entrenamiento y pertenencias en la casa familiar, a la que no podía volver. Tampoco atendía el teléfono celular. Días después el chico apareció en el entrenamiento sin ropa para entrenar y habló con el entrenador. Repitió un discurso similar y agregó que tampoco estaba yendo a la escuela. El entrenador le dijo que él también pensaba que estaba bajo de competencia y le propuso que se tomara hasta diciembre para ver qué quería. Que no tomara una decisión apresurada y que intentara superarse y recuperar la competitividad que le estaba faltando. Le sugirió que le pidiera disculpas al padre, que le dijera que se equivocó y que le pidiera al padre la posibilidad de cambiar. 
Días después, cuando el club se contactó con el padre, la historia cambió: el chico en efecto se había ido de la casa y no estaba asistiendo ni al club ni a la escuela, pero porque estaba "encerrado" con una novia en la casa de la abuela. Cuando el entrenador pudo volver a hablar con el chico, me contó que le dijo frases como las siguientes: ¿Tú sabes las mujeres que podrías tener si llegas a Primera? ¿En serio te pones de novio ahora y dejas todo? ¿Tú conoces a la primera mujer de Cuauhtemoc Blanco y las que tuvo después? Además, ¿qué clase de noviazgo es ese? ¿Qué pasa con la chica que no está en la escuela? ¿Qué pasa contigo que no vienes al entrenamiento ni a la escuela? ¿Es un noviazgo para hacerse bien mutuamente o no?

En otra ocasión el coordinador de la cantera me dijo, enojado, que no se podía dejar ir a un jugador así, que en muchas ligas desearían largamente un defensor como él y que sin dudas había que sentarse con el chico, con el padre y que el joven volviera a entrenar. La coordinadora académica fue por el mismo camino: que invitara al padre a tomar un café y hablaran "de hombre a hombre". En resumen, al poco tiempo el joven se reincorporó y a modo de castigo comenzó entrenando con la Tercera, es decir una categoría menor. ¿Qué significó esto? Que en el momento en que un joven con condiciones intentó (por el motivo que fuera) romper el camino que había trazado hasta el momento, desligarse de la inversión, de su formación y de la vida que había hecho hasta el momento, todo el entorno se puso en funcionamiento (no tengo información sobre la reacción familiar). En mis últimas visitas el chico continuaba oscilando entre Sub17 y la Tercera, con altibajos en sus rendimientos y cada vez menos elementos para ser considerado una promesa.

En uno de los primeros párrafos de la tesis hablaba de la metáfora del embudo y proponía que me interesa trabajar con el centro de formación como una suerte de signo, de manifestación de una estructura social más vasta. Podría decir incluso que cuando me hago la pregunta por la constitución del deseo, por las relaciones al interior de la organización/institución, por las formas de poder (y podemos agregar por la agencia) también me estoy preguntando hasta qué punto lo visto aquí es factible de ser trasladado a otras instancias. Un trabajo futuro implicará pasar de lo particular a lo global, de lo específico a lo general: ¿hay elementos que unifiquen diversos recorridos -los académicos y los empresariales, los políticos y los oficios-, hay representaciones que en nuestra época contemporánea se repitan más allá de los devenires y puedan establecerse como dominantes? 
Personalmente encuentro en esas preguntas una suerte de mapa, un método de abordaje y un campo teórico a problematizar.

¿Por dónde más seguir? Por el cuerpo, volver al cuerpo y observar esa relación que aquí dejamos ausente y a la que le escapamos un poco. Analizar también los discursos massmediáticos y la construcción de significaciones masivas y transnacionales a partir de su relación con los patrocinadores y con los Estados-Nación, aunque siempre observando cómo son recepcionados en las diversas geografías porque no hay sentido por fuera de los individuos.

Se hace necesario también incorporar otras perspectivas. El Dr. García Canclini me propuso dos (que, pido disculpas, no supe incorporar en este trabajo): trabajar a partir de Bruno Latour y pensar a los actores en red para pensar lo social, y preguntarse cómo opera "la invención y los estilos personales en la configuración de los sujetos-jugadores y en su interpelación (¿creativa?) con los disciplinamientos estructurales de las instituciones".

Para cerrar, volver a los análisis en producción. Por ejemplo: si Castaintgs-Teillery proponía pensar un paralelismo entre deporte y empresa a partir de la competitividad ${ }^{140}$, ahora sí observar y cotejar, con el análisis en recepción ya realizado, cuánto del paralelismo que podría existir entre empresa y deporte se está llevando a la práctica, un gesto que significa salir del análisis sincrónico e intentar pasar al diacrónico, a lo estructural, para observar a lo largo del tiempo si hay tendencias que se reproducen, si hay tendencias que se reproducen transformadas, o si hay transformaciones absolutas que auguran nuevos mundos.

\footnotetext{
140 "Tanto el deporte como la empresa conducen a una sociedad de competencia generalizada. En esa competencia se le da gran valor al individuo y se ensalzan la cualidades de flexibilidad, independencia, movilidad, autonomía, la de buscar y encontrar sus referencias en sí mismos y la de realizarse por medio de su acción personal" (Castaingts Teillery 2011: 327)
} 


\section{Referencias bibliográficas}

Alabarces, P. (2001) Fútbol y patria.: Deporte, narrativas nacionales e identidades en la Argentina, 1920-1998. Tesis de doctorado. Reino Unido: University of Brighton.

Alabarces, P. (2004). Crónicas del Aguante. Fútbol, violencia y política. Buenos Aires: Capital Intelectual.

Alabarces, P. (2010). "Entre la banalidad y la crítica: perspectivas de las ciencias sociales sobre el deporte”. Martínez, S. (coord.). Fútbol-espectácilo, cultura y sociedad. México: Universidad Iberoamericana - Afínita Editorial

Alabarces, P. (2014). Héroes, machos y patriotas. El fútbol entre la violencia y los medios. Buenos Aires: Aguilar.

Althusser, L. (1976). "Freud y Lacan”. Posiciones. Barcelona: Editorial Anagrama."

Althusser, L. (1988) Aparatos ideológicos del Estado. Freud y Lacan. Buenos Aires: Nueva Visión. Disponible: http://perio.unlp.edu.ar/teorias2/textos/m3/althusser.pdf.

Archetti, E. (1985). Fútbol y ethos. Buenos Aires: Flacso

Arnold-Cathalifaud, M (2008). "Las Organizaciones desde la Teoría de los Sistemas Sociopoiéticos". Santiago de Chile: Facultad de Ciencias Sociales, Universidad de Chile. Disponible: http:// www.facso.uchile.cl/publicaciones/moebio/32/arnold.html

Barthes, R. (2010). Mitologías. Buenos Aires: Siglo Veintiuno.

Boas, F. (1993 [1896]). "Las limitaciones del método comparativo de la antropología”. En Bohannan, P. y Glazer, M. (comp.) Antropología: lecturas. Madrid: McGraw Hill.

Bosshardt, A. Green, M. y otros (2015). Revolution. Annual Review of Football Finance. Deloitte. Disponible: http://www2.deloitte.com/cr/es.html

Bourdieu, P. (2010). El sentido práctico. Buenos Aires. Siglo Veintiuno.

Brand Finance (2015). Football 50. 2015. The annual report on the world's most valuable football brands. June 2015. Disponible: http://brandfinance.com/images/upload/ bf_football_50_low_res.pdf

Castaingts-Teillery, J. (2011). Antropología simbólica y neurociencia. Barcelona: Anthropos Editorial; México: UAM-Iztapalapa. División de Ciencias y Humanidades. 
Castaingts-Teillery, J. (2016). "Campos, organizaciones, empresas y cambios estructurales. Un punto de vista a partir de la teoría de los sistemas complejos adaptativos". Ponencia ante el 6to Coloquio Internacional ISEOR - AOM. 9 y 10 de junio, Lyon.

Collazo, C. (2011) "Mito, ideología e inconsciente. Orígenes perdidos de la estructura, el sujeto y la historia”. En: La Trama de la Comunicación, Volumen 15. Rosario: UNR Editora.

Czesli, F. (2013). “Apuntes sobre la identidad en la hinchada de Platense”. Garriga Zucal, J. (comp). Violencia en el fútbol. Investigaciones sociales y fracasos políticos. Buenos Aires: Ediciones Godot.

Czesli, F. (2015). “Las instituciones ¿un puente entre lo material y lo simbólico?”. Ensayo de finalización de cursada de la asignatura Antropología de los sistemas económicos. Ciudad de México: Universidad Autónoma Metropolitana-Unidad Iztapalapa. Inédito.

Damo, Arlei (2005). Do dom à profissao. Uma etnografia do futebol de espetáculo a partir da formação de jogadores no Brasil e na França. Tesis presentada para la obtención del título de doctor junto al programa de Posgraduación en Antropología social de la Universidad Federal de Río Grande do Sul. Porto Alegre: inédito.

Durkheim, E. (1912). Las formas elementales de la vida religiosa. México: Colofón

Eco, U. (1988 [1977]) Cómo se hace una tesis. Técnicas y procedimientos de estudio, investigación y escritura. Barcelona: Gedisa.

Fernández Fernández, J.M \& Puente Ferraras, A. (2009). "La noción de campo en Kurt Lewin y Pierre Bourdieu: un análisis comparativo”. En: Revista Española de Investigaciones Sociológicas N ${ }^{\circ} 127$, pp. 33-53. Madrid: REIS.

Fortes, M. y Evans Pritchard, E.E. (2010 [1940]). Sistemas políticos africanos. México: Centro de Investigaciones y Estudios Superiores en Antropología Social: Universidad Autónoma Metropolitana: Universidad Iberoamericana.

Foucault, M. (1973). El orden del discurso. Barcelona: Tusquets

Foucault, M. (1980). Microfísica del poder. Madrid: La Piqueta.

García Canclini, N. (1990). "Introducción: La sociología de la cultura de Pierre Bourdieu". En: Bourdieu, P. Sociología y cultura. México: Grijalbo

García Canclini, N. (2005). Diferentes, desiguales y desconectados. México: Gedisa.

Garriga Zucal, J. (2007). Haciendo amigos a la piñas. Violencia y redes sociales en una hinchada de fútbol. Buenos Aires: Prometeo Libros. 
Giddens, A. (1995) La constitución de la sociedad. Bases para la teoría de la estructuración. Buenos Aires: Amorrortu Editores.

Glockner, V. (2014). “Trabajo infantil y regímenes de gubernamentalidad: slums flexibles, ONGs y producción de subjetividad en la India contemporánea”. Tesis de doctorado en Ciencias Antropológicas. México: Universidad Autónoma Metropolitana-Unidad Iztapalapa.

Gonzalez, A. (2015). “Pelotismo, cortito y a cobrar”. Disponible: http://www.futbol-pf.com.mx/

González Echevarría, A. (1990). Etnografía y comparación. La investigación intercultural en antropología. Barcelona: Universidad Autónoma de Barcelona.

Hall, R. (1982). Organizaciones, estructura y procesos. Madrid: Editorial Dossat [Prentice Hall Inc.]

Jodelet, D. (1986). "La representación social: fenómenos, concepto y teoría". En Moscovici, S. Psicología social II, Pensamiento y vida social. Psicología social y problemas sociales. Barcelona: Paidós, pp. 469- 494

Jodelet, D. (2011). “Aportes del enfoque de las representaciones sociales al campo de la educación”. En Revista Espacios en Blanco - Serie indagaciones - No 21 - pp.133-154. Traducción: María Matilde Balduzzi

Kertzer, D. (1988). Ritual, politics and power. NY: Vail - Ballou Press

Logatt Grabner, C. (sin fecha). "Neurobiología del deseo y el placer". Disponible: http:// www.asociacioneducar.com/articulo-neurobiologia-deseo-placer.php

Moscovici, S. (1979 [1961]). El psicoanálisis, su imagen y su público. Buenos Aires: Editorial Huemul S.A.

Moscovici, S. (2004). Precondiciones para la explicación en psicología social. En: Revista Polis 03, Investigación y análisis sociopolítico y psicosocial. Volumen 2. Ciudad de México: Universidad Autónoma Metropolitana, Unidad Iztapalapa. ISBN: 970-31-0282-4

Murayama, C. (2014). La economía del fútbol. México: Cal y Arena.

Murzi, D \& Czesli, F. (2014) De aprendices a profesionales. Un análisis comparativo de la formación de futbolistas en Europa y en América Latina. Investigación realizada gracias a la João Havelange Research Scholarship. CIES-FIFA.

North, D. (1990). Instituciones, cambio institucional y proceso económico. México: Fondo de Cultura Económica. 
Parrini Roses, R. (2015). Deseografías. Antropología del deseo y prácticas de la diferencia (El Club Gay Amazonas). Tesis de Doctorado en Ciencias Antropológicas. Universidad Autónoma Metropolitana - Unidad Iztapalapa. Ciudad de México: Inédita

Peirce, C. (1974). La ciencia de la semiótica. Buenos Aires: Nueva visión

Ribeiro, L. C. (2008). "Impacts du football mondialisé en Europe et en Amérique Latine". Segura Trejo, F. Y Martinez Andrade, L. (Coords). Primer encuentro transdisciplinario. París: Casa de México en Paris.

Rodríguez, M.G. (2013). “¿Qué es un campo, y tú me lo preguntas?”. Branz, Garriga Zucal \& Moreira.Deporte y ciencias sociales: claves para pesar las sociedades contemporáneas. La plata: EDULP

Segalen, M. (2005). Ritos y rituales contemporáneos. Madrid: Alianza Editorial.

Segura Trejo, F. Y Martinez Andrade, L. (Coords). Primer encuentro transdisciplinario. París: Casa de México en Paris.

Solares, B. (2003) "La pedagogía imaginal del mito". En: Símbolos y arquetipos en el hombre contemporáneo V. Formas arquetípicas de la relación maestro discípulo. Ciudad de México: Universidad Autónoma Metropolitana - Unidad Xochimilco. Área de Polemología y Hermenéutica.

Tudela Sancho, A. (2000). "El deseo y sus máquinas: en torno al sujeto nómada en Deleuze y Guattari". En: Revista de Filosofía, N³6, pp. 47-73. Murcia: Universidad de Murcia.

Turner, V. (1980). La selva de los símbolos: aspectos del ritual ndembu. Madrid: Siglo XXI editores.

Turner, V. (2002) “Dramas sociales y metáforas rituales”. Geist, I. (comp), Antropología del ritual. México: ENAH.

Uribe Echeverry, J.G. (2015) “Deseo, lenguaje, moral: perspectiva psicoanalítica”. En: Revista Affectio Societatis, Vol. 12, No 22, enero-junio (pp. 37-46). Medellín: Universidad de Antioquia Medellín. Disponible: www.iatreia.udea.edu.co/index.php/affectiosocietatis/article/download/21378/17750

Voloshinov, V. (1976). El signo ideológico y la filosofía del lenguaje. Buenos Aires: Nueva Visión.

Zizek, S. (1992). “Che vuoi?”. El sublime objeto de la ideología. México: Siglo Veintiuno

\section{Referencias periodísticas}

Collazo, J. (14 de marzo de 2014). “Los 'otros' mexicanos en el extranjero”. Disponible en: http:// www.mediotiempo.com/futbol/mexico/noticias/2014/03/14/los-otros-mexicanos-en-el-extranjero 
El Mundo, (30 de abril de 2015) "Objetivo: 1.500 millones para el fútbol”. Disponible en: http:// www.elmundo.es/deportes/2015/04/30/554262b3ca4741a87a8b4572.html

Fútbol Finanzas (10 de enero de 2014). "El Gobierno utiliza el fútbol para lavar la imagen de la "marca España"”. Disponible en: http://futbolfinanzas.com/el-gobierno-utiliza- el-futbol-para-lavar-laimagen-de-la-marca-espana/

futbolistasaxem.com.ar (5 de noviembre de 2015). "Estos son los 1693 jugadores argentinos que juegan en el exterior (Noviembre de 2015)". Disponible en: http://futbolistasaxem.com.ar/archivo-3/

Guerrero Atiliano, Rubén (1 de enero de 2016.) "La camada que viene". Disponible en: http:// laaficion.milenio.com/pumas/Pumas-Memo Vazquez-cantera-Bernabe Magana-jesus gallardoomar_islas_0 656934355.html

Guerrero Atiliano, Rubén (1 de marzo de 2016.) "La camada que viene". Disponible en: http:// laaficion.milenio.com/pumas/Israel_Landa-canetera-pumas-liga_mxclausura_2016_0 692930822.html

Heras, R. (2 de julio de 2014). "Brasil, la cantera del fútbol mundial". Disponible en: http:// www.rtve.es/deportes/20140702/brasil-2014-brasilenos-mundo/960561.shtml

Ibarra, Marisol (14 de septiembre de 2015). "El liderato de Pumas no pasa por la cantera". Disponible en: http://www.mediotiempo.com/futbol/mexico/noticias/2015/09/14/el-liderato-de-pumas-nopasa-por-la-cantera

Inferiores Plateases (9 de septiembre de 2015). "El caso ireba". Disponible en: http:// www.inferioresplatenses.com.ar/noticia/el-caso-ireba

juanfutbol.com (25 de julio de 2015). "Televisa hace suyos partidos con hasta 15 puntos de rating". Disponible en: http://juanfutbol.com/articulo/tpadilla/televisa-hace-suyos-partidos-con-hasta-15puntos-de-rating

LosPumasUnam.com (19 de agosto de 2014). "Memo Vázquez Mejía fuera de las fuerzas básicas... francotirador". Disponible en: http://www.lospumasunam.com.mx/ memo_vazquez_mejia_fuera_de las_fuerzas_basicas_francotirador-noticias de_pumas_unamispyp-1096604.htm

Ozanian, M. (2015). "Las 40 marcas deportivas más valiosas del mundo". Revista Forbes, edición online, sin fecha. Disponible en: http://www.forbes.com.mx/las-40-marcas- deportivas-masvaliosas-del-mundo/

Pérez, I. (26 de enero de 2014). "Los equipos de Futbol más valiosos en México". Revista Forbes, edición online. Disponible en: http://www.forbes.com.mx/el-valor-de-la- industria-del-gol-enmexico/ 
Pérez I. (10 de abril de 2015). "Futbol y televisión, el negocio más codiciado". Revista Forbes, edición online. Disponible: http://www.forbes.com.mx/futbol-y-television-el-negocio-mas-codiciado/

Romero, M. (26 de noviembre de 2015). "Pumas: ni un peso para la UNAM". Disponible: http:// www.contralinea.com.mx/archivo-revista/index.php/2014/01/26/pumas-ni-1-peso-para-la-unam/

Terra.com (3 de septiembre de 2015). "Futbolistas mexicanos que también juegan en el extranjero". Disponible en: http://deportes.terra.com.mx/futbol/mexicanos-en-el-extranjero/futbolistasmexicanos-que-juegan-en-diferentes-1igas-de $1-m u n d o$, 33e1d68605026ca84d0439fd15d69d93z9k1RCRD.html

Tóvar, R. (10 de febrero de 2015). "Cuauhtémoc Blanco será candidato por el PSD para Cuernavaca". Disponible: http://www.espn.com.mx/news/story//id/2295684/cuauhtemoc-blanco-seracandidato-por-el-psd-para-cuernavaca 


\section{Anexo}

*1 Análisis de las cuatro dificultades de la metodología comparativa expuestas por Aurora González Echeverría (1990): la calidad de los datos etnográficos, la homogeneidad de las unidades analizadas, el lenguaje en el que se realiza la comparación y el problema de Galton.

Respecto de la calidad de los datos etnográficos en el trabajo se pusieron de manifiesto dos situaciones. Mientras en el Club Universidad Nacional toda la investigación fue realizada por mi persona, en Estudiantes de la Plata realicé el trabajo etnográfico y ocho de las diez entrevistas en profundidad. Las dos restantes pertenecen al Magíster en Sociología Diego Murzi, quien se ha desempeñado en un proyecto similar tanto en Francia como en Argentina, consiguió el contacto con el equipo francés gracias a haber residido en Francia y cuya colaboración me permitió superar la necesidad de resolver las entrevistas que yo no pude realizar durante el mes en que estuve presente en Estudiantes de la Plata. En Marsella es donde esta situación es algo más compleja, ya que si bien perfeccioné mis conocimientos de idioma francés con el objetivo de realizar la mejor etnografía posible, no fue suficiente para realizar las entrevistas con solidez, de modo que fue Murzi quien se hizo cargo de la cuestión mientras que yo trabajé sobre la observación participante en los entrenamientos.

Si bien el trabajo conjunto con Murzi se probó sumamente fructífero y provechoso, y aunque se pautaron los ejes para las entrevistas y las preguntas centrales, debo conceder que el modo en que ambos pusimos en práctica las entrevistas en profundidad resultó ser distinto. Como consecuencia, en algunos casos observé que las respuestas cambiaron en función del modo de realizar la pregunta y que la calidad de los datos se transformó. Por ende, el contenido de las entrevistas realizadas por el colega sólo será utilizado si observo que son pertinentes y con la referencia a su autoría. En este sentido y considerando la clasificación que González Echevarría recupera de Haekel (1990:58), toda la información recopilada por mí corresponde a fuentes directas, mientras que la proveniente de Murzi será considerada como evidencia indirecta.

Por fuera del detalle de las entrevistas mencionado, podemos imaginar que todas las entrevistas y observaciones realizadas cuentan con la misma calidad de datos en la medida que fueron realizadas por mí mismo, a excepción de un elemento: que como se trata de la primera experiencia en clubes de fútbol hubo un proceso de aprendizaje y de evolución. Por tal motivo, si bien los ejes de análisis se mantuvieron estables, progresivamente fui generando diversas estrategias para intentar alcanzar los resultados más satisfactorios. A modo de ejemplo puedo afirmar que recién en la última entrevista realizada en Pumas (la última de todas, en consecuencia) creo haber dado un paso importante para indagar en las imágenes respecto de la influencia de la fama y el dinero en el deseo. Lo conseguí cuando le pregunté al jugador cómo se imaginaba dentro de diez años y -luego de que me diera las respuestas tradicionales- repregunté cómo se imaginaba viviendo, es decir su rutina, su pareja y cómo lo/la habría conocido, el espacio en el que habitaría, el tipo de vehículo en el que se transportaría, su vida social, etc. Lo que salió a la luz fue una innumerable cantidad de fantasías desbocadas que, si se continuara la indagación y tales respuestas se constituyeran como tendencia darían la pauta de haber dado en la tecla en lo referente a dichas representaciones.

Agrego un dato sobre la realización de las entrevistas: decidí realizar conversaciones semiestructuradas y priorizar la búsqueda de un clima para promover un clima de confianza con los futbolistas que contar con respuestas para todos ejes de análisis. Eso significa que si bien contaba con una entrevista base, fui conduciéndome con los entrevistados a través de conversaciones en las que fui preguntando a partir de la percepción que del otro tuve. Preguntar, por ejemplo, “¿cuánto crees que vales?” podía generar desconcierto (“¿acaso tengo un valor?”) o desconfianza (“¿me querrá comprar?"). Por este motivo no en todos los casos realicé la misma cantidad de preguntas ni las 
formulé de la misma manera. No obstante, creo que la posibilidad de repreguntar que ofrece este sistema es más provechoso que realizar una entrevista estructurada que priorice contar con respuestas de todos los actores a todas las preguntas.

Sobre la homogeneidad de las unidades analizadas sucede algo similar: se partió con una serie de ejes a analizar en función de las preguntas e hipótesis propuestas, que se fueron ajustando en función de los elementos que ofrecía la observación. Sin embargo, las unidades analizadas terminó siendo similar en los tres casos, ya que el foco estuvo puesto en los tres casos en las categorías seleccionadas y sus cuerpos técnicos; en Pumas y en Estudiantes -gracias a contar con más tiempo- se trabajó con las autoridades del club y encargados de la educación de los jugadores; en Marsella, finalmente, se entrevistó a uno de los encargados de la casa-club, pero la entrevista con el coordinador de la cantera fue realizada por el Mg. Murzi.

Respecto del lenguaje en el que se realiza la comparación, puedo mencionar que para las entrevistas en francés tomaré la traducción que el propio Murzi realizó -excepto en el caso de conceptos centrales como reussir ma vie, para el que se consultó a un traductor especializado-, y que en relación a la observación utilizaré mis propias notas e interpretaciones, que se suman a múltiples notas grabadas y vueltas a escuchar con más tiempo, a los que se agregan las conversaciones en idioma español con el técnico de la categoría U17, con quien se cotejaron interpretaciones al finalizar los entrenamientos.

Finalmente, el problema de Galton expresa la necesidad de asegurarse de que los elementos comparados no son producto de un accidente que se originó sólo una vez -sobre todo producto de la difusión- sino que es la matriz cultural la que les da origen ${ }^{141}$. Pero por el tipo de trabajo realizado, al interior de una organización, la difusión no es una cuestión que se presente como relevante, ya que incluso cuando los jugadores manifestaron anécdotas de clubes anteriores nos resulta un elemento relevante porque continúa expresando una representación a través de la que practica el fútbol. En paralelo, la posibilidad de que lo observado haya sido accidental sí es un riesgo, sobre todo si pensamos las organizaciones como estructuras estáticas con una fuerte lógica interna. Debemos conceder que dado que las observaciones fueron de un mes en el caso más extenso, un trabajo más prolongado en el tiempo permitirá definir qué elementos son nucleares y cuáles periféricos, pero jamás rechazaremos un dato por no generar tendencia. Incluso, si adoptamos la propuesta de Raymond Williams (1988) de pensar la cultura a partir de tres elementos: lo dominante (aquellos elementos que en un punto del proceso histórico se presentan como preponderantes), lo residual (los aspectos que provienen del pasado) y lo emergente (los nuevos significados, prácticas y relaciones que se crean continuamente).

Esto significa, asimismo, que si bien la dimensión temporal del estudio realizado expone énfasis en el plano sincrónico, se concibe al Centro de Formación como una organización en permanente transformación, algo que se pone de manifiesto no en un abordaje histórico sino en haber estado atento a los elementos que podrían provenir de tradiciones y formas de hacer pasadas. El ejemplo más claro más adelante lo veremos con más profundidad- es la recurrente mención por parte de los entrenadores de que "antes las cosas eran distintas", y que ahora "los jugadores tienen todo".

\footnotetext{
141 “...estar seguro de la independencia de las costumbres de las razas y pueblos que se comparan antes de establecer conclusiones a partir de la correlación de rasgos culturales de distintas sociedades, puesto que estas correlaciones no siempre eran consecuencia de conexiones causales entre los elementos de la cultura, sino que podían ser resultado de procesos de difusión. Nos encontraríamos así ante un fenómeno que se originó una sola vez y no ante el producto repetido del ajuste entre rasgos culturales" (Gonzalez Echevarría 1990: 84).
} 
*2 Ejes utilizados para la realización de la entrevista en profundidad en Pumas

Sin nombre. Decir en el grabador entrevista número $X$

Puesto y edad.

Empezamos con 3 dibujos.

7 minutos

a) Consigna: "Dibuja tres imágenes que se te vengan cuando pensás en tu sueño futbolístico"

b) Pedirles que expliquen las imágenes.

c) Preguntas complementarias, por las dudas

- ¿Cual es tu sueño como jugador?

- ¿Que significa el éxito para vos?

\section{Situación social}

a) De dónde es, dónde vive. Cuánto tiempo viaja por día, cómo se traslada

Ver si aparece la noción de sacrificio.

a1) Si vive en la casa-club, preguntar por la situación ahí.

b) ¿Cómo empezaste a jugar el fútbol? ¿A qué edad?

// ¿Quién te llevó a tu primer club? ¿Qué te acuerdas de esa época?

c) ¿Qué clubes anteriores antes de Pumas?

d) ¿Cómo llegaste a jugar en Pumas? ¿Por qué elegiste Pumas? ¿A qué club le vas?

// Cómo fue el proceso de selección e ingreso a la institución

\section{Su familia}

a) ¿Cómo está compuesta tu familia?

b) ¿A qué se dedican?

c) ¿Qué opina tu familia de que te dediques al fútbol?

d) ¿Alguien en tu familia jugó al fútbol?

e) ¿Te ayudan a que juegues? ¿De qué manera lo hacen?

f) ¿Vienen a verte a los partidos?

g) ¿Te dan consejos? ¿Qué te dicen?

h) ¿Estudias? ¿Cómo te va en la escuela?

i) ¿Qué hacés el resto del día?

¿Playstation? ¿Con qué equipo jugás? ¿Por qué?

¿Tratas de hacer en la cancha jugadas que hacés en la Play?

k) ¿Tenés amigos? ¿Qué hacen ellos? ¿Qué dicen de tu vida como jugador?

Relación con la institución

a) ¿Qué es lo que más te gusta de Pumas? ¿Qué es lo que menos te gusta?

b) ¿Qué ídolos de Pumas conocés?

c) ¿Cuántos técnicos tuviste hasta ahora? ¿Cuáles son los que más te gustaron y por qué?

d) ¿Qué es lo que más recuerdas que te enseñaron?

e) ¿Cómo te dicen que tenés que jugar? ¿Por qué hay que jugar de esa manera?

f) ¿Qué te dicen que corrijas? ¿Para vos por qué aún no lo corregiste?

g) ¿Qué cosas buenas te pasaron acá?

h) ¿Y cosas no tan buenas? ¿Con quién las hablas?

h1) ¿En qué o quién pensás cuando las cosas no te salen? ¿Cómo te das ánimos? 
i) ¿Cómo llegaste a tener tu posición en el campo de juego? ¿Siempre jugaste ahí?

j) ¿Qué opinas de tu equipo? [Ver cómo funciona una pregunta bien general]

k) ¿Cuáles son los puntos fuertes de tu equipo? ¿Y las debilidades?

1) ¿Para vos cómo tiene que jugar tu equipo?

m) ¿Cómo crees que lo están haciendo? (Si es distinto) ¿Por qué?

n) ¿Por qué venís todos los días a entrenar?

\section{Relación con el fútbol}

a) ¿Para vos cuáles son las características que tiene que tener un profesional del fútbol?

// ¿Vos te consideras futbolista profesional? ¿De qué depende para vos?

b) ¿Como qué jugador te gustaría ser? ¿Por qué?

c) ¿Dónde lo ves / lo viste? ¿Seguís su carrera?

d) ¿Miras, lees o escuchas fútbol o sobre fútbol? ¿Qué te interesa? ¿Qué buscas ver?

e) ¿Qué opinas de la vida de los jugadores fuera de la cancha?

f) ¿Con las chicas, es mas fácil siendo jugador?

\section{Plan B}

a) ¿Qué crees que tenés que hacer para llegar a Primera?

// ¿Qué es lo que más te cuesta de jugar al fútbol?

b) ¿Te da miedo la posibilidad de no llegar?

c) ¿Qué pensás hacer si no llegaras a Primera?

d) ¿Y si Pumas no te renovara para la próxima temporada qué harías?

e) ¿Alguna vez pensaste en no jugar más? ¿Y qué pasó?

\section{Relación con el dinero}

a) ¿Cómo te costeas los gastos?

b) ¿Cuánto cobras?

c) ¿Tienes manager? ¿Qué relación tenés? ¿Te gustaría tener? ¿Por qué?

d) ¿Qué tipo de relación/vínculo tenés con el club?

e) ¿Cuánto imaginas que vales?

f) ¿Que te genera que los jugadores sean comprados y vendidos?

g) Ahora se escucha muy seguido que los jugadores juegan solo por la plata: ¿qué opinas?

h) ¿Cuánto crees que ganarías si firmaras contrato?

i) ¿Qué harías con tu primer salario como profesional?

Final: Asociación libre.

Las primeras 5 palabras o ideas que se te ocurran. No hay ningún problema, podés decir lo que sea

- fútbol

- Pumas

- profesional

- mamá

- dinero

- equipo

- papá [separado de "mamá", para ver si aparecen distintas relaciones familiares]

- chamba

- dirigentes,

- mujer [para ver si sale lo de la fama/fiesta] 
*3 Formato de encuesta

Club Universidad Nacional A.C.

Encuesta número

Esta encuesta es absolutamente anónima. No escribas tu nombre en ningún lugar.

Si no te alcanza el espacio para seguir escribiendo puedes continuar del otro lado de la página. Sólo agrega el número de pregunta y continúa.

1) Edad actual:

1b) ¿A qué edad empezaste a jugar al fútbol?

2) ¿Dónde empezaste? (Puedes marcar más de una opción)
a) En el barrio/en la calle
b) En una escuelita de fútbol

c) En una filial de un club

(¿De qué club?

d) En la escuela

e) En otro lado ¿īónde?

¿Había clases de fútbol ahí? Sí _ No

3) ¿A qué edad fuiste por primera vez a una escuelita de fútbol?

¿Por qué decidiste ir?

4) ¿Cuántos años tenías cuando llegaste a Pumas?

5) ¿Alguien en tu familia (o un allegado) se dedicó al fútbol? (puedes marcar más de 1)

Madre__ Padre___ Hermana___ Hermano___ Tío___ Abuelo___ Ninguno

Otro/a ¿quién? ¿Dónde jugó/jugaron? ¿Hasta qué categoría llegó/llegaron? Si no llegó a Primera, ¿por qué?

7) ¿Qué opinan en tu familia de que te dediques al fútbol?

8) ¿Podrías contar tres consejos que se te hayan quedado grabados? (De tu familia o de otros)

9) ¿A qué jugabas cuando eras chiquito? (No solo deportes sino todos los juegos que recuerdes)

10) ¿Por qué quieres ser futbolista?

11) ¿Qué es lo que más te gusta de estar en Pumas?

12) ¿Qué es lo que menos te gusta de estar en Pumas?

13) De todos los profesores y técnicos que tuviste hasta ahora ¿qué consejos te quedaron grabados?

14) ¿Qué características crees que tiene que tener un futbolista profesional?

15) a. ¿Te sientes un futbolista profesional? Sí __ No

b. Si la respuesta es Sí: ¿En qué momento te sentiste así por primera vez?

16) Además de la exigencia ¿cuál es la diferencia de jugar en Pumas? 
17) ¿Qué cosas consideras que aprendes en Pumas (además de a jugar fútbol)?

18) ¿Quién es tu jugador favorito? ¿Por qué?

19) ¿Te da miedo la posibilidad de no llegar a Primera? Si

No ¿Por qué?

20) ¿Cuántas horas a la semana miras programas de fútbol?

21) ¿Qué programas miras, diarios lees o a qué sitios de fútbol sueles ingresar?

22) Si no llegaras a Primera ¿qué harías?

No sé

23) ¿Alguna vez pensaste en no jugar más? Sí __ No _ _ Si la respuesta es Sí: ¿Qué pasó?

24) ¿Tienes manager/representante?

Sí __ No pero me gustaría ___ No me interesa ___ ¿Qué es un manager/representante?

25) Si un club quisiera que juegues para ellos, ¿crees que tu transferencia vale dinero? Sí __ No __ No sé ___ Si la respuesta es Sí: ¿Cuánto?

26) ¿Cuánto imaginas que ganarías en tu primer contrato en Primera por quincena?

27) ¿Qué harías con ese primer salario?

No sé

28) Cuando piensas en tu futuro en el fútbol, ¿qué sueños se te vienen a la mente? Escribe 3

29) ¿Con qué estilo de vida te imaginas viviendo como profesional? Menciona 5 situaciones de lo que sería tu vida cotidiana. (Continúa al reverso si no alcanza el espacio)

30) ¿Juegas al FIFA en la Play/Xbox etc? Sí _ No

a) Si la rta. es Sí: ¿Cuántas horas por semana?

b) ¿Intentas llevar al campo de juego jugadas que haces en el FIFA? Sí

c) Si la respuesta es Sí: ¿Cuáles?

29) ¿Qué crees que Pumas debería mejorar?

30) ¿Quieres pedirle/sugerirle algo al Profe? (Aprovecha para enviarle tus comentarios de manera anónima) 
*4 Casos de jugadores en Estudiantes de la Plata que aprendieron a relacionarse con los padres de una manera que les resulta más adecuada. “-¿Cómo es eso de tener a tu papá en la tribuna [su padre fue futbolista profesional]? - No, me gusta. -¿Te gusta o te presiona más? -No, igual él sabe desde chiquito que si me viene a ver que vea callado y después me diga las cosas. - Ah, ¿por qué? ¿Antes te gritaba mucho? -No, porque veía padres yo de chiquito que ya les gritaban a los hijos y no me gustaba. Hasta los hijos se ponían mal que les gritaba el padre -Y vos que conocías a esos compañeros, ¿de verdad se ponían mal? -Sí, se ponían mal, eran chiquitos, muy chiquitos todavía. Pero desde ahí mi papá nunca me gritó. -Y en general ¿qué cosas te dice después del partido? -Antes del partido me dice 'jugá tranquilo, tratá de no equivocarte que vos sabés' y después del partido me felicita, aunque haya jugado bien o mal me apoya, está bueno" (Entrevistado E4). Otro caso: “- ¿Tu padre te dice cómo jugar? -Sí. ¿Vienen a verte a los partidos? -Sí. - ¿Y qué te dicen? -Nada, que juego bien, que tengo que empezar a gritar. Todo como siempre ¿no? ¿ ¿Siempre desde chiquito te iban a ver y te iban indicando? -Sí, cuando era más chico más todavía, ahora casi nada. -¿Para vos cambia algo jugar y que esté tu papá en la tribuna o no cambia nada? -R: Está bueno ¿no? Porque te vienen a ver, pero ya es normal. -P: Pero no te genera una sensación de presión... -R: No" (Entrevistado E6).

*5 Testimonio del Entrevistado E8: “- Yo sigo por mi familia. (...) - Por lo que han hecho por mí. ¿Qué hicieron por vos? - Y... me han bancado [apoyado]. Cuando estuve acá una semana a prueba estuve en un hotel allá en el Banco Provincia, y no sé cuánto salió, estuve cuatro días, mi viejos están separados. - ¿A qué se dedican? -Mi vieja trabaja en una cárcel, en una unidad y mi viejo trabaja... es silero, ¿viste los silos que hay, los grandes? - Sí, de trigo, de maíz. -Claro, de hecho ahora está en La Pampa. Y se ha dedicado, cuando yo estaba en Racing y tuvo que firmar él, ponele que estaba en... No me acuerdo dónde estaba, y se vino del trabajo, firmó y se fue de vuelta porque se tenía que ir a trabajar. Yo creo que ellos me han ayudado mucho, mi papá, mi mamá más que nada. Es por eso que sigo. ¿¿No lo hacés por vos mismo? - Y, yo lo hago por mí, lo hago por mi mamá, por mi familia más que nada, por mi hermano. Sigo por ellos, porque yo lo que veo si le digo "no mamá, me quiero ir a mi casa, no quiero seguir más" yo veo que todo lo que ellos hicieron yo lo estoy tirando a la mierda".

*6 Dibujos y descripción de los jóvenes sobre su sueño futbolístico ligado a las familias.

(Entrevistado P1) "El primero [sueño y dibujo] sería debutar en C.U. Y yo voy a entrar, y que por uno de mis motivos o de lo que estoy luchando, que mi familia vea que apenas estoy empezando, y que voy a lograr lo que tanto había trabajado. Por lo que tanto sacrificio había hecho. (...) -O sea lo que aparece ahí en el... digamos en el círculo es tu familia. - Es mi familia. -¿Y cómo es tu familia? ¿Quiénes son? -Eh... es mi mamá, mi papá, mi hermana, mi sobrina y mi cuñado, y mi hermana está embarazada otra vez (...) ¿Y te los imaginas a todos ellos en la tribuna? - Ajá. ¿Y acá en el estadio en C.U.? -En el estadio. -¿Y estás entrando de suplente ahí? -Sip. - ¿Y entras a...? Debutar. -Y decías recién que por todo lo que trabajaste ¿eso es que lo estás consiguiendo? -Sí, como que... sentirse orgulloso de mi ya está, pero como que, yo agradecerles por todo el esfuerzo que han hecho para mí, para que yo cumpliera o cumpla mi sueño".

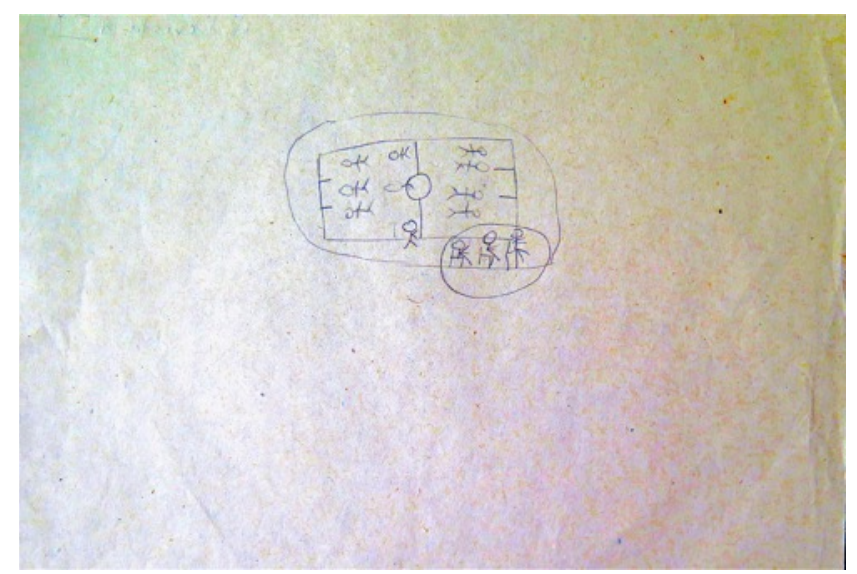




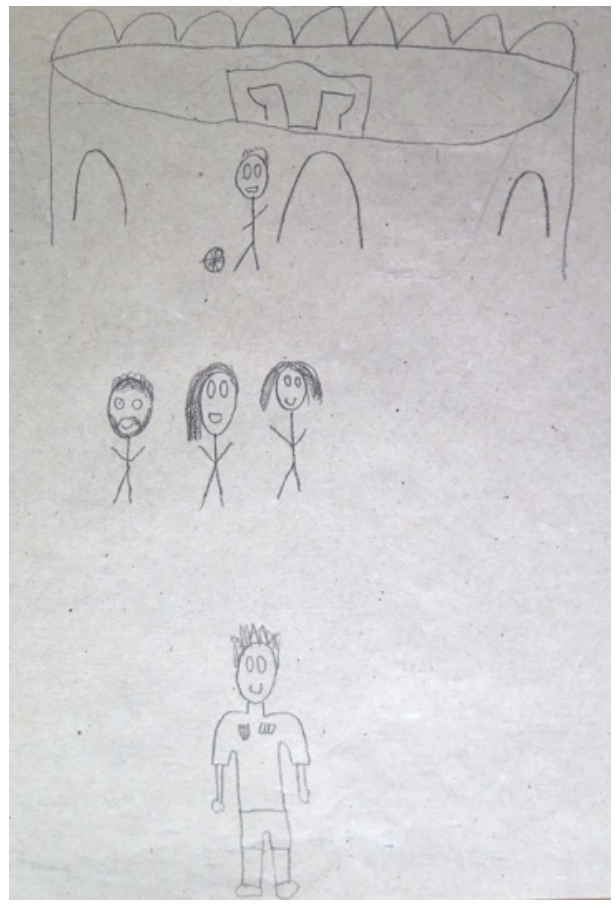

(Entrevistado P4) “-Bueno, la siguiente, es de mi familia. Mi familia que siempre me ha apoyado en todo y pues, me gustaría, bueno siento que son orgullosos, pero quiero los quiero verlos feliz. ¿Eso sería en algún lugar en especial? ¿En la puerta de tu casa o en algún espacio? -Pues, en mi casa y en el estadio, por que siempre están ahí apoyándome en todo lugar. Este, mi madre, mi padre, mi hermana, o mis amigos. - $Y$ esta imagen ¿sería de ellos alentándote? ¿O tú haciendo qué con ellos? - Alentándome, alentándome. En el estadio".

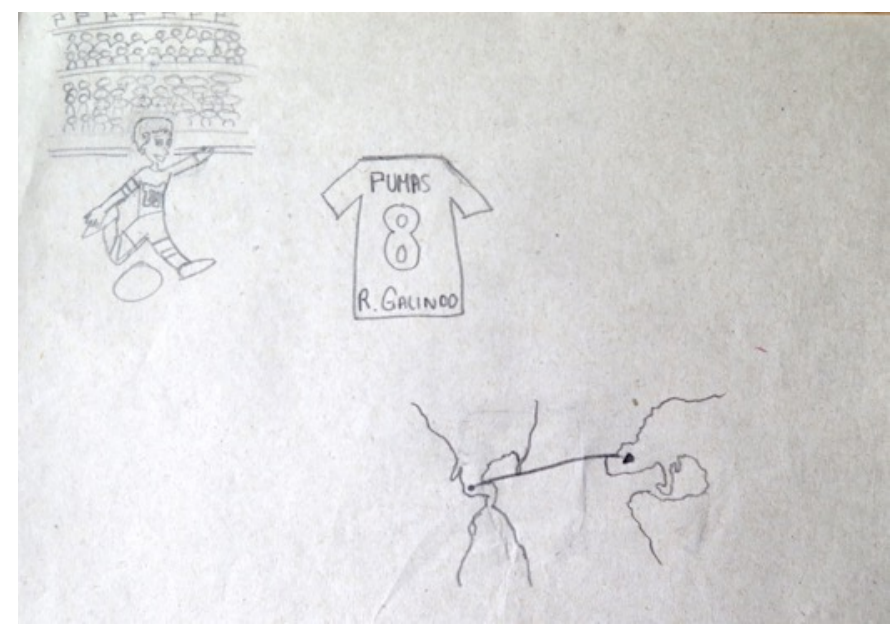

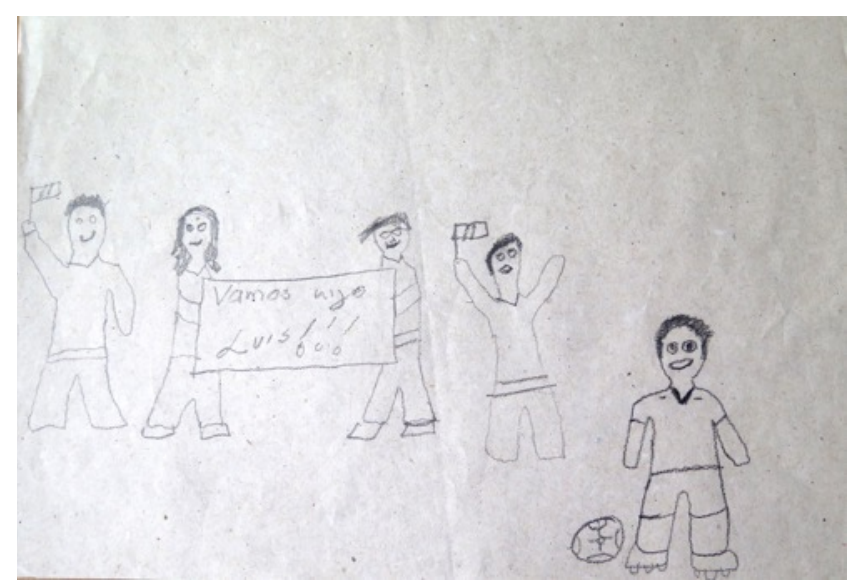

(Entrevistado P5) “-Y también sí, tan sólo portar la playera para mí es muy bonito, la verdad. Siento, siento bonito cuando porto la playera y si se llega a dar, llegar, portarla en Primera División en un estadio, con mi nombre, je, la playera, todo sería muy bonito por todo, todo el esfuerzo que he llevado a cabo, tanto mi familia que son los que me apoyan siempre y ps todas las personas que me han apoyado durante mi carrera futbolística, por decirlo así’". 
*7 Discurso de apertura a los encuentros de coaching:

José Luis Arce: Antes que nada gracias por venir porque como quedamos con esta empresa que yo considero que es la mejor en esto del coaching, quedamos que este asunto no iba a ser obligatorio para nadie, porque ese asunto del trabajo mental depende de la persona que lo está llevando a cabo. Los de la Sub17 los integramos ahora en este proyecto porque estamos considerando que para ustedes a lo mejor les brinda el trabajo para mejorar en el desarrollo mental, que es la que en definitiva termina haciendo la diferencia entre un buen jugador y un jugador de alto rendimiento, un jugador mediocre y un jugador de excelencia. Aquí lo que necesitamos son jugadores de excelencia, pero para tener jugadores de excelencia es importante que las personas sean de excelencia, porque de lo contrario tenemos una silla de 3 patas, donde la cuarta pata siempre le faltará y la silla se caerá. Siempre habrá una parte que falte y en este caso no es una parte cualquiera, es la parte medular de la persona que es el aspecto mental. Eso también lo tenemos que entender y es importante: si alguien no quiere, si alguien no puede o no está convencido al cien de que le hace falta o cree que ya le sobra, perfecto, no nos vamos a meter con eso. Lo que pasa es que al final del día lo que nosotros queremos son jugadores para la Primera División, jugadores que no me los regresen de la Primera sino que se consoliden, que debuten y se queden, triunfen y que lo que aparezca, si es que se repite lo del otro día, es que sean jugadores emblemáticos. ¿Alguna duda chavos? Entonces ahora les van a hacer una presentación bastante breve, irán a comer y luego comienzan con el coaching individual.

Coach 1: Buenas tardes a todos, muchas gracias por estar aquí. Un gustazo conocerlos, es un honor estar aquí con ustedes. Estaba pensando ¿cuántos jugadores tienen aquí en pumas?

Baeza: Como 230.

Coach 1: De 230 aquí hay 24, pero de más de 200 jugadores están aquí ustedes. ¿Ya lo habían pensado? ¿Por qué están aquí? A lo mejor ni saben por qué están aquí. Vamos a ver si en esta charla se dan una idea de por qué están aquí. Vamos a arrancar. Viendo esta foto de unos colegas de ustedes [muestra una foto de jugadores sin una pierna], que al verla seguramente estás pensando cosas, ¿verdad? Y yo te pregunto a ti: ¿Qué le impide a un deportista alcanzar su máximo nivel? ¿Qué se les ocurre? Los que ya vinieron no vayan a soplarles.

Jugador: la mentalidad.

Coach 1: Pues sí, ¿verdad? Yo de estos cuates, ¿si no tienes dos piernas cómo vas a jugar futbol? ¿Sabían que hay un mundial de estos cuates? ¿Lo han visto? Hay un Mundial... a lo mejor les falta una pierna, y ya me imagino qué otro tipo de cosas tienen que desarrollar para suplir... ¿Se imaginan qué hay en la mente de esos cuates? La primera es imagínense qué les habrá pasado. Y la siguiente es que después de lo que les pasó, qué tipo de pensamientos y de mentalidad tuvieron para estar jugando futbol. ¿Se imaginan? Piensen. También hubo un caso de un cuate que no le faltaba una sino dos piernas, y ese cuate una vez dijo "Yo quiero competir en las Olimpíadas en atletismo, quiero correr en 200 y 400 metros". Y le dijeron "Sí, perfecto, hay olimpíadas para especiales", y él dijo "No no no, yo quiero competir en las Olimpíadas normales, de gente común y corriente, correr 200 y 400 metros". "Pero tu no tienes piernas, le dijeron, tú no puedes". Le dijeron "tú no puedes, tú-nopuedes". Y el cuate dijo "¿Y eso qué? Voy a demostrarles que sí puedo". Él solo no podía, ¿pero qué hizo? Se dio cuenta de que aparte de él, él extendió su cuerpo y dijo: ¿Quiénes son los mejores ingenieros biomecánicos? Ayúdenme. ¿Quiénes son los mejores entrenadores, PF, nutriólogos? Y él juntó a esas personas y dijo "quiero que me ayuden a competir en las Olimpíadas". ¿Lo han visto? Y ese cuate persiguiendo su sueño, lo que buscaba, que muchos le dijeron tú no puedes, aparte de haber logrado lo que quería, este cuate ha aportado infinidad de cosas a la medicina deportiva y a la biomecánica en el mundo. Si él se hubiera quedado cuando le dijeron que no podía, el mundo nos hubiéramos perdido primero de verlo a él competir, y luego nos hubiéramos perdido de grandes avances de la tecnología aplicada al deporte, por una persona que hubiera caducado si creía que no podía.

Ahí vamos aterrizando por qué estamos aquí. ¿Quién me diría cuál es la diferencia entre algunos deportistas mexicanos y algunos deportistas americanos? ¿qué se les ocurre? Podrían decir la mentalidad ¿no? Pues sí ¿y cómo se mide eso? Muchos de ustedes ya han ido a jugar giras internacionales, estoy en lo cierto ¿no? O que han jugado con gente de Estados Unidos o de Europa. ¿Cómo se explica esa mentalidad? [no responden] ¿Hay aquí algún capitán de equipo? O que señalen los demás ¿quién es el capitán? ¿Tú qué crees? ¿Cuál es la diferencia entre la mentalidad de un americano y un mexicano? Todas las respuestas son buenas, al fin y al cabo es tu opinión

Jugador: Pues aparte de la mentalidad, yo creo que nos ponen un pero y ya no podemos solucionar las cosas. Como que siempre nos dicen que no y ya no no le cae bien; los americanos yo creo que aunque les pongan peros encuentran la forma de sacarlo adelante 
Coach: [se dirige a otro jugador] Te veo muy pensativo ¿cómo te llamas? ¿Qué piensas tú? ¿Qué le sumas a lo que dijo Carlos?

Jugador: Que los americanos luchan por conseguir lo que quieren, y por conquistar lo que trabajan.

Coach: Y sí, les voy a contar una anécdota, y de ahora en más les voy a pedir que pongan atención a las entrevistas de los deportistas mexicanos y los americanos. Ahora van a ser las Olimpíadas. Un mexicano consigue su pase a las Olimpíadas y sale en el periódico: lo logró, consiguió su pase a las Olimpíadas. "Oye Samuel, conseguiste tu pase a las Olimpíadas, ¿cómo te sientes?" Y responde Samuel, mexicano: "Sí, para esto me preparé toda mi vida, y lo logré". Y la gente ah bravo, y va a preparar las maletas, que empiezan las Olimpíadas, y el desfile, las maletas, ¿lo han visto? Vean TVC deportes y vean los clasificatorios de las Olimpíadas, de natación, y las competencias, y vean cuando van saliendo de la alberca los deportistas americanos: "-Oye este muy bien, acabas de conseguir tu clasificación a las olimpiadas. -Sí, este es el paso normal en la búsqueda de romper el récord mundial”. ¿Lo han oído? ¿Hay diferencia o no? El cuate dice "Sí, normal, normal, yo estoy en mi entrenamiento y mi (...) es tardar 1 minuto, voy por 50 segundos para romper el récord mundial en un año". ¿Hay diferencias? Como hablamos creamos nuestra realidad. Acá: "Para esto me preparé toda mi vida, para calificar a las Olimpíadas". Claro, llega a las olimpiadas y se queda en la primera eliminatoria, no? Y hay algunos que se empiezan a cambiar el chip. ¿Se ve la diferencia? En cómo se habla se crea la realidad. Por esto es que los que vamos a hacer de coaching vamos a estar muy atentos a cómo es que hablas tú. ¿Para qué nos preparamos en México comúnmente en el fútbol, a nivel de selección? Para calificar al Mundial. Para que califiquemos y busquemos el quinto partido. Pero uno no puede contra el país, contra 120 millones que piensan así. Entonces vamos a la concentración para el Mundial: "Bien muchachos, vamos a prepararnos para calificar". Ese tipo de cosas hablarán ellos, porque como hablan crean su realidad. Primera reflexión: ¿Cómo hablan entre ustedes en el equipo? ¿Como los de acá o como los de allá? Si empiezo a hablar como los de allá los de aquí me empiezan a decir que no. O me quedo extra al gimnasio y los demás no me dejan entrar. $\mathrm{O}$ me dicen que no. O quiero traer mi comida para mi dieta y me critican. ¿Carlos? ¿Vamos bien? Si yo les pregunto a ustedes, sean honestos: ¿para qué están aquí en Pumas? ¿Qué me van a decir? ¿Qué buscan al llegar aquí? Jugar en Primera División. ¿Qué más? Consolidarme. ¿Qué más? Jugar en Europa. ¿Qué más? Ser seleccionado. ¡Claro! Y trabajamos con deportistas, con futbolistas en Monterrey, en Querétaro, en Guadalajara, y no soy mago pero ¿tu por qué juegas en pumas? Ahí están. No soy mago pero aparecieron sus respuestas. Pero falta una: por eso estamos aquí nosotros. Por esa última respuesta que falta estamos todos aquí, ustedes. Por esa única respuesta que exactamente falta. Porque en cada club que vamos se vuelve a cumplir y acá se repite. Falta una respuesta. Levante la mano quién se le ocurre una. Quiero que piensen, falta una. Falta una que si tú tienes esa acá, de corbata te llevas todas las demás.

Jugador: ¿consolidarme en Europa?

Coach: Mmm es buena, es buena respuesta, pero eso pasa.

Jugador: ¿Para ser el mejor?

Coach: ¿Dónde?

Jugador: En el mundo

Coach: Falta una poquita aquí: ¿en qué equipo juegas?

Jugador: En los Pumas

Coach: ¿Por qué aquí nadie dijo "yo quiero ser el mejor jugador de la historia de Pumas”? Díganme los mejores jugadores de la historia de Pumas.

Jugadores: Hugo Sánchez, David Patiño [risas, Patiño está presente], Jorge Campos, Luis García.

Coach: ¿Jugó en Europa? ¿Jugó en Mundiales, Copas América? Con esa, de corbata te llevas todas las demás. Pero estamos, casi todos en el fútbol estamos como borregos en lo que se dice "Llegar a Primera, jugar en Europa, en la Selección". Y hemos perdido esa... Entonces ¿qué va a pasar en este proceso? A ustedes los han invitado para empezar a trabajar. Un proceso personal con coaches deportivos, que trabajan la parte vital y emocional basada en el siguiente esquema. Fíjense: toda la vida... ¿desde qué edad han jugado fútbol? ¿6 años? ¿Están de acuerdo? Unos llevan 11 años jugando futbol, otros llevan 14 años jugando futbol, ahí está su base física, técnica y táctica. Por supuesto que hay algo mental y emocional que han trabajado ahí, y hasta el momento ustedes traían esta idea de que busco que me convoquen, en primer equipo, que debute, que juegue en la Selección... Esto vamos a hablar en el coaching. Levante la mano si alguno se había propuesto alguna vez ser un símbolo Puma. Honestamente. Por ahí uno, dos, tres. Pero lo tenemos ahí, nos vamos más por las otras. Esa base que ustedes tienen nosotros la vamos a hacer como la pretemporada, y en vez de preparación física les vamos a dar una base para que se suban a un escalón y desde aquí ese escalón se va a construir en ese proceso que vamos a trabajar. A eso que está ahí le vamos a poner unas bases totalmente enfocadas a la parte mental y emocional. Practicamos con la directiva varias veces y sabemos que el sello Puma se ve y se vive en la 
honestidad, lealtad, la tolerancia, la congruencia, el compromiso, la fortaleza mental y el sello Puma. Son cosas que se viven todos los días aquí, ¿no? Pero uno dice ¿y entonces? Entonces esa histórica selección del 94 era la base de los Pumas creo yo, casi casi 20 años... Todo esto tan abstracto como las virtudes las vamos a aterrizar en un modelo de trabajo que les va a ser más cómodo. Todos entrenan diario ¿verdad? Todos juegan, entonces tienen un análisis del partido, durante el partido, después del partido. Entonces vamos a trabajar en todos estos elementos: la actitud, la confianza, el autocontrol, la concentración, la visualización del éxito, la fortaleza mental, la competitividad, la motivación. ¿Por qué? Porque hay algunos que la revientan cada vez que juegan ¿no? Pero el tema de ellos son los entrenamientos. O hay muchos de ustedes que entrenan como Pumas, como fieras, ¿o no? Pero llega el antes del partido, que algo pasa, empiezan a jugar y no acaban de jugar. Llegan totalmente clavados al partido, llegan al partido y la rompen, pero el árbitro te dice algo y te expulsan. Entonces juegas un partido y te expulsan 3, porque además golpeaste a un rival. Entrenadores también, entrenadores que se preparan todo el tiempo y que por una u otra cosa durante el partido impiden que el equipo fluya. ¿Se van dando cuenta de las cosas que vamos a ver? Cada uno sabe sus fortalezas en los entrenamientos, antes del partido, durante el partido, después del partido. Pero todo el mundo automáticamente puede encontrar un área que sabe que si esa área la mejorara su rendimiento sería muchísimo mejor ¿o no? Levante la mano quién sabe un área que si la trabajara sería mucho mejor futbolista. ¿Y la han trabajado? Muchos han trabajado la parte técnico táctica. Ahora vamos a trabajar la parte de aquí, la parte de adentro, la presión que se siente acá, que se sienten en las orejas, jugando a las 12 del día con el calor, esos pensamientos que vienen, ese tipo de cosas vamos a trabajar. ¿Va quedando clara la idea? Esto es un entrenamiento, ustedes entrenan diario dos horas. Es un proceso, 8 sesiones, tendrás un coach personal, un entrenador personal, así como está de moda el crossfit y el $54 . .$. Un nutriólogo ustedes ya lo tienen: tienen entrenadores, tienen nutriólogo, todo eso ya lo tienen. Ahora los que decidan seguir adelante en el proceso van a tener un coach personal, que son los que estamos aquí. Te vas a reunir con él cada 15 días. "El entrenamiento lo que a mí más me cuesta es el arranque del entrenamiento. Me cuesta mucho arrancar las semanas y luego el entrenador se enoja porque empiezo como qué..." Vamos a trabajar cómo lo vives, cómo lo procesas, de dónde viene. Tendrás tu coach personal durante 4 meses para tocar tus temas. Se verán aquí, se echarán whatsapp, se echarán llamadas... Todo eso está dentro de un proyecto mucho más amplio de lo que tú te imaginas. Llevamos desde el año pasado trabajando con los entrenadores, las pláticas con la directiva, ahorita julio y agosto está este lanzamiento, las sesiones quincenales están marcadas, el seguimiento electrónico entre cada sesión. Skype si a algunos se les familiariza esa cuestión. Vendremos los coaches a observarte, es más si tu nos invitas "Oye ya me convocaron voy a jugar el fin de semana" tratamos de venir a verte y te observamos. El coach te observa, el coach te da retroalimentación, vas a tener a alguien que va a estar pendiente de ti cuatro meses. ¿Cómo les suena? Algo va a pasar en 4 meses, ¿enfocado a qué? A lo que estamos diciendo. [Menciona 4 coach en el extranjero] Es decir, hay muchísima gente que trabaja desde hace tiempo al servicio de ustedes. Les pongo el video que Ricardo nos mandó por whatsapp.

[saludan los del video desde afuera]

Coach 2: Levante la mano quién realmente quiere ser mejor persona y téngala arriba quien (...) mejor jugador pero a veces no sabemos cómo. Somos lo mejor que podemos, yo les estoy marcando a ustedes que ahorita hacen lo mejor que pueden. Y que quisiéramos hacer más pero no sabemos cómo. De eso se trata el coaching. Ustedes tienen todo un equipo de expertos en el trabajo físico, técnico, táctico, ahora lo van a tener a los expertos en trabajo mental y emocional. Así como entrenan lo físico para desarrollarlo y llevarlo al máximo nivel, ahora en lo personal es a los expertos para trabajar lo mejor que pueden. Queremos que tu mente y tu corazón (...). Estaremos en los límites. Solos no podemos. El coach no te va a decir qué tienes que hacer. Una característica esencial del coach es que eres tú el que encuentra la respuesta, ya que nadie puede profundizar a tu interior más que tú, pero el coach te va a dar estas líneas para que puedas encontrar aquello que sabes que está ahí pero que puedes fácil de accesar ahí. Para eso está todo este equipo de coaches que ahora se van a presentar. Así como les dijimos que es voluntario, también les decimos que es un trabajo serio. Son 8 sesiones, con 2 sesiones de falta es baja del proceso y se le dará el turno a otra persona que sí pueda estar en las sesiones

Alguien acota al final: La reflexión es que para muchos esto será algo nuevo. Hay que ajustar, hay que ajustar. Menos horas de Playstation, preparar mi comida, si me tengo que quedar a lo mejor una hora cada 15 días para preparar mi sesión, así como el deportista que no tenía piernas buscó la forma de conseguir las piernas para competir en las Olimpíadas, si ustedes quieren van a poder cumplir este procesos satisfactoriamente. Seguramente habrán escuchado cómo Messi tuvo coach, y otros jugadores tuvieron coaches, es lo más normal que existe en muchas partes del mundo; ustedes están teniendo esa premisa de que en México se está comenzando, en otros equipos también se hace. Entonces ahí está, la oportunidad. Llegan ustedes con dos piernas, con dos grandes piernas, llegan ustedes con un gran corazón, llegan con una mentalidad, ya están aquí sus coaches. Los que regresen aquí después de comer yo sabré que están buscando este proceso. Entran en este 
camino de 4 meses de ir a por todo en la búsqueda de explorar qué cosas van a ayudarme a encontrar mi potencial al máximo. Si no vienen ya estaremos entendiendo que no están y buscaremos una alternativa con Luis.

*8 Encuesta: ¿con qué estilo de vida te imaginas viviendo como profesional?

\begin{tabular}{|c|c|c|c|c|}
\hline \multicolumn{5}{|c|}{$\begin{array}{c}\text { Sub17 - ¿Con qué estilo de vida te imaginas viviendo como profesional? } \\
\text { (Cómo sería tu casa, tu pareja si tuvieras, tu vida cotidiana?) }\end{array}$} \\
\hline \multirow[t]{2}{*}{$\begin{array}{l}\text { Respuestas ligadas a } \\
\text { la sencillez y el trabajo }\end{array}$} & $\begin{array}{l}\text { entrenar, comer bien, } \\
\text { descansar, trabajar, salir } \\
\text { con mi familia }\end{array}$ & $\begin{array}{l}\text { entrenar, descansar, } \\
\text { estar con mi familia, } \\
\text { firmar autógrafos, } \\
\text { aceptar fotos }\end{array}$ & $\begin{array}{l}\text { jugando, siendo humilde, } \\
\text { (no se entiende) }\end{array}$ & $\begin{array}{l}\text { con un estilo normal, una } \\
\text { vida sin tanto lujo }\end{array}$ \\
\hline & $\begin{array}{l}\text { con una vida, humilde, } \\
\text { sencilla; disfrutando con } \\
\text { mi familia; seguiría } \\
\text { preparándome } \\
\text { académicamente; me } \\
\text { compraría algunas cosas } \\
\text { que no tengo ahora; } \\
\text { abriendo nuevos } \\
\text { negocios }\end{array}$ & $\begin{array}{l}1 \text { levantarme para ir a } \\
\text { entrenar, } 2 \text { regresar a } \\
\text { comer a la casa, } 3 \\
\text { jugara con mis hijos, } 4 \\
\text { estudiaría algún idioma, } \\
5 \text { dormir }\end{array}$ & $\begin{array}{l}\text { estar con mi familia, ir a } \\
\text { la escuela }\end{array}$ & $\begin{array}{l}\text { en una casa bien, darlo } \\
\text { todo a mi mamá, familia }\end{array}$ \\
\hline \multirow[t]{2}{*}{$\begin{array}{l}\text { Respuestas que } \\
\text { combinan trabajo y } \\
\text { placer }\end{array}$} & $\begin{array}{l}\text { felicidad, satisfacción, } \\
\text { compromiso, alegría y } \\
\text { mucho dinero }\end{array}$ & \multirow{2}{*}{$\begin{array}{l}\text { salir a pasear con mi } \\
\text { familia y tenerlos bien } \\
\text { económicamente, ir de } \\
\text { compras con mi } \\
\text { familia,visitar distintos } \\
\text { lugares culturales y } \\
\text { sociales, pasar mucho } \\
\text { tiempo con la familia, } \\
\text { tener una casa grande y } \\
\text { muy bonita }\end{array}$} & $\begin{array}{l}\text { vivir en una casa grande, } \\
\text { tener carro, tener } \\
\text { buenas cosas, ser } \\
\text { humilde y ayudar a la } \\
\text { gente que lo necesite }\end{array}$ & $\begin{array}{l}\text { casa, carro, familia } \\
\text { comida amor }\end{array}$ \\
\hline & $\begin{array}{l}\text { felicidad, satisfecho, con } \\
\text { composic, [sic] }\end{array}$ & & $\begin{array}{l}\text { mínimo como el que } \\
\text { tengo, salir a comer } \\
\text { diario con mi novia sin } \\
\text { estar preocupado }\end{array}$ & \\
\hline $\begin{array}{l}\text { Respuestas ligadas al } \\
\text { status y el placer }\end{array}$ & $\begin{array}{l}\text { entrenar, jugar, (...) } \\
\text { fiesta, conferencias, }\end{array}$ & $\begin{array}{l}\text { salir a muchas partes, } \\
\text { comprar carros, ir con mi } \\
\text { familia, entrenar }\end{array}$ & $\begin{array}{l}\text { saliendo a lugar que no } \\
\text { conocía, comer en } \\
\text { restaurantes, mujeres } \\
\text { más guapas, felicidad, } \\
\text { constancia }\end{array}$ & $\begin{array}{l}\text { lujos, comería donde } \\
\text { quisiera, le daría dinero } \\
\text { a mi familia }\end{array}$ \\
\hline
\end{tabular}


*9 Imágenes de la relación con el barrio en Estudiantes
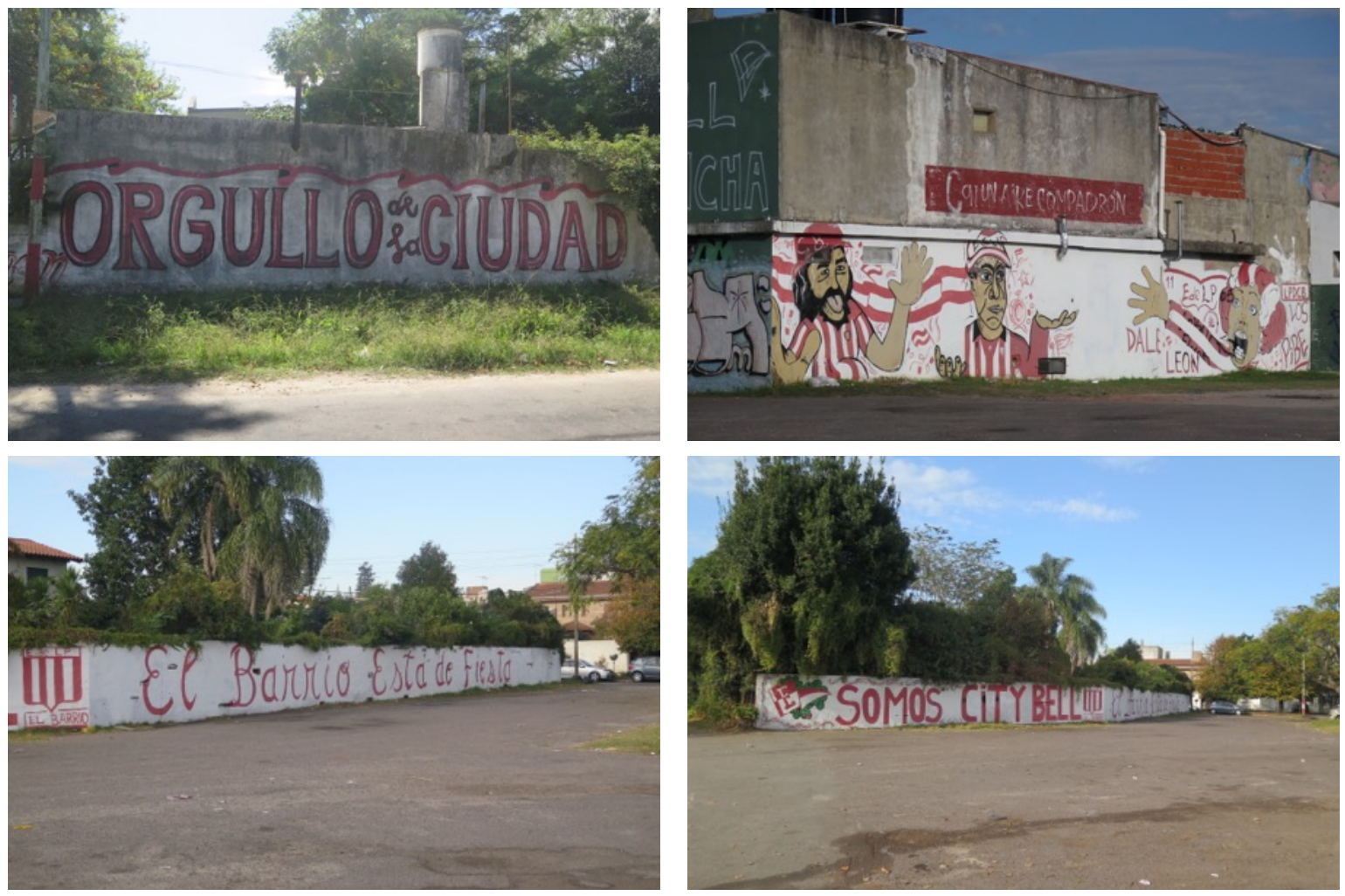
*10 Imágenes de los accesos a las 3 canteras

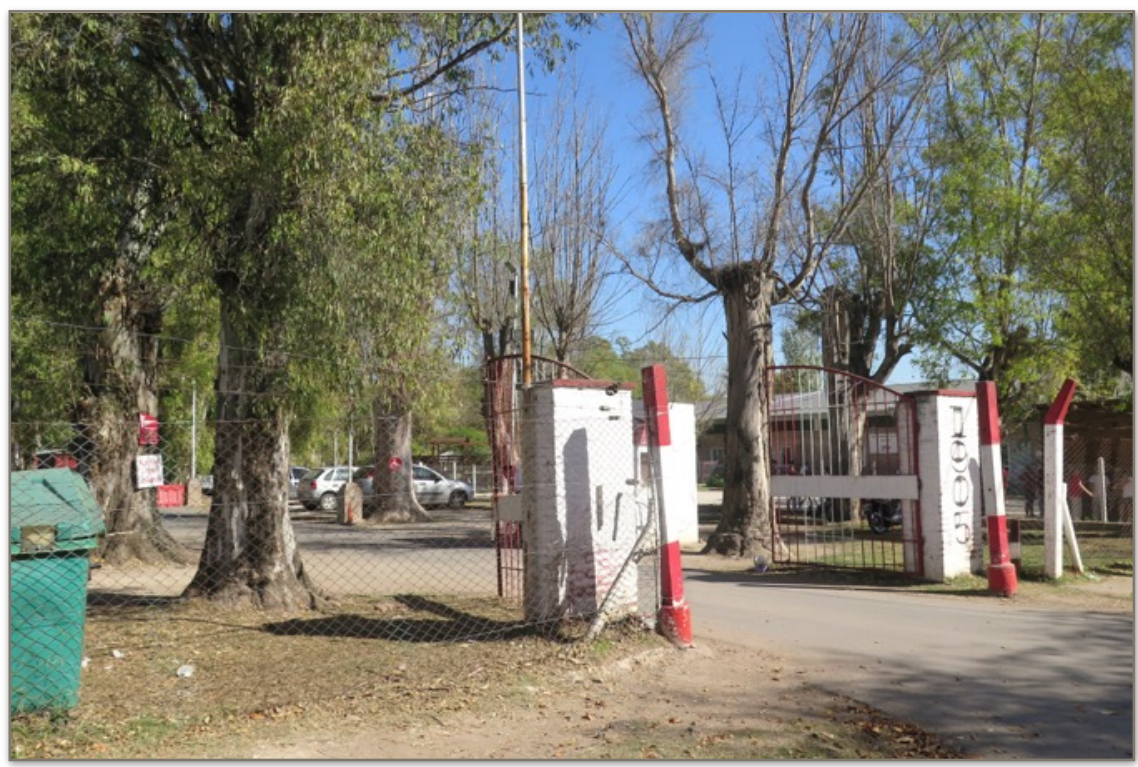

Acceso a Estudiantes de la Plata

Acceso al Olympique de Marsella
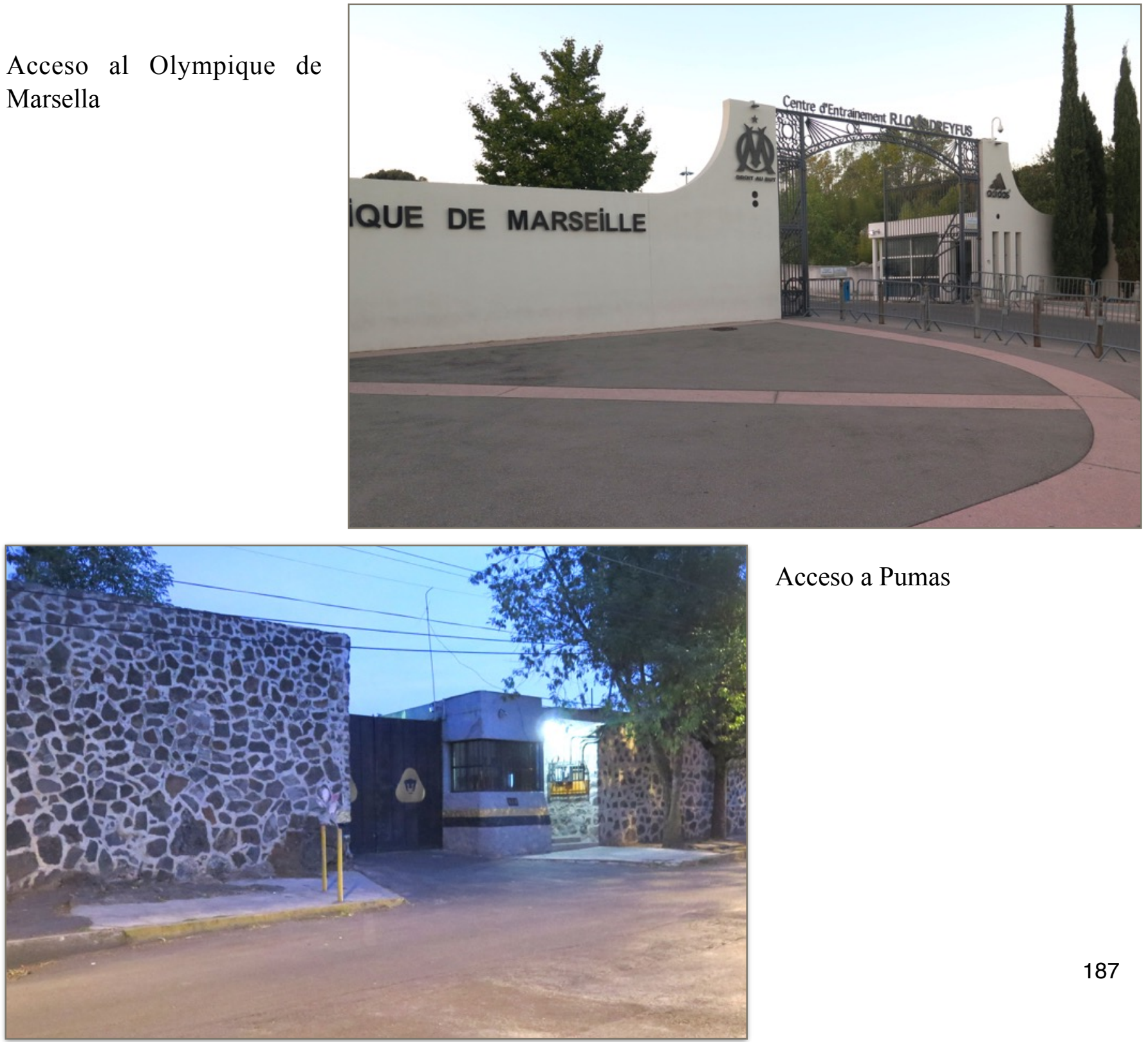

Acceso a Pumas 
*11 Fotografías de instalaciones de la cantera Pumas

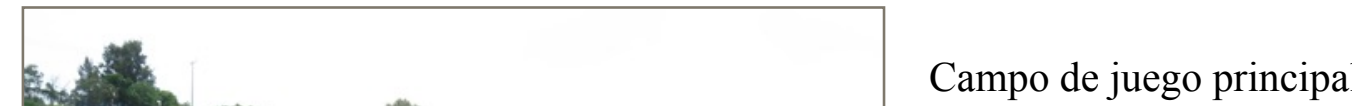

Ingreso y cartel "territorio Puma"

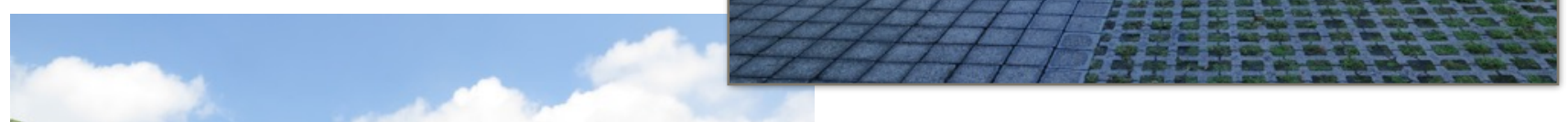

Campo de entrenamiento

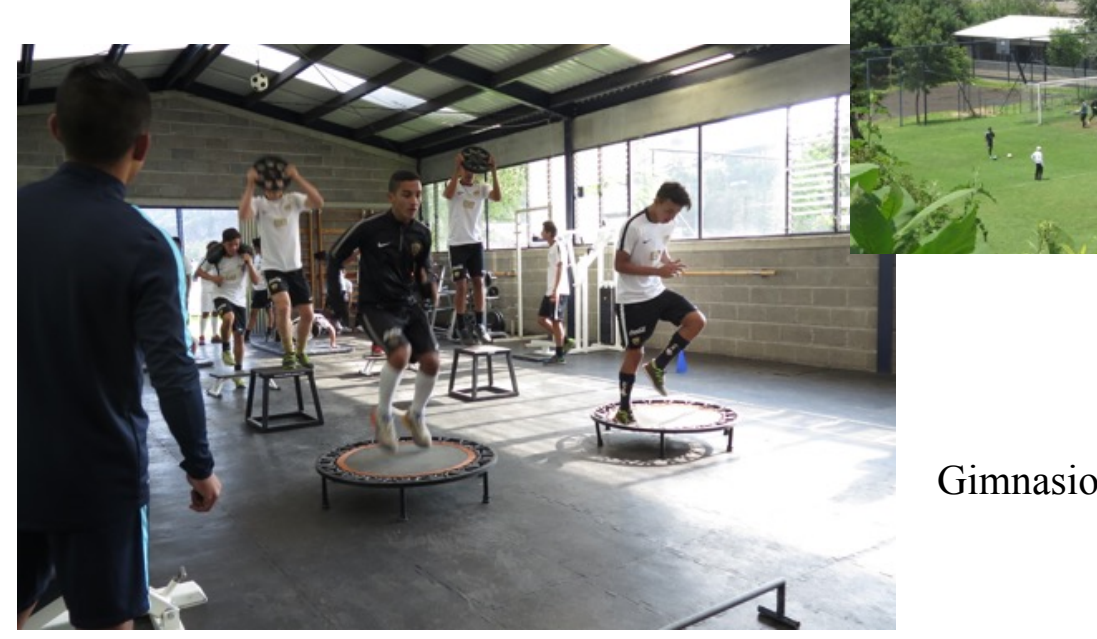


*12 Testimonios ligados a la estructura de observación:

-La vez pasada que los estaba mirando Verón ¿cómo les impacta?

-Sí. Nos preguntaron si sentíamos presión u orgullo. (...) Y la mayoría dijo que sentían algo de presión a no equivocarse, Verón dijo que la 99 era su categoría, entonces ya nos tenemos que acostumbrar siempre, el año es largo y nos van...

- ¿Y vos cómo te sentís en ese sentido?

-No, bien. Está bueno que nos sale, porque Verón es una figura importante y está bueno, está lindo.

-Y en relación a la presión, ¿vos sentís cuando hacés los entrenamientos que te estás mostrando todo el tiempo, que te están mirando, que no te podés equivocar?

-Sí, sí, porque es una competencia. La categoría es muy pareja, y si vos regalás algo te pasan por arriba digamos, tenés que... cuesta...

- ¿eso a vos te cansa mentalmente, no te cansa, de golpe llegás a tu casa y decís la puta madre...?

-A veces yo en los partidos, capaz que hago, la otra vez fue con Temperley y creo que hice dos o tres pases mal y yo cuando terminé el partido pensé que no, que había hecho todo mal, por esos tres pases te sentís que hiciste un montón de cosas mal. (Entrevistado E4).

$-¿$ Se quieren mostrar ante quién?

- Y, ante el técnico. Por ahí nos van a ver los técnicos de reserva o viene Verón, y quieren hacer una de más, se quieren mostrar.

- ¿Eso a vos no te pasa?

- No, yo soy el tipo de jugador que juega simple y busca asociarse" (Entrevistado E7)

-Cuando habló Hermes que estaba Verón mirándonos, esas cosas a mi no me afectan, que esté Verón, porque yo sé que adentro de la cancha tenés que estar concentrado en el partido, no en quien está afuera.

-¿Vos sabías que estaba Verón?

- Sí

-¿Cuándo lo viste?

-Yo lo vi cuando terminó el primer tiempo, que me habló.

- ¿Qué te dijo? -Me dijo que siga así ayudando a la defensa, que si pasaba de dos, que lo tenga cerquita" (Entrevistado E2);

-¿Qué encontraste en el cuerpo técnico?

-Y, yo cuando jugaba allá en [su club anterior] me veía el técnico y el preparador físico, acá me ve el técnico de Reserva, a veces viene Verón, a veces bueno, el técnico, el preparador físico, a veces vienen los técnicos más grandes también y bueno, es distinto.

-¿Qué es lo distinto ahí, qué sentís distinto?

-Ves que el día de mañana te pueden llamar y estar ahí arriba, y eso es distinto. Por ahí allá [en su club previo] no le daban mucha bola a las inferiores, como te digo yo, por ahí no metían tanto pibe arriba, bueno, acá sí. En Reserva hay pibes uno, dos años más grandes, en un par de años podría estar yo ahí si me va bien" (Entrevistado E10). 
*13 Encuesta: 3 consejos que les quedaron grabados

\begin{tabular}{|c|c|c|c|c|c|c|c|c|}
\hline \multirow[t]{9}{*}{$\begin{array}{l}\text { Promotores } \\
\text { del esfuerzo } \\
\text { físico }(30)\end{array}$} & $\begin{array}{l}\text { Siempre dar todo de } \\
\text { sí }\end{array}$ & 9 & \multirow[t]{6}{*}{$\begin{array}{l}\text { Motivadores de } \\
\text { otro tipo (8) }\end{array}$} & $\begin{array}{l}\text { Échale ganas porque eres } \\
\text { el mejor / Siempre querer } \\
\text { se el mejor }\end{array}$ & 3 & \multirow[t]{6}{*}{$\begin{array}{l}\text { Otros } \\
\text { consejos }\end{array}$} & $\begin{array}{l}\text { Habrá altas y bajas } \\
\text { pero debes mantenerte } \\
\text { lo más que puedas }\end{array}$ & 1 \\
\hline & $\begin{array}{l}\text { Que sea constante / } \\
\text { persistente / } \\
\text { dedicado }\end{array}$ & 6 & & Tú puedes & 1 & & Cuidarme & 1 \\
\hline & $\begin{array}{l}\text { Luchar por tus } \\
\text { sueños }\end{array}$ & 5 & & Lo que hagas hazlo bien & 1 & & Ser humilde & 1 \\
\hline & $\begin{array}{l}\text { Que nunca me } \\
\text { desmotive / No } \\
\text { darme por vencido }\end{array}$ & 5 & & $\begin{array}{l}\text { Trabaja para ti, no para } \\
\text { los demás }\end{array}$ & 1 & & $\begin{array}{l}\text { Que nunca dejara el } \\
\text { fútbol }\end{array}$ & 1 \\
\hline & $\begin{array}{l}\text { Todo sacrificio tiene } \\
\text { una buena } \\
\text { recompensa }\end{array}$ & 1 & & $\begin{array}{l}\text { Ten confianza en lo que } \\
\text { eres }\end{array}$ & 1 & & $\begin{array}{l}\text { Llega a Primera } \\
\text { División }\end{array}$ & 1 \\
\hline & Todo está en uno & 1 & & $\begin{array}{l}\text { Que me prepare hasta } \\
\text { que llegue la oportunidad }\end{array}$ & 1 & & Siempre di sí & 1 \\
\hline & $\begin{array}{l}\text { Nadie regala nada en } \\
\text { esta vida }\end{array}$ & 1 & \multirow[t]{2}{*}{$\begin{array}{l}\text { Enfocados en el } \\
\text { placer (6) }\end{array}$} & Hacer lo que me gusta & 3 & $\begin{array}{l}\text { Religioso } \\
\text { s }\end{array}$ & $\begin{array}{l}\text { Pedirle a Dios / Los } \\
\text { tiempos de Dios son } \\
\text { perfectos }\end{array}$ & 2 \\
\hline & $\begin{array}{l}\text { Siempre da el extra, } \\
\text { trabaja más que los } \\
\text { demás }\end{array}$ & 1 & & $\begin{array}{l}\text { Que me divierta en lo que } \\
\text { haga }\end{array}$ & 3 & & & \\
\hline & $\begin{array}{l}\text { Como se entrena se } \\
\text { juega }\end{array}$ & 1 & & & & & & \\
\hline
\end{tabular}

